Atmos. Chem. Phys., 14, 317-398, 2014

www.atmos-chem-phys.net/14/317/2014/

doi:10.5194/acp-14-317-2014

(c) Author(s) 2014. CC Attribution 3.0 License.

\title{
Online coupled regional meteorology chemistry models in Europe: current status and prospects
}

A. Baklanov ${ }^{1}$, K. Schlïnzen ${ }^{2}$, P. Suppan ${ }^{3}$, J. Baldasano ${ }^{4}$, D. Brunner ${ }^{5}$ S. Aksoyoglu ${ }^{6}$, G. Carmichael ${ }^{7}$ J. Douros $^{8}$, J. Flemming ${ }^{9}$, R. Forkel ${ }^{3}$, S. Galmarini ${ }^{10}$, M. Gauss ${ }^{11}$, G. Grell ${ }^{12}$, M. Hirtl ${ }^{13}$, S. Joffre ${ }^{14}$, O. Jorba ${ }^{4}$, E. Kaas ${ }^{15}$, M. Kaasik ${ }^{16}$, G. Kallos $^{17}$, X. Kong ${ }^{18}$, U. Korsholm ${ }^{1}$, A. Kurganskiy ${ }^{19}$, J. Kushta ${ }^{17}$, U. Lohmann ${ }^{20}$, A. Mahura ${ }^{1}$, A. Manders-Groot ${ }^{21}$, A. Maurizi ${ }^{22}$, N. Moussiopoulos ${ }^{8}$, S. T. Rao $^{23}$, N. Savage $^{24}$, C. Seigneur ${ }^{25}$, R. S. Sokhi ${ }^{18}$,

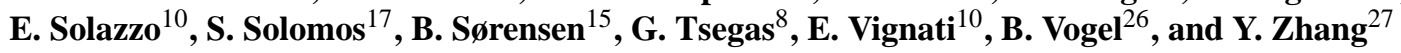

${ }^{1}$ Danish Meteorological Institute, Copenhagen, Denmark

${ }^{2}$ Meteorological Institute, University of Hamburg, Hamburg, Germany

${ }^{3}$ Karlsruhe Institute of Technology, Garmisch-Partenkirchen, Germany

${ }^{4}$ Barcelona Supercomputing Center, Barcelona, Spain

${ }^{5}$ Empa, Swiss Federal Laboratories for Materials Science and Technology, Dübendorf, Switzerland

${ }^{6}$ Paul Scherrer Institute, Villigen, Switzerland

${ }^{7}$ Center for Global and Regional Environmental Research, University of Iowa, USA

${ }^{8}$ Aristotle University, Thessaloniki, Greece

${ }^{9}$ European Centre for Medium-Range Weather Forecasts, Reading, UK

${ }^{10}$ European Commission, Joint Research Centre, Institute for Environment and Sustainability, Ispra, Italy

${ }^{11}$ Norwegian Meteorological Institute, Bergen, Norway

${ }^{12}$ NOAA/ESRL, Boulder, Colorado, USA

${ }^{13}$ Central Institute for Meteorology and Geodynamic, Vienna, Austria

${ }^{14}$ Finnish Meteorological Institute, Helsinki, Finland

${ }^{15}$ Niels Bohr Institute, University of Copenhagen, Copenhagen, Denmark

${ }^{16}$ University of Tartu, Tartu, Estonia

${ }^{17}$ University of Athens, Athens, Greece

${ }^{18}$ Centre for Atmospheric and Instrumentation Research, University of Hertfordshire, Hatfield, UK

${ }^{19}$ Russian State Hydrometeorological University, St.-Petersburg, Russia

${ }^{20}$ Institute for Atmospheric and Climate Science, ETH, Zurich, Switzerland

${ }^{21} \mathrm{TNO}$, Utrecht, the Netherlands

${ }^{22}$ Institute of Atmospheric Sciences and Climate, Italian National Research Council, Bologna, Italy

${ }^{23}$ US Environmental Protection Agency, Research Triangle Park, NC, USA

${ }^{24}$ Met Office, Exeter, UK

${ }^{25}$ CEREA, Joint laboratory École des Ponts ParisTech/EDF R\&D, Université Paris-Est, Marne-la-Vallée, France

${ }^{26}$ Karlsruhe Institute of Technology, Eggenstein-Leopoldshafen, Germany

${ }^{27}$ North Carolina State University, Raleigh, USA

Correspondence to: A. Baklanov (alb@dmi.dk) and K. H. Schlünzen (heinke.schluenzen@uni-hamburg.de)

Received: 24 March 2013 - Published in Atmos. Chem. Phys. Discuss.: 14 May 2013

Revised: 24 November 2013 - Accepted: 4 December 2013 - Published: 10 January 2014

Published by Copernicus Publications on behalf of the European Geosciences Union. 
Abstract. Online coupled mesoscale meteorology atmospheric chemistry models have undergone a rapid evolution in recent years. Although mainly developed by the air quality modelling community, these models are also of interest for numerical weather prediction and regional climate modelling as they can consider not only the effects of meteorology on air quality, but also the potentially important effects of atmospheric composition on weather. Two ways of online coupling can be distinguished: online integrated and online access coupling. Online integrated models simulate meteorology and chemistry over the same grid in one model using one main time step for integration. Online access models use independent meteorology and chemistry modules that might even have different grids, but exchange meteorology and chemistry data on a regular and frequent basis. This article offers a comprehensive review of the current research status of online coupled meteorology and atmospheric chemistry modelling within Europe. Eighteen regional online coupled models developed or being used in Europe are described and compared. Topics discussed include a survey of processes relevant to the interactions between atmospheric physics, dynamics and composition; a brief overview of existing online mesoscale models and European model developments; an analysis on how feedback processes are treated in these models; numerical issues associated with coupled models; and several case studies and model performance evaluation methods. Finally, this article highlights selected scientific issues and emerging challenges that require proper consideration to improve the reliability and usability of these models for the three scientific communities: air quality, numerical meteorology modelling (including weather prediction) and climate modelling. This review will be of particular interest to model developers and users in all three fields as it presents a synthesis of scientific progress and provides recommendations for future research directions and priorities in the development, application and evaluation of online coupled models.

\section{Introduction}

Coupling of atmospheric dynamics, pollutant transport, chemical reactions and atmospheric composition for modelling environmental impacts, climate change, weather forecasts and air quality will remain one of the most challenging tasks over the next decades as they all involve strongly integrated processes. It is well accepted that weather has a profound impact on air quality (AQ) and atmospheric transport of hazardous materials. It is also recognised that atmospheric composition can influence both weather and climate directly by changing the atmospheric radiation budget or indirectly by affecting cloud formation and precipitation. Until recently however, because of the scientific complexities and lack of computational power, atmospheric chemistry and weather forecasting have developed as separate disciplines, leading to the development of separate modelling systems that are only loosely coupled. This is particularly true for regional scale models, which are the focus of this review, whereas for global scale and in particular stratospheric modelling, the development and availability of online coupled models is more advanced.

The dramatic increase in computer power during the last decade enables us to use high spatial resolutions (e.g. < a few $\mathrm{km}$ ) in numerical weather prediction (NWP) and meteorological modelling. Fronts, convective systems, local wind systems, and clouds are being resolved or partly resolved. Furthermore, the complexity of the parametrization schemes in the models has increased as more and more processes are considered. Additionally, this increased computing capacity can be used for closer coupling of meteorological models (MetM) with atmospheric chemical transport models (CTM) either offline or online (Fig. 1). Offline modelling implies that the CTM is run after the meteorological simulation is completed, while online modelling allows coupling and integration of some of the physical and chemical components to various degrees.

In recognition of the rapid development of coupled meteorology and chemistry modelling, Action ES1004 (EuMetChem) in the European Cooperation in Science and Technology (COST) Framework was launched in February 2011 to develop a European strategy for online integrated air quality (AQ) and meteorology modelling. The Action does not aim at determining or designing one best model, but to identify and review the main processes and to specify optimal modular structures for online Meteorology Chemistry (MetChem) models to simulate specific atmospheric processes. Furthermore, the COST Action will develop recommendations for efficient interfacing and integration of new modules, keeping in mind that there is no one best model, but that the use of an ensemble of models is likely to provide the most skilful simulations.

In this review paper, these coupled models are distinguished with respect to the extent of online coupling: online integrated and online access coupling. Online integrated meteorology chemistry models handle meteorology and chemistry using the same grid in one model and using one main time step for integration. Online access models use independent meteorology and chemistry models that might even be using different grids, but exchange information from meteorology to chemistry and back to meteorology on a regular and frequent basis. The frequency of data exchange needs to increase as the timescale of the relevant processes becomes smaller. In contrast to online access models, offline models do not exchange data, but merely provide, e.g. meteorology information to drive the chemistry model. The ultimate stage is the online integration of CTM and MetM to produce a unified modelling system with consistent treatments of processes such as advection, turbulence and radiation for both meteorological and chemical quantities. Such an integration 


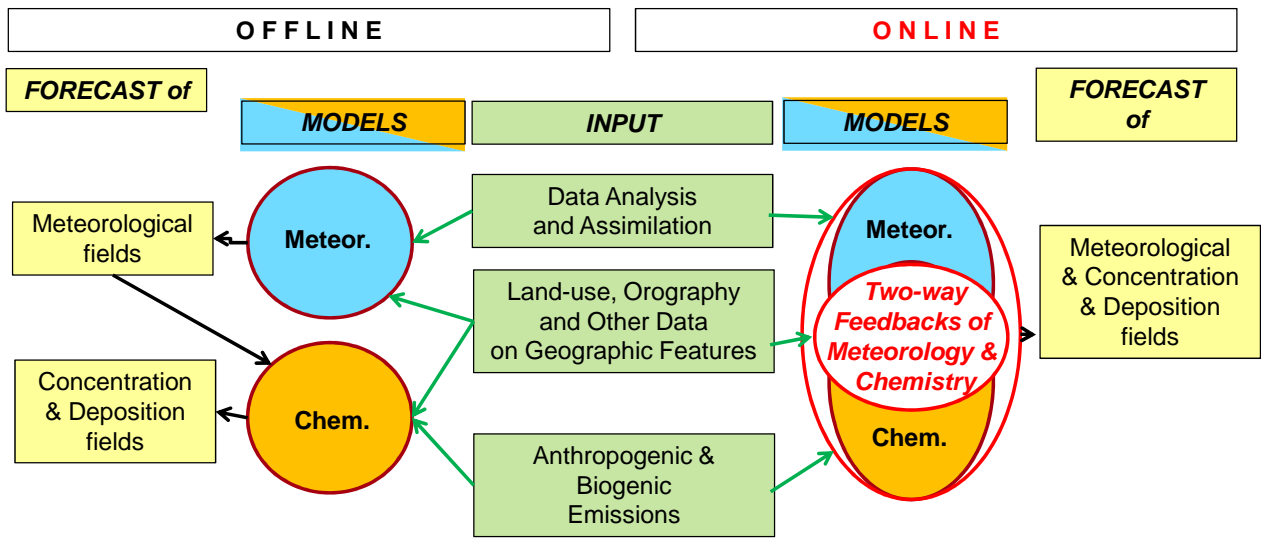

Fig. 1. Schematic diagram of (left) offline and (right) online coupled meteorology and chemistry modelling approaches for air quality and meteorology simulation and forecasting.

allows online integrated meteorology chemistry simulations with two-way interactions (also referred to as feedbacks). Climate modelling is also expanding its capability through the use of an earth system modelling approach that integrates the atmosphere, hydrosphere (including both fresh water and oceans) and biosphere with high spatial and temporal resolution. Climate modelling, however, does not require the implementation of near-real-time data assimilation, which is crucial for the skill of NWP and can also help improve AQ forecasts.

For performing a simulation, the input data need to be tailored to the specific requirements of the atmospheric model. For this purpose several programs are employed for each model, that pre-process data, e.g. meteorology measurements on model grids as initial data, land use data consistent with the model land use categories and emission data in agreement with the used chemical mechanism. Specific programs are also needed for providing output data from an atmospheric model. In the context of this paper, "model" refers to a combination of pre-processors' and post-processors' tools along with the core MeM and CTM models all comprising a detailed modelling system. For shortness we mainly use the word "model" and only use "modelling system" in places, where pre- and post-processors are particularly relevant.

Combining two modelling systems for operational applications, each of which have high CPU time and memory requirements, still poses many problems in practice and thus is not always feasible at NWP or chemical weather forecasting centres. Nevertheless, one can argue that such gradual migration towards ever stronger online coupling of CTMs with MetMs poses a challenging but attractive perspective from the scientific point of view for the sake of both high-quality meteorological and chemical weather forecasting (CWF). While NWP centres, as well as entities responsible for AQ forecasting, are only beginning to discuss whether an online approach is important enough to justify the extra cost
(Baklanov, 2010; Grell and Baklanov, 2011; Kukkonen et al., 2012; Zhang et al., 2012a, b), the online integrated approach is already used in many research atmospheric models.

For NWP/CWF centres, an additional benefit of the online approach would be its possible application for meteorological data assimilation (Hollingsworth et al., 2008). This assumes that the modelling system can outperform pollutant concentration climatologies when forecasting concentrations of aerosols and radiatively active gases. The retrieval of satellite data and direct assimilation of radiances is likely to improve both weather and chemical weather forecasts.

Online coupled mesoscale meteorology and chemistry models have been developed in recent years, particularly in the United States (US) (e.g. Zhang, 2008) and these models are becoming increasingly popular in Europe. Historically, Europe has not adopted a community approach to modelling and this has led to a large number of model development programmes, usually working almost independently, thereby yielding results tailored for specific applications. However, a strategic framework could help to provide a common goal and direction to European research in this field, while still having various models as part of a European model ensemble. The task is manifold since it requires scientific knowledge and practical experience in Met and AQ modelling and forecasting, numerical analysis, atmospheric physics, chemistry and data assimilation.

The focus on integrated systems is timely, since recent research has shown that meteorology and chemistry feedbacks are important in the context of many research areas and applications, including NWP and AQ forecasting, as well as climate and Earth system modelling. However, the relative importance of online integration and of the priorities, requirements, and level of details necessary for representing different processes can vary greatly between applications. Under these circumstances tailored solutions may be required for the three communities: (i) AQ forecasting and assessments, 
(ii) NWP and Met modelling, (iii) climate and earth system modelling.

For example, current NWP models do not incorporate detailed chemical processes, even though aerosols - via radiative and microphysical processes, can affect fog formation, visibility and precipitation, and thus forecasting skill. For climate modelling, feedbacks from greenhouse gases (GHGs) and aerosols are extremely important, though in most cases (e.g. for long-lived GHGs), online integration of full scale chemistry and aerosol dynamics is not critically needed. For CWF and prediction of atmospheric composition in a changing climate, online integration is expected to improve AQ and atmospheric chemical composition simulations and projections (e.g. Moran et al., 2010). The AQ, Met and climate modelling communities have different targets with respect to temporal and spatial scales, as well as to the processes involved in such modelling. For AQ forecasting, the key issue is usually the ground-level concentrations of pollutants, whereas for weather and climate models, skill is typically based on screen level temperature, precipitation and wind. Since short-lived pollutants influence climate and air quality conditions, the AQ community is interested in online modelling to understand the feedback mechanisms and to design air quality policies that can maintain future air quality at acceptable levels under changing climate conditions (Alapaty et al., 2011).

Several applications are likely to benefit from online modelling, although they do not clearly belong to one of these three main communities mentioned above. These include bioweather forecasting, pollen warnings, forecasting of hazardous plumes from volcanic eruptions, forest fires, oil and gas fires, dust storms, assessment of methods in geoengineering that involve changes in the radiation balance (e.g. input of sulfate aerosols, artificially increased albedo) and consequences of nuclear war.

This paper provides a comprehensive review on the current status of modelling practices towards online coupled modelling of meteorology and chemistry with a specific focus on European models and research. Section 2 is a survey of the potentially relevant processes in the interactions between atmospheric dynamics (meteorology/climate) and atmospheric composition. Sect. 3 gives a brief overview of European developments and existing online mesoscale models. Section 4 describes how feedback processes are treated in these models. Section 5 addresses the numerical issues of coupled models. Section 6 describes a few case studies and model evaluation methods. Section 7 summarises the review and provides recommendations for future research directions and priorities for online coupled models. Appendix A includes brief descriptions of the main regional online coupled or integrated models, which have been developed or are actively being used in Europe. A list of acronyms is provided in Table 9.

This paper focuses on models that simulate mainly mesoscale phenomena, thus with grid sizes ranging between $1 \mathrm{~km}$ and $20 \mathrm{~km}$ and it does not cover global or local scale models. Furthermore, the timescale of interest is for simulations of short-term episodes (e.g. on the order of hours and days (NWP) to months) rather than for long-term (e.g. multiple years/decades) relevant to climate simulations. Therefore, some aspects rated here as less relevant might be of much more importance for climate models (e.g. changes in biodiversity due to nutrient loads with impacts on evaporation and surface albedo). It should be noted that the time periods used for model evaluations are usually short, and in order to determine the impacts of online feedbacks on the meteorological forecast and vice-versa longer evaluation periods are needed.

\section{Survey of potential direct impact and feedback processes relevant in meteorology chemistry coupling}

Direct impacts of meteorology on chemistry or vice versa as well as feedback processes are varied. Their calculation only became possible only with the introduction of online meteorology chemistry models. Traditionally, aerosol feedbacks have been neglected in Met and AQ models mostly due to a historical separation between these communities, as well as a limited understanding of the underlying interaction mechanisms and associated complexities. Such mechanisms may, however, be important on a wide range of temporal and spatial scales (hours to decades and local to global). Field experiments and satellite measurements have shown that chemistry dynamics feedbacks exist among the Earth system components including the atmosphere (e.g. Kaufman and Fraser, 1997; Rosenfeld, 1999; Rosenfeld and Woodley, 1999; Givati and Rosenfeld, 2004; Jacobson, 2005; Lau and Kim, 2006; Rosenfeld et al., 2007, 2008).

The potential impacts of aerosol feedbacks can be broadly explained in terms of four types of effects: direct, semidirect, first indirect and second indirect. For example, the reduction in solar radiation reaching the Earth by aerosols is an example of direct effect (Jacobson et al., 2007). Changes in surface temperature, wind speed, relative humidity, clouds and atmospheric stability that are caused by absorbing aerosols are examples of the semi-direct effect (Hansen et al., 1997). A decrease in cloud drop size and an increase in cloud drop number as a result of aerosols in the atmosphere are named first indirect effect (Twomey, 1977). These changes might enhance cloud albedo. An increase in liquid water content, cloud cover and lifetime of low level clouds and suppression or enhancement of precipitation are examples of the second indirect effect (Albrecht, 1989). However, this simplified classification is insufficient to describe the full range of two-way, chains and loops of interactions between meteorological and chemical processes in the atmosphere. It should also be noted that these definitions are not always consistently used throughout the literature.

The main meteorology and chemistry/aerosol interacting processes and effects, which could be considered in online 
Table 1. Meteorology's impacts on chemistry.

\begin{tabular}{ll}
\hline Temperature & $\begin{array}{l}\text { Modulates chemical reaction and photolytic rates } \\
\text { Modulates biogenic emissions (isoprene, terpenes, dimethyl sulfide, etc.) } \\
\text { Influences biogenic emissions (isoprene, monoterpenes) } \\
\text { Influences the volatility of chemical species } \\
\text { Determines aerosol dynamics (coagulation, condensation, nucleation) }\end{array}$ \\
\hline Temperature vertical gradients & Determines vertical diffusion intensity \\
\hline Temperature \& humidity & $\begin{array}{l}\text { Affect aerosol thermodynamics (e.g. gas-particle partitioning, secondary } \\
\text { aerosol formation) }\end{array}$ \\
\hline Water vapour & Modulates OH radicals, size of hydrophilic aerosol \\
\hline Liquid water & Determines wet scavenging and atmospheric composition \\
\hline Cloud processes & Affects mixing, transformation and scavenging of chemical compounds \\
\hline Precipitation & Determines the wet removal of trace gases and aerosol \\
\hline $\begin{array}{l}\text { Land surface parameterization } \\
\text { (soil type and vegetation cover, }\end{array}$ & Affects natural emissions (e.g. dust, BVOCs) and dry deposition \\
\hline soil moisture, leaf area) & \\
\hline Lightning & Determines free troposphere NOx emissions \\
\hline Radiation & $\begin{array}{l}\text { Determines photolysis rates and influences many chemical reaction rates } \\
\text { Determines isoprene emissions }\end{array}$ \\
\hline Wind speed and direction & $\begin{array}{l}\text { Determines horizontal transport and vertical mixing of chemical species } \\
\text { Influences dust and sea-salt emissions }\end{array}$ \\
\hline ABL height & Influences concentrations \\
\hline
\end{tabular}

Table 2. Chemical species' impacts on meteorology.

\begin{tabular}{ll}
\hline Aerosols & Modulate radiation transfers (SW scattering/absorption, LW absorption, LW \\
& scattering by large particles like dust) \\
& Affect boundary layer meteorology (temperature, humidity, wind speed and di- \\
& rection, ABL height, stability) \\
& Extraordinary high concentrations can affect stability and wind speed \\
& Influence cloud formation, since they act as cloud condensation nuclei \\
& Influence cloud droplet and crystal number and hence cloud optical depth and \\
hence radiation \\
Aerosols physical properties \\
(size distribution, mass and \\
number concentrations, \\
hygroscopicity) & Influence precipitation (initiation, intensity) \\
& Affect haze formation and atmospheric humidity \\
& Influence scattering/absorption \\
\hline Soot deposited on ice & Influences albedo \\
\hline Radiatively active gases & Modulate radiation transfers \\
\hline
\end{tabular}

coupled MetM-CTMs, are summarised in Tables 1 and 2. The order in Table 1 does not reflect their importance or relevance, since their actual relevance depends on the model application. In addition to looking at the meteorological parameters affecting chemistry, it is also worth mentioning effects of altered meteorology on meteorology, in order to better understand chains and loops of interactions. For example, clouds modulate boundary layer outflow/inflow by changes in the radiative fluxes as well as alterations of vertical mixing and the water vapour modulates radiation. The temperature gradient influences cloud formation and controls turbulence intensity and the evolution of the atmospheric boundary layer (ABL). Similar feedback mechanisms exist for altered chemistry impacts on chemistry. For example, biogenic 
emissions affect the concentrations of ozone and secondary organic aerosols. The polymerisation of organic aerosols produces long chain secondary organic aerosol (SOA) with lower volatility.

On a more general level, a number of chains and loops of interactions take place and should be properly simulated in an online coupled model. These may include: (a) A loop feedback starting with temperature that affects chemistry and thus chemical concentrations (Table 1); the changes in chemical concentrations will in turn affect radiative processes (Table 2), which will then affect temperature to close the loop (illustrated in Fig. 2). (b) A chain feedback starting with aerosol that affects radiation (Table 2) and thus photolysis and chemistry (Table 1). (c) A chain feedback starting with temperature gradients that affects turbulence mixing (MetMet feedback); thus affecting surface-level pollutant concentrations (Table 1) and boundary layer outflow/inflow (MetMet feedback). (d) A chain feedback starting with aerosols that affect cloud optical depth through influence of droplet number on mean droplet size (Table 2); the resulting changes in cloud formation will then affect the initiation of precipitation (Met-Met feedback). (e) A chain feedback starting with aerosol absorption of sunlight which results in changes in the temperature profile of the atmosphere and vertical mixing (Table 2) and thereby changes in the cloud droplet formation, which affects cloud liquid water and thus cloud optical depth (Met-Met feedback).

Against the backdrop of the separate development of MetMs and CTMs together with the continued increase in computing power, a more detailed modelling description of physical and chemical processes and their interactions calls for a strategic vision. Such a vision will help to provide shared goals and directions for the European research and operational communities in this field, while still having a multiple model approach to respond to diverse national and European-wide mandates.

One of the initiatives of this COST Action was to perform an expert poll to identify the most important chemistrymeteorology interactions (as listed in Tables 1 and 2) and how they are represented in current models. The survey design was similar to the expert poll in the EU FP7 PEGASOS project (http://pegasos.iceht.forth.gr/) but extended to cover three model categories: NWP, CWF and climate models. This survey not only ranks the importance of the meteorology chemistry interactions, but also ranks how well they are represented in current online models. The survey questionnaire was sent to different experts in these communities in Europe and beyond, and the results of its analyses (based on 30 responses) are shown in Table 3. The original frequency of the votes has been listed in the "importance for models (\%)" and "representation in models (\%)" columns. In order to make it easier to sort these interactions based on their importance for the numerical models, an indicator "score1" has been derived from the weighted mean of: $4=$ high, $3=$ medium, $2=$ low and $1=$ negligible. In a similar way, the second indicator

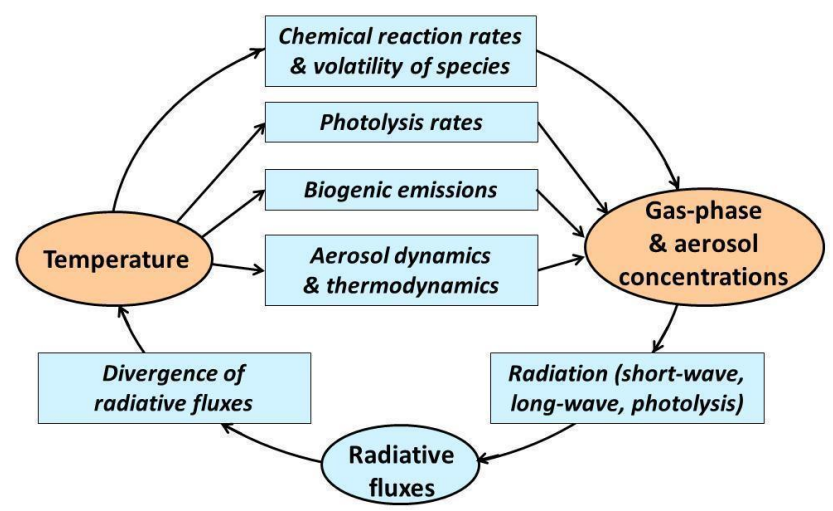

Fig. 2. Conceptual model of impacts from temperature on concentrations and vice versa.

"score2" used to rank the "adequacy of the representation of the interaction in models" was derived from the weighted mean of: $4=$ quite well, $3=$ fairly well, $2=$ poor and $0=$ not included. Based on Jamieson (2004) on how to use Likert scales, "score1" and "score2" should not be interpreted as statistical means but only as indication to judge the order of the importance or the adequacy of the representation.

Even though those participating in the survey were not experts on all aspects of the modelling, as they acknowledged themselves by marking "Don't know", the survey represents an expert view of the participants and hence is of considerable value. These results show that the perceived most important interactions differ from one model category to another. In general, most of the meteorology and chemistry interactions are more important for CWF models than NWP and climate models, and those interactions are represented better in CWF models than in NWP or climate models (averaged scores in Table 3). However, only a few interactions are considered to be represented "quite well" or "fairly well" in models. Therefore, primary attention needs to be given to interactions with high rank of importance (score1) together with low score in the model representation (score2), such as "improvement of aerosol indirect effects" for both NWP and climate models, "changes in liquid water affect wet scavenging and atmospheric composition" and "improvement of wind speed - dust/sea salt interactions" for CWF models (highlighted rows in Table 3). The aerosol indirect effects that need to be improved according to the survey responses include: (a) changes in aerosol effect on haze and changes in aerosol effect on cloud morphology in NWP models; (b) changes in aerosol effect on cloud droplet number or cloud optical depth and changes in aerosol effect on precipitation in both NWP and climate models. There is a critical need for further improvement of model treatments of key aerosol processes such as the size/composition-resolved aerosol/cloud microphysics for multiple size distributions and aerosol-cloud interactions, as well as subgrid variability associated with these processes (Zhang, 2008). However, 
Table 3. Summary of the survey (based on 30 participants) on expert assessment of the most important meteorology and chemistry interactions for online MetChem models. Only the top six ranked important interactions (out of 24 total interactions in the survey questionnaire) for each model category (NWP, CWF and climate) are reported here. Score 1 is an indicator for ranking the "importance of the interaction" from the weighted mean of: 4 = high, $3=$ medium, 2 = low and $1=$ negligible; while score 2 is another indicator for ranking the "adequacy of the representation of the interaction in models" as the weighted mean of: $4=$ quite well; $3=$ fairly well; $2=$ poor; $0=$ not included.

\begin{tabular}{|c|c|c|c|c|c|c|c|c|c|c|c|c|c|}
\hline \multirow[t]{2}{*}{ Rank } & \multirow{2}{*}{$\begin{array}{l}\text { Top six ranked Meteorology and chemistry interactions } \\
\text { Changes in } \ldots \text { affect }(\rightarrow) \ldots\end{array}$} & \multicolumn{5}{|c|}{ Importance for models (\%) } & \multirow[t]{2}{*}{ Score1 } & \multicolumn{5}{|c|}{ Representation in models (\%) } & \multirow[t]{2}{*}{ Score2 } \\
\hline & & High & Medium & Low & Neg. & Don't know & & Quite well & Fairly well & Poor & Not incl. & Don't know & \\
\hline \multicolumn{14}{|c|}{ (A) Numerical Weather Prediction (NWP) } \\
\hline 1 & $\begin{array}{l}\text { aerosol } \rightarrow \text { precipitation (initiation and intensity of } \\
\text { precipitation) }\end{array}$ & 50 & 25 & 17 & 4 & 4 & 3.1 & 0 & 8 & 54 & 25 & 13 & 1.3 \\
\hline 2 & $\begin{array}{l}\text { aerosols } \rightarrow \text { radiation (shortwave scattering/absorption } \\
\text { and longwave absorption) }\end{array}$ & 38 & 46 & 13 & 0 & 4 & 3.1 & 8 & 21 & 46 & 17 & 8 & 1.9 \\
\hline 3 & temperature vertical gradients $\rightarrow$ vertical diffusion & 48 & 28 & 16 & 0 & 8 & 3.1 & 4 & 64 & 8 & 8 & 16 & 2.2 \\
\hline 4 & $\begin{array}{l}\text { aerosol } \rightarrow \text { cloud droplet or crystal number density and } \\
\text { hence cloud optical depth }\end{array}$ & 40 & 40 & 12 & 4 & 4 & 3.1 & 4 & 8 & 44 & 28 & 16 & 1.3 \\
\hline 5 & $\begin{array}{l}\text { aerosol } \rightarrow \text { haze (relationship between the hygroscopic } \\
\text { growth of aerosols and humidity) }\end{array}$ & 36 & 40 & 8 & 8 & 8 & 2.9 & 0 & 4 & 44 & 32 & 20 & 1.0 \\
\hline 6 & aerosol $\rightarrow$ cloud morphology (e.g. reflectance) & 32 & 36 & 16 & 4 & 12 & 2.7 & 0 & 8 & 48 & 32 & 12 & 1.2 \\
\hline \multicolumn{2}{|c|}{ Averaged score for all 24 interactions in NWP models } & 17 & 26 & 33 & 16 & 8 & 2.3 & 3 & 13 & 31 & 37 & 16 & 1.1 \\
\hline \multicolumn{14}{|c|}{ (B) Chemical Weather Forecast (CWF) } \\
\hline 1 & wind speed $\rightarrow$ dust and sea salt emissions & 81 & 15 & 4 & 0 & 0 & 3.8 & 8 & 42 & 46 & 0 & 4 & 2.5 \\
\hline 2 & $\begin{array}{l}\text { precipitation (frequency/intensity) } \rightarrow \text { atmospheric } \\
\text { composition }\end{array}$ & 76 & 24 & 0 & 0 & 0 & 3.8 & 14 & 57 & 21 & 0 & 7 & 2.7 \\
\hline 3 & temperature $\rightarrow$ chemical reaction rates and photolysis & 75 & 19 & 6 & 0 & 0 & 3.7 & 32 & 55 & 0 & 0 & 13 & 2.9 \\
\hline 4 & radiation $\rightarrow$ chemical reaction rates and photolysis & 69 & 28 & 3 & 0 & 0 & 3.7 & 20 & 53 & 13 & 0 & 13 & 2.7 \\
\hline 5 & $\begin{array}{l}\text { liquid water } \rightarrow \text { wet scavenging and atmospheric com- } \\
\text { position }\end{array}$ & 70 & 22 & 7 & 0 & 0 & 3.6 & 12 & 23 & 58 & 0 & 8 & 2.3 \\
\hline 6 & temperature vertical gradients $\rightarrow$ vertical diffusion & 64 & 32 & 4 & 0 & 0 & 3.6 & 4 & 70 & 15 & 4 & 7 & 2.6 \\
\hline \multicolumn{2}{|c|}{ Averaged score for all 24 interactions in CWF models } & 44 & 36 & 12 & 3 & 5 & 3.1 & 8 & 35 & 37 & 6 & 14 & 2.1 \\
\hline \multicolumn{14}{|c|}{ (C) Climate modelling } \\
\hline 1 & $\begin{array}{l}\text { aerosols } \rightarrow \text { radiation (shortwave scattering/absorption } \\
\text { and longwave absorption) }\end{array}$ & 75 & 13 & 0 & 0 & 12 & 3.4 & 17 & 41 & 17 & 0 & 25 & 2.3 \\
\hline 2 & $\begin{array}{l}\text { radiatively active gases (e.g. water vapour, } \mathrm{CO}_{2}, \mathrm{O}_{3} \text {, } \\
\left.\mathrm{CH}_{4}, \mathrm{NO} \text { and } \mathrm{CFC}\right) \rightarrow \text { radiation }\end{array}$ & 72 & 16 & 0 & 0 & 12 & 3.4 & 12 & 36 & 20 & 0 & 32 & 2.0 \\
\hline 3 & $\begin{array}{l}\text { aerosol } \rightarrow \text { precipitation (initiation and intensity of pre- } \\
\text { cipitation) }\end{array}$ & 56 & 24 & 4 & 0 & 16 & 3.0 & 0 & 20 & 40 & 4 & 36 & 1.4 \\
\hline 4 & radiation $\rightarrow$ chemical reaction rates and photolysis & 37 & 43 & 10 & 3 & 7 & 3.0 & 10 & 21 & 24 & 4 & 41 & 1.5 \\
\hline 5 & $\begin{array}{l}\text { aerosol } \rightarrow \text { cloud droplet or crystal number density and } \\
\text { hence cloud optical depth }\end{array}$ & 60 & 20 & 0 & 0 & 20 & 3.0 & 4 & 12 & 44 & 0 & 40 & 1.4 \\
\hline 6 & temperature $\rightarrow$ chemical reaction rates and photolysis & 37 & 43 & 10 & 0 & 10 & 3.0 & 17 & 37 & 13 & 0 & 33 & 2.0 \\
\hline \multicolumn{2}{|c|}{ Averaged score for all 24 interactions in climate models } & 38 & 35 & 8 & 1 & 18 & 2.8 & 6 & 20 & 31 & 4 & 39 & 1.5 \\
\hline
\end{tabular}

the complexity of these interactions might hamper their improved representations directly if only a simple change is made.

There might be a few important interactions that have not been identified by the community. However, this does not mean that they are unimportant. The deviations from different individual opinions might exist, but this should be averaged out when calculating the weighted mean ranks.

\section{Overview of currently applied mesoscale online coupled meteorology and air quality models}

The main characteristics of online and offline approaches are discussed in several review papers, e.g. Peters et al. (1995), Zhang (2008), Grell and Baklanov (2011) and Zhang et al. (2012a, b). We will proceed from the definitions provided by Baklanov et al. (2007) for offline and online models and offer a brief overview on the development of online models in Sect. 3.2.

\subsection{Offline models}

Offline models do not exchange information in two directions but merely provide meteorological data to drive the chemistry model. The CTM is driven by meteorological input data that are often derived from meteorological pre-processors. CTMs can use meteorological data from measurements and/or diagnostic models, or the meteorology is taken from analysed or forecasted meteorological data from MetM archives. Offline CTMs might also directly read output-files from operational NWP models or specific MetMs with a given time interval (e.g. every 1, or 3, or $6 \mathrm{~h}$ ). An overview on offline models has been given by Kukkonen et al. (2012) and will not be included here.

\subsection{Online models}

Two types of online models can be distinguished: online integrated models and online access models, each having distinct characteristics: in online access models, meteorological and chemical data are simultaneously available at defined time 
intervals (ideally at every time step), but the CTM and MetM are separate models linked via a model interface and use individual time steps for integration. The CTM and MetM can have also different spatial grids, but they exchange data on regular and frequent bases in both directions. The smaller the timescale of the relevant processes, the smaller the exchange interval needs to be (Mathur et al., 2010).

In online integrated models all meteorological and chemical composition fields are available every time step to both composition and meteorological parameterisations. These fields are calculated simultaneously on the same grid; no interpolation or aggregation to other grids is needed. An online integrated model employs one time step for integration. Processes are treated consistently for both chemical and meteorological quantities. In contrast to offline models, where feedbacks between meteorology and chemistry are not possible, feedbacks are typically included in online integrated models and sometimes in online access models.

The theoretical development of online modelling started more than $90 \mathrm{yr}$ ago. Richardson (1922), the pioneer in numerical weather prediction, suggested an online integrated meteorology pollution model by including a dust transport equation into his NWP model formulation; this was, however, not completely realised at that time. More than half a century later, online coupling started to be considered, for example, at the Novosibirsk scientific school in the USSR (Marchuk, 1982; Penenko and Aloyan, 1985; Baklanov, 1988) and in the German non-hydrostatic modelling community (MESOSCOP, Alheit and Hauf, 1992; METRAS, Schlünzen and Pahl, 1992; GESIMA, Eppel et al., 1995; also see Schlünzen, 1994, for an overview on the German nonhydrostatic models of that period). The earliest online approach for the simulation of climate, air quality and chemical composition may have been a model developed by Jacobson $(1994,1997 \mathrm{a}, \mathrm{b})$. However, the online calculation was still very computationally expensive, and online integration was used without chemistry to meteorology feedbacks (e.g. aerosol composition change studied for a coastal area by von Salzen and Schlünzen, 1999c). Online integration with inclusion of a wider range of feedbacks has only become possible in the past two decades and has been included in only a few models.

American, Canadian and Japanese institutions have developed and used online coupled models operationally for AQ forecasting and for research (GATOR-MMTD: Jacobson et al., 1996, 1997a, b; WRF-Chem: Grell et al., 2005; GEM-AQ: Kaminski et al., 2007; WRF-CMAQ: Mathur et al., 2008; Yu et al., 2011; GEM-MACH: Moran et al., 2010). The European Centre for Medium Range Weather Forecasting (ECMWF) also noted the relevance of online chemistry (Hollingsworth et al., 2008) and several national weather services (such as DMI, UK MetOffice) and research institutions (such as KIT, ISAC, UniHH) are developing online models. For operational or climate applications the cost of online integration is still an issue. Therefore, it is important to deter- mine which feedbacks have the largest impact, and what the minimum requirements are for accurately representing them in an online integrated model.

The atmospheric model database initiated within the COST Action 728 (http://www.mi.uni-hamburg.de/ costmodinv) and the related overview by WMO and COST 728 (Baklanov et al., 2007; Schlünzen and Sokhi, 2008; Baklanov et al., 2011a) show a number of online coupled MetM and CTM systems being developed and used in Europe. Great progress has been made during the past $5 \mathrm{yr}$. with currently 28 online coupled modelling systems in use (Table 4). In 2007, only one European model considered aerosol indirect feedbacks (Enviro-HIRLAM) and about 10 models as of now. The list and current status of online access or online integrated models developed or applied in Europe are presented in Table 4. These models use grid sizes ranging from 1 to $20 \mathrm{~km}$.

The models are applicable to different timescales, ranging from short-term episodes to long-term applications. We define here the length of a short-term episode as ranging between a few days to a couple of weeks (forecast mode), while the long-term horizon addresses integrations over periods of more than 2 weeks (projection mode). Short descriptions of these models are given in Appendix A with some examples of their main applications. Further assessment of online MetChem models in the subsequent sections of this paper will mostly involve these listed models as examples.

\section{Current treatments of interacting processes in online coupled models}

How well feedback is described in an online coupled model will depend on the quality and the degree of detail of all relevant modules of the models' chemistry part. Frequently, meteorological models without chemistry also rely on a certain amount of chemistry information. For example, spatial distributions of the aerosol optical depth or distributions of aerosol and trace gas extinction coefficients from current observations or climatology are used as input for the model's radiation module. Another important parameter that affects the result of a meteorological model is the number of cloud condensation nuclei, where "typical" CCN numbers (e.g. $250 \mathrm{~cm}^{-3}$ at $1 \%$ supersaturation) might be used as input for the meteorological model's cloud module. Within online coupled models these quantities can be derived from simulated trace gas concentrations and aerosol particle number and composition, thus accounting for the spatial and temporal variability. Therefore, the description of the transport and chemistry of gaseous compounds and in particular the dynamics, thermodynamics, composition and mixing state of the atmospheric aerosol as well as its interaction with cloud droplets and ice particles is essential and determines how well chemistry meteorology interactions are represented in an online coupled model. The following sections summarise 
Table 4. Online integrated or online access Meteorology Chemistry models developed or applied in Europe. Typical grid-sizes are from $1 \mathrm{~km}$ to $20 \mathrm{~km}$.

\begin{tabular}{|c|c|c|c|c|c|c|c|}
\hline$N$ & Model, Country, Web-site & $\begin{array}{l}\text { Online ac- } \\
\text { cess (OA) } \\
\text { Online } \\
\text { integrated } \\
\text { (OI) }\end{array}$ & $\begin{array}{l}\text { Meteorology } \\
\text { component }\end{array}$ & $\begin{array}{l}\text { Gas phase chemistry }(\mathrm{gpc}) \& \\
\text { aerosol module (amo) compo- } \\
\text { nents }\end{array}$ & $\begin{array}{l}\text { Feedback of pollution } \\
\text { to meteorology } \\
\text { DAE - Direct aerosol } \\
\text { effect } \\
\text { IAE - Indirect aerosol } \\
\text { effect }\end{array}$ & $\begin{array}{l}\text { Applications } \\
\text { ER - episodes run } \\
\text { LR - long-term runs }\end{array}$ & $\begin{array}{l}\text { Scale } \\
\text { G - global } \\
\mathrm{H} \text { - hemispheric } \\
\mathrm{C} \text { - continental } \\
\mathrm{R} \text { - regional } \\
\mathrm{U} \text { - urban } \\
\mathrm{L} \text { - local }\end{array}$ \\
\hline 1 & BOLCHEM, Italy http://bolchem.isac.cnr.it & $\mathrm{OA}$ & BOLAM & SAPRC90 gpc, AERO3 amo & Under development & $\begin{array}{l}\text { CWF, climate } \\
\text { (ER) }\end{array}$ & $\mathrm{C} \rightarrow \mathrm{R}$ \\
\hline 2 & $\begin{array}{l}\text { COSMO-ART, Germany } \\
\text { http://www.imk-tro.kit.edu/3509.php }\end{array}$ & OI & COSMO & $\begin{array}{l}\text { Extended RADM2 gpc, modal } \\
\text { amo, soot, pollen, mineral } \\
\text { dust, volcanic ash }\end{array}$ & DAE on radiation, IAE & $\begin{array}{l}\text { Climate mode } \\
\text { (ER) }\end{array}$ & $\mathrm{C} \rightarrow \mathrm{R}$ \\
\hline 3 & $\begin{array}{l}\text { COSMO-MUSCAT, Germany }{ }^{\mathrm{b}} \\
\text { http://projects.tropos.de/cosmo_muscat/ }\end{array}$ & $\mathrm{OA}$ & COSMO & $\begin{array}{l}\text { RACM gpc, } 2 \text { modal amo, } \\
\text { mineral dust module }\end{array}$ & $\begin{array}{l}\text { DAE on radiation for } \\
\text { mineral dust }\end{array}$ & (ER) & $\mathrm{C} \rightarrow \mathrm{R}$ \\
\hline 4 & $\begin{array}{l}\text { Enviro-HIRLAM, Denmark and } \\
\text { HIRLAM countries } \\
\text { http://www.hirlam.org/index.php/projects/ } \\
\text { chemistry-branch }\end{array}$ & OI & HIRLAM $^{\mathrm{a}}$ & $\begin{array}{l}\text { NWP and CBM-Z gpc, modal } \\
\text { and sectional amo, liquid } \\
\text { phase chemistry }\end{array}$ & DAE and IAE & $\begin{array}{l}\text { CWF } \\
\text { (ER) }\end{array}$ & $\mathrm{H} \rightarrow \mathrm{R} \rightarrow \mathrm{U}$ \\
\hline 5 & $\begin{array}{l}\text { GEM-AQ Canada and Poland } \\
\text { http://ecoforecast.eu }\end{array}$ & $\mathrm{OA}$ & GEM & ADOM-IIb gpc & $\begin{array}{l}\text { DAE on radiation, IAE } \\
\text { (in-cloud chemistry and } \\
\text { aerosol formation) }\end{array}$ & ER & $\mathrm{C} \rightarrow \mathrm{R}$ \\
\hline 6 & $\begin{array}{l}\text { IFS-MOZART (MACC/ECMWF), C-IFS http: } \\
\text { //www.gmes-atmosphere.eu }\end{array}$ & $\begin{array}{l}\text { OA, } \\
\text { OI }\end{array}$ & IFS & $\begin{array}{l}\text { MOZART gpc with updates to } \\
\text { JPL-06, MACC amo, CBM-05 }\end{array}$ & DAE and IAE & $\begin{array}{l}\text { Forecasts,Reanalysis } \\
\text { (ER) }\end{array}$ & G \\
\hline 7 & $\begin{array}{l}\text { MCCM, Germany } \\
\text { http://www.imk-ifu.kit.edu/829.php }\end{array}$ & OI & MM5 & $\begin{array}{l}\text { RADM2, RACM or RACM- } \\
\text { MIM } \\
\text { gpc with modal amo }\end{array}$ & DAE & $\begin{array}{l}\text { climate-chemistry } \\
\text { (ER) }\end{array}$ & $\mathrm{C} \rightarrow \mathrm{R} \rightarrow \mathrm{U}$ \\
\hline 8 & $\begin{array}{l}\text { MEMO/MARS, Greece } \\
\text { http://pandora.meng.auth.gr/mds/ } \\
\text { showlong.php?id=19 }\end{array}$ & $\mathrm{OA}$ & MEMO & $\begin{array}{l}\text { RACM gpc, } 3 \text { modal amo, SOA } \\
\text { based on SORGAM }\end{array}$ & DAE & (ER \& LR) & $\mathrm{R} \rightarrow \mathrm{U}$ \\
\hline 9 & $\begin{array}{l}\text { Meso-NH, France } \\
\text { http://mesonh.aero.obs-mip.fr/mesonh }\end{array}$ & OI & Meso-NH & $\begin{array}{l}\text { RACM, ReLACS, CACM or } \\
\text { ReLACS2 gpc, ORILAM- } \\
\text { SOA, modal amp (Tulet et al., } \\
\text { 2006), } \\
\text { cloud chemistry including } \\
\text { mixed phase processes (Leriche } \\
\text { et al., 2013) }\end{array}$ & DAE & (ER) & $\mathrm{C} \rightarrow \mathrm{R} \rightarrow \mathrm{U} \rightarrow \mathrm{L}$ \\
\hline 10 & $\begin{array}{l}\text { MetUM (Met Office Unified Model), UK } \\
\text { http://www.metoffice.gov.uk/research/ } \\
\text { modelling-systems/unified-model }\end{array}$ & OI & MetUM & $\begin{array}{l}2 \text { tropo- and } 1 \text { stratospheric } \\
\text { chem. schemes, } 2 \text { alternative } \\
\text { aerosol } \\
\text { schemes }\end{array}$ & $\begin{array}{l}\text { DAE and IAE, radiative } \\
\text { impacts of } \mathrm{N}_{2} \mathrm{O}, \mathrm{O}_{3} \text {, } \\
\mathrm{CH}_{4}\end{array}$ & $\begin{array}{l}\text { CWF, } \\
\text { chemistry } \\
(E R)\end{array}$ & $\mathrm{G} \rightarrow \mathrm{R}$ \\
\hline 11 & $\begin{array}{l}\text { M-SYS (online version), Germany } \\
\text { http://www.mi.uni-hamburg.de/ } \\
\text { SYSTEM-M-SYS.651.0.html }\end{array}$ & OI & METRAS & $\begin{array}{l}\text { RADM2 gpc, sectional amo, } \\
\text { pollen module }\end{array}$ & $\begin{array}{l}\text { None, radiative impacts } \\
\text { of } \mathrm{O}_{3}, \mathrm{CH}_{4}\end{array}$ & (ER) & $\mathrm{R} \rightarrow \mathrm{U} \rightarrow \mathrm{L}$ \\
\hline 12 & $\begin{array}{l}\text { NMMB/BSC-CTM (BSC-CNS), Spain } \\
\text { http://www.bsc.es/earth-sciences/ } \\
\text { mineral-dust-forecast-system }\end{array}$ & $\mathrm{OA}$ & NMMB & $\begin{array}{l}\text { BSC-mineral dust scheme } \\
\text { CBM-IV and CBM05 chemical } \\
\text { mechanisms }\end{array}$ & $\begin{array}{l}\text { DAE on radiation for } \\
\text { mineral dust }\end{array}$ & $\begin{array}{l}\text { Forecast, } \\
\text { Reanalysis } \\
\text { (ER) }\end{array}$ & $\mathrm{G} \rightarrow \mathrm{U}$ \\
\hline 13 & $\begin{array}{l}\text { RACMO2/LOTOS-EUROS } \\
\text { Netherlands } \\
\text { http://www.knmi.nl/research/regional_climate/ } \\
\text { models/racmo.html } \\
\text { http://www.lotos-euros.nl }\end{array}$ & $\mathrm{OA}$ & RACMO2 & $\begin{array}{l}\text { CBM-IV and EQSAM chem- } \\
\text { istry, sectional approach } \\
\left(\mathrm{PM}_{2.5}, \mathrm{PM}_{10}\right)\end{array}$ & $\begin{array}{l}\text { DAE, Effect of aerosol } \\
\text { on CCN }\end{array}$ & $\begin{array}{l}\text { Climate \& policy ori- } \\
\text { ented studies }\end{array}$ & $\mathrm{R}$ \\
\hline 14 & $\begin{array}{l}\text { RAMS/ICLAMS, USA/Greece http://forecast. } \\
\text { uoa.gr/ICLAMS/index.php }\end{array}$ & $\mathrm{OA}$ & RAMS & $\begin{array}{l}\text { Online photolysis rates, cou- } \\
\text { pled SAPRC } 99 \text { gas phase, } \\
\text { modal amo }\end{array}$ & $\begin{array}{l}\text { DAE and IAE } \\
\text { chemistry ISORROPIA } \\
\text { equilibrium and SOA } \\
\text { cloud chemistry }\end{array}$ & $\begin{array}{l}\text { CWF, meteo- } \\
\text { interactions (ER) }\end{array}$ & $\mathrm{C} \rightarrow \mathrm{U}$ \\
\hline 15 & $\begin{array}{l}\text { RegCM-Chem4, Italy } \\
\text { http://users.ictp.it/RegCNET/model.html or } \\
\text { http://gforge.ictp.it/gf/project/regcm }\end{array}$ & OI & RegCM4 & $\begin{array}{l}\text { CBM-Z, uni-modal amo, } \\
\text { sectional mineral dust, sulfur } \\
\text { chemistry }\end{array}$ & DAE & Climate-chemistry & $\mathrm{C} \rightarrow \mathrm{R}$ \\
\hline
\end{tabular}

how these processes are described, which usually also hold for offline CTMs as well, and how their interaction with meteorology is implemented in the different online coupled meteorology chemistry models.

\subsection{Meteorological modelling: dynamical and physical processes - interactions with chemistry}

The wide range of coupled chemistry meteorology models used in Europe is based upon an equally large variety of meteorological models. The scope of this review paper is not to provide any detailed theoretical descriptions of various 
Table 4. Continued.

\begin{tabular}{|c|c|c|c|c|c|c|c|}
\hline$N$ & Model, Country, Web-site & $\begin{array}{l}\text { Online ac- } \\
\text { cess (OA) } \\
\text { Online } \\
\text { integrated } \\
\text { (OI) }\end{array}$ & $\begin{array}{l}\text { Meteorology } \\
\text { component }\end{array}$ & $\begin{array}{l}\text { Gas phase chemistry (gpc) \& } \\
\text { aerosol module (amo) compo- } \\
\text { nents }\end{array}$ & $\begin{array}{l}\text { Feedback of pollution } \\
\text { to meteorology } \\
\text { DAE - Direct aerosol } \\
\text { effect } \\
\text { IAE - Indirect aerosol } \\
\text { effect }\end{array}$ & $\begin{array}{l}\text { Applications } \\
\text { ER - episodes run } \\
\text { LR - long-term runs }\end{array}$ & $\begin{array}{l}\text { Scale } \\
\text { G - global } \\
\mathrm{H} \text { - hemispheric } \\
\mathrm{C} \text { - continental } \\
\mathrm{R} \text { - regional } \\
\mathrm{U} \text { - urban } \\
\mathrm{L} \text { - local }\end{array}$ \\
\hline 16 & $\begin{array}{l}\text { REMO-HAM/REMOTE, Germany } \\
\text { http://www.remo-rcm.de/The-REMO-model. } \\
\text { 1190.0.html }\end{array}$ & $\mathrm{OA}$ & REMO & $\begin{array}{l}\text { RADM2 gas phase, Wal- } \\
\text { cec\&Taylor liquid phase, M7 } \\
\text { (Vignati et al., 2004) }\end{array}$ & $\begin{array}{l}\text { GHGs effects on radia- } \\
\text { tion }\end{array}$ & $\begin{array}{l}\text { (ER) (e.g. volcanic } \\
\text { ash), climate }\end{array}$ & $\mathrm{C} \rightarrow \mathrm{R}$ \\
\hline 17 & $\begin{array}{l}\text { WRF-Chem }{ }^{c} \text {, US (used in Germany, UK, } \\
\text { Spain, Austria, Slovenia, Italy, etc.) } \\
\text { http://wrf-model.org/development/wg11/wg } 11 . \\
\text { php }\end{array}$ & OI & WRF & $\begin{array}{l}\text { Many chemical mechanisms } \\
\text { using KPP software (such } \\
\text { as RADM, RACM, CBM- } \\
\mathrm{Z} \text {, CRIMech as well as } \\
\text { many aerosol approaches } \\
\text { such as bulk (GOCART), } \\
\text { modal (MADE/SORGAM, } \\
\text { MADE/VBS, MAM), and sec- } \\
\text { tional (MOSAIC, MADRID)) }\end{array}$ & DAE and IAE & $\begin{array}{l}\text { CWF, climate- } \\
\text { chemistry } \\
(\mathrm{ER})\end{array}$ & $\begin{array}{l}\mathrm{C} \rightarrow \mathrm{R}, \mathrm{G} \rightarrow \mathrm{U} \rightarrow \\
\mathrm{LES}\end{array}$ \\
\hline 18 & $\begin{array}{l}\text { WRF-CMAQ Coupled System, USA (used in } \\
\text { UK) }\end{array}$ & OA & WRF & $\begin{array}{l}\text { gpc: CB05 with up- } \\
\text { dated toluene chemistry, } \\
\text { SAPRC07TB; AERO6 amo }\end{array}$ & $\begin{array}{l}\text { DAE on radiation and } \\
\text { photolysis }\end{array}$ & ER \& LR & $\mathrm{H} \rightarrow \mathrm{U}$ \\
\hline
\end{tabular}

a New version of the model based on the HARMONIE meteorological core is under development.

b The COSMO-MUSCAT and RACMO2/LOTOS-EUROS systems are not online models and only partly/conditionally can be included into the category of online access

Meteorology-Chemistry models, because the MetM and CTM interfaces not on each time step, but they have started implementing some feedback mechanisms.

c Besides the official version of WRF-Chem mentioned here, there exist several other versions, e.g. by Li et al. (2010), MADRID: Zhang et al. (2010a, 2012d, 2013).

meteorological models since they are extensively described in meteorology textbooks and the specific model descriptions. The purpose of this section is to summarise the processes that are most relevant to coupling with atmospheric composition modules. A list of meteorological models with the main numerical schemes or physical parametrizations used in coupled models is summarised in Table 5. This table also contains a number of references for further reading.

Equations for meteorological variables are solved partly by the dynamics part that calculates the evolution of the atmospheric flow due to grid-resolved processes and partly via parametrizations that describe unresolved (i.e. subgrid) dynamical processes (e.g. boundary layer turbulence, subgrid scale orographic drag, non-orographic gravity wave drag and convection) or non-fluid dynamical processes (e.g. radiation, clouds and large scale precipitation, surface-atmosphere interactions). NWP models differ greatly in terms of their treatments of dynamical and physical processes, their discretisation schemes, approximations (hydrostatic vs. nonhydrostatic) as well as their advection formulation (semiLagrangian vs. Eulerian).

The dynamical and physical processes that are relevant for coupling meteorology and atmospheric chemistry (i.e. which have a strong direct influence on atmospheric composition) include:

1. Advection is a grid-resolved process in meteorological models, which largely controls the atmospheric transport of chemical species in coupled models. Mass conservation can become an issue if meteorological and chemical variables are not advected using the same numerics. There are large differences among models, with Eulerian and semi-Lagrangian schemes as the two main classes (Sect. 5.1). Eulerian schemes can be made trivially conservative (e.g. weighted average flux methods; Toro, 1992), but sophisticated methods have been developed also for semi-Lagrangian formulations (e.g. Kaas, 2008).

2. Vertical diffusion is typically implemented by solving the advection-diffusion equation with diffusion coefficients computed by different methods. Some are diagnostic, while others are based on prognostic equations for the turbulent kinetic energy (TKE) and a diagnostic estimation of the mixing length scale. Vertical profiles of turbulent diffusion coefficients determine the dispersion properties in the atmospheric boundary layer (ABL) and, therefore, have great influence on surface concentrations (Dandou et al., 2009; Schafer et al., 2011). Stable cases are the most problematic, and large differences exist among models (Zilitinkevich and Baklanov, 2002; Svensson et al., 2011).

3. Convection is known to be an extremely important process for simulating and forecasting weather and air quality. It can transport tracers quickly from the boundary layer into the free troposphere, or even into the stratosphere for some deep convective events. Convection is often divided into shallow, mid-level and deep convection. Several parametrization schemes are widely used for parametrizing deep convection (Tiedtke, 1989; Kain and Fritsch, 1993; Zhang and McFarlane, 1995; Manabe et al., 1965; Grell and Devenyi, 2002). In models with a resolution of the order of magnitude of $10 \mathrm{~km}$, deep convection impacts aerosol concentrations through microphysics and 
Table 5. Meteorology models currently used as basis for coupled models.

\begin{tabular}{|c|c|c|c|c|c|c|c|}
\hline $\begin{array}{l}\text { NWP } \\
\text { model }\end{array}$ & References/documentation & $\begin{array}{l}\text { Continuity } \\
\text { Eq. Approx. }\end{array}$ & Advection & Convection & $\begin{array}{l}\text { Vertical } \\
\text { diffusion }\end{array}$ & Radiation & $\begin{array}{l}\text { Underlying } \\
\text { meteorology } \\
\text { component } \\
\text { in CTM }\end{array}$ \\
\hline BOLAM & $\begin{array}{l}\text { http://www.isac.cnr.it/ dinamica/ } \\
\text { bolam/index.html }\end{array}$ & $\begin{array}{l}\text { Incompressible, } \\
\text { hydrostatic }\end{array}$ & $\begin{array}{l}\text { Weighted } \\
\text { Average Flux } \\
\text { (Toro, 1992) }\end{array}$ & $\begin{array}{l}\text { Kain and Fritsch } \\
\text { (1993) }\end{array}$ & Prognostic TKE & $\begin{array}{l}\text { Mixed: } \\
\text { Morcrette (1991); } \\
\text { Ritter and Geleyn } \\
(1992)\end{array}$ & BOLCHEM \\
\hline COSMO & $\begin{array}{l}\text { Baldauf et al. (2011), Steppeler } \\
\text { et al. (2003) http://www.cosmo- } \\
\text { model.org/content/model/documentation/ } \\
\text { core/default.htm }\end{array}$ & $\begin{array}{l}\text { Non- } \\
\text { hydrostatic }\end{array}$ & $\begin{array}{l}\text { Semi- } \\
\text { Lagrangian, } \\
\text { Lin and Rood } \\
\text { (1996), Bott } \\
(1993)\end{array}$ & $\begin{array}{l}\text { Moist: Tiedtke } \\
\text { (1989). Option for } \\
\text { the Kain-Fritsch } \\
\text { (1993) scheme } \\
\text { Shallow: Reduced } \\
\text { Tiedtke scheme }\end{array}$ & Prognostic TKE & $\begin{array}{l}\delta \text { two-stream } \\
\text { radiation scheme } \\
\text { after Ritter and } \\
\text { Geleyn (1992) }\end{array}$ & $\begin{array}{l}\text { COSMO-ART, } \\
\text { COSMO-LM- } \\
\text { MUSCAT }\end{array}$ \\
\hline ECWMF-IFS & $\begin{array}{l}\text { http://www.ecmwf.int/research/ } \\
\text { ifsdocs/CY38r1/index.html }\end{array}$ & hydrostatic & $\begin{array}{l}\text { Semi- } \\
\text { Lagrangian } \\
\text { (Hortal, 2002) }\end{array}$ & $\begin{array}{l}\text { Mass-flux scheme } \\
\text { described in } \\
\text { Bechtold } \\
\text { et al. (2008) }\end{array}$ & $\begin{array}{l}\text { Based on local } \\
\text { Richardson } \\
\text { number and } \\
\text { Monin-Obukov } \\
\text { profile (Beljaars } \\
\text { and Viterbo, 1999) }\end{array}$ & $\begin{array}{l}\text { McRad } \\
\text { Morcrette et al. (2009) }\end{array}$ & $\begin{array}{l}\text { C-IFS, } \\
\text { IFS-MOZART } \\
\text { HAMMOZ } \\
\text { EHAM5/6 }\end{array}$ \\
\hline GEM & $\begin{array}{l}\text { Côté et al. (1998) } \\
\text { http://collaboration.cmc.ec.gc.ca/ } \\
\text { science/rpn/gem }\end{array}$ & $\begin{array}{l}\text { Hydrostac and } \\
\text { Non-hydrostatic } \\
\text { depending on } \\
\text { resolution }\end{array}$ & $\begin{array}{l}\text { Semi- } \\
\text { Lagrangian }\end{array}$ & $\begin{array}{l}\text { Kuo-type deep } \\
\text { convection scheme } \\
\text { Kain and Fritsch } \\
\text { (1993) }\end{array}$ & Prognostic TKE & $\begin{array}{l}\text { LW: Garand (1983), } \\
\text { Garand and } \\
\text { Mailhot (1990) } \\
\text { SW: Fouquart-Bonnel } \\
\text { Correlated K } \\
\text { Li and Barker (2005) }\end{array}$ & $\begin{array}{l}\text { On-line in the } \\
\text { GEM model }\end{array}$ \\
\hline HARMONIE & $\begin{array}{l}\text { http://hirlam.org/index.php?option= } \\
\text { com_content\&view=article\&id= } \\
\text { 65\&ltemid=102 }\end{array}$ & $\begin{array}{l}\text { Compressible } \\
\text { non-hydrostatic }\end{array}$ & $\begin{array}{l}\text { Semi- } \\
\text { Lagrangian }\end{array}$ & As AROME & As AROME & $\begin{array}{l}\text { ACRANEB } \\
\text { (Ritter and Geleyn, 1992) }\end{array}$ & $\begin{array}{l}\text { Enviro- } \\
\text { HIRLAM/ } \\
\text { HARMONIE }\end{array}$ \\
\hline HIRLAM & $\begin{array}{l}\text { http://hirlam.org/index.php?option= } \\
\text { com_content\&view=article\&id= } \\
64 \& \text { Itemid=101 }\end{array}$ & $\begin{array}{l}\text { Hydrostatic } \\
\text { and non- } \\
\text { hydrostatic } \\
\text { versions }\end{array}$ & $\begin{array}{l}\text { Semi- } \\
\text { Lagrangian }\end{array}$ & $\begin{array}{l}\text { Modified STRACO } \\
\text { (Sass and Yang, 2002) or } \\
\text { Kain and Fritsch (1993) }\end{array}$ & $\begin{array}{l}\text { CBR Cuxart } \\
\text { et al. (2000) }\end{array}$ & Savijärvi (1990) & $\begin{array}{l}\text { Enviro- } \\
\text { HIRLAM }\end{array}$ \\
\hline MEMO & $\begin{array}{l}\text { http://pandora.meng.auth.gr/mds/ } \\
\text { showlong.php?id=19 }\end{array}$ & $\begin{array}{l}\text { Non- } \\
\text { hydrostatic }\end{array}$ & $\begin{array}{l}\text { TVD and FCT } \\
\text { schemes }\end{array}$ & NA & Prognostic TKE & $\begin{array}{l}\text { LW, SW: } \\
\text { Moussiopoulos } \\
\text { (1987), Halmer } \\
(2012)\end{array}$ & MEMO/MARS \\
\hline Meso-NH & $\begin{array}{l}\text { http://mesonh.aero.obs-mip.fr/ } \\
\text { mesonh/ }\end{array}$ & $\begin{array}{l}\text { Non- } \\
\text { hydrostatic }\end{array}$ & $\begin{array}{l}\text { 4th order } \\
\text { difference } \\
\text { Eulerian } \\
\text { schemes }\end{array}$ & $\begin{array}{l}\text { Mass flux } \\
\text { (Bechtold et al., } \\
\text { 2001) }\end{array}$ & $\begin{array}{l}\text { Turbulence } \\
\text { scheme } \\
\text { Cuxart et al. } \\
(2000)\end{array}$ & $\begin{array}{l}\text { LW: RRTM } \\
\text { (Mlawer et. al., } \\
\text { 1997); SW: } \\
\text { Fouquart (1980) }\end{array}$ & Meso-NH \\
\hline METRAS & $\begin{array}{l}\text { Schlunzen et al. (2012) } \\
\text { http://www.mi.uni-hamburg.de/ } \\
\text { 692.html }\end{array}$ & $\begin{array}{l}\text { Anelastic, non- } \\
\text { hydrostatic }\end{array}$ & $\begin{array}{l}\text { Adams } \\
\text { Bashfort } \\
\text { scheme with } \\
\text { centred or up } \\
\text { to 3rd order } \\
\text { (W)ENO } \\
\text { (Schroeder } \\
\text { et al., 2006) } \\
\text { advection }\end{array}$ & $\begin{array}{l}\text { Explicit scheme } \\
\text { for clouds by for- } \\
\text { atmosphere } \\
\text { turbulence, counter } \\
\text { gradient scheme } \\
\text { for shallow con- } \\
\text { vection (Lupkes and } \\
\text { Schlunzen, 1996) }\end{array}$ & $\begin{array}{l}\text { Choice of different } \\
\text { schemes, normaly } \\
\text { chosen: maximum } \\
\text { of Blackadar and } \\
\text { counter gradient } \\
\text { scheme (Lupkes and } \\
\text { Schlunzen, 1996) }\end{array}$ & $\begin{array}{l}\text { LW and SW } \\
\text { calculated Using } \\
\text { 2-stream } \\
\text { approximation }\end{array}$ & M-SYS \\
\hline
\end{tabular}

complex storm dynamics. However, the processes lack a complete understanding (Khain et al., 2008; Khain, 2009). Few attempts have been made to implement these processes in convection parametrizations (Grell and Freitas, 2013). An important complication is that with currently used horizontal and vertical resolutions, convection needs either to be parametrized (still used in most CTM's, resolution $\sim 10 \mathrm{~km}$ ), or resolved with high-resolution cloud resolving models (resolution $1 \mathrm{~km}$ to $4 \mathrm{~km}$ ), or there needs to be a mixture of the two. The use of parameterisations in convection-aware simulations (sometimes also called grey scales), when no clear-cut scale separation exists, has become a major area of research (Kuell et al., 2007; Gerard et al., 2009; Arakawa et al., 2011; Grell and Freitas, 2013). Some approaches for parametrizing shallow convection are available and are used in high-resolution numerical models (Holtslag and Moeng, 1991; Lüpkes and Schlünzen, 1996). However, they also lack the treatment of chemical reactions within the convective plumes.

4. Cloud microphysics determines the formation and lifetime of clouds and has important effects on chemical (water-soluble) species in coupled models. Cloud schemes usually also take into account important cloud processes such as cloud-top entrainment, precipitation of water and ice and evaporation of precipitation (Sect. 4.4 and overview in Lohmann, 2006; Stensrud, 2007; Sokhi et al., 2014).

5. Radiation schemes calculate radiative fluxes from temperature, specific humidity, liquid/ice water content and cloud fraction and radiatively active chemical components. These should include black and organic carbon (BC and OC, respectively), sulfate, sea salt, nitrate, ammonia, dust and other aerosols as well as the main greenhouse gases (GHG) such as $\mathrm{CO}_{2}, \mathrm{O}_{3}, \mathrm{CH}_{4}$, 
Table 5. Continued.

\begin{tabular}{|c|c|c|c|c|c|c|c|}
\hline $\begin{array}{l}\text { NWP } \\
\text { model }\end{array}$ & References/documentation & $\begin{array}{l}\text { Continuity } \\
\text { Eq. Approx. }\end{array}$ & Advection & Convection & $\begin{array}{l}\text { Vertical } \\
\text { diffusion }\end{array}$ & Radiation & $\begin{array}{l}\text { Underlying } \\
\text { meteorology } \\
\text { component } \\
\text { in CTM }\end{array}$ \\
\hline MM5 & $\begin{array}{l}\text { Grell et al. (1994), NCAR Tech } \\
\text { Note TN-398 + STR, } \\
\text { http://www.mmm.ucar.edu/mm5/ } \\
\text { http://www.mmm.ucar.edu/mm5/ } \\
\text { documents/mm5-desc-doc.html }\end{array}$ & $\begin{array}{l}\text { Non- } \\
\text { hydrostatic }\end{array}$ & $\begin{array}{l}\text { Leap frog with } \\
\text { Asselin filter } \\
\text { For tracers: } \\
\text { Smolarciewicz } \\
\text { and Grabowski } \\
\text { (1990) }\end{array}$ & $\begin{array}{l}\text { Choice between } \\
\text { Anthes-Kuo, Grell, } \\
\text { Arakawa-Schubert, } \\
\text { Fritch-Chapell, } \\
\text { Kain-Fritsch, and } \\
\text { Betts-Miller- } \\
\text { scheme }\end{array}$ & $\begin{array}{l}\text { Choice be- } \\
\text { tween Blackadar, } \\
\text { Burk-Thomson, } \\
\text { ETA, MRF, } \\
\text { Gayno-Seaman, } \\
\text { and Pleim-Chang } \\
\text { scheme; for } \\
\text { MCCM limited to } \\
\text { Burk-Thomson } \\
\text { (1989) scheme }\end{array}$ & $\begin{array}{l}\text { Choice between } \\
\text { "Cloud" (Dudhia), } \\
\text { CCM3, and } \\
\text { RRTM scheme }\end{array}$ & MCCM \\
\hline NMMB & Janjic and Gall (2012) & $\begin{array}{l}\text { Non- } \\
\text { hydrostatic }\end{array}$ & $\begin{array}{l}\text { Eulerian, Adams } \\
\text { Bashforth } \\
\text { (Janjic and } \\
\text { Gall, 2012) }\end{array}$ & $\begin{array}{l}\text { Betts-Miller- } \\
\text { Janjic } \\
\text { (Janjic, 2000) }\end{array}$ & Prognostic TKE & $\begin{array}{l}\text { RRTM (Mlawer } \\
\text { et al., 1997) }\end{array}$ & $\begin{array}{l}\text { NMMB/ } \\
\text { BSC-CTM }\end{array}$ \\
\hline RACMO2 & $\begin{array}{l}\text { http://www.knmi.nl/research/regional_limate/ } \\
\text { uploads/models/FinalReportCS06.pdf }\end{array}$ & Hydrostatic & $\begin{array}{l}\text { Semi- } \\
\text { Lagrangian }\end{array}$ & $\begin{array}{l}\text { Tiedtke (1989), } \\
\text { Nordeng (1994), } \\
\text { Neggers et al. } \\
(2009)\end{array}$ & $\begin{array}{l}\text { Lenderink and } \\
\text { Holtslag (2004), } \\
\text { Siebesma et al. } \\
(2007)\end{array}$ & $\begin{array}{l}\text { Fouquart and } \\
\text { Bonnel (1980), } \\
\text { Mlawer et al. } \\
(1997)\end{array}$ & $\begin{array}{l}\text { LOTOS- } \\
\text { EUROS }\end{array}$ \\
\hline RAMS & $\begin{array}{l}\text { Cotton et al. (2003) } \\
\text { http://www.atmet.com/ }\end{array}$ & $\begin{array}{l}\text { Non- } \\
\text { hydrostatic } \\
\text { or } \\
\text { hydrostatic }\end{array}$ & $\begin{array}{l}\text { Hybrid } \\
\text { combination } \\
\text { of leapfrog } \\
\text { and forward } \\
\text { in time } \\
\text { (Tremback, } \\
\text { 1987) }\end{array}$ & $\begin{array}{l}\text { Modified Kuo } \\
\text { (Tremback 1990) } \\
\text { Kain-Fritsch } \\
\text { cumulus } \\
\text { parameterization }\end{array}$ & $\begin{array}{l}\text { Smagorinsky } \\
\text { (1963), Lilly } \\
\text { (1962) and Hill } \\
\text { (1974). } \\
\text { Deardorff and } \\
\text { Mellor-Yamada } \\
\text { level 2.5 } \\
\text { Isotropic TKE }\end{array}$ & $\begin{array}{l}\text { L\&SW: Chen and } \\
\text { Cotton (1983), } \\
\text { Harrington (1997), } \\
\text { Solomos et al. (2011) } \\
\text { RRTM Mlawer et al. } \\
\text { (1997), lacono } \\
\text { et al. (2000) }\end{array}$ & $\begin{array}{l}\text { RAMS/ } \\
\text { ICLAMS }\end{array}$ \\
\hline RegCM4 & http://www.ictp.it/research/esp/models/regcm4.aspx & Hydrostatic & $\begin{array}{l}\text { Weighted } \\
\text { Average Flux } \\
\text { Semi- } \\
\text { lagrangian }\end{array}$ & $\begin{array}{l}\text { mass-flux cumulus } \\
\text { scheme (Grell, } \\
\text { 1993; Tiedke, } \\
\text { 1989) }\end{array}$ & $\begin{array}{l}\text { Holtslag and } \\
\text { Bouville (1993), } \\
\text { UW pbl } \\
\text { (Bretherton } \\
\text { et al., 2004) }\end{array}$ & $\begin{array}{l}\text { CCM3 Kiehl } \\
\text { et al. (1996), } \\
\text { RRTM/MclCA, } \\
\text { Mlawer et al. } \\
(1997)\end{array}$ & $\begin{array}{l}\text { RegCM- } \\
\text { Chem4, } \\
\text { EnvClimA }\end{array}$ \\
\hline REMO & $\begin{array}{l}\text { http://www.remo-rcm.de/The-REMO- } \\
\text { model.1190.0.html }\end{array}$ & Hydrostatic & $\begin{array}{l}\text { Second order } \\
\text { horizontal and } \\
\text { vertical } \\
\text { differences }\end{array}$ & $\begin{array}{l}\text { Mass-flux } \\
\text { convection } \\
\text { scheme after } \\
\text { Tiedke (1989) }\end{array}$ & $\begin{array}{l}\text { Louis (1979) in } \\
\text { Prandtl layer, ext. } \\
\text { level-2 scheme } \\
\text { Mellor and Yamada } \\
\text { (1974) in Ekman } \\
\text { layer and free- } \\
\text { flow, modif. for } \\
\text { clouds }\end{array}$ & $\begin{array}{l}\text { Delta-two-stream } \\
\text { radiation scheme } \\
\text { after Ritter and } \\
\text { Geleyn (1992) }\end{array}$ & $\begin{array}{l}\text { REMOTE, } \\
\text { REMO-HAM }\end{array}$ \\
\hline MetUM & $\begin{array}{l}\text { Davies et al. (2005), } \\
\text { http://www.metoffice.gov.uk/research/ } \\
\text { modelling-systems/unified-model }\end{array}$ & $\begin{array}{l}\text { Non- } \\
\text { hydrostatic } \\
\text { for latest } \\
\text { version }\end{array}$ & $\begin{array}{l}\text { Semi- } \\
\text { Lagrangian }\end{array}$ & Lock et al. (2000) & Lock et al. (2000) & $\begin{array}{l}\text { Edwards and } \\
\text { Slingo (1996) }\end{array}$ & MetUM \\
\hline WRF & $\begin{array}{l}\text { Skamarock et al. (2008), } \\
\text { http://www.wrf-model.org/index.php }\end{array}$ & $\begin{array}{l}\text { non- } \\
\text { hydrostatic, } \\
\text { fully } \\
\text { compressible }\end{array}$ & $\begin{array}{l}\text { RK3 scheme, } \\
\text { described in } \\
\text { Wicker and } \\
\text { Skamarock } \\
\text { (2002) }\end{array}$ & $\begin{array}{l}\text { Modified Kain } \\
\text { and Fritsch } \\
\text { (1993), Grell } \\
\text { and Devenyi } \\
\text { (2002) and others }\end{array}$ & $\begin{array}{l}\text { Choices between } \\
\text { over } 10 \text { schemes, } \\
\text { e.g.,YSU and MYJ } \\
\text { (Hong et al., 2006; } \\
\text { Janjic, 2002) }\end{array}$ & $\begin{array}{l}\text { SW: Goddard; } \\
\text { Dudhia, and others } \\
\text { LW: RRTM and others }\end{array}$ & $\begin{array}{l}\text { WRF-Chem } \\
\text { WRF-CMAQ }\end{array}$ \\
\hline
\end{tabular}

$\mathrm{N}_{2} \mathrm{O}, \mathrm{CFCl}_{3}$ and $\mathrm{CF}_{2} \mathrm{Cl}_{2}$. Major issues are how accurately these species are represented and how refractive indices are defined for aerosols (e.g. internal/external mixing, etc.; Sect. 4.2) (e.g. overview in Stensrud, 2007; Sokhi et al., 2014).

6. Turbulent fluxes at the surface are parametrized through different surface layer formulations (e.g. Louis, 1979; Zilitinkevich et al., 2006) and canopy (vegetation or urban) models (Hidalgo et al., 2008). Surface fluxes depend considerably on the land cover. Some models only consider one land cover type per grid cell, but others parametrize the effects of subgrid scale land use on turbulent fluxes (e.g. Schlünzen and Katzfey, 2003). Above the sea surface, drag is often parametrized using the Charnock (1955) formula, due to missing wave data. It works reasonably well for flat coastal regions, while for deeper water recent studies suggest a different approach (Foreman and Emeis, 2010). In particular, this latter approach has a much better asymptotic behaviour for high wind speeds and hurricanes. In some cases (e.g. ECMWF-IFS) a twoway interaction has already been established between wind and the wave model (e.g. Janssen et al., 2002).

\subsection{Atmospheric chemical mechanisms: gas and aqueous-phase}

The chemical mechanism implemented in a model can only represent a simplified set of all the chemical reactions among all chemical species in the actual atmosphere. This is necessary due to the complexity of the atmospheric system for both predicting concentrations of gases or calculating the source of pollutants. The chemical reactions needed to 
Table 6. Comparison of chemical mechanisms used in coupled models. In the photolysis rate column, "+" means documentation available does not separately list the photolysis reactions and so they are included in the chemical reactions. NA means the available documentation either did not include the relevant data or that the mechanism does not include any heterogeneous reactions. Note that most of these mechanisms are explicitly gas phase chemistry mechanisms - the models in which they are implemented may include in addition aqueous phase chemistry.

\begin{tabular}{|c|c|c|c|c|c|c|c|}
\hline Mechanism & $\begin{array}{l}\text { Chem } \\
\text { Species }\end{array}$ & $\begin{array}{l}\text { Chem } \\
\text { rxns }\end{array}$ & $\begin{array}{l}\text { Photol } \\
\text { rxns }\end{array}$ & $\begin{array}{l}\text { Het. } \\
\text { rxns }\end{array}$ & $\begin{array}{l}\text { Aq. } \\
\text { chem }\end{array}$ & Model(s) & Reference(s) \\
\hline ADOM-IIb & 50 & 100 & + & NA & NA & GEM & Venkatram et al. (1988) \\
\hline CACM & 189 & 349 & + & NA & NA & Meso-NH & Griffin et al. (2002) \\
\hline CBM-IV (aka CB4) & 33 & 81 & + & NA & NA & $\begin{array}{l}\text { NMMB/BSC-CTM, BOLCHEM, } \\
\text { RACMO2/LOTOS-EUROS }\end{array}$ & Gery et al. (1989) \\
\hline CBM-05 (aka CB05) & 52 & 156 & + & NA & NA & NMMB/BSC-CTM, WRF-CMAQ, C-IFS & Sarwar et al. (2008) \\
\hline CBM-Z & $55-66$ & 132 & + & NA & NA & $\begin{array}{l}\text { RegCM-Chem, Enviro-HIRLAM, WRF- } \\
\text { Chem }\end{array}$ & Zaveri and Peters (1999) \\
\hline GEOS-CHEM & 80 & $>300$ & + & $\begin{array}{l}\mathrm{N}_{2} \mathrm{O}_{5} \text { and } \mathrm{NO}_{3} \text { to } \\
\text { nitric acid in sulphate }\end{array}$ & NA & RegCM-Chem (under testing) & Bey et al. (2001) \\
\hline CRIMech & 240 & 652 & + & NA & NA & WRF-Chem & Watson et al. (2008) \\
\hline MECCA1 & 116 & 295 & + & NA & NA & MESSy(ECHAM5) & Sander et al. (2005) \\
\hline MOZART2 & 63 & 132 & 32 & $\begin{array}{l}\mathrm{N}_{2} \mathrm{O}_{5} \text { and } \mathrm{NO}_{3} \text { on } \\
\text { sulphate }\end{array}$ & NA & ECHAM5/6-HAMMOZ & Horowitz et al. (2003) \\
\hline MOZART3 & 108 & 218 & 18 & 71 & NA & IFS-MOZART & Kinnison et al. (2007) \\
\hline MOZART4 & 85 & 157 & 39 & 4 & NA & ECHAM5/6-HAMMOZ, WRF-Chem & Emmons et al (2010) \\
\hline NWP-Chem & $17-28$ & $27-32$ & 4 & NA & 17 & Enviro-HIRLAM v1 & Korsholm et al. (2008) \\
\hline RADMK & 86 & 171 & 22 & 1 & NA & COSMO-ART & Vogel et al. (2009) \\
\hline RADM2 & 63 & 136 & 21 & NA & NA & $\begin{array}{l}\text { MCCM, M-SYS, REMO,WRF-Chem; } \\
\text { M-SYS }\end{array}$ & Stockwell et al. (1990) \\
\hline RACM & 77 & 214 & 23 & NA & NA & $\begin{array}{l}\text { COSMO-LM-MUSCAT, MCCM, Meso- } \\
\text { NH, RegCM-Chem,MEMO/MARS, WRF- } \\
\text { Chem }\end{array}$ & Stockwell et al. (1997) \\
\hline RACM-MIM & 84 & 221 & 23 & NA & NA & MCCM, WRF-Chem & Geiger et al. (2003) \\
\hline RAQ (plus CLASSIC) & 61 & 115 & 23 & NA & $\begin{array}{l}\text { Oxidation of } \mathrm{SO} 2 \text { by } \\
\mathrm{H} 2 \mathrm{O} 2 \text { and } \mathrm{O} 3\end{array}$ & MetUM & Collins et al. $(1997,1999)$ \\
\hline ReLACS & 37 & 128 & + & NA & NA & Meso-NH & Crassier et al. (2000) \\
\hline ReLACS2 & 82 & 343 & + & NA & NA & Meso-NH & Tulet et al. (2006) \\
\hline ReLACS-AQ & 41 & 128 & + & NA & $\begin{array}{l}\text { Complete Aq. Phase } \\
\text { chemistry }\end{array}$ & Meso-NH & $\begin{array}{l}\text { Crassier et al. (2000), } \\
\text { Leriche et al. (2013) }\end{array}$ \\
\hline SAPRC90 SOA & 43 & 131 & 16 & NA & NA & BOLCHEM & Carter (1990) \\
\hline SAPRC99 & 72 & 198 & + & NA & NA & $\begin{array}{l}\text { RAMS/ICLAMS, WRF-CMAQ, WRF- } \\
\text { Chem }\end{array}$ & Carter (2000) \\
\hline SAPRC07 & $44-207$ & $126-640$ & + & NA & NA & WRF-CMAQ & Carter (2010) \\
\hline $\begin{array}{l}\text { StdTrop } \\
\text { (plus CLASSIC) }\end{array}$ & 42 & 96 & 25 & NA & $\begin{array}{l}\text { Oxidation of } \mathrm{SO} 2 \text { by } \\
\mathrm{H} 2 \mathrm{O} 2 \text { and } \mathrm{O} 3\end{array}$ & MetUM & Law et al. (1998) \\
\hline
\end{tabular}

model air quality include gas phase reactions (both thermal and photolytic reactions), heterogeneous reactions on surfaces of condensed phases (e.g. the surface of dry and wet aerosols and other surfaces such as the ground or buildings) and aqueous-phase reactions. These reactions are coupled to various other meteorological processes in the atmosphere. Therefore, online modelling is a better framework for estimating the chemical reaction rates and resultant pollutant concentrations. For example, gas phase reactions depend on the temperature; photolytic rates depend on radiative transfer, which in turn depends on cloud and aerosol processes; the production of the hydroxyl radical depends on the water vapour concentration. Heterogeneous reactions on the surface of aerosols depend on the surface area and composition as well as the liquid water content of the aerosol. Last but not least, aqueous-phase chemistry is a function of the cloud liquid water content. The concentrations of chemically and radiatively active gases (in particular, ozone and methane) are important for climate modelling timescales, while chemistry leading to aerosol formation has a greater role for meteorology on timescales of days. Online modelling explicitly takes into account these linkages.

As shown in Table 6, there is a wide variety of chemistry schemes/mechanisms currently in use to simplify the chemistry to varying extent. For comparison, the current version of the Master Chemical Mechanism (MCM - Jenkin et al., 1997; Saunders et al., 2003) contains about 17000 reactions, 6700 primary, secondary and radical species, as well as nearly 800 reactions of explicit aqueous-phase mechanisms (Herrmann et al., 2005), whereas the mechanisms described operationally in 3-D models include at most a few hundred reactions (i.e. so-called condensed or reduced mechanisms).

Since the number of species and reactions of atmospheric inorganic chemistry is manageable computationally, most of the reduction concerns the organic chemistry pathways. Although comprehensive mechanisms such as MCM have 
been incorporated into 3-D models (e.g. Jacobson and Ginnebaugh, 2010; Ying and Li, 2011), most 3-D models use reduced mechanisms for computational efficiency. Simplification can be achieved in a number of ways, e.g. by neglecting volatile organic compounds (VOCs) of lesser importance, by removing less important chemical reactions from the full mechanism, or by lumping together related chemical species or functional groups. This simplification (or "mechanism reduction") can be achieved by using automated tools that analyse the mechanism (e.g. Szopa et al., 2005) or by expert knowledge. The reduced mechanism is then evaluated by comparison to laboratory "smog chamber" data and/or to the full mechanism. Most chemical mechanisms used in 3-D models have been developed independently from full mechanisms. One can distinguish two main categories of reduced mechanisms: the surrogate molecule mechanisms and the carbon-bond mechanisms. In a surrogate molecule mechanism, several VOC molecules of the same class (e.g. short-chain alkanes) are grouped and represented by a single molecule. The mechanism associated with that molecule is then typically a weighted average of the molecules that it represents. In a carbon-bond mechanism, each VOC molecule is broken down into functional groups (e.g. carbonyl group, double-bond) and an oxidation mechanism is developed for each of those functional groups. The creation of a chemical mechanism is a significant investment. Another issue is that in different parts of the atmosphere, different chemical reactions are important. In this paper, we focus on regional models and on tropospheric chemistry, but it should be noted that some global models incorporate both stratospheric and tropospheric chemistry. In general, most models use both gas and aqueous-phase mechanisms, with relatively more detail in the gas phase mechanisms. The more explicit treatment of liquid-phase chemistry is included in limited area models that simulate interactions with cloud systems (Tilgner et al., 2010; Lim et al., 2010). Lim et al. (2010) showed the importance of aqueous-phase chemistry in the production of secondary organic aerosol (SOA).

There is a wide variety of chemical mechanisms currently in use. Among the most commonly used are the following surrogate molecule mechanisms, RADM2, RACM, RACM2, RACM-MIM, SAPRC90, SAPRC99, SPARC07TB, MELCHIOR, ADOM, MOZART2, 3 and 4, NWP-Chem, RADMKA, ReLACS, RAQ, MECCA1 and GEOS-Chem and the most recent carbon-bond mechanisms, CB-IV, CB05, CB06 and CBM-Z. Some mechanisms were developed independently (e.g. SAPRC99, CB05) while others were developed in connection with a specific CTM (e.g. NWPChem developed for Enviro-HIRLAM, RAQ for the MetUM). Some mechanisms even carry the name of the corresponding CTM (MOZART, GEOS-CHEM). By using a mechanism developed previously, less effort is required in setting it up and in updating to account for new laboratory findings. However, the advantage of a group creating its own mechanism is that they can make their own judgments about the importance of specific reactions and the cost/benefit to the desired model applications.

A complication in attempting to review chemical mechanisms in use is that some mechanisms offer options to include or exclude some chemical reactions, depending on the requirements of a specific study. This means that the number of tracers and reactions is not a single number for each mechanism. Table 6 includes a range of the number of tracers and reactions for such mechanisms with options. Furthermore, some groups take an existing mechanism and make their own modifications (for example, RADMK is a modified version of RADM) or keep an existing mechanism but update the reaction rates with the latest recommended values.

Today, the most commonly used mechanisms have converged in terms of the state of the science and comparable results are obtained, for example, with a surrogate molecule mechanism and a carbon-bond mechanism. Nevertheless, differences occur in the simulated concentrations, which result from differences in the oxidation mechanisms of VOCs (e.g. for aromatics) as well as in the kinetic data (e.g. for the oxidation of $\mathrm{NO}$ and $\mathrm{NO}_{2}$ ). Such differences have been quantified in recent studies conducted over the US (e.g. Luecken et al., 2008; Faraji et al., 2008; Zhang et al., 2012d) and Europe (Kim et al., 2009, 2011). Note that differences in gas phase chemistry affect not only the concentrations of gaseous pollutants but also those of secondary particulate matter (PM) compounds.

Chemical mechanisms will continue to vary substantially, given the different needs for different applications. At present, there remain open issues regarding improving the chemical mechanisms, as adding complexity by itself does not always lead to increased accuracy (Kuhn et al., 1998). However, improved scientific understanding is needed to improve the mechanisms. Some common issues which will likely be addressed in the near future include: correctly modelling the $\mathrm{HO}_{\mathrm{x}}$ budget, especially in areas with high isoprene concentrations (e.g. Stone et al., 2010), the influence of aerosol composition on heterogeneous chemistry (e.g. Riedel et al., 2012) and addressing the tendency for many models to underpredict SOA (e.g. Volkamer et al., 2006; Farina et al., 2010).

During the last decade, new software tools have become available, in particular, the Kinetic Pre-Processors (KPP) (Damian et al., 2002; Sandu and Sander, 2006), that greatly facilitate the computer simulation of chemical kinetic systems (e.g.: http://people.cs.vt.edu/ asandu/Software/Kpp/). They can automatically generate a code for a user-defined chemical mechanism and a numerical solver chosen by the user for a specific task. Tools such as KPP have the additional advantage of generating not only new mechanisms if equations or reaction rates change and new reactions are added, but also they may be able to generate adjoints. KPP makes updating of chemical mechanisms much easier as illustrated in the MECCA module (Sander et al., 2005). Changing the chemical mechanism also has implications for other aspects 
of the modelling system. The introduction of new species may require new emissions and associated speciation, as well as information on dry and wet deposition rates.

As was mentioned already, the requirements and levels of complexity necessary for representing different chemical processes are different for NWP, CWF and climate online modelling. For example, current NWP does not include detailed chemical processes, but there is some evidence that aerosols have strong effects on radiative and precipitation processes (Khain, 2009). It is important to include these effects and to determine what level of complexity is needed in which meteorological situation. Enviro-HIRLAM for NWP and long-term simulations is developing a highly simplified chemical scheme based on the ECHAM chemistry. For climate modelling, chemistry of greenhouse gases and aerosols become very important, however, for long-lived GHGs, online integration of full scale short-term chemical reactions are not critically needed. For CWF and predictions of atmospheric composition in a changing climate, more advanced and comprehensive chemical mechanisms are much more important. It will be important to quantify the impacts of these approaches on the quality of the predictions.

Future model intercomparisons would greatly benefit from the establishment of a central mechanisms database, to which mechanism owners could upload their schemes and provide further updates as necessary. This would allow true versioning and openness for chemical mechanisms. All modelling groups should be encouraged to upload their own mechanisms whenever they make changes, even if they only change the reaction rates in an existing mechanism. Ideally, this could be interfaced to a set of box model inter-comparisons, including evaluation against smog chamber data, field campaigns and highly complex mechanisms. It would also allow direct comparisons of the computing costs of the mechanisms. To help achieve the aforementioned objectives, an international effort was initiated as part of AQMEII (Rao et al., 2011)

\subsection{Aerosol dynamics and thermodynamics}

According to state-of-science knowledge, aerosols play the key role in feedback of atmospheric chemistry on atmospheric transport. Thus, the online coupled models need a dynamic treatment of aerosols, not merely climatology-based aerosol distributions, as typically applied in offline models. Aerosol particles differ by morphology, size and chemical composition. They have an impact on atmospheric radiation and cloud microphysics, and they interact with gas phase chemistry. These interactions depend on size and chemical composition. In this respect, water is an important component of the aerosol particles as the water content determines the chemical composition and at the same time chemical composition determines the water content. The size range of atmospheric aerosol particles covers several orders of magnitude. Aerosols can be composed of hundreds of chemical compounds. Therefore, the numerical treatment of aerosol particles in atmospheric models needs sophisticated methods and considerable simplifications.

There are several processes modifying physical and chemical properties of aerosol particles that need to be taken into account by the models. These include nucleation, coagulation, condensation and evaporation, sedimentation, in-cloud and below-cloud scavenging and deposition at the surface. The approaches that are currently used in online coupled models can be classified in the following sections (Table 7).

\subsubsection{Representation of particle size distribution}

The simplest way to take into account aerosols in a numerical model is the so-called bulk approach, whereby aerosols are represented by mass density only. The size distribution is neglected or prescribed when necessary, and assumptions have to be made when other physical or chemical variables that depend on size or surface are treated. Still, it is possible to simulate the chemical composition of the aerosol particles. Processes like coagulation cannot be taken into account.

The more advanced ways to represent the size distribution of aerosols in tropospheric air quality models are the modal approach, the sectional approach and the moment approach, as reviewed by Zhang et al. (1999) and McKeen et al. (2007).

One possibility to simulate the size distribution is the socalled modal approach. This approach assumes, justified to some extent by observations, that real world size distributions can be approximated by several overlapping modes, each of them described by a log-normal distribution. In principle, prognostic equations for three moments of the lognormal distributions have to be solved, e.g. for total number density, standard deviation and total mass concentration, but the process of advection makes a consistent treatment of three moments at the same time quite difficult. Therefore, in most aerosol models and for the same reason also in cloud models, prognostic equations for two moments are solved and the standard deviations of the log-normal distributions are kept constant. However, this may lead to large errors (Zhang et al., 1999) and, accordingly, some models (e.g. CMAQ, Polair3D/MAM) treat the standard deviations of variables to obtain better accuracy. Examples of the modal approach include: COSMO-ART with 11 modes (Vogel et al., 2009); Enviro-HIRLAM with 3 modes (Baklanov, 2003; Korsholm, 2009); MCCM, WRF-Chem with the aerosol module MADE-SORGAM (Ackermann et al., 1998; Schell et al., 2001) and MADE/VBS (Ahmadov et al., 2012) with 3 modes, and MAM with 3 or 7 modes (Liu et al., 2012).

Another method to describe space and time dependent size distributions of aerosols is the so-called sectional approach. In this case, the size ranges are divided into fixed sections (or bins). As for the modal approach, processes such as nucleation, coagulation, condensation/evaporation, scavenging, sedimentation, and deposition can be treated as sizedependent. The number of bins may vary from 2 (fine and 
Table 7. Aerosol physics approaches applied in different models.

\begin{tabular}{|c|c|c|c|}
\hline Name of model & Approach & Number of modes or bins, comments & References \\
\hline BOLCHEM & Modal & 3 & Binkowski et al. (2003) \\
\hline CHIMERE & Sectional & 6 & Vivanco et al. (2009) \\
\hline CMAQ AERO5/AERO6 & Modal & 3 (aitken, accumulation and coarse) & Byun and Schere (2006) \\
\hline COSMO-ART & Modal & 11 & Vogel et al. (2009) \\
\hline Enviro-HIRLAM v1 & Modal & 3 & $\begin{array}{l}\text { Baklanov (2003), Gross and Baklanov (2004), } \\
\text { Korsholm (2009) }\end{array}$ \\
\hline GAMES & Sectional & 10 & Carnevale et al. (2008) \\
\hline $\begin{array}{l}\text { ICLAMS, Enviro-HIRLAM v2, } \\
\text { REMO-HAM /REMOTE }\end{array}$ & Pseudo-modal & M7 aerosol module (configurable) & Vignati et al. (2004), Solomos et al. (2011) \\
\hline LOTOS-EUROS & Sectional & 2 & Schaap et al. (2008) \\
\hline $\begin{array}{l}\text { Meso-NH with ORILAM- } \\
\text { SOA }\end{array}$ & Modal & $\begin{array}{l}3 \text { for dust and sea salt, } 2 \text { for } \\
\text { chemically active aerosol }\end{array}$ & Tulet et al. $(2005,2006)$ \\
\hline MetUM & Mass only & $\begin{array}{l}\text { CLASSIC. } 8 \text { aerosol species, dust has } 2 \text { or } 6 \text { size } \\
\text { bins, other aerosols bulk scheme with } 2 \text { or } 3 \\
\text { modes each }\end{array}$ & Bellouin et al. (2011) \\
\hline MetUM & Modal & $\begin{array}{l}\text { UKCA-GLOMAP-mode, based on M7 approach, } \\
\text { configurable. }\end{array}$ & Bellouin et al. (2013) \\
\hline $\mathrm{MCCM}, \mathrm{WRF} / \mathrm{Chem}$ & Modal & $\begin{array}{l}3 \text { (modules MADE-SORGAM, MADE-VBS, } \\
\text { MAM) }\end{array}$ & $\begin{array}{l}\text { Ackermann et al. (1998), Schell et al. (2001), } \\
\text { Ahmadov et al. (2012), Liu et al (2012) }\end{array}$ \\
\hline M-SYS & Sectional & 4 to 64 & Von Salzen and Schlünzen (1999a, b) \\
\hline NorESM & Modal & 5 (nucleation and Aitken particles not included) & Storelvmo et al. (2008) \\
\hline PMCAMx and GATOR & Sectional & 10 & Jacobson et al. $(1996,1997 a, b)$ \\
\hline Polair3D/Siream & Sectional & user specified & Jacobson et al. $(1996,1997 a, b)$ \\
\hline $\mathrm{RegCM}$ & Sectional & Coupling of MOSAIC in development & Zaveri et al. (2008) \\
\hline WRF/Chem with MOSAIC & Sectional & 4 or 8 bins & $\begin{array}{l}\text { Fast et al. (2006), Shrivastava et al. (2011), Zaveri et } \\
\text { al. (2008) }\end{array}$ \\
\hline $\begin{array}{l}\text { WRF-Chem-MADRID, CMAQ- } \\
\text { MADRID }\end{array}$ & Sectional & 8 & Zhang et al. (2010a) \\
\hline
\end{tabular}

coarse particles; e.g. LOTOS-EUROS, Schaap et al., 2008) to 24 or more. Both sectional and modal approaches have pros and cons that were evaluated in detail by Zhang et al. (1999).

The third method, called the moment approach, is similar to the modal approach but is more general since the size distribution can have an arbitrary shape and does not need to be log-normal. Rather, the distribution is described with several moments, and the evolution of the moments is predicted by the model (Yu et al., 2003).

\subsubsection{Treatment of secondary inorganic and organic aerosol}

The chemical compounds found in aerosols can be differentiated between inorganic and organic species. The main inorganic compounds are nitrate, sulfate, ammonium, chloride and sodium. Calcium, magnesium, potassium, and carbonate can be considered to represent alkaline dust. The partitioning of these species between gas and particle phase and their thermodynamic state in the particle phase (solid or liquid) can be calculated by solving the equations of thermodynamic equilibrium and minimizing the Gibbs energy of the system.
The exact solution is computationally expensive (e.g. AIM2 - Wexler and Seinfeld, 1991) and has been seldom used in 3-D models. Solving the system via a set of selected equilibrium relationships that can be optimised according to the chemical regime of the system is the most widely used approach in 3-D modelling. Such thermodynamic models of inorganic aerosols include, for example, EQUISOLV II (Jacobson, 1999), ISORROPIA, ISORROPIA II (Nenes et al., 1998; Fountoukis and Nenes, 2007), MESA (Zaveri et al., 2005) and PD-FiTE (Topping et al., 2009, 2012). Zhang et al. (2000) present a comparative evaluation of various inorganic thermodynamic aerosol models that are currently used in 3-D models. The equilibrium between the gas phase and the particulate phase can be reached rapidly for fine particles but may take a longer time (e.g. several minutes) for coarse particles. Some aerosol modules such as MOSAIC (Zaveri et al., 2008) account for this potential mass transfer limitation by implementing a dynamic approach, which may be limited to coarse particles for computational efficiency.

Carbonaceous components of aerosol particles include black carbon $(\mathrm{BC}$, also referred to as elemental carbon or 
light-absorbing carbon) and organic compounds. BC is typically treated as entirely present in the particulate phase and chemically inert. The number of organic species found on aerosol particles is huge and it is impossible to treat each single one in 3-D online coupled models. To solve this problem, similarly to gas phase chemistry, surrogate species are introduced to represent organic aerosols (OA), which can be primary (POA) and secondary (SOA). Three main approaches are currently in use to model organic aerosols: the two-product Odum approach, the volatility basis set (VBS) and the molecule surrogate approaches.

The two-product Odum approach is an empirical one that assumes the production of SOA from the oxidation of a VOC precursor by a given oxidant (i.e. $\mathrm{OH}, \mathrm{NO}_{3}$, or $\mathrm{O}_{3}$ ) can be represented by two surrogate SOA semi-volatile species, which are represented by their mass stoichiometric coefficient and their gas-/particle partitioning coefficient and can be temperature dependent (Odum et al., 1996; Schell et al., 2001). No assumption is made about the molecular structure of those surrogate species, but it is implicitly assumed that they are hydrophobic and that their activity coefficients are constant.

The VBS approach (Donahue et al., 2006) is also an empirical approach, but it differs from the previous one by its definition of surrogate SOA compounds, which also allows the treatment of additional processes such as chemical aging and semi-volatile POA (Donahue et al., 2006). Surrogate SOA species are predefined according to a set of saturation vapour pressures (i.e. the VBS, which corresponds to a discretisation of all the possible volatilities of SOA species). Then, chemical aging via gas phase reactions moves a fraction of a compound to a less volatile compound. Semi-volatile POA can also be treated with this formulation. The approach has been recently extended to account also for the degree of oxidation of SOA species (Donahue et al., 2011). A simplified version of such a scheme is described by Athanasopoulou et al. (2013).

The molecule surrogate approach is based on a mechanistic approach to organic aerosol formation by using surrogate SOA molecules that are determined from the experimental characterisation of the chemical composition of organic aerosols (Pun et al.,2002, 2006). As for gas phase mechanisms, uncertain parameters (e.g. stoichiometric coefficients and gas-particle partitioning constants) are specified following comparison with experimental data. This approach offers the advantage that SOA species can be either hydrophilic or hydrophobic (or both) and that the activity coefficients are not constant, but may evolve with the aerosol chemical composition. Semi-volatile POA can also be treated with this approach.

Another process is the formation of non-volatile SOA species via heterogeneous uptake and particle phase reaction. One example is the glyoxal processing by aerosol multiphase chemistry (Ervens and Volkamer, 2010).

\subsubsection{Aerosol mixing state and chemical aging of particles}

It is computationally too expensive to describe the full complexity of aerosol chemical composition in 3-D numerical photochemical models. A common approximation is to assume that the percentage contribution of the individual compounds is the same for all particles within one mode or one section. This mixing state is then called an internal mixture. It is used in most aerosol modules.

The opposite approximation would be that each mode or section consists of particles that may have different chemical composition. This state is then called an external mixture. The simulation of an aerosol population that is distributed both in size and chemical composition is challenging and, to date, 3-D simulations have typically included various approximations to simulate external mixtures (Jacobson et al., 1994; Kleeman and Cass, 2001; Oshima et al., 2009; Riemer et al., 2009; Lu and Bowman, 2010). A full discretisation of both size and chemical composition is feasible (Dergaoui et al., 2013), but computationally rather expensive. It has not yet been incorporated into 3-D models. Models often include a combination of internal and external mixtures by simulating several overlapping modes (representing the external mixture) each having a different (internally mixed) chemical composition.

Heterogeneous reactions and condensational growth during transport alter the mixing state and the physical and chemical properties of particles. These transformation processes are named atmospheric aging. Atmospheric aging is important for several aspects. Examples are given below. Pure soot particles are hydrophobic. This means there is no hygroscopic growth when inhaled by humans and, as they are small, they can get deep into the lungs causing health problems. Aging of pure soot particles occurs by condensation of gas phase compounds or by coagulation with particles of different chemical composition. If these compounds form a soluble shell around the soot core, those internally mixed particles become hygroscopic. Such particles, when inhaled, grow very rapidly and are deposited high in the respiratory tract. In addition, soluble shells alter the specific shortwave absorption of soot particles to higher values (Riemer et al., 2003). The potential of soot particles to act as cloud condensation nuclei (CCN) or ice nuclei (IN) is also modified by the aging process. The aging of mineral dust particles changes their capability to act as IN or CCN (Kumar et al., 2009). Therefore, the explicit treatment of the aging process is an important process that should not be neglected. Example models that treat soot aging explicitly are MADEsoot (Riemer et al., 2003) and PartMC-MOSAIC (Ching et al., 2012).

\subsubsection{Aqueous phase formation of aerosol species}

The formation of inorganic and organic aerosols may also occur via aqueous chemical reactions and subsequent cloud 
droplet evaporation. Many 3-D models treat the oxidation of $\mathrm{SO}_{2}$ to sulfate and $\mathrm{NO}_{\mathrm{x}}$ to nitrate in clouds via homogenous and heterogeneous reactions, as those processes contribute significantly to sulfate and nitrate formation. A comprehensive overview on the mechanisms currently applied in air quality models, including those used in Europe, is given by Gong et al. (2011). Knote and Brunner (2013) included the SCAV model (Tost et al., 2006) into the COSMOART model. It accounts for wet scavenging of gases and aerosols and aqueous-phase chemistry. Few 3-D models have included the formation of SOA in clouds so far, but simulations conducted to date suggest that this pathway could contribute significantly to SOA concentrations locally and on the order of $10 \%$ on average (Chen et al., 2007; Carlton et al., 2008; Ervens et al., 2011; Couvidat et al., 2013).

\subsubsection{Thermal diffusion}

According to recent studies, a newly discovered aerosol phenomenon, called turbulent thermal diffusion (TTD), has a rather small but systematic contribution to the global distribution of coarse particles. TTD, first predicted theoretically by Elperin et al. (1996) and then found in laboratory experiments (Buchholz et al., 2004), entails the transport of particles against the temperature gradient and is more effective at low pressure. Sofiev et al. (2009b) showed that TTD is most likely responsible for the aerosol layer at tropopause height - a phenomenon not well explained so far. Their simulations with the SILAM model have shown that this regional effect on the long-term average $\mathrm{PM}_{10}$ concentrations is of the order of $5-10 \%$ in most areas, but in certain mountainous regions the concentrations are enhanced by $40 \%$ (with respect to model simulations without TTD) due to more efficient upward transport.

\subsection{Model treatments of cloud properties}

\subsubsection{Bulk schemes}

Regional models treat cloud properties to various degrees of complexity with respect to the size and phase distribution. The most common approach is to use bulk schemes, in which the moments of a given number of hydrometeors are predicted. With only one moment, the mass mixing ratio is predicted, then the number concentration has to be prescribed or parametrized and the size distribution is highly idealised (e.g. Kessler, 1969; Lin et al., 1983; Sass, 2002). The simplest example of such a one-moment scheme is the Sundqvist (1978) scheme, in which only the sum of cloud water and cloud ice is predicted and the distinction between cloud water and cloud ice is based only on temperature. In one standard NWP model used by several European weather services (Baldauf et al., 2011), clouds are represented by a bulk microphysics scheme, which describes different categories of cloud hydrometeors by size distribution functions, for which the mass mixing ratio is predicted and the number concentration is prescribed. Following Houze (1994), cloud droplets, raindrops, cloud ice and snow are taken into account. Microphysical processes are represented by transferring hydrometeors from one of those categories to another.

In order to consider the different freezing mechanisms and their dependence on the available ice nuclei, separate prognostic variables for cloud water and ice need to be solved. General circulation models (GCM) typically use onemoment schemes for predicting cloud water and ice separately (e.g. Lohmann and Roeckner, 1996). Regional models often solve additional prognostic equations for falling hydrometeors (rain, snow, graupel and sometimes hail) (e.g. Seifert and Beheng, 2006).

Two-moment schemes (e.g. Seifert and Beheng, 2006) predict the number concentrations of the hydrometeors in addition to their mass mixing ratios. Scientifically, they are superior to one-moment schemes because the nucleation of cloud droplets can be parametrized according to Koehler's theory (e.g. Abdul-Razzak et al., 1998) and can take the dependence of the aerosol number concentration into account. They can also account for the size-dependent sedimentation rate (Spichtinger and Gierens, 2009).

The size spectrum of cloud droplets can be better resolved by bin schemes (e.g. Khain et al., 2008). However, they are computationally more expensive and are usually only used for research applications.

\subsubsection{Parametrization of microphysical processes}

The main processes in clouds are condensation of vapour, the growth of cloud nuclei with the eventual formation of rain, snow, graupel, hail, etc. and the fall out of precipitation.

\section{Condensation/deposition of water vapour}

Condensation is treated with a saturation adjustment scheme, which means that all the water vapour above $100 \%$ relative humidity is converted into cloud water based on the assumption that sufficient $\mathrm{CCN}$ are available to deplete the supersaturation. This assumption is justified for water clouds, where the supersaturation with respect to water is at most $1 \%$. However, it is questionable for ice clouds, where supersaturation with respect to ice can reach $70 \%$. Therefore, GCMs and regional climate models (RCMs) have started to abandon the saturation adjustment scheme for cirrus clouds and allow supersaturation with respect to ice (Lohmann and Kaercher, 2002; Liu et al., 2007; Tompkins et al., 2007; Gettelman et al., 2010; Salzmann et al., 2010).

In two-moment schemes (Sect. 4.4.1), the number of activated aerosol particles determines the number of nucleated cloud droplets. If parametrizations based on the Köhler theory (Abdul-Razzak and Ghan, 2002; Nenes and Seinfeld, 2003) are used in online coupled models, it is reasonable to abandon the saturation adjustment scheme and instead 
solve the droplet growth equation. More details as well as the parametrization of ice nucleation are given in Sect. 4.5.

\section{Formation of precipitation}

The first microphysical scheme was developed by Kessler (1969). It distinguishes between cloud water with small drop sizes $(5-30 \mu \mathrm{m})$ having negligible velocity and rain drops that reach the surface within one model time step. The conversion from cloud water to rain, the autoconversion rate, depends only on cloud water content and starts once the critical cloud water content is exceeded. A similar scheme for the ice phase (Lin et al., 1983) is widely used in RCM and NWP models.

If cloud water and cloud ice are predicted as separate prognostic variables, the Bergeron-Findeisen process can be parametrized to describe the growth of ice crystals at the expense of water droplets due to the lower vapour pressure over ice in mixed-phase clouds. The process depends on the updraft velocity inside the cloud and the number concentration of ice crystals (e.g. Storelvmo et al., 2008).

Proceeding from the fact that the formation of precipitation depends on aerosol concentrations, online models with two-way feedbacks, where aerosol-cloud interaction is considered together, have a very good potential to improve the precipitation process modelling (Sect. 4.5).

\section{Falling of precipitation}

If the falling of precipitation takes place within one time step of the model, the evaporation is normally neglected. For high resolution models (vertical resolution of a few decametres), the evaporation has to be considered, as done by some highresolution models (e.g. M-SYS; Schlünzen et al., 2012). In online models, this process is closely connected with wet deposition (Sect. 4.7.2).

\subsection{Aerosol-cloud interactions and processes}

\subsubsection{Aerosol-cloud interactions in online models without indirect aerosol effect}

Aerosols are a necessary condition for cloud formation and influence cloud microphysical and physical properties as well as precipitation release. Hence, all online models have cloud schemes that either explicitly or implicitly represent the effect of aerosols on clouds (e.g. RegCM, Giorgi et al., 1993; some versions of MetUM, Birch et al., 2012). Physically based schemes that explicitly resolve the activation of CCN into cloud droplets (e.g. Abdul Razak and Ghan, 2002) are currently not included in all online coupled models (Table 4). If aerosol number and mass concentrations are not coupled to the cloud scheme, cloud droplet numbers have to be implicitly assumed in the parameterisations of the microphysics. One example is the widely used diagnostic calculation of $\mathrm{CCN}$ number concentration (often assumed to be the cloud droplet number concentration) in the warm phase: $n_{\mathrm{d}}=c s^{k}$, where $s$ is the supersaturation and $c$ and $k$ are empirically derived coefficients that differ for different aerosol loadings. The cloud droplet number is often used in parameterisations of the cloud droplet effective radius, which is a basic parameter for parameterizing cloud-radiation interactions. The values of $c$ correspond to the $\mathrm{CCN}$ concentration at $1 \%$ supersaturation, while $k$ is a tuning coefficient. Information on aerosol number, size, and composition is contained within $c$ and $k$. Accordingly, $c$ retains large values (e.g. $3500 \mathrm{~cm}^{-3}$ ) in continental and polluted locations, but small values (e.g. $100 \mathrm{~cm}^{-3}$ ) in remote marine locations (Hegg and Hobbs, 1992). The supersaturation field is, however, also strongly influenced by the aerosol concentration, composition and size distribution. The parametrization of $s$ likewise implicitly contains information on aerosol number, size and composition (Fitzgerald, 1973; Mircea et al., 2002).

\subsubsection{Aerosol-cloud interactions in online models with prognostic aerosols}

One-moment cloud schemes (Sect. 4.4.1) are typically used in operational models with strict execution time requirements. They often assume a constant droplet number in order to close the equations describing cloud droplet radiation interactions and possibly also the autoconversion calculation (Rasch and Kristjansson, 1998). Such schemes have limited possibility of diagnosing cloud droplet number. This may be done by using empirical relationships, e.g. between aerosol number and the cloud droplet nucleation term near the base of the cloud (Martin et al., 1994; Menon et al., 2002; Storelvmo et al., 2008). The usage of such relations may induce inconsistencies between cloud mass and droplet number in a model, and double moment schemes describing the evolution of the droplet number are more appropriate for online models.

Coupling a two-moment cloud scheme (Lin et al., 1983; Ghan et al., 1997; Meyers et al. 1997; Seifert and Beheng, 2001; Morrison et al., 2005; Morrison and Gettleman, 2008) with prognostic aerosols opens the possibility of more detailed size and composition dependent aerosol activation for both number and mass (Abdul-Razzak and Ghan, 2002). Cloud droplet number concentration may be calculated based on a prognostic representation of aerosol size and chemical composition within the framework of an ascending adiabatic cloud parcel (Nenes and Seinfeld, 2003; Fountoukis and Nenes, 2005). This scheme can be extended to include: (a) adsorption activation from insoluble CCN (Kumar et al., 2009), (b) giant CCN equilibrium-timescales on aerosol activation (Barahona et al., 2010), or (c) the effect of entrainment on activation (Barahona and Nenes, 2007). The supersaturation needed for activating a $\mathrm{CN}$ is determined by the modified Köhler theory that takes the effects of surfactants and slightly soluble species into account. Another advantage of coupling two moment cloud schemes with prognostic 
aerosols is a more physically detailed approach to autoconversion (Khairoutdinov and Kogan, 2000; Liu et al., 2005). The most widely used approach is to assume specific size distributions for cloud droplets and rain drops (Seifert and Beheng, 2001).

A major shortcoming when coupling prognostic aerosols with a cloud scheme in an operational model is that aerosol mass and number are difficult to predict accurately due to uncertainties in emissions and deposition. Hence, although this coupling is more physically correct, in practice it may be difficult to achieve better verification scores than without prognostic aerosols. Currently, it is not known which aerosolcloud interaction processes are of the greatest importance, and not all feedbacks are represented in current online models. As the cloud droplet number increases and the droplet effective radius decreases with an increased aerosol loading, the microphysical processes are also affected. For instance, the changed surface area of the droplets leads to alteration of evaporation and condensation. However, when diagnosing cloud droplet number concentration, these effects are not taken into account. The importance of such effects and the associated changes in cloud dynamics has been discussed by several authors (e.g. Jiang et al., 2006; Xue and Feingold, 2006). Recently, it has been suggested that for clouds with liquid water path less than about $50 \mathrm{~g} \mathrm{~m}^{-2}$, the evaporation/condensation effect is of greater importance in controlling liquid water path than the precipitation suppression effect (Lee and Penner, 2011). Therefore, it might be misleading to represent aerosol-cloud interactions in terms of the effect on autoconversion only (i.e. second indirect effect).

Full microphysical bin-resolved descriptions of cloud and aerosol microphysics are still computationally expensive and generally not feasible for operational forecasting. The influences of aerosols on clouds must, therefore, be parameterised. In order to simulate the interaction processes in short-range models, it is important that the parameterisations are based on the relevant coupling processes and that tuning affects only parameters that are not influenced by the coupling. Physically based schemes that explicitly resolve the activation of CCN into cloud droplets (e.g. Abdul Razak and Ghan, 2002; Nenes and Seinfeld, 2003; Fountoukis and Nenes, 2005; Barahona et al., 2010) are expected to improve the representation of these processes in regional and global models.

\subsubsection{Parameterisation of ice nucleation}

Aerosol effects on ice clouds are even more uncertain than aerosol effects on water clouds. A small subset of aerosols, such as mineral dust, acts as ice nuclei (IN) and determines the formation of the ice phase in clouds. The importance of other aerosols (biological particles, black carbon, organic carbon, or crystalline ammonium sulfate) acting as IN is still a matter of debate. While biological particles have been found to nucleate ice at the warmest temperatures, their con- centrations in the atmosphere seem to be too low to have a global impact (Hoose et al., 2010a, b; Sesartic et al., 2012). Black carbon and carbonaceous particles, on the other hand, are much more numerous, but it is not yet clear if they nucleate ice well above the homogeneous freezing temperature. Cirrus clouds form at temperatures below $-35^{\circ} \mathrm{C}$. Here homogeneous freezing of solution droplets prevails. Heterogeneous freezing on ice nuclei seems to be of minor importance but can be important in determining the maximum supersaturation (Lohmann and Kärcher, 2002). Parameterisations of cirrus schemes that consider the competition between homogeneous and heterogeneous nucleation have been developed by Kärcher et al. (2006), Barahona and Nenes (2009), Gettelman et al. (2010), Salzmann et al. (2010) and Wang and Penner (2010).

At temperatures above $-35^{\circ} \mathrm{C}$, ice forms heterogeneously in the mixed-phase cloud regime. Most models describe ice formation in mixed-phase clouds with empirical schemes (e.g. Lohmann and Diehl, 2006; Phillipps et al., 2008; DeMott et al., 2010). In order to consider which aerosols act as IN at a given temperature, laboratory data are used. As the ice nucleating properties of $\mathrm{BC}$ are still very uncertain, the potential anthropogenic effect of $\mathrm{BC}$ on ice clouds is also questionable. There are two possibilities. On one hand, more $\mathrm{BC}$ aerosols cause a faster glaciation of supercooled liquid clouds inducing faster precipitation and shorter cloud lifetime. This counteracts the warm indirect aerosol effects and will reduce the total anthropogenic aerosol effect (Lohmann, 2002). On the other hand, if anthropogenic BC is predominantly coated with soluble species, this may reduce its ability to act as an IN and works in the opposite way (Hoose et al., 2008; Storelvmo et al., 2008). Which of these effects dominates remains an open question. The newest and most physically based approach is to parameterize heterogeneous freezing in mixed-phase clouds based on classical nucleation theory (Hoose et al., 2010b).

\subsection{Radiation schemes in coupled models}

Online coupling imposes additional requirements on the setup and implementation of radiation modelling schemes, particularly when gas and aerosol feedbacks are explicitly considered. Most of these requirements reflect the need to maintain physical and numerical consistency between the various modules and computational schemes of the model, against the increased frequency of interaction (typically on the order of a few dynamical time steps) and the multitude of simulated effects. 


\subsubsection{Radiative effects of gases and aerosols}

Trace gases such as ozone, nitrogen oxides, and methane absorb incoming short-wave radiation and thereby modify the radiation balance at the ground as well as photolytic rates. The key parameter determining the absorption of radiation by a particular gas is its concentration profile. Aerosol particles absorb, scatter and re-emit both short and long-wave radiation, thus directly affecting the surface radiation balance and heating rates in the atmosphere (i.e. direct aerosol radiative effect). Additionally, aerosol particles impact photolysis frequencies and visibility. Key species to be considered are water attached to aerosol particles, sulfate, nitrate and most organic compounds, which mostly result in a cooling of the atmosphere and BC, iron, aluminium and polycyclic/nitrated aromatic compounds, which warm the air by absorbing solar and thermal-infrared radiation.

The properties of cloud droplets can create significant radiative feedbacks, as optical properties of the droplet ensemble are influenced by the size distribution and composition of the aerosol particles acting as $\mathrm{CCN}$ and IN. In the case of absorbed particles, not only the mass concentration but also their composition, the size distribution of both aerosol particles and cloud droplets, and the mixing state (external; internal homogeneous; core/shell) have a strong effect on the interaction with solar radiation (Conant et al., 2002; Nenes et al., 2002; Cubison et al., 2008; Péré et al., 2009; Wang et al., 2010; Jacobson, 2012).

All direct radiative effects will result in the development of semi-direct effects like changes in thermal stability, cloudiness, etc. Although the inclusion of semi-direct effects does not generally require the explicit incorporation of extra processes in the models, the radiation modules need to be able to adequately resolve the atmospheric radiation fluxes associated with each process.

\subsubsection{Implementation considerations}

Although most online coupled models consider the aerosol direct effect, the level of details for considering this effect differs largely between models. There are also major differences between the models with respect to the inclusion of the radiative effect of trace gases, aerosol particles and cloud droplets.

Some of the online coupled models follow the approach of simulating aerosol radiative properties by calculating complex refractive indices and extinction coefficients of PM and cloud components as a function of size distributions and chemical composition for a specific mixing state by Mie calculations during the model runtime (Barnard et al., 2010). In order to speed up costly calculations of radiative feedbacks, some other radiation modules use externally stored data in the form of a pre-computed parameter cache (e.g. tabulated results of a priori Mie calculations or from the Optical Properties of Aerosols and Clouds (OPAC) software library mod- ule (d'Almeida et al., 1991). OPAC defines a data set of typical cloud components as well as aerosol components and component mixtures, in order to calculate the optical properties from the concentration fields of simulated PM compositions.

Even when optical properties of aerosol particles and droplets are directly calculated, the result may still depend on the representation of size distributions (i.e. modal vs. sectional vs. moments and the number of moments/sections/bins), the compounds considered, and the assumptions about the mixing state of the particles (i.e. external; internal homogeneous; core/shell). In addition to these differences in the description of the optical properties of trace gases, aerosol particles and cloud droplets, which are input to the radiation scheme, the degree of detail of the radiation scheme may depend on the level of accuracy of the radiation scheme itself (e.g. 2-stream or higher order, spectral resolution).

The introduction of such advanced radiation schemes in online coupled models can often require significant development effort, due to both the inherent limitations of traditional radiation modules as well as incompatible representations of chemical speciation and thermodynamic properties between CTMs and radiation modules. It also imposes a significant computational burden, by requiring that radiation modules are invoked typically at every (or every few) dynamical step(s) of the model. Inevitably, modellers have to resort to simplifications in both the selection of parameterisations and simulated effects, as well as the number of particle size bins and mixing states. Even more stringent limits have to be imposed on the number of simulated spectral bands, which are required for an accurate account of the full range of radiative effects of complex PM mixtures. Nielsen et al. (2013) have investigated ways to reduce the computational footprint of short-wave spectral calculations by substituting 2-stream calculations for averages of aerosol optical properties weighted over the entire solar spectrum.

\subsubsection{Radiation schemes in online coupled models}

Online coupled modelling offers the theoretical possibility of enabling the full range of known radiative feedbacks. In practice, however, most current model implementations support only selected subsets of these radiative couplings. Interactions between gas phase chemistry and radiation are frequently introduced via an online coupling between the dynamics part of the model and radiation modules with the photolysis module.

Only a few models account for the effect of variable trace gas concentrations on solar and long-wave radiation. Absorption by variable tropospheric $\mathrm{O}_{3}$ and $\mathrm{CO}_{2}$ is included in COSMO-ART, Enviro-HIRLAM, and in the RRTMG and CAM radiation parameterisations of WRF-Chem, while RAMS/ICLAMS includes the option of using simulated $\mathrm{O}_{3}$ in the radiation schemes (Table 8). 
Table 8. Radiative schemes (including shortwave, longwave and photolysis modules which are considering gas [G], aerosol [A] and cloud water [C] effects) and ways of their coupling in selected online coupled models.

\begin{tabular}{|c|c|c|c|c|}
\hline Model & Shortwave (SW) & Longwave (LW) & Photolysis (PH) & Coupling step \\
\hline $\begin{array}{l}\text { BOLCHEM } \\
\text { Mircea et al. (2008) }\end{array}$ & $\begin{array}{l}\text { G: Climatology } \\
\text { A: Calculation of local (grid-scal) } \\
\text { optical properties for } 5 \text { dry aerosol } \\
\text { types ( } \mathrm{SO}_{4}, \mathrm{NH}_{4} \text {, Organic and } \\
\text { Elemental Carbon, Dust) in three } \\
\text { modes (Aitken, accumulation and } \\
\text { coarse) and correction for aerosol } \\
\text { water content. } \\
\mathrm{C} \text { : Cloud fraction and liquid/ice } \\
\text { water content, at every level, from } \\
\text { the prognostic cloud scheme. }\end{array}$ & $\begin{array}{l}\text { G: Climatology } \\
\text { A: Same as for SW } \\
\text { C: Cloud fraction and liquid/ice water } \\
\text { content, at every level, from the } \\
\text { prognostic cloud scheme. }\end{array}$ & $\begin{array}{l}\text { Photolysis rates are computed as a } \\
\text { clear sky climatology modified } \\
\text { locally by a grid-scale factor } \\
\text { computed from the ratio between } \\
\text { clear-sky and water content } \\
\text { modified shortwave radiation. This } \\
\text { factor accounts for the actual } \\
\text { composition (gas, aerosol, water) } \\
\text { seen by the model (see SW } \\
\text { column on the left). }\end{array}$ & $\begin{array}{l}\text { SW, LW, PH: User-defined; } \\
\text { typically every } 4 \text { model } \\
\text { time steps } \\
\text { t } \\
\text { the }\end{array}$ \\
\hline $\begin{array}{l}\text { COSMO-ART } \\
\text { Vogel et al. (2009), } \\
\text { Bangert et al. (2011) }\end{array}$ & $\begin{array}{l}\text { G: None } \\
\text { A: scattering and absorption by } \\
\text { aerosols, depending on aerosol } \\
\text { size distribution and chemical } \\
\text { composition (all aerosol types), } \\
\text { pre-computed lookup-tables (Mie } \\
\text { calculations) } \\
\text { C: Cloud optical properties based } \\
\text { on effective radii of cloud droplets } \\
\text { and ice crystals affected by } \\
\text { aerosols acting as CCN, and by } \\
\text { soot and dust acting as IN. }\end{array}$ & $\begin{array}{l}\mathrm{G}: \mathrm{O}_{3} \text { (climatology), } \mathrm{CO}_{2} \text { (clim), } \mathrm{H}_{2} \mathrm{O} \\
\mathrm{A}: \text { scattering and absorption by } \\
\text { aerosols, depending on aerosol size } \\
\text { distribution and chemical } \\
\text { composition (all aerosol types), pre- } \\
\text { computed lookup-tables (Mie } \\
\text { calculations) } \\
\mathrm{C} \text { : Cloud optical properties based on } \\
\text { effective radii of cloud droplets and } \\
\text { ice crystals affected by aerosols } \\
\text { acting as } \mathrm{CCN} \text {, and by soot and dust } \\
\text { acting as IN. }\end{array}$ & $\begin{array}{l}\mathrm{G}: \mathrm{O}_{3} \text { (climatology) } \\
\mathrm{A}: \text { Photolysis rates scaled } \\
\text { proportional to SW radiation } \\
\mathrm{C}: \text { Photolysis rates scaled } \\
\text { proportional to SW radiation. } \\
\end{array}$ & $\begin{array}{l}\text { SW, LW, PH: User-defined, } \\
\text { typically every } 15 \text { minutes }\end{array}$ \\
\hline $\begin{array}{l}\text { COSMO-LM-MUSCAT } \\
\text { Wolke et al. (2004a, } \\
\text { 2012), } \\
\text { Renner and Wolke, } \\
\text { (2010), } \\
\text { Heinold et al., (2007, } \\
\text { 2008, 2009), Helmert et } \\
\text { al. (2007) } \\
\end{array}$ & $\begin{array}{l}\text { G: None } \\
\text { A: Direct and semi-direct aerosol } \\
\text { effect. As regards mineral dust: } \\
\text { - Modified COSMO radiation } \\
\text { scheme (Ritter and Geleyn, 1992), } \\
\text { considering variations in the } \\
\text { modelled size-resolved dust load. } \\
\text { - Bin-wise offline Mie calculations } \\
\text { of spectral optical properties using } \\
\text { dust refractive indices from Sokolik } \\
\text { and Toon (1999). } \\
\text { For Biomass burning smoke } \\
\text { (PM }{ }_{2.5} \text { ), as with the dust radiative } \\
\text { feedback, but using mass } \\
\text { extinction efficiency from Reid et } \\
\text { al. (2005) for the computation of } \\
\text { smoke optical thickness (Heinold et } \\
\text { al., 2011a,b) } \\
\text { Anthropogenic aerosol (EC, } \\
\text { primary organic particles, } \mathrm{NH}_{4} \mathrm{NO}_{3} \text {, } \\
\left.\mathrm{H}_{2} \mathrm{SO} \mathrm{H}_{4} \text {, (NH } \mathrm{H}_{4}\right)_{2} \mathrm{SO}_{4} \text { ) is treated as } \\
\text { dust but using mass extinction } \\
\text { efficiencies from Kinne et al. (2006) } \\
\text { to compute the optical thickness for } \\
\text { each species. In addition, external } \\
\text { mixing of the different components } \\
\text { is assumed (Meier et al., 2012a). } \\
\text { C: None }\end{array}$ & $\begin{array}{l}\text { G: None } \\
\text { A: Direct and semi-direct aerosol } \\
\text { effect. As regards mineral dust: } \\
\text { - Modified COSMO radiation scheme } \\
\text { (Ritter and Geleyn, 1992), } \\
\text { considering variations in the } \\
\text { modelled size-resolved dust load. } \\
\text { - Bin-wise offline Mie calculations of } \\
\text { spectral optical properties using dust } \\
\text { refractive indices from Sokolik and } \\
\text { Toon (1999). } \\
\text { For Biomass burning smoke }\left(\mathrm{PM}_{2.5}\right) \text {, } \\
\text { as with the dust radiative feedback, } \\
\text { but using mass extinction efficiency } \\
\text { from Reid et al. (2005) for the } \\
\text { computation of smoke optical } \\
\text { thickness (Heinold et al., 20111a,b) } \\
\text { Anthropogenic aerosol (EC, primary } \\
\text { organic particles, } \mathrm{NH}_{4} \mathrm{NO}_{3}, \mathrm{H}_{2} \mathrm{SO}_{4} \text {, } \\
\left.\text { (NH })_{4}\right)_{2} \mathrm{SO} \mathrm{O}_{4} \text { ) is treated as dust but } \\
\text { using mass extinction efficiencies } \\
\text { from Kinne et al. (2006) to compute } \\
\text { the optical thickness for each } \\
\text { species. In addition, external mixing } \\
\text { of the different components is } \\
\text { assumed (Meier et al., 2012a). } \\
\mathrm{C} \text { None None }\end{array}$ & $\begin{array}{l}\text { G: None } \\
\text { A: None } \\
\text { C: Modification of "clear sky" rates } \\
\text { in dependence on the cloud cover } \\
\text { or, alternatively, the liquid water } \\
\text { pathway of the grid cells above. } \\
\\
\text { ather } \\
\end{array}$ & $\begin{array}{l}\text { SW, LW, PH: Coupling at } \\
\text { every MUSCAT advection } \\
\text { time step, given by time } \\
\text { r step control; cOSMO } \\
\text { r radiation computation in } \\
\text { separately-specified } \\
\text { intervals of (usually) } 1 \mathrm{~h}\end{array}$ \\
\hline $\begin{array}{l}\text { ENVIRO-HIRLAM } \\
\text { Baklanov et al. } \\
\text { (2008a), } \\
\text { Korsholm et al. (2008) }\end{array}$ & $\begin{array}{l}\text { G: Climatology - stratospheric } \mathrm{O}_{3} \\
\text { A: Absorptance and transmittance } \\
\text { calculation for } 10 \text { GADS aerosol } \\
\text { types: insoluble, water soluble, } \\
\text { soot, sea salt (acc. and coa. } \\
\text { modes), mineral (nuc./ acc./ coa. } \\
\text { modes), mineral (transported), } \\
\text { sulfate droplets } \\
\text { C: Grid and sub-grid scale bulk }\end{array}$ & $\begin{array}{l}\text { G: } \mathrm{H}_{2} \mathrm{O}, \mathrm{GHGs} \text { by constants } \\
\text { A: Absorptance and transmittance } \\
\text { calculation for } 10 \text { GADS aerosol } \\
\text { types: insoluble, water soluble, soot, } \\
\text { sea salt (acc. and coa. modes), } \\
\text { mineral (nuc./ acc./ coa. modes), } \\
\text { mineral (transported), sulfate } \\
\text { droplets } \\
\text { C: Grid and sub-grid scale bulk }\end{array}$ & $\begin{array}{l}\text { G: None } \\
\text { A: Only through temperature } \\
\text { change caused by LW/SW } \\
\text { C: Grid and sub-grid scale bulk } \\
\end{array}$ & $\begin{array}{l}\text { SW, LW, PH: Model time } \\
\text { step }\end{array}$ \\
\hline $\begin{array}{l}\text { GEM } \\
\text { Kaminski et al. (2008) }\end{array}$ & $\begin{array}{l}\text { Correlated K (Li and Barker, 2005) } \\
\text { with } \mathrm{O} 3, \mathrm{H} 2 \mathrm{O} \text { and aerosols from } \\
\text { chemistry }\end{array}$ & $\begin{array}{l}\text { Correlated K (Li and Barker, 2005) } \\
\text { with } \mathrm{O} 3, \mathrm{H} 2 \mathrm{O} \text { and aerosols from } \\
\text { chemistry }\end{array}$ & $\begin{array}{l}\text { G,A,C all taken into account in J- } \\
\text { value calculations using method of } \\
\text { Landgraf and Crutzen, } 1998\end{array}$ & $\begin{array}{l}\text { SW, LW, PH: model time } \\
\text { f step }\end{array}$ \\
\hline $\begin{array}{l}\text { IFS-MOZART } \\
\text { C-IFS } \\
\text { (MACC/ECMWF) } \\
\text { Flemming et al. (2009) }\end{array}$ & $\begin{array}{l}\text { G: Climatology based on the } \\
\text { MACC- reanalysis (Inness et al, } \\
\text { 2013) } \\
\text { A: Climatology or first direct effect } \\
\text { and indirect effect, climatology is } \\
\text { default. } \\
\text { C: Various parameterisations } \\
\text { (Morcrette et al. 2009) }\end{array}$ & $\begin{array}{l}\text { G: Climatology based on the MACC- } \\
\text { reanalysis } \\
\text { A: Climatology or first direct effect } \\
\text { and indirect effect, climatology is } \\
\text { default. } \\
\text { C: Various parameterisations } \\
\text { (Morcrette et al. 2009) }\end{array}$ & $\begin{array}{l}\text { G: Overhead } \mathrm{O}_{3} \\
\text { A: None Shading } \\
\text { C: Simple sarameterisation } \\
\text { paran she }\end{array}$ & SW, LW, PH: $1 \mathrm{~h}$ \\
\hline $\begin{array}{l}\text { NMMB/BSC-CTM } \\
\text { (BSC-CNS) } \\
\text { Perez et al. (2011) }\end{array}$ & $\begin{array}{l}\text { G: Climatology } \\
\text { A: compute extinction efficiency for } \\
\text { each mineral dust sectional bin and } \\
\text { wavelength (Direct Aerosol Effect) } \\
\text { C: Grid and sub-grid scale bulk }\end{array}$ & $\begin{array}{l}\text { G:Climatology } \\
\text { A:compute extinction efficiency for } \\
\text { each mineral dust sectional bin and } \\
\text { wavelength (Direct Aerosol } \\
\text { Effect) } \\
\text { C: Grid and sub-grid scale bulk }\end{array}$ & $\begin{array}{l}\text { G: None } \\
\text { A: None } \\
\text { C: Bulk water content }\end{array}$ & $\begin{array}{l}\text { SW, LW, PH: User-defined } \\
\text { (typically every hour) }\end{array}$ \\
\hline $\begin{array}{l}\text { MCCM } \\
\text { Grell et al. (2000), } \\
\text { Forkel \& Knoche } \\
\text { (2006) }\end{array}$ & $\begin{array}{l}\text { G: None } \\
\text { A: Bulk total dry mass and aerosol } \\
\text { water, fixed 'typical' mass } \\
\text { extinction coefficient for dry aerosol } \\
\text { C: Cloud droplet number: grid } \\
\text { scale bulk only }\end{array}$ & $\begin{array}{l}\text { G: None } \\
\text { A: None } \\
\text { C: Grid scale bulk }\end{array}$ & $\begin{array}{l}\text { G: } \mathrm{O}_{3} \\
\text { A: Bulk total dry mass and aerosol } \\
\text { water, fixed 'typical' mass } \\
\text { extinction coeff. for dry aerosol } \\
\text { C: Cloud droplet number: grid scale } \\
\text { bulk only }\end{array}$ & SW, LW, PH: User-defined \\
\hline $\begin{array}{l}\text { MEMO/MARS-aero } \\
\text { Moussiopoulos et al. } \\
\text { (2012), } \\
\text { Halmer et al. (2010), } \\
\text { d'Almeida et al. (1991) }\end{array}$ & $\begin{array}{l}\text { G: Constant background } \\
\text { A: OPAC PM, PNC for water- } \\
\text { soluble aerosols, averaged } \\
\text { extinction coefficients for dry } \\
\text { aerosol } \\
\text { C: Cloud droplet number, } \\
\text { parameterised profiles }\end{array}$ & $\begin{array}{l}\text { G: Constant background } \\
\text { A: OPAC PM, PNC for water-soluble } \\
\text { aerosols, absorption+ scattering } \\
\text { coeff. for dry aerosol } \\
\text { C: Cloud droplet number, } \\
\text { parameterised profile }\end{array}$ & $\begin{array}{l}\mathrm{G}: \mathrm{O}_{3} \\
\text { A: None } \\
\text { C: None }\end{array}$ & $\begin{array}{l}\text { SW, LW: } \\
\text { PH: None }\end{array}$ \\
\hline
\end{tabular}


Table 8. Continued.

\begin{tabular}{|c|c|c|c|c|}
\hline Model & Shortwave (SW) & Longwave (LW) & Photolysis (PH) & Coupling step \\
\hline $\begin{array}{l}\text { Meso-NH } \\
\text { Lafore et al. (1998) }\end{array}$ & $\begin{array}{l}\text { G: Climatology for } \mathrm{O}_{3} \text { (Fortuin and } \\
\text { Langematz, 1994), constant background } \\
\text { for } \mathrm{CO}_{2}, \mathrm{CH}_{4}, \mathrm{~N}_{2} \mathrm{O}, \mathrm{CFC} 11, \mathrm{CFC} 12 \\
\text { A: With prognostic aerosol (Tulet et al., } \\
\text { 2005), radiative properties of aerosols } \\
\text { according to Mie theory (Aouizerats et } \\
\text { al., 2010). Without aerosol scheme, } \\
\text { climatological aerosols. } \\
\text { C: Effective radius calculated from the 2- } \\
\text { moment microphysical scheme when } \\
\text { explicitly used. }\end{array}$ & $\begin{array}{l}\text { G: Climatology for } \mathrm{O}_{3} \text { (Fortuin and } \\
\text { Langematz, 1994), constant background } \\
\text { for } \mathrm{CO}_{2}, \mathrm{CH}_{4}, \mathrm{~N}_{2} \mathrm{O}, \mathrm{CFC} 11, \mathrm{CFC} 12 \\
\text { A: climatological aerosols. } \\
\mathrm{C} \text { : Effective radius calculated from the 2- } \\
\text { moment microphysical scheme when } \\
\text { explicitly used. }\end{array}$ & $\begin{array}{l}\mathrm{G}: \mathrm{O}_{3} \text { climatology } \\
\text { A: aerosols climatology } \\
\mathrm{C}: \text { LWC when coupled on-line (1D } \\
\text { simulations) vs. Parametrisation of cloud } \\
\text { impact (Chang et al., 1987) for 3D } \\
\text { simulations. }\end{array}$ & SW, LW, PH: User-defined \\
\hline $\begin{array}{l}\text { MetUM (MetOUnified } \\
\text { Model) } \\
\text { O'Connor et al. (2013), } \\
\text { Savage et al. (2013) }\end{array}$ & $\begin{array}{l}\mathrm{G}: \mathrm{N}_{2} \mathrm{O}, \mathrm{O}_{3}, \mathrm{CH}_{4} \text {, depending on } \\
\text { configuration }-\mathrm{N}_{2} \mathrm{O} \text { is not prognostic in } \\
\mathrm{AQ} \text { simulations } \\
\mathrm{A}: \text { Ammonium sulphate, ammonium } \\
\text { nitrate, fossil-fuel } \mathrm{BC} \text { \& OC, mineral dust, } \\
\text { biomass-burning, sea salt; based on } \\
\text { mass \& assumptions about hygroscopic } \\
\text { growth and optical properties (see } \\
\text { Bellouin et al, 2011) } \\
\text { C: droplet number parameterised based } \\
\text { on aerosol concentrations }\end{array}$ & $\begin{array}{l}\mathrm{G}: \mathrm{N}_{2} \mathrm{O}, \quad \mathrm{O}_{3}, \mathrm{CH}_{4} \text {, depending on } \\
\text { configuration }-\mathrm{N}_{2} \mathrm{O} \text { is not prognostic in } \mathrm{AQ} \\
\text { simulations } \\
\mathrm{A} \text { : Ammonium sulphate, ammonium nitrate, } \\
\text { fossil-fuel } \mathrm{BC} \& \mathrm{OC} \text { mineral dust, } \\
\text { biomass-burning, sea salt; based on mass } \\
\text { and assumptions about hygroscopic } \\
\text { growth and optical properties (see Bellouin } \\
\text { et al., 2011) } \\
\text { C: droplet number parameterised based on } \\
\text { aerosol concentrations. }\end{array}$ & $\begin{array}{l}\text { G: None }\left(\mathrm{O}_{3} \text { from climatology) }\right. \\
\text { A: Ammonium sulphate only } \\
\text { C: Optical depth calculated based on } \\
\text { cloud liquid water content only }\end{array}$ & $\begin{array}{l}\text { SW, LW: User-defined (in AQ } \\
\text { simulations typically every } \\
\text { hour) } \\
\text { PH: Every timestep }\end{array}$ \\
\hline $\begin{array}{l}\text { M-SYS (METRAS online } \\
\text { version) } \\
\text { von Salzen and } \\
\text { Schlünzen (1999a) }\end{array}$ & $\begin{array}{l}\text { G: Water vapour, } \mathrm{O}_{3} \\
\text { A: Climatology prescribed } \\
\text { C: Liquid water content }\end{array}$ & $\begin{array}{l}\text { G: Water vapour, } \mathrm{CO}_{2} \\
\text { A: Climatology prescribed } \\
\text { C: Liquid water content }\end{array}$ & $\begin{array}{l}\text { G: Standard atmosphere } \\
\text { A: Climatology prescribed } \\
\text { C: Direct dependence on liquid water } \\
\text { content (in test, Uphoff, 2013) }\end{array}$ & $\begin{array}{l}\text { SW, LW: Every minute } \\
\text { PH: User defined, mostly every } \\
\text { hour }\end{array}$ \\
\hline $\begin{array}{l}\text { RACMO2/LOTOS-EUROS, } \\
\text { van Meijgaard et al. 2008, } \\
\text { Schaap et al. (2008) }\end{array}$ & $\begin{array}{l}\text { G: RRTM, } \mathrm{H} 2 \mathrm{O}+\text { climatology } \mathrm{CO}_{2}, \mathrm{~N}_{2} \mathrm{O} \text {, } \\
\mathrm{SO}_{2}, \mathrm{O}_{3}, \mathrm{CFC} 11, \mathrm{CFC} 12 \\
\mathrm{~A}: \mathrm{RRTM} \text {, Direct aerosol effect (dust, sea } \\
\text { salt, black carbon, primary } \\
\text { anthropogenic, sulfate, nitrate, } \\
\text { ammonium), } \\
\mathrm{C}: \mathrm{CCN} \text { based on sea salt, sulfate, } \\
\text { nitrate concentrations (Menon 2004). } \\
\text { Spectrally resolved subgrid scale, using } \\
\text { cloud water path and cloud fraction }\end{array}$ & $\begin{array}{l}\mathrm{G}: \mathrm{RRTM}, \mathrm{H}_{2} \mathrm{O}+\text { climatology } \mathrm{CO}_{2}, \mathrm{~N}_{2} \mathrm{O} \text {, } \\
\mathrm{SO}_{2}, \mathrm{O}_{3}, \mathrm{CFC} 11, \mathrm{CFC} 12 \\
\mathrm{~A}: \text { RRTM, no scattering, aerosol from } \\
\text { climatology } \\
\mathrm{C} \text { : Spectrally resolved subgrid scale, using } \\
\text { cloud water path and ice path, cloud } \\
\text { fraction }\end{array}$ & $\begin{array}{l}\mathrm{G}: \mathrm{CBM}-\mathrm{IV}\left(\mathrm{O}_{3}, \mathrm{NO}_{2} \text { etc.) }\right. \\
\text { A: None } \\
\text { C: Cloud cover attenuation factor (bulk } \\
\text { per grid cell) combined with Roeths flux } \\
\text { (clear sky radiation) }\end{array}$ & $\begin{array}{l}\text { Exchange of meteo and aerosol } \\
\text { fields every } 3 \text { hours, } \\
\text { interpolation to hourly values } \\
\text { SW: Every internal model time } \\
\text { step, using hourly transmissivity } \\
\text { update and solar angle per } \\
\text { model timestep } \\
\text { LW: Every internal time step, } \\
\text { using hourly emissivity update } \\
\text { and temperature profile per } \\
\text { model time step } \\
\text { PH: hourly update of photolysis } \\
\text { rate based on meteorology and } \\
\text { solar angle. }\end{array}$ \\
\hline $\begin{array}{l}\text { RegCM4-Chem } \\
\text { Zakey et al. (2006), } \\
\text { Somon et al. (2006), } \\
\text { Shalaby et al. (2012) }\end{array}$ & $\begin{array}{l}\text { G: Gas climatology, except } \mathrm{O}_{3} \text { which can } \\
\text { be interactive. } \\
\text { A: Sulphate, fossil-fuel BC \& OC, mineral } \\
\text { dust, biomass-burning BC \& OC, sea }\end{array}$ & $\begin{array}{l}\text { G: Gas climatology, except } \mathrm{O}_{3} \text { which can } \\
\text { be interactive. } \\
\text { A: Aerosol emission / absorption. } \\
\text { C: None }\end{array}$ & $\begin{array}{l}\text { G: None } \\
\text { A: None } \\
\text { C: Cloud OD effects on photolysis } \\
\text { coefficients. }\end{array}$ & $\begin{array}{l}\text { SW, LW: User-defined } \\
\text { PH: Chemical time step, user - } \\
\text { defined ( typically } 900 \text { s). }\end{array}$ \\
\hline
\end{tabular}
dust, biomass-burning $\mathrm{BC} \& \mathrm{OC}$, sea C: None

salt; based on mass \& assumptions

properties

$\mathrm{C}$ : Coupling with prognostic microphysics

in development

RAMS/ICLAMS

Kallos et al. (2009),
Solomos et al. (2011)

G: Harrington radiation scheme with G: Harrington radiation scheme with $\mathrm{H}_{2} \mathrm{O}, \mathrm{G}, \mathrm{A}, \mathrm{C}$ : Photolysis rates are computed SW, LW: User-defined $\mathrm{H}_{2} \mathrm{O}, \mathrm{O}_{3}$ and $\mathrm{CO}_{2}$ and other gases $\mathrm{O}_{3}$ and $\mathrm{CO}_{2}$ and other gases; RRTMg online according to Madronich et al., PH:
RRTMg OPAC OPAC 1987. Absorption cross sections and

A: Option to use Harrington radiation quantum yields according to Carter,

scheme with simulated natural aerosols scheme with simulated natural aerosols 2000.

and anthropogenic sulphates; RRTMg and anthropogenic sulphates; RRTMg

OPAC PM, option for online treatment of OPAC PM, option for online treatment of

$\begin{array}{lrl}\text { natural } & \text { aerosols natural } & \text { aerosols } \\ \text { C: Interaction with explicitly solved liquid } C \text { : Interaction with explicitly solved liquid }\end{array}$ and ice hydrometeor size-spectra and ice hydrometeor size-spectra

\begin{tabular}{|c|c|c|c|c|}
\hline $\begin{array}{l}\text { WRF/Chem } \\
\text { Grell et al. (2005, 2011), } \\
\text { Fast et al. (2006), Zhang et } \\
\text { al. (2010a) }\end{array}$ & $\begin{array}{l}\text { G: Only climatologies } \\
\text { A: Dhudia: Bulk total dry mass, EC, and } \\
\text { aerosol water, fixed typical mass } \\
\text { extinction coefficients for dry aerosol } \\
\text { GSFCSW: Aerosol optical depth } \\
\text { C: Cloud droplet number: considered } \\
\text { RRTM, CAM: use aerosol optical } \\
\text { properties from complex optical } \\
\text { calculation module (MIE calculations) }\end{array}$ & $\begin{array}{l}\text { G: Only climatologies } \\
\text { A: RRTM: None } \\
\text { C: RRTMG, CAM use aerosol optical } \\
\text { properties and explicit cloud microphysics }\end{array}$ & $\begin{array}{l}\text { G: } \mathrm{O}_{3} \\
\text { A: TUV: like MCCM } \\
\text { Fast-J: depending on simulated } \\
\text { composition and size distribution } \\
\text { (available for all aerosol modules) } \\
\text { F_TUV: Acc. mode masses of } \mathrm{EC} \text {, } \\
\text { organic, } \mathrm{NO}_{3}, \mathrm{NH}_{4}, \mathrm{SO}_{4} \text {, sea salt (for } \\
\text { modal aerosol and bulk aerosols only) } \\
\text { C: Cloud droplet number, bulk only }\end{array}$ & $\begin{array}{l}\text { SW: User-defined } \\
\text { LW: Equal to SW } \\
\text { PH: User-defined }\end{array}$ \\
\hline $\begin{array}{l}\text { WRF-CMAQ Coupled } \\
\text { System } \\
\text { Pleim et al. (2008), } \\
\text { Mathur et al. (2010), } \\
\text { Wong et al. (2012) }\end{array}$ & $\begin{array}{l}\text { RRTMG or back } \\
\text { G: CAM } \\
\text { A: } 5 \text { groups: water-soluble, insoluble, } \\
\text { sea-salt, BC and water; Direct aerosol } \\
\text { effect } \\
\text { C: Scattering and absorption of cloud } \\
\text { water droplet (parameterised) }\end{array}$ & $\begin{array}{l}\text { RRTMG or CAM } \\
\text { G: constant background } \\
\text { A: } 5 \text { groups: water-soluble, insoluble, sea- } \\
\text { salt, BC and water; Direct aerosol effect } \\
\text { only } \\
\text { C: Scattering and absorption of cloud water } \\
\text { droplet (parameterised) }\end{array}$ & $\begin{array}{l}\text { G:from the look-up table } \\
\text { A:from the look-up table } \\
\text { C: Uses a parameterization to correct the } \\
\text { clear-sky photolysis rates for cloud cover }\end{array}$ & $\begin{array}{l}\text { SW: User-defined } \\
\text { LW: User-defined } \\
\text { PH: N/A }\end{array}$ \\
\hline
\end{tabular}

The complexity of the treatment of the effect of simulated aerosol concentrations on short-wave and long-wave radiation fluxes varies substantially among models. For example, MCCM considers only the simulated total mass of dry aerosol in each layer in combination with a "typical" mass extinction coefficient and the water attached to the aerosol in order to calculate the extinction of short-wave ra- diation. Different chemical species, which include BC, organic mass (OM), water and various ionic species, such as sulfate and nitrate, can be considered in WRF-Chem, EnviroHIRLAM and COSMO-ART. Within WRF-Chem an aerosol optical property module (Barnard et al., 2010) treats bulk, modal, and sectional aerosol size distributions using a similar methodology for refractive indices and multiple mixing 
rules to prepare 3-D distributions of aerosol optical thickness, single scattering albedo and asymmetry parameters. These aerosol optical variables are then passed into some of the short-wave and long-wave radiation schemes available in WRF. WRF-Chem offers the option of runtime Mie calculations for the optical parameters (using bulk, modal, or sectional aerosol modules) as well as BOLCHEM (Russo et al., 2010) and COSMO-MUSCAT (Heinold et al., 2008) for dust aerosols. The Enviro-HIRLAM radiation module can also account for the effects of dissolved sulfate, speciated PM, as well as trace gases within cloud droplets. In COSMOART, actual optical parameters are calculated based on tabulated values derived from aerosol distributions of a previous COSMO-ART simulation, and the actually simulated aerosol masses of each mode (Vogel et al., 2009). A slightly different approach is employed in MEMO/MARS-aero, where radiative effects of aerosol particles are introduced using the OPAC software library.

It is interesting to note that few consistent assumptions about the mixing state of pollutants exist among different models and radiation modules, most of which tend to employ widely differing approaches. For example soot is considered as externally and internally mixed and its aging process is explicitly simulated in the model COSMO-ART. In WRFChem all soot compounds are simulated as being internally mixed. The OPAC speciation, on the other hand, defines a set of internally mixed aerosol components, which are subsequently externally mixed in order to represent PM concentration fields of a given composition.

\subsection{Emissions and deposition and their dependence on meteorology}

Emissions are essential inputs for CTMs. Uncertainties in emissions and emission parameterisations rank among the largest uncertainties in air quality simulations. In the context of online coupled modelling, the most relevant emissions are those that depend on meteorology, because they could potentially be treated more accurately and consistently than in offline models. This section therefore focuses on this type of emissions. Chemical species are ultimately removed from the atmosphere by dry and wet deposition which are strongly driven by meteorology and, therefore, almost always calculated online. However, similarly to emissions, meteorological dependencies are sometimes neglected or simplified, for example, when constant dry deposition rates are a priori prescribed.

\subsubsection{Emissions}

Inventories of anthropogenic emissions typically contain annual total mass emissions of the most important species and compound families such as $\mathrm{NO}_{\mathrm{x}}, \mathrm{SO}_{\mathrm{x}}$, methane and other VOCs, $\mathrm{NH}_{3}$ and some PM species (e.g. OM, EC, trace metals). The most commonly used emission inventories in $\mathrm{Eu}-$ rope are those of the European Monitoring and Evaluation Programme (EMEP - http://www.ceip.at/) and the inventory developed within the EU FP7 MACC project (Monitoring Atmospheric Composition and Climate; Kuenen et al., 2011). Annual emissions are translated into emissions for a given month of the year on a given day of the week and a given hour of the day by using category-specific time factors based on activity data. Recently, meteorological dependencies of anthropogenic emissions have started to be taken into account in some models, like the increased energy demand under cold/hot periods due to residential heating/cooling (Petrik et al., 2013). Also, changes in energy production mechanisms (wind/solar versus power plants based on combustion) are directly related to meteorology. Agricultural emissions of $\mathrm{NH}_{3}$ and dust are typically affected by meteorology, which is at present not taken into account other than by inclusion of the natural seasonal variability. A more interactive treatment of these types of meteorology dependent emissions would be desirable. Shipping and aviation emissions are relevant as they take place in remote areas. In particular, open-ocean shipping emissions are not well constrained as they are not subject to regulations, and their feedback to meteorology is evident from satellite-observed cloud patterns associated with ships. Although emissions from aircraft are known to have potentially significant impacts on the radiative budget of the troposphere through the formation of contrail cirrus (Burkhart and Kärcher, 2011) and upper tropospheric ozone (Lee et al., 2009), they are often not taken into account in regional scale models, except for emissions during landing and take-off which are included in the national emission reports.

Natural emissions are closely related to meteorology and are in general already calculated online even in offline models using the meteorological input driving the CTM. Sea spray is the dominant aerosol source over the oceans and therefore, its proper quantification is highly relevant for a coupled model. Sea salt emissions depend on wind speed and sea water temperature, but there is also evidence of a dependency on wave state and organic matter concentrations (De Leeuw et al., 2011). The fluxes and composition of the smallest particles are especially uncertain. In addition to direct radiative effects (Lundgren et al., 2012), sea-salt aerosols may feedback on meteorology by acting as CCNs, their activity being dependent on the organic fraction contributed by phytoplankton (Ovadnevaite et al., 2011). In addition, phytoplankton is a source of dimethyl sulfide (DMS) and a minor source of isoprene (Guenther et al., 1995; Gantt et al., 2010; Meskhidze et al., 2011). All models include sea-salt, but DMS and the organic emissions from oceanic sources are not always taken into account, as they are more uncertain.

Windblown dust refers to particles from a broad range of sources. Due to their direct relationship with meteorology, simulation of windblown dust emissions is advisable in online coupled models. Natural emissions of dust, for example, from deserts, depend on wind speed and soil characteristics (type, vegetation, texture, wetness). If such relations are non- 
linear, online models can have a clear advantage. Some parameterisations account for the dependence of the size distribution of the vertically emitted particles on the size of the saltation particles (Alfaro and Gomez, 2001; Shao, 2001), while others do not consider this dependency (Marticorena and Bergametti, 1995). Road resuspension may be an important source in some areas depending on traffic intensities, use of studded tires, the amount of dust on a road, sanding activities, soil moisture, rain and snow. Agricultural activities also contribute to windblown dust, depending on arable soil land fractions, timing of activities and their intensity, translations of activity to dust release, as well as rain, snow and temperature. Agricultural emissions are taken into account in only a few models and even in those models, they are crudely calculated and poorly validated. A more detailed description of windblown dust emissions can be found in the report of Schaap et al. (2009) and references therein. Apart from uncertainties in parameterisations of wind-blown dust emissions, there is uncertainty in the underlying land use and soil texture maps. This includes soil moisture which is directly coupled to meteorology and difficult to represent correctly in meteorological models.

Emissions of biogenic VOCs (BVOCs) such as isoprene and terpenes are strong functions of meteorological conditions. Measurements on individual plant species demonstrated that temperature and photosynthetically active radiation (PAR) are the key driving variables for these emissions (e.g. Tingey et al., 1980; Guenther et al., 1991; Staudt et al., 1997). Most models, therefore, calculate these emissions online, based usually on the Model of Emissions of Gases and Aerosols from Nature (MEGAN) emission scheme (Guenther et al., 1993, 1995, 2006, 2012) or its variants (Vogel et al., 1995), or a tree species database, but effects of stress like high $\mathrm{O}_{3}$ concentrations or drought are usually not taken into account. BVOC emissions contribute to $\mathrm{O}_{3}$ formation and can also give a significant contribution to the formation of SOA, which in turn may affect radiation and hence feedback on BVOC emissions in an online coupled model.

Other biogenic emissions of potential relevance for air quality simulations and chemistry-meteorology interactions are NO emissions from soils (Yienger and Levy II, 1995) and emissions of bacteria, fungal spores and pollen which have been reported to act as efficient ice nuclei (e.g. Hoose et al., 2010a, b; Pummer et al., 2012). Lightning is an important natural source of $\mathrm{NO}_{\mathrm{x}}$ in the free troposphere, but lightning as a source of $\mathrm{NO}_{\mathrm{x}}$ production is often neglected in mesoscale models. Online coupled models with access to convective mass fluxes or cloud fields calculated by the meteorological model, however, would be perfectly suited to simulate this source (Tost et al., 2007). In contrast to most gases that are consistently deposited, $\mathrm{NH}_{3}$ fluxes over fertilised agricultural lands and grazed grasslands are bi-directional, with both deposition and emission occurring in parallel (Sutton et al., 1998; Zhang et al., 2008). Advanced resistance models accounting for capacitance of leaf surfaces have been developed to simulate the bi-directional $\mathrm{NH}_{3}$ exchange (e.g. Nemitz et al., 2001; Wu et al., 2009) and incorporated into WRF-CMAQ (Cooter et al., 2012; Bash et al., 2013 and Pleim et al., 2013). Wichink Kruit et al. (2012) showed that by including bi-directional exchange in the LOTOS-EUROS model, $\mathrm{NH}_{3}$ concentrations increased almost everywhere in Europe and nitrogen deposition shifted away from agricultural areas towards large natural areas and remote regions. The bi-directional fluxes are directly and non-linearly related to meteorology, soil and vegetation conditions and should, therefore, be calculated online, following the approach proposed by Sutton et al. (2013). Pollen emissions depend on meteorology and season (e.g. Sofiev et al., 2009a) and have an impact on visibility. Pollen emissions are included in Enviro-HIRLAM (birch), COSMO-ART (birch and grass) and METRAS (oak).

The occurrence of forest fires is dependent on drought and their spread is partly determined by wind conditions. However, a forest fire can start randomly initiated by lightning or human beings. Therefore, fire emissions cannot be calculated as being purely dependent on meteorological conditions but, are based on satellite observations of wildfires. When forecasting air quality or weather near wildfires, fires are usually held constant in strength and location during the forecast period. However, injection height and diurnal variation is modelled by some online models (WRF-Chem, Grell et al., 2011). These wildfires emit large amounts of $\mathrm{CO}_{2}, \mathrm{CO}$ and VOCs as well as primary PM (e.g. EC, OC) and have an impact on $\mathrm{O}_{3}$ and $\mathrm{PM}$ concentrations, as well as on visibility. Because wildfires represent such a large signal in simulated aerosol concentrations, it is somewhat easier to show improvements in weather forecasting (Grell et al., 2011) when using online models.

Volcanic emissions, in particular sudden eruptions, are not influenced by meteorology. But they have a strong impact on meteorology, being strong point sources, emitting large amounts of heat, ash and gases high into the atmosphere and should, therefore, be taken into account in a coupled model.

Most of the problems and uncertainties associated with emissions of gaseous and particulate pollutants of anthropogenic and natural origin are not specific to online coupled models. However, due to the important role of aerosols in chemistry-meteorology feedback processes, the main efforts of the online modelling community should be devoted to improved descriptions of primary aerosol emissions and of emissions of the most relevant gaseous and aerosol precursors including $\mathrm{NH}_{3}, \mathrm{NO}_{\mathrm{x}}$ and BVOCs (Zhang, 2008). For any type of emitted primary aerosol, a better physicochemical characterisation in terms of number and mass size distributions, hygroscopicity, and internal versus external mixture, would be desirable as number concentrations and size distribution have a major impact on their cloud forming properties and radiation effects, rather than their mass concentrations. Such inventories are currently being developed (Denier van der Gon et al., 2009). Wind-blown dust 
emissions from dry soils and resuspension of particles are still poorly understood and described in models. While not being a major health concern, mineralogical particles play an important role in cloud formation notably by acting as ice condensation nuclei (Hoose et al., 2008, 2010b; Gettelmann et al., 2010). A better meteorology-dependent parametrization of agricultural particle emissions would be also advisable as they contribute significantly in some areas. Regarding emissions of gaseous precursors of secondary aerosol, model improvements should particularly focus on several issues. First $\mathrm{NH}_{3}$ emissions should be described in an integrated model, thus taking into account meteorology and agricultural practices in a fully interactive way and considering bi-directional exchange. Second, a better quantification of emission factors of BVOCs for the major tree species in Europe and better geographical maps of their spatial distribution are needed to reduce the large spread in BVOC emissions between models. Third, primary emissions of organic particles from fossil and wood burning may make a significant contribution to total carbon within Europe (Simpson et al., 2007) and thus, should receive more attention. The contribution of anthropogenic VOC emissions to SOA formation appears to be rather minor on both the global (Henze et al., 2008) and European (Szidat et al., 2006; Simpson et al., 2007) scales, although they may be relevant downwind of densely populated areas with relatively high emissions. Last but not least, a critical aspect of all the natural emissions is that their estimations depend on land use and conditions of the surface (e.g. vegetation type and state, soil type, soil moisture), parameters that also impact meteorology. Improving the accuracy of these data sets directly impacts emission data, but is a challenge, especially in geographic areas where land use changes quickly (e.g. China).

\subsubsection{Wet and dry deposition and sedimentation}

Wet and dry depositions are the only possible pathways to remove pollutants previously released into and (chemically) processed in the atmosphere. Both processes are directly driven by meteorology and thus, online coupled models have higher potential to describe these processes more accurately than offline models, e.g. because all meteorological fields are directly accessible at high temporal resolution.

Dry deposition mainly affects surface concentrations, except for large particles (diameters larger than about $10 \mu \mathrm{m}$ ) which fall out relatively quickly. Dry deposition is speciesdependent and directly driven by meteorology through vertical mixing, temperature, humidity, wind speed and indirectly through soil moisture and snow or water on the surfaces (Wesely, 1989; Zhang et al., 2001, 2003; Seinfeld and Pandis, 2003; Pleim and Ran, 2011). Land cover types and vegetation properties (e.g. leaf area surface, stomata resistance) play an important role, and they are also influenced by meteorology. The complex interaction between all these factors make dry deposition a process that benefits from online coupling with meteorology and meteorological land surface models, with main impact on atmospheric composition close to the surface, in particular for species like $\mathrm{O}_{3}$ and $\mathrm{NH}_{3}$.

Wet deposition is an efficient removal mechanism for many gases and aerosols, depending on the scavenging ratio and collection efficiency for the species. In contrast to dry deposition at the surface, it impacts gases and aerosols over a larger vertical extent from the surface to cloud top. It is often simulated as two separate processes, in-cloud and belowcloud scavenging and depends on the presence of clouds, cloud and droplet properties and the precipitation rate. Due to the online availability of these parameters, modelling of wet deposition can be more accurate in an online coupled model. Treatments of wet scavenging and cloud processing are often highly simplified and vary strongly between models (Gong et al., 2011). More detailed approaches were implemented in COSMO-ART and WRF-Chem, taking full advantage of the access to microphysical tendencies (e.g. condensation, evaporation, autoconversion, etc.) simulated by the meteorological model, which would not easily be possible in an offline model (Knote and Brunner, 2013).

\subsection{Chains and loops of interactions and other feedback mechanisms}

The above described interaction mechanisms between aerosol, chemical and meteorological processes depend on and can interact with each other. The range of interactions can be much broader and hence cannot be fully covered by the simplified classification of aerosol feedbacks of the direct, semi-direct and first and second indirect effects (e.g. Jacobson, 2002). So, different chains and loops of interactions take place and should be properly simulated in online coupled models. Some examples of these chains of interactions are provided in Sect. 2 with Fig. 2 schematically demonstrating an interaction chain on the example of impacts of temperature on concentrations and vice versa.

Zhang et al. (2010a) analysed with the online model WRFChem such a "chain effect" over the continental US and simulated enhanced stability as a result of the warming caused by $\mathrm{BC}$ in the $\mathrm{ABL}$ and the cooling at the surface that results from reduced solar radiation by all aerosols. This effect in turn further increases air pollution concentrations over areas where air pollution is already severe. Similar chain effects were found in applications of WRF-Chem over East Asia, Europe and globally (Zhang et al., 2012c, 2013).

Due to strong non-linearity and space and time inhomogeneity of different interacting mechanisms, such chains and loops of interactions can be reproduced only by using online integration of aerosol dynamics, chemistry, and meteorological processes calculating them together at the same time step. The online access approach for coupling chemistry and meteorology models is limited in its ability to reproduce such chain effects due to possible inconsistencies and limited frequency of data exchange in between meteorological and 
chemical models (e.g. such exchanges may not happen during each time step and on the same grid, leading to inevitable inconsistencies).

The number of interactions between aerosols, gases and other components of the Earth system is large (Fig. 3). Some feedback mechanisms have been described in previous sections, other relevant chemistry meteorology interactions are described below.

Light-absorbing particles such as $\mathrm{BC}$ and dust affect climate not only by absorbing solar radiation, but also by changing snow albedo (Warren and Wiscombe, 1980, 1985; Painter et al., 2007). Dirty snow absorbs more radiation, thus heating the surface and warming the air even more. This warming initiates a positive feedback that can further reduce snow depth and surface albedo (Hansen and Nazarenko, 2004; Jacobson, 2004; Flanner et al., 2009). Through enhancing downwelling thermal infrared radiation, airborne $\mathrm{BC}$ influences the ground snow cover by increased melting and sublimation of snow at night.

Absorption of solar radiation by $\mathrm{BC}$ and dust also perturbs the atmospheric temperature structure and thus affects clouds. By increasing atmospheric stability and decreasing relative humidity, $\mathrm{BC}$ is responsible for reducing the lowcloud cover and by absorbing the enhanced sunlight, BC warms the atmosphere, leading to a further reduction in cloud cover (Jacobson, 2006). While absorbing aerosols through the semi-direct effect contribute to cloud evaporation, their presence below the cloud level can enhance vertical motions due to their heating effect and increased liquid water path and cloud cover. The effects of absorbing aerosols could be a cooling caused by the effect of $\mathrm{BC}$ on cloud cover; the cooling due to $\mathrm{BC}$ could be as strong as its warming direct effects (Koch and Del Genio, 2010).

Intensification of air stability due to aerosol particles reduces surface winds and emissions of particles and gaseous precursors that are wind dependent. The reduction of emissions due to thermal IR absorption is called the "smudge pot effect"; when the effect is due to both scattering and absorption of the solar radiation, it is coined the "daytime stability effect" (Jacobson, 2002). Furthermore, the local effect of aerosols on temperature, relative humidity, clouds, and winds can influence the large scale temperatures, altering the thermal pressure systems and jet streams (Jacobson, 2002). Moreover, aerosols can influence gas concentrations in the atmosphere through their direct interactions or by changing the actinic fluxes of ultraviolet radiation and thus, accelerating or inhibiting photochemical reactions (Dickerson et al., 1997).

Gases also interact with solar and IR-radiation to influence heating rates (photochemistry effect) (Jacobson, 2002). Among gaseous pollutants, tropospheric $\mathrm{O}_{3}$ is known to contribute to both $\mathrm{AQ}$ degradation and atmospheric warming. At high concentrations, $\mathrm{O}_{3}$ can damage plant tissues resulting in a reduction of agricultural crop yields and forest tree growth (Turner et al., 1974; Krupa et al., 2000). In addition to its

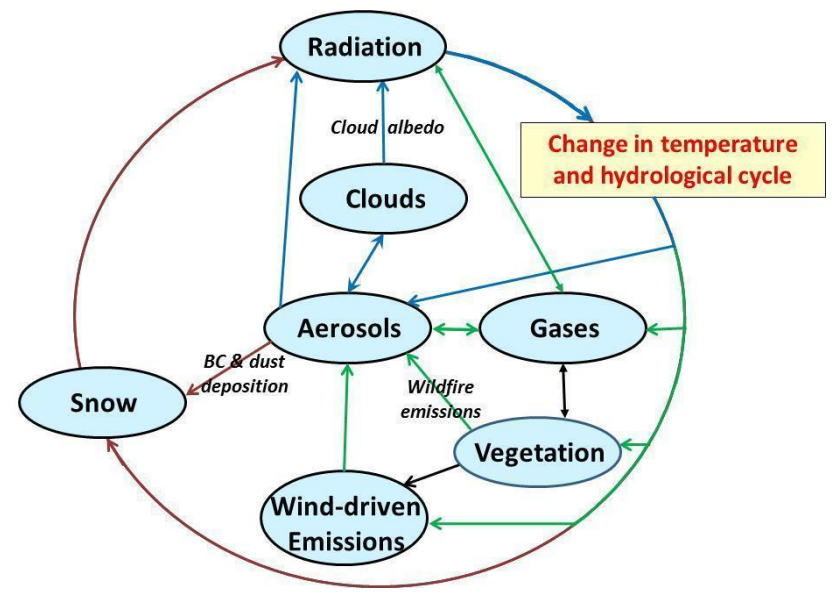

Fig. 3. Interactions between aerosols, gases and components of the Earth System.

direct effect as a warming GHG, $\mathrm{O}_{3}$ generates an "indirect effect" onto the climate system through feedbacks with the carbon cycle. High $\mathrm{O}_{3}$ or $\mathrm{CO}_{2}$ can cause stomata closure, thus limiting the uptake of other gases and thereby reducing deposition. If $\mathrm{O}_{3}$ damages can be limited by increasing $\mathrm{CO}_{2}$, higher $\mathrm{O}_{3}$ can act on the photosynthesis, reducing $\mathrm{CO}_{2}$ uptake and plant productivity, hence suppressing an important carbon sink. As a result, $\mathrm{CO}_{2}$ accumulates in the atmosphere, and on the global scale this effect can contribute more than the direct forcing due to $\mathrm{O}_{3}$ increase (Sitch et al., 2007). If the timescale of the simulation is up to a year, the short-time effects of $\mathrm{CO}_{2}$ and $\mathrm{O}_{3}$ can be taken into account.

The inclusion of the interactions depicted in Fig. 3 would allow consideration of the effects of the most important feedback mechanisms (see also Table 4). Most of the regional models contain the aerosol direct effect on radiation, but only some of them simulate the aerosol indirect effects (blue lines in Fig. 3). The chain of interactions from emissions (including wind-driven natural emissions), gas phase chemistry, formation of new particles, aerosol-cloud coupling and precipitation, and interactions with radiation (blue and green lines in the figure) is treated in some regional models. These models have undergone significant developments in the realisation of feedback mechanism chains to some degree of complexity and in the direction of online coupling (Table 4).

An important feedback mechanism (red lines in Fig. 3) is linked to the light absorbing aerosol - albedo effect. Evaluation at a regional scale (the western US) using the WRFChem and WRF-RCM models showed that changes in snow albedo due to BC deposition could significantly change both regional climate and the hydrological cycle (Qian et al., 2009). Both $B C$ and mineral dust deposition can reduce snow albedo and shorten the snow cover duration with feedbacks on regional climate (Krinner et al., 2006). Thus, inclusion of $\mathrm{BC}$ and dust effects on snow albedo in regional models is desirable. 
Vegetation dynamics and ecosystem biogeochemistry (black lines in Fig. 3) can have positive feedbacks on temperature also on the regional scale (Smith et al., 2011), as they can influence surface albedo and also emissions. Aerosols can influence the ocean biogeochemistry, biosphere and carbon cycle through other feedbacks (Carslaw et al., 2010). However, the level of understanding of many of these feedbacks is still low and their inclusion in models is still in an early phase.

\section{Numerical and computational aspects of importance in online models}

With the increase of computational resources, more complex numerical models are becoming feasible, and an increase of the spatial resolution is affordable. Consequently, integrated meteorology air quality models are experiencing closer attention in Europe. Key points in such models are the numerical schemes (especially those for the transport of chemical species), the treatment of the coupling or integration between meteorology and chemistry, the role of initial and boundary values and the efficient performance of the system in a specific high performance computing (HPC) environment. This chapter addresses these issues with a final section discussing the state of development of data assimilation in chemical models and more specifically in online European models.

\subsection{Numerical methods: advection schemes, mass consistency issues and other specifics}

A number of different numerical techniques have been used and proposed for the transport of chemical tracers in online models in Europe. Some of them are able to maintain consistency (Sect. 5.1.3) of the numerical methods applied for both meteorological and chemical tracers (e.g. BOLCHEM, COSMO-ART, M-SYS, NMMB/BSC-CTM, REMOTE, WRF-Chem, some configurations of EnviroHIRLAM, ICLAMS and AQUM), while others apply different transport schemes for meteorology and chemistry species, partly because the transport requirements for chemical species are stronger than those for hydrometeors in NWP (e.g. WRF-CMAQ, RACMO2/LOTOS-EUROS, some configurations of Enviro-HIRLAM). This may be a relevant deficiency when explicitly treating aqueous phase chemistry.

Rasch and Williamson (1990) listed the following desirable properties for transport schemes: accuracy, stability, computational efficiency, transportability, locality, conservation and shape-preservation (positive definiteness, monotonicity, etc.). The last two are of particular interest in chemistry modelling. It is important also to mention the so-called wind mass inconsistency problem, which turns out not to be trivially resolved in online models (e.g. Jöckel et al., 2001). For both offline and online transport of chemical species the prevention of mixing induced by the numerical scheme is one of the important properties (Lauritzen and Thuburn, 2011).

We briefly discuss below some of the above listed properties having particular relevance for chemical online modelling.

\subsubsection{Conservation of mass}

In some applications, particularly for long-lived tracers, formal conservation of the tracer mass in the transport equation is of paramount importance. Formal or inherent mass conservation of a numerical scheme can only be achieved if one solves, in one way or the other, the continuity equation for each chemical compound, $i$ :

$\frac{\partial \rho_{i}}{\partial t}=-\nabla \cdot \rho_{i} \boldsymbol{V}+S_{i}+D_{i}$ or $\frac{\mathrm{d} \rho_{i}}{\mathrm{~d} t}=-\rho_{i} \nabla \cdot \boldsymbol{V}+S_{i}+D_{i}$

where $\rho_{i}$ is the density (i.e. mass per unit volume) and $\boldsymbol{V}$ the velocity, while $S_{i}$ represents sources/sinks (i.e. chemical reactions, emissions, or deposition, etc.) and $D_{i}$ turbulent diffusion/mixing.

Just solving the corresponding transport equation for mixing ratio $q_{i}=\rho_{i} / \rho_{\mathrm{d}}$, with $\rho_{\mathrm{d}}$ the actual dry density of air,

$\frac{\partial q_{i}}{\partial t}=-\boldsymbol{V} \nabla q_{i}+\tilde{S}_{i}+\tilde{D}_{i}$ or $\frac{\mathrm{d} q_{i}}{\mathrm{~d} t}=\tilde{S}_{i}+\tilde{D}_{i}$,

as typically done in offline chemical transport models (e.g. Borrego and Incecik, 2012), will not ensure mass conservation unless special a posteriori mass fixers are introduced. When $\rho_{i}$ is the prognostic variable, as in Eq. (1), one has to solve also an equation for the full dry mass of the atmosphere then calculate the mixing ratio $q_{i}=\rho_{i} / \rho_{\mathrm{d}^{\prime}}$, before calling the chemistry component of the model.

Obtaining a formal mass conservation from Eq. (1) requires a mass conserving Eulerian or semi-Lagrangian numerical scheme. Traditionally, mass conservation has been obtained via Eulerian type flux based schemes (examples in Machenhauer et al., 2009). In recent years, a number of inherently mass conserving semi-Lagrangian schemes have been introduced, e.g. CISL (Rančić, 1992; Nair and Machenhauer, 2002), SLICE (Zerroukat et al., 2004, 2007), LMCSL (Kaas, 2008) and CSLAM (Lauritzen et al., 2010).

\subsubsection{Shape preservation - monotonicity and positive definiteness}

First-order accurate finite volume methods used to solve Eq. (1) are generally attractive in the sense that they are positive definite and generally monotonic. However, since they are excessively damping for small Courant numbers, they are of little interest in practical applications.

In their native forms finite-volume schemes based on higher order polynomial, sub-cell representations do not, in general, fulfil properties such as positive definiteness and monotonicity. Lack of positive definiteness is unacceptable since negative concentrations are completely unphysical, and 
they cannot be dealt with by chemistry schemes. Lack of monotonicity is normally seen as spurious numerical oscillations, which often develop near discontinuities or at large variability in gradients, which can also trigger unrealistic chemical reactions. It is possible to introduce different filters or constraints on the subgrid-cell representations to reduce or eliminate these shape preservation problems. The applications of such filters often tend to reduce the accuracy of the schemes because of the implied clippings and smoothings of the subgrid-cell polynomials. For flux-based finite volume schemes, it is also possible to introduce a posteriori corrections of the fluxes (often referred to as flux limiters) to ensure fulfilment of the desired properties (Machenhauer et al., 2009).

\subsubsection{Wind mass consistency}

Wind mass consistency (Byun, 1999; Jöckel et al., 2001) concerns the coupling between the continuity equation for air as a whole and for individual tracer constituents. In the nondiscretised case (omitting sources, sinks and diffusion), the flux-form Eq. (3) for a constituent with mixing ratio $q$

$\frac{\partial q \rho_{\mathrm{d}}}{\partial t}=-\nabla \cdot q \rho_{\mathrm{d}} \boldsymbol{V}$

degenerates to

$\frac{\partial \rho_{\mathrm{d}}}{\partial t}=-\nabla \cdot \rho_{\mathrm{d}} \boldsymbol{V}$

for $q=1$. This should ideally be the case numerically as well. If the two equations are solved using exactly the same numerical method (preferably mass conservative), on the same grid and using the same time step and exactly the same wind fields, the consistency is guaranteed. In offline and also online access models, this is not readily possible due to, e.g. different grids and temporal resolution of the wind field, which is part of the dynamical model solving Eq. (4). This problem has been realised for many years. Different approaches have been developed to generate wind fields, which can improve consistency (e.g. Kitada et al., 1983) and mass conservation at the same time (Mathur and Peters, 1990; Odman and Russell, 2000). A helpful approach might be the employment of (weighted) essentially non-oscillatory advection schemes, which have been derived for scalar quantities, but have also successfully been extended for the flux conserving momentum equations (Schroeder et al., 2006).

In online models all prognostic variables, including the wind field, are known on the same grid and main time step, with some interpolation included for online access models. Therefore, the wind mass inconsistency should be less of a problem. However, in many online models, the mass field of the dry air (Eq. 3) is not calculated with exactly the same numerical schemes. Therefore, they are not consistent and sometimes not even mass conservative. As discussed by Jöckel et al. (2001) and other researchers, mass wind inconsistency can result in unrealistic dispersion of tracers. In offline air quality models it can even result in instabilities (Odman and Russell, 2000). As mentioned above, some European online models are formally consistent, but not all of them.

\subsubsection{Spurious numerical mixing/unmixing}

In the atmosphere, chemical tracers are often functionally related in the sense that the mixing ratio of a chemical species depends (non-linearly) on that of one or more others. As an example, Plumb (2007) pointed out the surprisingly distinct non-linear relationship between concentrations of $\mathrm{N}_{2} \mathrm{O}$ and $\mathrm{NO}_{\mathrm{y}}$ observed in the lower stratosphere and important for the ozone chemistry there. Lauritzen and Thuburn (2011) pointed out that transport schemes used in atmospheric modelling should respect such functional relations and not disrupt them in unrealistic ways. The implications of not maintaining functional relationships will generally lead to the introduction of artificial chemical reactions.

Turbulent mixing occurs in the real atmosphere. However, for chemical models operating on a fixed Eulerian grid, depending on the model resolution, the horizontal mixing introduced by the numerical truncation errors is generally stronger than the actual physical turbulent mixing (e.g. Thuburn and Tan, 1997). This means that chemical species are often excessively mixed in models and near large density gradients this can trigger spurious chemical reactions.

A related and even more severe problem, unmixing, i.e. unphysical up-gradient transport, also appears to some extent in Eulerian-based transport schemes. Unmixing - or antimixing - will tend to increase the roughness of the transported field purely due to the numerical method used. Of course such unmixing can/will also trigger spurious chemical reactions. Lauritzen and Thuburn (2011) proposed a set of numerical tests to investigate whether a numerical transport scheme introduces unmixing or overshooting. Recently, a number of transport schemes in various models around the world were inter-compared using the recommended tests (Lauritzen et al., 2013). It is strongly recommended that the numerical schemes (including all filters/limiters) used in European models and models elsewhere are investigated via these tests.

\subsubsection{Numerical schemes implemented in European applied models}

Some characteristics of online applied European models are briefly presented here. The BOLCHEM model solves the transport of passive tracers with the Weighted Average Flux (WAF) scheme (Toro, 1992) except for hydrometers to which a semi-Lagrangian treatment is applied (Mircea et al., 2008). In METRAS, the non-hydrostatic mesoscale model component of the M-SYS system, all equations are solved in flux conserving form on the same grid in space and time (Schlünzen, 1990) using the same numerical schemes for 
thermodynamic and chemical properties (e.g. von Salzen and Schlünzen, 1999c). However, process-optimisation approaches for the meteorology that were introduced to reduce turn-around time (Augustin et al., 2008) need to be reevaluated if used in combination with the chemistry module. The WRF-Chem (ARW dynamics model, Skamarock et al., 2005) solves fully compressible prognostic equations cast in conservative flux form. The transport scheme exactly conserves mass and scalar mass (Grell et al., 2005). In order to maintain consistency, monotonicity, positive definiteness and mass conservation, Enviro-HIRLAM model includes the Locally Mass Conserving Semi-Lagrangian LMCSLLL and LMCSL-3D schemes (Kaas, 2008; Sørensen et al., 2013). Additionally, the model contains several options for the advection scheme previously implemented (Central Difference, Semi-Lagrangian, Bott), which does not maintain consistency between meteorology and chemistry. The usage of one or the other scheme is experiment-dependent. In the NMMB/BSC-CTM, a fast Eulerian conservative and positive-definite scheme was developed for model tracers. Conservative monotonisation is applied in order to control over-steepening within the conservative and positive-definite tracer advection scheme (Janjic et al., 2011).

\subsection{Techniques for coupling/integration of meteorology and chemistry/aerosols}

As already outlined in Sect. 3, we distinguish online access models and online integrated models (Baklanov and Korsholm, 2008). Both are characterised by the implementation of the chemistry and meteorological processes within one modelling system. The meteorological information is available at each time step directly (online integrated) or through a coupler (online access), i.e. a process transferring information between model components and which may compute diagnostic or remapping tasks. In the online integrated approach, two-way interactions or feedbacks are allowed between meteorology and chemistry and represent the more complete integration of $\mathrm{AQ}$ within meteorological processes. Computational requirements within online integrated and online access models may vary strongly. More efficient use of the computational time can be achieved with the online integrated approach, where no interpolation or double transport of passive species is performed.

On the other hand, offline models are based on several independently working components or modules (e.g. meteorology, emissions and chemistry) that exchange information through a specific interface. The main characteristic is that the exchange follows only a one-way direction and no feedbacks are possible. Grell and Baklanov (2011) pointed out the main strengths and disadvantages of both approaches. Online integrated modelling systems represent the atmospheric physico-chemical processes more realistically, since the chemistry and meteorology are solved with the same time steps, spatial grids and ideally the same numerical methods.
Thus, no interpolation in time or space is required, and the same numerical schemes can in principle be used for the transport of pollutants and passive meteorological variables. In this sense, feedback mechanisms can be considered and the model is suited for studies of aerosol effects. The inclusion of the chemistry and feedback processes may in the future improve the medium-range forecasts ( 3 to 15 days). On the other hand, offline modelling systems require lower computational resources. Usually, the meteorological output is already available from previous forecast or analysis runs. This allows the application only of the CTM and provides more flexibility in specifying ensembles or performing several simulations with different inputs (e.g. different emission scenarios). This approach is probably most significant for regulatory agencies, but also for emergency response, where a multitude of ensembles can quickly be performed. Grell and Baklanov (2011) pointed out that errors introduced with offline approaches will usually increase as the horizontal resolution is increased to cloud resolving scales, requiring that meteorological fields are available with much higher frequency (possibly on an order of minutes). For simulations on cloud resolving scales, Grell et al. (2004) found that the variability of the vertical velocity becomes much more important as compared to the situation on coarser resolution. At cloud resolving scale the vertical mass transport is therefore usually underestimated with offline approaches, unless meteorological data are available at very high frequency intervals. These intervals can be determined by a power spectrum analysis (Grell and Baklanov, 2011). For MCCM (Grell et al., 2004) and for WRF-Chem (Grell and Baklanov, 2011) the offline approach lead to almost identical results compared to online simulations with an output frequency of about 10 times the model time step. To give one example, for WRF-Chem one would use a model time step of $15 \mathrm{~s}$ for $3 \mathrm{~km}$ horizontal resolution. Using an output interval of $150 \mathrm{~s}$ would lead to almost no difference in results. But even an output interval of $30 \mathrm{~min}$ gave a significant degradation in terms of the estimate of vertical mass flux.

As mentioned previously the coupling in online models varies in complexity. Zhang (2008) identified different degrees of coupling within online models from slightly coupled to moderately, or fully coupled. The slightly or moderately coupled models only couple selected species (e.g. $\mathrm{O}_{3}$ or aerosols) and/or processes (e.g. transport) and may not account for all important feedbacks among processes, they are named in the present paper online access models. The fully coupled models couple all major processes at every main time step and simulate a full range of atmospheric feedbacks (corresponding to online integrated models). Not all coupled models enable a full range of feedbacks among components and processes. Selected species and processes are coupled in the slightly coupled models, while most of the processes remain decoupled. In these systems, only specific feedbacks among processes are accounted for. In the fully coupled models, major processes are coupled and a wide 
range of feedbacks are allowed. Zhang (2008) pointed out that few online integrated or online access models exist in the US. This is true also for European models, where only few systems account for a full range of feedbacks (Sect. 2), but there is a clear trend towards fully coupled systems.

Examples of online integrated models applied in Europe (including both direct and indirect aerosol effects) are Enviro-HIRLAM, RAMS/ICLAMS, WRF-Chem, AQUM and COSMO-ART. Other models do not consider all the feedbacks between meteorology and chemistry, but still maintain consistency among transport of meteorology and chemical species (e.g. BOLCHEM, MCCM, M-SYS, NMMB/BSC-CTM). As online access models, LOTOSEUROS, WRF-CMAQ and MEMO/MARS couple meteorology and chemistry through an in-house or community-based coupler, but different transport schemes are applied for meteorology and the chemistry.

Nesting techniques allow modelling of high horizontal resolution domains using information of parent grids. This can go from regional scale down to the obstacle resolving scale with different nesting approaches applicable for different phenomena as outlined by Baklanov and Nuterman (2009) and Schlünzen et al. (2011). The last mentioned authors distinguish the time-slice approach that uses steady state boundary values for a time dependent integration, from one-way nesting (coarse models give information to a higher resolved domain) and two-way-nesting (exchange of information between the two domains). They recommend considering the characteristic times of atmospheric phenomena, when deciding for one of the three nesting approaches. In online models, most efforts have been directed to the implementation of one-way nesting approaches (e.g. AQUM, BOLCHEM, COSMO-ART, Enviro-HIRLAM, M-SYS, NMMB/BSC-CTM), though some models also allow the two-way approach (e.g. WRF-Chem, MCCM and MesoNH). The consistency between nests should be carefully maintained in online models, whereby feedbacks with the meteorology are turned-on. A traditional two-way nesting approach may create many consistency problems due to the non-linear reactive effects of the chemistry between nested domains.

There is a very valid question to be answered for online access models: How tight does the coupling need to be to generate a realistic representation of feedback effects? To answer this question similar ideas as used for nesting can be considered: The two-way coupling interval in online access models should be at least shorter than the timescale of the relevant processes involved. For aerosol direct effects, for example, there is no strong need for exchanging meteorology and aerosol fields very frequently. For aerosol indirect effects, however, frequent data exchanges are critical due to the short live time of clouds. However, there is no simple and universal answer to the above question. More studies for different feedback mechanisms and applications are needed.

\subsection{Computational requirements of online models and system optimisations}

When developing an online coupled model, there are several computational considerations to take into account. Traditional "good habits" should of course be applied, that is, proper commenting, naming conventions, consistency, etc. However, from the more technical aspect, one should also consider the basic structure of the code. When using online coupled models the number of prognostic variables in the model increases dramatically. To make sure that the code is still efficient, the numerical schemes must be highly multitracer efficient (Lauritzen et al., 2010). All variables that can be reused should be so, since the possible increase in memory for storing those variables is often negligible when using a large number of prognostic variables. The amount of data communication between the individual nodes also increases dramatically, which means that one should ensure that the communication is highly optimised, otherwise the scalability of the code can be severely limited. Because the increase in computing power is mainly due to an increased number of processors/cores and not clock frequency, the scalability of the models has become more important. The models are mostly parallelised in the horizontal, meaning that, at a given resolution there is a limit where it is not possible to split the domain into smaller sections. Ideally it could be one grid box (or column) per processing core, however, communication, halo zones and numerical methods often limit this. For an operational model, the wall-clock time becomes a hard constraint, and with the use of highly complex chemical schemes this can become a real problem, even if the model itself is very efficient and parallelised. It is, therefore, essential to choose efficient numerical schemes which are usable in an operational setup.

The current state of online coupled models in Europe is that they are run on traditional supercomputers and written in a mixture of Fortran 95/90 and some Fortran 77, which are using either Message Passing Interface (MPI), Open MultiProcessing (OpenMP), or a combination of the two for the parallelisation of the code. Both methods have advantages and disadvantages, but by combining the two methods, one can ideally optimize the code for use on all types of machine architectures. In practice though, many models are only optimised for one of the methods, since writing the code for both is more cumbersome and time consuming, especially in a code under constant development. A third option for parallelising models using Fortran has recently been made available. Coarray Fortran (CAF) is a rather simple extension to the standard Fortran syntax. It has not been used extensively since it was until recently only available using the Cray Fortran compiler. It was defined by Numrich and Reid in 1998 (Numrich and Reid, 1998; Reid, 2010a) and introduced into the Fortran 2008 standard in 2010 (Reid, 2010b). CAF can be implemented on shared and distributed memory computers alike and should in either case be as fast as the OpenMP 
or MPI counterpart. It does, however, come with a caveat: rewriting a big part of the parallelisation code.

Graphical processing units (GPUs) have been mentioned as a new possibility to achieve better performance in models (Michalakes and Vachharajani, 2008; Horn, 2012). At this point none of the European online coupled models use GPUs alone or in combination with CPUs (central computing units). GPU parallelisation can be implemented either using CUDA (compute unified device architecture) or OpenCL (open computing language), where CUDA is only supported by NVIDIA and OpenCL can be used on all GPUs. Including either method in already developed online coupled models is not trivial since the optimal choices for traditional parallelisation with MPI and OpenMP cannot be assumed to be the same for CUDA and OpenCL. All attempts have, however, suggested that a significant performance gain could possibly be achieved, but this will again require rewriting large parts of the code.

\subsection{Initial conditions and boundary values}

Different approaches can be used to obtain the initial conditions and boundary values for online coupled models (both online integrated and online access). The methodology to prepare initial and boundary values do not present large differences from the procedures applied for offline models. In addition to the meteorological fields that have to be provided from the MetM in the offline approach, the 3-D distribution of chemical species has to be provided right at the beginning of the forecast, when online coupled models are used.

Concerning initial fields of chemical species (chemical initial conditions), these values can either be obtained from a previous forecast using the same modelling system, global chemical initial fields from a global modelling system (e.g. Flemming et al., 2009), prescribed fields describing clean or polluted background atmospheres (e.g. climatological averages, see also Tang et al., 2007), or either of those methods modified with increments from a chemical data assimilation system (Elbern and Schmidt, 2001). In offline models the improvement of the initial pollutant fields brings only a limited improvement in the forecast, because the forcing from meteorology and emissions makes the model quickly converge from any reasonable initial condition to a stable solution. Indeed, a spin-up of 24-48 h is usually performed for the chemistry in such systems. As the online approach may consider interactions between meteorology and the pollutants, the best possible knowledge of chemical initial conditions is required to obtain a reasonable feedback onto the meteorological forecast. In this sense, the chemical initialisation between online and offline models may substantially differ.

The lateral boundary values of the chemistry have to be provided at every forecast step. Since detailed information about the vertical profiles of all chemical species are not always available, models commonly use idealised climatological profiles for boundary values (Winner et al., 1995; Chen et al., 2003), if measurement data are not available. This is especially convenient, if the modelling domain is sufficiently large so that the influence of the concentrations at the boundary is small in the area of interest. With the improvement of global chemistry models, it is becoming more common to use chemical fields from coarse model simulations in the same way as for limited area meteorological forecasts. If predefined boundary values are used, the concentrations have reasonable values, but there is usually little temporal and spatial variation since it is often connected with a time-slice approach in nesting (Sect. 5.2). For applications which require short-term forecasts on a fine scale and a small domain it is more appropriate to obtain concentrations from a larger scale model in order to dynamically adjust boundary values (oneway nesting). If the model has also two-way nesting capabilities (e.g. Solomos et al., 2011), the simultaneous description of long-range transport phenomena and aerosol-cloud interactions at cloud resolving scales are possible.

An important problem appears when coarse or global models have different chemistry from the finer resolving models; then the species from the larger scale model have to be assigned and resembled to their respective representations in the finer resolving model, or for two-way nesting to the coarser resolving model. These difficulties can be even larger when different aerosol schemes are used, where assumptions need to be made to map from different size aerosol modes (e.g. number of size bins used to represent mineral dust) with incompatible descriptions of the aerosols composition (e.g. differences between organic matter and organic carbon mass).

\subsection{Data assimilation in online coupled models}

\subsubsection{Overview of chemical data assimilation in atmospheric models}

Data assimilation consists in the combination of modelling and observations to obtain a most probable representation of the state of the variables considered. It has been used in meteorology for over six decades (e.g. Panofsky, 1949). It is performed routinely in numerical weather prediction (Kalnay, 2003) to obtain accurate initial conditions for the forecast. Chemical data assimilation (CDA), i.e. the assimilation of observations of atmospheric chemical concentrations, is a more recent development and operational applications in air quality modelling are still limited. CDA aims to improve model performance by modifying model inputs such as initial conditions, emissions or boundary values or some model parameters.

Various mathematical techniques are used to assimilate the chemical observations and modify the model components. These techniques have been reviewed in the literature (e.g. Carmichael et al., 2008; Zhang et al., 2012b) and can be grouped into two main categories: (1) sequential methods, which assimilate data as the model simulation proceeds 
forward in time (i.e. correcting the field of the state variable at successive time steps by means of a corrective term that is function of the difference between the model and the observation) and (2) variational methods, which assimilate data over a time period (4DVar) or at given time (3DVar), by minimizing the square of the difference between the model and the observations. 4DVar methods require the adjoint formulation of the model, which may be challenging, particularly when dealing with large chemical kinetic mechanisms and multiphase aerosol modules (the adjoint can be considered as the formulation of the inverse problem, i.e. calculating the model inputs from the model outputs). Examples of sequential methods used in CDA include optimal interpolation (OI), ensemble Kalman filter (EnKF) and reduced-rank square root Kalman filter (RRSQRT).

The modification of the chemical initial conditions is a natural extension of data assimilation in meteorology, where the chaotic nature of the primitive equations makes the system very sensitive to its initial conditions. However, the impact of modified chemical initial conditions in an AQ model is limited by the lifetime of the species. The lifetime is characterised by exponential-decay type terms describing chemical reactions (e.g. first- or second-order kinetic decay terms) and physical removal (e.g. first-order decay terms representing precipitation scavenging and dry deposition). Therefore, the atmospheric concentrations of air pollutants tend to be governed by other inputs rather than their initial conditions, namely the emission fields of primary pollutants and the boundary values. Some model parameters such as vertical transport coefficients and dry deposition velocities may also have a significant effect on air pollutant concentrations and are, therefore potential candidates for improvement by data assimilation. Thus, the chemical transport component of an online coupled model differs significantly from the meteorological model and, consequently, requires a different approach for data assimilation.

Recent efforts for CDA have mostly focused on CTMs and to date only limited work has been conducted for online coupled models. We briefly discuss here the observational data used in CDA, past examples of CDA in AQ modelling using CTMs, some recent work with online coupled models and future prospects for CDA in online coupled meteorology/air quality modelling.

\subsubsection{Observational data}

The data used in CDA come from a variety of sources. Surface air quality data are the most commonly used in AQ forecasting because they are typically readily available to the organisation conducting the forecast. However, these data only provide information near the surface at a limited number of locations, which are typically situated in strongly polluted areas. Then, filtering of the AQ data in regimes resolved by the online coupled models may be necessary before AQ data can be successfully assimilated (Flemming et al., 2005).
Remote sensing (e.g. lidars, soundings, satellite observations) provide a representation of the atmosphere with more complete spatial coverage. Remote sensing has, however, limitations such as uncertainties in converting a radiance signal to a concentration, limited vertical profile information, autocorrelation between observations, reduced temporal coverage, and limited number of substances monitored. Clearly, there should be some advantages in using the maximum amount of information available in an optimal manner during CDA. However, the operational implementation of a CDA system that embodies a large number of data sources involves some methodological and technical challenges.

\subsubsection{Past examples of CDA in air quality modelling}

Because the use of CDA in online coupled models is still limited, it is useful to summarise previous work conducted with CTMs in order to describe a large array of potential applications of CDA. Most examples of past CDA in AQ modelling concern the correction of initial conditions of major air pollutants of interest such as $\mathrm{O}_{3}, \mathrm{NO}_{2}$ and PM. CDA has been implemented using satellite data (e.g. Elbern et al., 1997; Jeuken et al., 1999; Collins et al., 2001; Generoso et al., 2007; Boisgontier et al., 2008; Niu et al., 2008; Wang et al., 2011), ground-based concentrations (e.g. Elbern and Schmidt, 2001; Carmichael et al., 2008; Wu et al., 2008), radiosonde measurements (e.g. Elbern and Schmidt, 2001) and airborne measurements (e.g. Chai et al., 2006). For such CDA, both sequential methods and variational methods have been used.

There are also some examples of CDA for correcting emission fields (Elbern et al., 2007; Barbu et al., 2009), boundary values (Roustan and Bocquet, 2006) and model parameters (Barbu et al., 2009; Bocquet, 2011). These studies involved inverse modelling and used variational methods. CDA to correct boundary concentrations of $\mathrm{O}_{3}$ appears warranted based on the potential impact of long-range transport of $\mathrm{O}_{3}$ (Zhang et al., 2011; Waked et al., 2013; Collette et al., 2013).

\subsubsection{Current efforts on CDA in online coupled models}

Although most work on CDA for AQ forecasting has been conducted with CTMs, there are a few examples of recent efforts aimed at conducting CDA with online coupled models. ECMWF uses the 4DVar data assimilation developed for data assimilation in NWP to assimilate observations of atmospheric composition. In its current configuration, ECMWF's IFS (Table 4) has been extended to simulate transport, source and sink processes of atmospheric chemical species as follows (Hollingsworth et al., 2008): aerosol processes are simulated in an online coupled manner in IFS (Morcrette et al., 2009), whereas source and sink processes of reactive gaseous species are treated via a two-way coupled global chemical transport model (Flemming et al., 2009). This coupled system has been run with MOZART-3 and TM5. The coupled 
modelling system IFS-MOZART has been used to produce a global re-analysis of atmospheric composition and meteorology by applying a 4D-VAR technique (Inness et al., 2013). This current configuration of the IFS is an intermediate step and more complex chemical kinetic mechanisms are being implemented online in IFS.

The future direct online coupled configuration will be computationally far more efficient than the current two-way coupled system. No interaction between atmospheric chemical composition and NWP is considered in current applications. However, research has been initiated to explore the impact of the feedbacks, for instance with respect to aerosol radiative forcing (J.-J. Morcrette, personal communication, 2012), or the benefit of online $\mathrm{CO}_{2}$ for the assimilation of satellite data (Engelen and Bauer, 2011). The use of the NWP system for data assimilation allows the use of the existing infra-structure for satellite data handling and the MACC system is able to assimilate more than one data set from a large array of satellite instruments (GOME, MIPAS, MLS, OMI, SBUV, SCIAMACHY, MOPITT, IASI, TANSO, AIRS) for $\mathrm{O}_{3}, \mathrm{CO}, \mathrm{NO}_{2}, \mathrm{SO}_{2}, \mathrm{HCHO}, \mathrm{CH}_{4}, \mathrm{CO}_{2}$ and AOD. In the USA, CDA is conducted in WRF-Chem using both 3DVAR (Pagowski et al., 2010; Liu et al., 2011; Schwartz et al., 2012; Saide et al., 2012, 2013) and EnKF (Pagowski and Grell, 2012); there is an on-going project to assimilate surface $\mathrm{PM}_{2.5}$ data as well as AOD using a hybrid approach that employs both EnKF and 3DVAR. Furthermore, the adjoint of WRF-Chem is currently under development with the objective of performing sensitivity analysis with a variational method in the near future and possibly CDA with inverse modelling of parameter fields later. WRF-Chem is used in Europe (Table 4) and advances implemented in the USA will benefit European applications. Other models listed in Table 4 have not been used to date with CDA.

\subsubsection{Recommendations for operational developments in online coupled models}

As mentioned above, chemical concentrations are not as sensitive as meteorological variables to initial conditions; nevertheless, CDA to improve initial conditions has often been implemented because it has been widely used in NWP and it is now also used in AQ forecasting. However, one may expect more gain from CDA when used to perform inverse modelling of the emission fields. Since air quality is mostly driven by emissions, their modifications will have a longer influence than those of the initial conditions. Therefore, advances in that area are likely to lead to significant benefits for online coupled models. The use of CDA for parameter estimation (e.g. vertical dispersion coefficient and dry deposition velocities) by inverse modelling is of interest from a research point of view but its implementation for AQ forecasting will be more challenging than CDA of initial conditions. Nevertheless, as a diagnostic tool, it can lead to interesting results. An additional benefit of the online approach of CDA is its useful- ness for meteorological data assimilation and modelling. For example, the improved retrieval of satellite data and direct assimilation of radiances may in turn improve the forecasting of aerosol concentrations and some radiation-absorbing gases as well as day-to-day weather forecasts. Assimilated aerosol fields may lead to better simulations of the cloudaerosol feedbacks. Semane et al. (2009) have shown that the assimilation of stratospheric ozone can have a positive effect on the assimilated wind fields. Finally, it seems plausible that the knowledge of the locations of tracer plumes (e.g. from biomass fires) may lead to improved wind fields through data assimilation (similarly to the improvement of wind fields from satellite cloud observations).

\section{Case studies and evaluation of online coupled models}

This section reviews applications of online coupled models in Europe published during the past $20 \mathrm{yr}$, thereby documenting the historic evolution of this type of models. Note that in most of these studies, in particular in the early studies, the coupling was only made from meteorology on to chemistry. These early applications, which do not use the full potential of coupled models except for a more consistent numerical and physical treatment of chemical and meteorological quantities, are summarised in Sect. 6.1. Studies using the advantage of online coupled models to consider feedbacks of chemistry on meteorology are highlighted in Sect. 6.2. In Sect. 6.3, the focus is on model evaluation and in particular on methodological aspects specific for online coupled models.

\subsection{Applications without feedbacks}

The first attempts towards online coupled atmospheric modelling in Europe considered only the transport of chemical species, but not their chemical transformation (Baklanov, 1988; Schlünzen, 1988; Kapitza and Eppel, 2000). One of the earliest studies of the fully coupled chemical and meteorological evolution was the application of a coupled model during the VOTALP campaign (Vertical Ozone Transports in the ALPs) in August 1996 in southern Switzerland (Grell et al., 2000). In this study, the non-hydrostatic mesoscale model MM5 was augmented with transport of scalars and extended with modules for the simulation of chemically active species including the computation of photolysis rates, chemical reactions, biogenic emissions and deposition. The coupled numerical model was named Multiscale Climate Chemistry Model (MCCM) and later MM5-CHEM. The simulations, which were performed in three nests with grid cell sizes down to $1 \mathrm{~km}$, depicted the complex daily thermally induced valley and mountain wind systems and demonstrated the importance of these systems for air pollutant budgets in Alpine valleys. MCCM has later been applied in various air quality studies for Europe and Mexico City, the first 
online coupled regional climate chemistry simulation for Europe (Forkel and Knoche, 2006) and the simulation of the 2010 Eyjafjallajökull ash plume (Emeis et al., 2011). MCCM was also used to compare online versus offline simulations at cloud resolving scales (Grell et al., 2005) to demonstrate the deficiencies of the offline approach at high spatial resolutions.

One year before MCCM, the French mesoscale simulation system MesoNH-C for online coupling between dynamics and chemistry was introduced and applied to a pollution episode in July 1996 in the northern half of France (Tulet et al., 1999). For performance reasons, the simulations were carried out with a strongly reduced chemical scheme but satisfactorily depicted the location and spatial extent of the pollution plume of Paris and elevated $\mathrm{O}_{3}$ levels downwind of the city. The modelling system was described in more detail in Tulet et al. (2003) and compared with $\mathrm{O}_{3}$ observations in France for a simulation period in August 1997. It was extended with the sectional aerosol model ORISAM (Cousin et al., 2004) as well as with the three-moments aerosol scheme ORILAM for the simulation of aerosol dynamics and secondary inorganic and organic aerosols (Tulet et al., 2005), which laid the foundation for studies of chemistrymeteorology feedbacks. MesoNH-C was subsequently employed for a wide range of applications to study the effect of biogenic emissions on regional $\mathrm{O}_{3}$ levels (Solmon et al., 2004), the impact of convection on aerosol hygroscopicity (Crumeyrolle et al., 2008), for regional scale $\mathrm{CO}_{2}$ source inversion (Lauvaux et al., 2009), sulfur transport and chemical conversion in a volcanic plume (Tulet and Villeneuve, 2011), or to investigate Saharan dust transport (Bou Karam et al., 2010) to name but a few.

In the same year as MesoNH-C, von Salzen and Schlünzen (1999a, b) presented the modelling system METRAS online integrated with gas phase chemistry and the Sectional Multicomponent Aerosol Model (SEMA). They applied the model to study the dynamics and composition of coastal aerosol in northern Germany and demonstrated the importance of sea salt aerosols for the partitioning of nitrates into the coarse mode (von Salzen and Schlünzen, 1999c). Sea salt emissions and dry deposition as well as biogenic emissions were calculated in direct dependence on the meteorological parameters. Without aerosol formation, the model has been employed to study nitrogen deposition in coastal waters including sea level rise (Niemeier and Schlünzen, 1995). The coupled model is now specifically applied for studies of pollen emission, transport and dispersion (e.g. Buschbom et al., 2012).

Using the Regional Atmospheric Modeling Systems (RAMS) extended with online coupled chemistry, Arteta et al. (2006) studied the impact of two different lumped chemical mechanisms on air quality simulations. Simulations were performed for the ESCOMPTE experiment conducted over Marseilles in southern France and showed that both chemical mechanisms produced very similar results for the main pollutants $\left(\mathrm{NO}_{\mathrm{x}}\right.$ and $\left.\mathrm{O}_{3}\right)$ in 3-D modelling, despite large discrepancies in 0-D (box) modelling. To judge the quality of simulations using the two schemes, the results were compared with $\mathrm{NO}_{\mathrm{x}}$ and $\mathrm{O}_{3}$ measurements at 75 surface stations.

The potential benefits of online coupling with respect to the quality of simulated transport and dispersion of chemical species was demonstrated by Korsholm et al. (2009). They employed the online coupled model Enviro-HIRLAM, which can also be run offline, to study differences in the dispersion of a plume in the presence of mesoscale disturbances between online and offline representations of transport. The dispersion simulated by the online model was evaluated against data from the European Tracer Experiment ETEX-1 and showed satisfactory results, particularly at stations further away from the tracer release.

The Bologna limited area model for meteorology and chemistry (BOLCHEM, Mircea et al., 2008) is currently the only online coupled model operated in the EU MACC project for operational chemical-weather forecasting on the regional scale. The model recently participated in a coordinated modelling exercise to study the evolution of air pollution over Western Europe during the last decade (Colette et al., 2011).

Several groups in Europe are beginning to implement and apply the online coupled model WRF-Chem developed primarily in the US as a successor of MM5-Chem (Sect. 2). Early examples are the studies by Schürmann et al. (2009), investigating the influence of synoptic and local scale meteorology and emissions on $\mathrm{O}_{3}$ concentrations in southern Italy during four selected 5-7 days periods in all seasons and by Zabkar et al. (2011) investigating three high $\mathrm{O}_{3}$ episodes in the north-eastern Mediterranean Basin. Both studies made use of the nesting capabilities of WRF-Chem and extensively compared model simulated $\mathrm{O}_{3}$ with in-situ observations.

\subsection{Applications with feedbacks}

The first European modelling studies investigating feedbacks between chemistry and meteorology were published around 2005, initially focusing on direct effects and later including aerosol-cloud interactions.

The impact of dust aerosol on short- and longwave radiative effects in weather forecasts was first analysed by Pérez et al. (2006). They applied the NCEP/Eta NWP model with the DREAM model of Nickovic et al. (2001) for mineral dust transport extended with radiative feedbacks of dust aerosols on radiation to simulate a major Saharan dust outbreak over the Mediterranean in April 2002. They found significant improvements of the atmospheric temperature and mean sealevel pressure forecasts over dust-affected areas by considerably reducing warm and cold temperature biases existing in the model without dust radiation interactions. Figure 4 shows a comparison of vertical temperature profiles with radiosonde observations over the Mediterranean region most affected by the dust. 

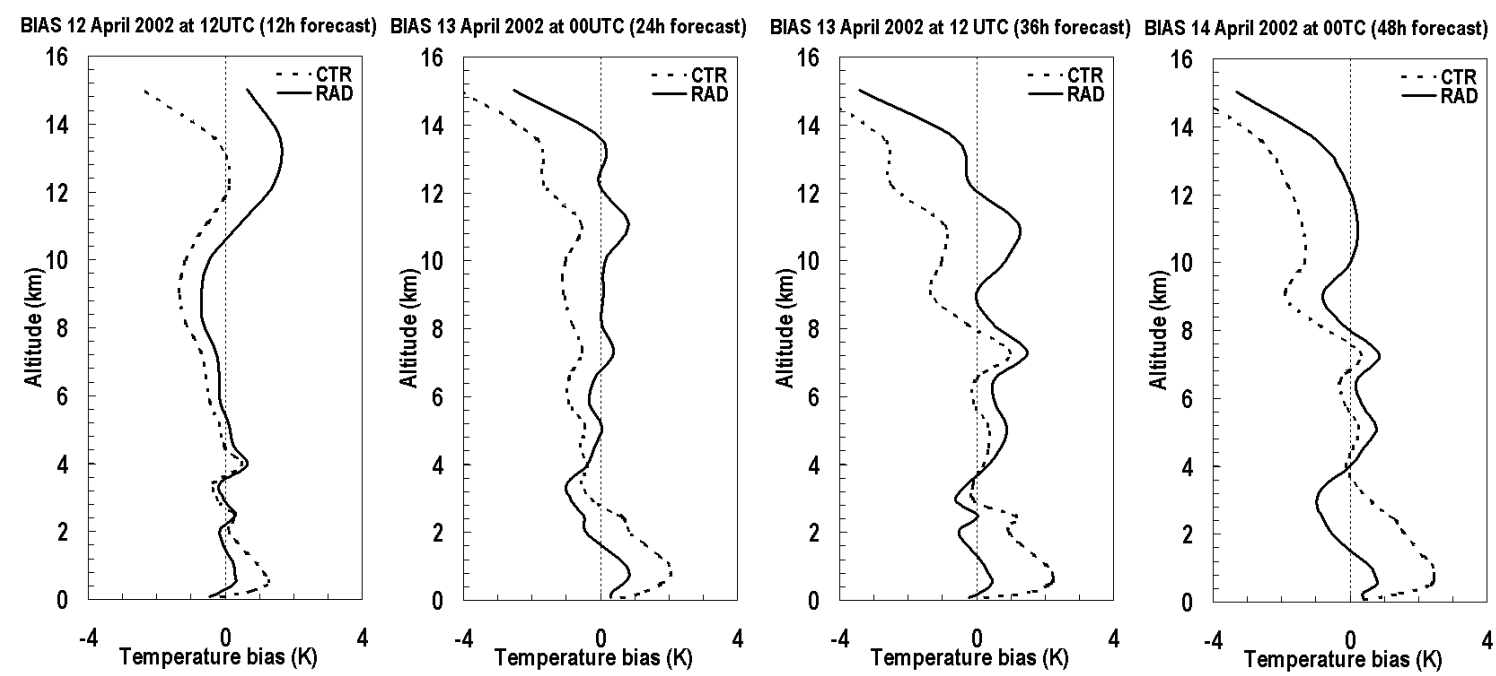

Fig. 4. Vertical profiles of the atmospheric temperature bias between a control run (CTR) without and a full run (RAD) with SW and LW radiative interaction of dust aerosols. Profiles are over an area most strongly affected by Saharan dust $\left(30-45^{\circ} \mathrm{N}, 0-20^{\circ} \mathrm{E}\right)$ for the $12,24,38$, and $48 \mathrm{~h}$ forecasts of the 00:00 UTC forecast cycle on 12 April 2002 (Adopted from Pérez et al., 2006).

Shortly after Pérez et al. (2006), another study investigating the importance of direct radiative effects of dust aerosols on weather forecasting was published by Grini et al. (2006). They applied the MesoNH-C model for simulations of the weather over north-western Africa in September 2000 and found that over the ocean dust aerosols decreased convection, while over land they increased vertical stability and reduced surface latent heat fluxes leading to reduced convection as well, notably over the Sahel region. They concluded that the vertical aerosol profile and single scattering albedo are particularly critical parameters and recommended that direct aerosol effects should be included in weather prediction in the Sahel region. In a similar study using MesoNH$\mathrm{C}$ but addressing a region in south-western Germany and eastern France during the Convective and Orographically induced Precipitation Study experiment COPS, Chaboureau et al. (2011) studied the effect of Saharan dust transport to Europe on precipitation forecasts. From comparison with rain gauge observations, they concluded that precipitation was better predicted when the dust prognostic scheme and radiative feedbacks were included in the model.

Aerosol direct effects were also studied by Vogel et al. (2009) using their new online coupled modelling system COSMO-ART by comparing model simulations for two episodes in August 2005 over western Europe with and without including aerosol radiative effects. They found an average reduction of global radiation by $-6 \mathrm{~W} \mathrm{~m}^{-2}$ and decreases in $2 \mathrm{~m}$ temperatures and in temperature differences between day and night of the order of $0.1^{\circ} \mathrm{C}$ each.

The two-way coupled meteorological and chemical transport modelling system MEMO/MARS-aero was used for calculating the direct aerosol effect on mesoscale meteorological and dispersion fields over the urban area of Paris, France
(Halmer et al., 2010). The impact of the direct aerosol effect was found to be substantial with regard to the turbulence characteristics of the flow near the surface. High aerosol concentrations near the surface, such as those present in and around densely populated urban areas were also found to increase stability and, unlike effects at larger scales, also lead to small increases in $2 \mathrm{~m}$ temperatures. However, the performance of the online coupled model in predicting urban meteorology and air quality in the specific case was only improved marginally.

European studies of aerosol indirect effects or combined direct and indirect effects are still comparatively sparse. Korsholm (2009) implemented a parametrized version of the first and second aerosol indirect effects in the Enviro-HIRLAM modelling system by considering the dependence of cloud droplet number concentrations on aerosol number concentrations and the dependence of the auto-conversion of cloud to rain droplets on effective cloud droplet radius. He then studied the impact of aerosol indirect effects on surface temperatures and air pollutant concentrations for a $24 \mathrm{~h}$ simulation over a domain in northern France including Paris in a convective case with low precipitation. He found a marginally improved agreement with observed $2 \mathrm{~m}$ temperatures and a marked redistribution of $\mathrm{NO}_{2}$ in the domain, primarily as a result of the second indirect effect.

WRF-Chem has been used in various studies to investigate the impact of the aerosol interaction with radiation and microphysics outside Europe (e.g. Gustafson et al., 2007; Chapman et al., 2009; Zhang et al., 2010a, b, 2012c, d; Grell et al., 2011; Saide et al., 2012). Two European studies investigating not only the impact of aerosol direct and indirect effects on meteorology but also on air quality $\left(\mathrm{O}_{3}\right.$ and $\left.\mathrm{PM}_{10}\right)$ were recently presented by Forkel et al. (2012) and Zhang 

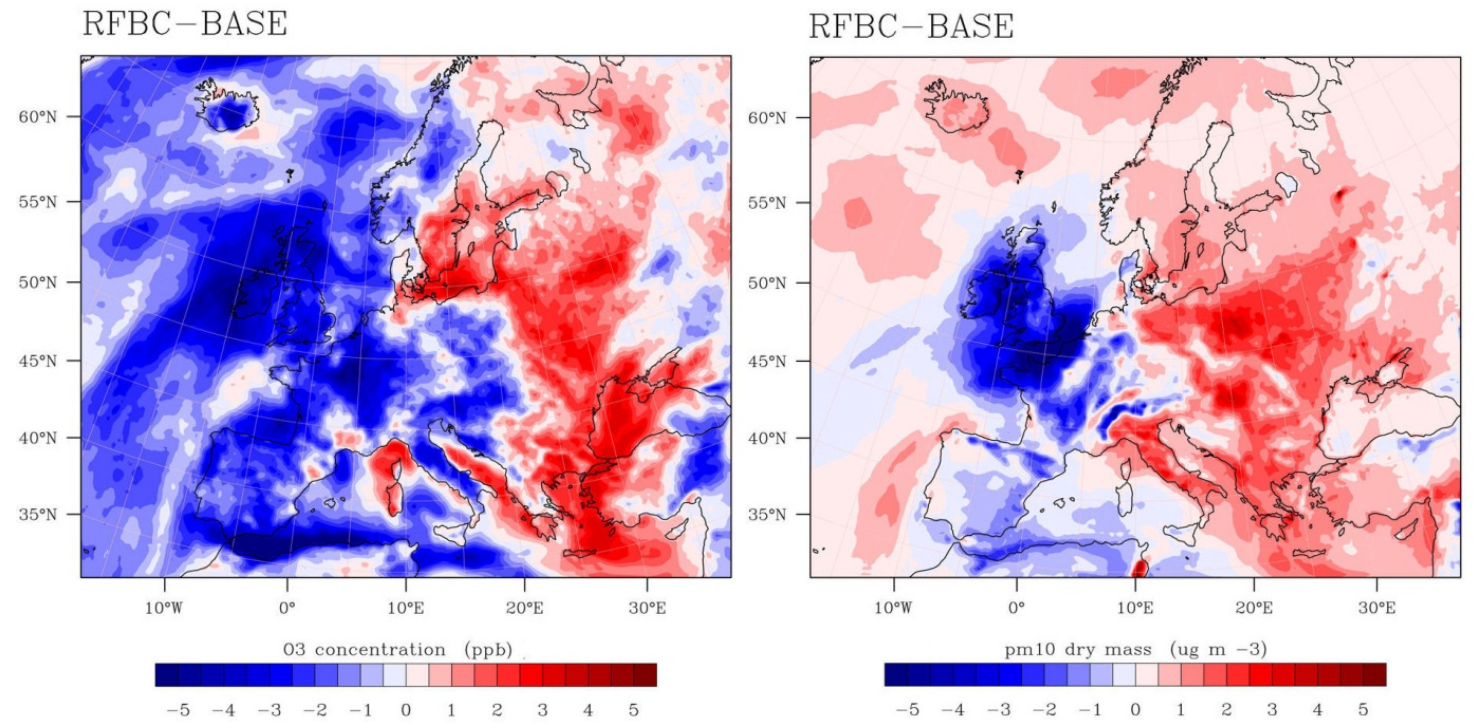

Fig. 5. Differences in ozone (left) and $\mathrm{PM}_{10}$ (right) concentrations in July 2006 between two WRF-Chem simulations. The BASE simulation does not consider interactions between aerosols and meteorology, whereas the RFBC simulation considers both direct and indirect effects (Adopted from Forkel et al., 2012).

et al. (2013). Forkel et al. (2012) applied the WRF-Chem model to simulate the two-month period (June-July 2006) without any feedbacks (BASE), with aerosol direct effects only and with both direct and indirect effects (RFBC). As shown in Fig. 5, differences in July monthly mean concentrations between the simulations RFBC and BASE had a pronounced spatial pattern and show differences in the range of $0-5 \mathrm{ppb}$ for $\mathrm{O}_{3}$ and $0-5 \mu \mathrm{g} \mathrm{m}^{-3}$ for PM dry mass. These differences are the result of a complex interplay between small changes in surface radiative heating due to the aerosols, important semi-direct effects modifying vertical stability and cloud cover and indirect aerosol effects which, for example, led to a substantial reduction in cloud cover over the Atlantic and hence stronger photochemical depletion of $\mathrm{O}_{3}$ over this area. Increases in $\mathrm{PM}_{10}$ over the Atlantic were a result of increased wind speeds in simulation RFBC as compared to BASE and, therefore, higher sea salt emissions. Over continental Europe, ABL heights were mostly reduced in simulation RFBC leading to higher $\mathrm{PM}_{10}$ surface concentrations particularly over the eastern part of the domain. In Zhang et al. (2013), WRF-Chem-MADRID was applied to simulate AQ in July 2001 at horizontal grid resolutions of $0.5^{\circ}$ and $0.125^{\circ}$ over Western Europe. They found that aerosol led to reduced net SW radiation fluxes, $2 \mathrm{~m}$ temperature, $10 \mathrm{~m}$ wind speed, $\mathrm{ABL}$ height and precipitation in most areas, with domain-average values of $-3.5 \mathrm{~W} \mathrm{~m}^{-2},-0.02^{\circ} \mathrm{C}$, $-0.004 \mathrm{~m} \mathrm{~s}^{-1},-4.0 \mathrm{~m},-0.04 \mathrm{~mm} \mathrm{day}^{-1}$, respectively. It increased AOD and CCN over the whole domain and cloud optical thickness (COT) and cloud droplet number concentrations (CDNC) over most of the domain.
Solomos et al. (2011) addressed the effects of pollution on the development of precipitation in both clean and polluted hazy environments in the Eastern Mediterranean by using the RAMS/ICLAMS. The model was run for a case study during 26-29 January 2009 over the Eastern Mediterranean and both direct and indirect effects were investigated, the latter not only considering the effects of aerosols as CCN but also the effect of freshly emitted mineral dust as ice nuclei. As shown in Fig. 6, the simulations showed that the onset of precipitation in hazy clouds is delayed compared to pristine conditions. Increasing the concentration of hygroscopic dust particles by $15 \%$ resulted in more vigorous convection and more intense updrafts. Therefore, more dust particles were transported to higher cloud layers and acted as IN. Prognostic treatments of the aerosol concentrations in the explicit cloud droplet nucleation scheme improved the model performance for the daily accumulated precipitation. However, the spatial distribution and the amounts of precipitation were found to vary greatly between different aerosol scenarios, pointing towards large remaining uncertainties and the need for a more accurate description of aerosol feedback mechanisms.

Aerosol indirect effects were also recently studied using the model COSMO-ART by Bangert et al. (2011) and Bangert et al. (2012). For this purpose, the model was run with the two-moment cloud microphysics scheme of Seifert and Beheng (2001) to account for the interactions of aerosols with cloud microphysics. In the first study, Bangert et al. (2011) applied the model over Europe to a cloudy fiveday period in August 2005 to study the effect of aerosols on warm cloud properties and precipitation. They found that the mean cloud droplet number concentration and droplet 


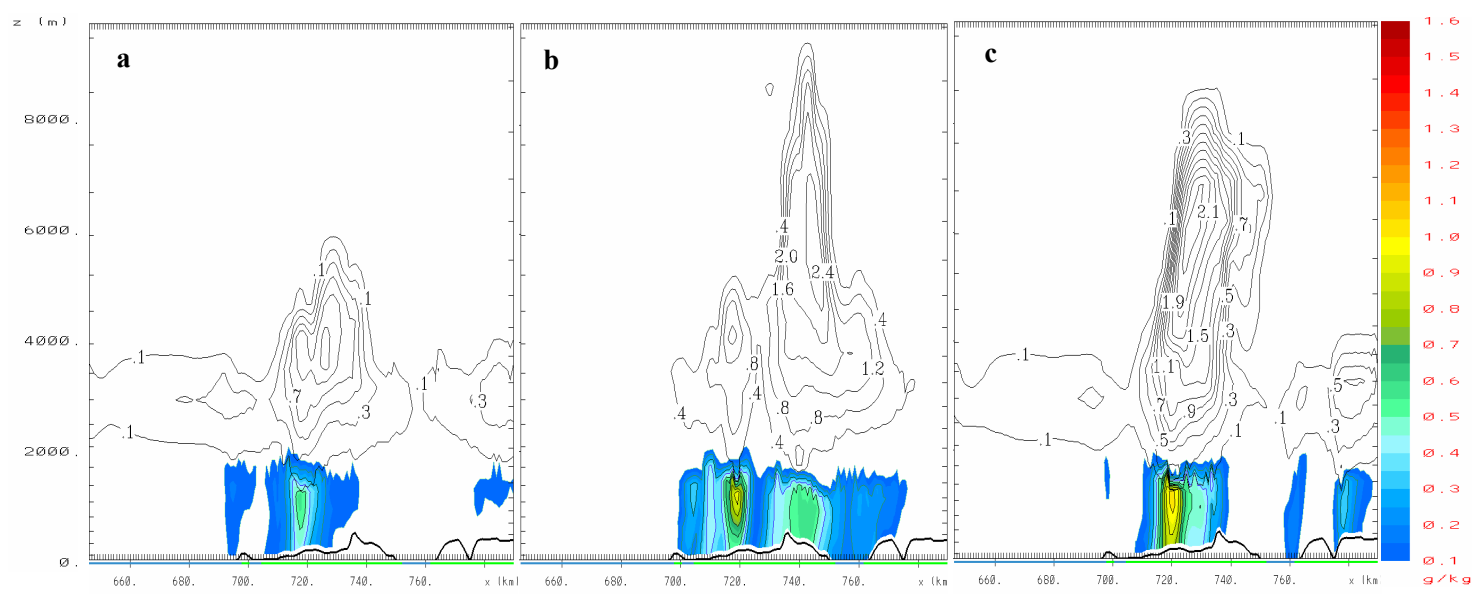

Fig. 6. West to East cross-section of rain mixing ratio (color palette in $\mathrm{g} \mathrm{kg}^{-1}$ ) and ice mixing ratio (black line contours in $\mathrm{g} \mathrm{kg}^{-1}$ ) at the time of highest cloud top over Haifa. (a) 09:00 UTC, 29 January 2003 assuming $5 \%$ hygroscopic dust. (b) 10:00 UTC, 29 January 2003 assuming $20 \%$ hygroscopic dust. (c) 09:00 UTC, 29 January 2003 assuming $5 \%$ hygroscopic dust and number of ice nuclei increased by a factor 10. (Adopted from Solomos et al., 2011).

diameter were closely linked to changes in the aerosol. In a further study, Bangert et al. (2012) focused on the effect of mineral dust aerosols to act as ice nuclei, and studied an episode of Saharan dust transport to central Europe. They found the largest impact of dust on clouds at temperatures where heterogeneous freezing is dominating, thus at temperatures between the freezing level and the level of homogeneous ice nucleation. Ice crystal number concentrations were increased twofold in this temperature range during the dust event, which had a significant impact on cloud optical properties and causing a reduction in SW radiation at the surface by up to $-75 \mathrm{~W} \mathrm{~m}^{-2}$. The dust layer also directly caused a reduction in $\mathrm{SW}$ radiation at the surface which entailed a reduction in surface temperatures on the order of -0.2 to $-0.5^{\circ} \mathrm{C}$ in most regions affected by the dust plume and up to $-1{ }^{\circ} \mathrm{C}$ in a region where regular numerical weather forecasted temperatures had been biased high by roughly the same amount.

Although a growing number of applications of online coupled chemistry and meteorology models have become available recently, the scope of these studies has been rather limited. For both aerosols direct and indirect effects, there has been a strong focus on Saharan dust events due to their strong and readily measurable impacts on radiation and due to their potential role as ice nuclei. Several of these studies suggested a clear positive impact of considering aerosol feedbacks on short-term weather forecasts under such high dust-load conditions. However, more work is needed to investigate similar effects for other more commonly present aerosols of anthropogenic and biogenic origin as well as for aerosols originated by biomass burning. More studies are also needed to address the question of whether considering feedbacks can benefit air quality forecasts both regarding summer and winter smog episodes.
In many studies mentioned in this section only the differences in chemical and meteorological parameters between simulations with and without feedbacks were highlighted, but no systematic comparisons with observations were performed to evaluate the potential benefits of considering feedbacks. There is a strong need for detailed evaluation studies as outlined in the next section.

\subsection{Model evaluation}

The evaluation of integrated meteorology atmospheric chemistry transport models is a complex but necessary task to help establishing model's credibility. A critical assessment of model performance is in fact imperative to build confidence in the use of models for research, forecasting and policymaking as well as to determine the model's strengths and limitations and to provide guidance for further improvement of modelling systems.

The aims of model evaluation are to assess the suitability of a model for a specific application ("fit for purpose"); benchmarking model performance against reality and other models; quantifying uncertainties; testing individual model components; and providing guidance for future model developments. Depending on the aim pursued, different evaluation strategies are put in practice.

Model evaluation is often recognised as a process of comparing model output against observations. However, although this is an important element, model evaluation may be understood in a more general sense to include all elements supporting the assessment of the quality of a model and its fitness for the intended purpose. As suggested in a joint report of the COST Action 728 (Enhancing Mesoscale Meteorological Modelling Capabilities for Air Pollution and Dispersion Applications) and GURME (GAW Urban Re- 
search Meteorology and Environment Project) (Schlünzen and Sokhi, 2008), model evaluation needs to encompass the following elements:

1. General evaluation. Model documentation (e.g. technical report and user's guide) needs to be provided. In addition, a model needs to be documented in peer-reviewed literature and the model's source-code should be made publically available for inspection.

2. Scientific evaluation. Identify the processes required in the model and based on these requirements evaluate suitability of model equations, approximations, parameterisations, boundary values and input data, etc.

3. Benchmark testing. Benchmarking of model performance against observations for well-defined test cases (domain and time period, model resolution, fixed input data sets including emissions and boundary values) using a set of statistical quality indicators. Similarly, model performance should be analysed for specific sensitivity tests.

4. Operational evaluation. This type of evaluation is specific for models used operationally as for example in air quality forecasting and regulatory applications. It involves operational online checking of model output, plausibility checks and quality control. However, the defined checks can also be applied in non-operational applications.

A further framework for evaluating regional scale photochemical transport modelling systems has been recently proposed by the US Environmental Protection Agency (EPA) (Dennis et al., 2010) building upon concepts proposed earlier (e.g. Seigneur et al., 2000). This framework is more specific with respect to model benchmarking as it distinguishes between operational, diagnostic, dynamic (also referred to as mechanistic) and probabilistic model evaluation, which are defined as follows:

- Operational evaluation involves the direct comparison of model output with routine observations of ambient pollutant concentrations and meteorological fields using statistical metrics such as normalized mean bias, root mean square error, etc.

- Diagnostic evaluation examines individual processes and input drivers that may affect model performance and requires detailed atmospheric measurements that are not, typically, routinely available.

- Dynamic evaluation investigates the model's ability to predict changes in air quality in response to changes in either source emissions or meteorological conditions. Note that with online coupled models it will also be necessary to evaluate responses in meteorology and regional climate.
- Probabilistic evaluation explores the uncertainty of model predictions and is used to provide a credible range of predicted values rather than a single estimate. It is based on knowledge of uncertainty embedded in observations and model predictions, the latter often being approximated by an ensemble of model simulations.

Exploitation of these four model evaluation components has been the subject of the Air Quality Model Evaluation International Initiative (AQMEII), where more than 20 research groups from Europe and North America participated. The aim of AQMEII was to collect almost all regional scale AQ models used for research and policy support in Europe and North America from public and private sectors and apply them to simulate AQ over North America and Europe for the year 2006. A large number of research and operational monitoring networks in the two continents provided a massive amount of experimental data for evaluation, mostly with hourly time resolution. These have included for the two continents one full year of continuous monitoring from almost 4000 stations for 5 gas phase species $\left(\mathrm{O}_{3}, \mathrm{CO}, \mathrm{SO}_{2}, \mathrm{HNO}_{3}\right.$ and $\mathrm{NO}_{2}$ ), 2700 stations of $\mathrm{PM}$ and $\mathrm{PM}$ composition, 4300 surface meteorology monitoring points, 1300 meteorological profiles at 30 locations, 800 ozone-sonde profiles and over 2000 aircraft profiles from MOZAIC. The large variety of sources of information led to a substantial effort in data harmonisation and screening. All observational data have been transferred to the JRC ENSEMBLE system (Galmarini et al., 2012) together with the model outputs in both gridded form and interpolated to the observation points.

The main focus of the phase 1 of AQMEII was the operational evaluation in the sense of Dennis et al. (2010) as presented in a first overall model assessment against groundlevel observational measurements (Solazzo et al., 2012a, b). Capability to capture the vertical distribution of pollutants was further evaluated by Solazzo et al. (2013a) for an ensemble of twelve air quality models. Other evaluation modes were also considered (Galmarini et al., 2012). The studies of Vautard et al. (2012), Schere et al. (2012) and Wolke et al. (2012), for example, investigated the influence of different drivers including meteorological input, grid resolution and initial conditions and boundary values, thus contributing to the diagnostic evaluation of the models. Also Forkel et al. (2012) presented in Sect. 6.2 can be classified as diagnostic evaluation as it investigated the sensitivity of the results to different processes. Solazzo et al. (2012a) conducted a multi-model ensemble analysis which is listed by Dennis et al. (2010) as one kind of probabilistic evaluation. The activity clearly demonstrated the usefulness of such multi-model activities, the necessity of collecting harmonised monitoring information for both meteorology and chemistry and the necessity of evaluating models in a global sense in three dimensional space and time as well as in the meteorological and chemical variable space. Too often models are only evaluated 
against a subset of variables for a number of reasons which may lead to false conclusions since compensating mechanisms could improve one variable at the expense of others (e.g. Solazzo et al., 2013a, b). The AQMEII exercise further revealed that a large amount of monitoring information is available but concealed or not easily accessible or simply not usable because it is not harmonised or documented.

Operational evaluation was not only a focus of AQMEII but has generally been the most widely used approach in the past for both offline (Trukenmüller et al., 2004; Schlünzen and Meyer, 2007; Appel et al., 2008; Wang et al., 2009; Zhang et al., 2009a; Liu et al., 2010) and online coupled models (Zhang et al., 2010a, b, 2012c, d, 2013; Knote et al., 2011; Tuccella et al., 2012).

Dynamic evaluation has been applied in numerous regional modelling studies relating observed changes in ozone and/or aerosol concentrations to anthropogenic emission changes (e.g. Jonson et al., 2006; van Loon et al., 2007; Vautard et al., 2007; Gilliland et al., 2008; Zhang et al., 2009b, 2013; Colette et al., 2011; Godowitch et al., 2011; Hogrefe et al., 2011; Zubler et al., 2011). It has been demonstrated that uncertain emission inventories, data assimilation approaches used in meteorology models, and initial/boundary conditions can influence dynamic evaluation of model-predicted changes in ambient air quality (Napolenock et al., 2011; Kang et al., 2012).

Given the increasing diversity and complexity of modelling systems currently being developed, diagnostic evaluation assessing the sensitivity of models to changing input data, and the uncertainty associated with the choice of model parameters and formulations, will become increasingly important. Methods for assessing parametric (input data and model parameters) and structural uncertainties (model formulation and process representation) have been outlined by Fine et al. (2003) and Pinder et al. (2009). Exploring the uncertainty space of a model may be computationally expensive and therefore requires efficient methods as developed e.g. by Tatang et al. (1997) or Lee et al. (2011). Applying such methods to online couple models will be crucial as they are able to reveal key model uncertainties and to identify those model aspects that need largest attention for further development.

In the context of regional online coupled models, interactions between meteorology and chemistry through aerosol direct and indirect effects are of particular interest. Evaluating the representation of these processes requires a comprehensive assessment of the various processes influencing aerosol distributions, their physical and chemical properties and consequently their effects on radiation and cloud and rain formation (Sects. 2 and 4 for an overview of processes and interactions). A key factor distinguishes the evaluation strategies of offline and online modelling systems, which is in the online case the evaluation of meteorological parameters being as important as the evaluation of trace gas and aerosol parameters.
Most evaluation studies of online coupled regional models performed so far (e.g. Zhang et al., 2010a, b, 2012c, d, 2013; Knote et al., 2011) followed approaches that had been applied to offline models for many years as exemplified by phase 1 of AQMEII, but these are not sufficient to emphasize the specific advantages of online modelling. Previous assessments of model representations of chemistry-meteorology feedbacks were mainly restricted to comparing simulations with and without the respective interactions. Demonstrating that inclusion of feedbacks improves model performance when compared with observations, however, has been and will remain a great challenge and will require new and improved strategies for model evaluation. For evaluating models that are to be re-applied for scenario studies, the dynamic evaluation is essential, since these models need to show that they properly simulate observed changes.

Application of process analysis tools as applied to analyse meteorological (Petrik et al., 2011) or chemical processes (Müller et al., 2000) in online coupled models would help to identify the contribution of feedbacks and other processes to the calculated concentration values. In addition, using ratios of calculated concentrations (e.g. EC/PM 2.5 or $\mathrm{NO}_{2} / \mathrm{PM}_{2.5}$ ) rather than just the $\mathrm{PM}_{2.5}$ or $\mathrm{PM}_{10}$ concentrations for validation with measurements would help to get information about the effect of feedbacks. Assessing feedbacks typically involves comparing small differences between simulations with and without a given feedback mechanism and evaluation of differences is inherently more challenging than evaluation of absolute levels. In some cases, judging whether including a given feedback improves model performance or not might only be possible by either integrating over a sufficiently long time, or by running a sufficiently large ensemble of simulations (e.g. with variable initial conditions). This is necessary to distinguish signals from numerical noises and to reliably quantify the magnitude of the response in a given meteorological situation. It will require mature models that are sufficiently close to reality to assure that the improved performance is not a mere compensation for model biases but rather a real improvement in the science. Both requirements pose great challenges since long-term simulations are computationally expensive and the details of many feedback mechanisms, particularly of aerosol-cloud feedbacks, are poorly understood at present and can only be modelled in a highly parametrized fashion. It also places high demands on observational data sets since many parameters required for a thorough evaluation are not routinely measured, for example, the photolytic rate of $\mathrm{NO}_{2}$, size-resolved chemical aerosol composition, aerosol size distributions and optical properties, SW and LW radiation fluxes, AOD, CCN and IN activity, CDNC and cloud droplet size distributions. Future measurement campaigns should, therefore, be planned carefully in collaboration with modellers to meet the needs of assessing chemistry-meteorology feedbacks in online integrated regional models. 
The improvements of forecasts resulting from online coupled models with feedbacks need to be critically addressed by the community in a well-coordinated way as is currently planned under the auspices of the phase 2 of AQMEII, being conducted in collaboration with the European COST Action EuMetChem. Detailed lists of chemistry-meteorology interactions to be considered in model evaluation studies and observational data sets available for model evaluation, as recommended by EuMetChem and AQMEII, are given in Tables B1-B3.

\section{Conclusions and recommendations}

In this paper, we have reviewed the current status of online coupled air quality and meteorology modelling and illustrated it with examples of 18 separate models developed or applied in Europe (Table 4 and Appendix A). All the selected models can address regional scale phenomena with horizontal grid resolutions in the range $20-1 \mathrm{~km}$, and applications ranging from the global scale (e.g. IFS-MOZART, MetUM, NMMB/BSC-CTM, WRF-Chem) to urban scale (e.g. Enviro-HIRLAM, MCCM, GEM-AQ, Meso-NH, M-SYS, NNMB/BSC-CTM, RAMS/ICLAMS, WRF-Chem, WRFCMAQ), down to the local scale (M-SYS, Meso-NH, WRFChem). All the models are applicable to studies of short-term episodes (forecast mode) and some of them also to longterm simulations and regional climate studies. Feedbacks of pollutants on meteorology are already considered in most of these. However, the models differ considerably in the number of interactions and the level of details of the process representations. Furthermore, not all of them feature an online integration of meteorology and chemistry. For example, RACMO2/LOTOS-EUROS and COSMO-MUSCAT follow the online access approach, i.e. with data exchange between the chemistry and meteorology modules not taking place at each main model time step. The great challenge for the community of online coupled modellers in the coming years will be to ensure that the incorporation of the complex and computationally demanding feedback mechanisms improves the model predictions and can contribute to the ensemble of reliable models in Europe.

\subsection{Major challenges and needs}

\subsubsection{Integrating European research}

European research on online coupled modelling is still highly fragmented with numerous modelling groups who are developing numerical prediction tools independently. The COST Action ES1004 EuMetChem was launched in 2011 and has built upon previous initiatives such as COST 728. Its main aim has been to develop a European framework for online integrated air quality and meteorology modelling and to better coordinate European research on this subject. The Action provides an ideal vehicle to foster the exchange of knowl- edge, review the current state-of-the-art in online coupled modelling, identify the most relevant processes for different applications and make recommendations on the best coding practices, model evaluation strategies and applications. The Action further seeks to provide recommendations for efficient interfacing and integration of modules in order to facilitate the exchange of codes developed by different research groups.

\subsubsection{Interacting processes and feedback mechanisms}

The focus on integrated systems is timely, since recent research has shown that interactions between meteorology and chemistry and feedback mechanisms are important in the context of many research areas and applications, which can broadly be separated into the fields of NWP, air quality/CWF and climate/earth system modelling. The relative importance of online integration and the level of detail necessary for representing different processes and feedbacks will vary greatly between the three mentioned application fields, as was also confirmed in an expert poll conducted among the members of the COST Action (Table 3).

The processes which are particularly critical for online coupling between the chemical and meteorological components include (i) advection, convection and vertical diffusion (which control the transport and dispersion of chemical species and hence critically affect surface concentrations); (ii) cloud microphysics (which determines cloud life cycle, interactions between clouds and aerosols and affects soluble chemical species); (iii) radiative transfer (which is determined by meteorological parameters and radiatively active chemical compounds); and (iv) turbulent fluxes at the surface (which influences transport and distribution of chemical species).

Convection and condensation schemes need to be updated to take the aerosol-microphysical interactions into account, and the radiation scheme needs to be modified to include the aerosol effects more accurately. The interactions of aerosols with gas phase chemistry and their impacts on radiation and cloud microphysics depend strongly on their physical and chemical properties. Several processes such as nucleation, coagulation, condensation, evaporation, sedimentation, incloud and below-cloud scavenging, and deposition at the surface need to be taken into account by the models. The aerosol-cloud interaction schemes used in models are still very uncertain, sometimes giving substantially different forcing and thus need to be improved and further developed (for example, for ice forming nuclei, interaction with cirrus clouds, contribution of different anthropogenic and biogenic/natural aerosol particles for cloud evolution). On the other hand, the inclusion of aerosol effects in convective parametrizations is only beginning to receive attention.

Online coupling imposes additional requirements on the setup and implementation of radiation parametrizations. Most of these requirements reflect the need to maintain 
physical and numerical consistencies between the various modules and computational schemes of the model, against the increased frequency of interactions and the multitude of simulated effects. The complexity of the treatment of the effect of simulated aerosol concentrations on shortwave and longwave radiation fluxes differs strongly among the models. A final recommendation on how complex the parametrization needs to be is currently not possible.

Finally, emissions and deposition also interact in a specific way with the meteorological part within online coupled models. The most interesting emissions are those which depend on meteorology as they could potentially be treated more accurately and consistently than in offline models. Natural emissions (e.g. isoprene, terpenes and pollen) strongly depend on meteorology and are in general already calculated online even in offline models using the meteorological input driving the CTM model. Sea spray is the dominant aerosol source over the oceans and therefore, its proper quantification is highly relevant for a coupled model. Wind-blown dust refers to particles from a broad range of sources. Due to their direct relationship with meteorology, such emissions must be calculated online.

A large variety of chemical mechanisms are currently in use in online coupled models. Nevertheless, the most commonly used mechanisms have converged in terms of the state of the science included in their formulation. Modifications of the chemical mechanisms, which not only affect gas phase chemistry but also the coupling with aqueous-phase and aerosol mechanisms, have faced practical difficulties in the past, requiring significant reprogramming. Methods of updating chemical mechanisms make updates much easier as illustrated in the MECCA module (Sander et al., 2005). Therefore, the following actions are recommended:

- Create a unified central database of chemical mechanisms, where mechanism owners can upload relevant codes and provide updates as necessary. Versions should be numbered and chemical mechanisms should be open.

- Enable interfacing of this database using, e.g. the Kinetic Pre-Processor (KPP) to develop a set of box model intercomparisons including evaluation against smog chamber data (e.g. the EUROCHAMP framework) and more comprehensive mechanisms and moreover an analysis of the computational cost.

\subsubsection{Numerical and computational aspects}

The desirable numerical properties of transport schemes have been outlined. The most relevant properties to be considered when developing integrated models and especially for considering feedback mechanisms are conservation, shapepreservation and prevention of numerical mixing or unmixing. Traditionally, Eulerian flux-based schemes are more suitable for mass conservation. Recently however, several
semi-Lagrangian schemes have been developed that are inherently mass conservative. Such schemes are applied in some European integrated models.

A detailed analysis of the numerical properties of European integrated models is recommended. A particularly relevant set of tests has been described by Lauritzen and Thuburn (2011), which shifts the focus from traditional, but still important, criteria such as mass-conservation to the prevention of numerical mixing and unmixing. Not maintaining the correlations between transported species is similar to introducing artificial chemical reactions in the system.

A clear trend towards integrated model development is becoming perceptible in Europe with several modelling systems that can be considered as online integrated models with main relevant feedbacks implemented. Complementing those, there are several ones that are built using an online integrated approach, but some major feedbacks are not included yet. A third group of models, the online access models, is characterised by applying an external coupler between meteorology and chemistry. All the information is passed through the coupler. Depending on the approach used, wind and mass consistency problems may arise. In this sense, online integrated models are desirable for a better representation of feedback processes.

Numerical performance is also an important issue for online models. The current parallelisation is based on wellestablished MPI and OpenMP programming models. Beyond these approaches there is no clear trend towards new parallelisation paradigms, even though supercomputers are experiencing a huge increase in computing power achieved mainly through an increase in the number of computing units rather than an increase in clock frequency. New processor types such as GPU's and MIC's are only beginning to be explored.

To adopt newer technologies, a conversion program that transfers existing code to the new technology would be advantageous. The transferred code would need to be still readable and maintainable. This would be very useful since a coupled meteorology chemistry model takes several decades of work to develop, and without software based support, transfers can take years to be completed reliably.

\subsubsection{Data assimilation}

Experience with chemical data assimilation (CDA) in integrated online models is still limited. Most applications of CDA use CTMs, rather than online coupled models, to improve the simulated concentration fields or model parameters such as emissions. First efforts have been made with integrated systems (IFS-MOZART and WRF-Chem) to assimilate chemical and meteorological observations in online integrated models. There is some evidence that CDA can also improve the assimilated meteorological variables, for example the assimilation of ozone can have a positive effect on the assimilated wind fields (Semane et al., 2009). CDA will 
be beneficial in online coupled model if it improves the realism of the chemical fields which are used to simulate the interaction between atmospheric composition and meteorology. The easiest approach is the adjustment of initial conditions through CDA in a manner similar to meteorological data assimilation. Optimal interpolation, variational approaches, EnKF or hybrid techniques combining the advantages of both variational and EnKF techniques are applicable. Other methodologies such as inverse modelling of emission fields appear as a promising technique to improve the skill of online integrated models and may have a stronger impact for short-lived pollutants than CDA has on initial conditions. However, it is debatable whether the results of inverse modelling should be used directly to correct emission fields or only to provide insights for the development of improved emission inventories.

\subsubsection{Evaluation of methodologies and data}

There is a crucial need for more advanced evaluation of methodologies and output data. Model validation and benchmarking are important elements of model development as they help identifying model strengths and weaknesses. Model validation has a long tradition in the NWP and AQ modelling communities, and many concepts can be applied to online integrated models as well. The MetM community has the necessary tools, for example, to analyse whether including certain feedbacks or not has a positive effect on weather forecast skill. Demonstrating these benefits however, requires running a model with and without feedbacks over extended periods of time - rather than for selected episodes - in order to draw statistically significant conclusions.

Evaluating whether relevant feedback processes are treated accurately by a model is challenging. The effects of aerosols on radiation and clouds, for example, depend on the physical and chemical properties of the aerosols. Thus, comprehensive measurements of aerosol size distributions, chemical composition, and optical properties are needed. Such observations should ideally be collocated with detailed radiation measurements (e.g. AERONET), with aerosol lidars probing the vertical distribution and with radiosondes providing profiles of temperature and humidity. Evaluating indirect aerosol effects on clouds and precipitation is even more challenging and requires additional detailed observations of cloud properties such as cloud droplet number concentrations. Measurements from polarimetric radars, disdrometers, and cloud particle imagers can provide information on hydrometeor phases and size distributions but are only sparsely available. Online integration can also be beneficial for AQ modelling. Dense observational networks are available for the validation of classical air pollutants such as $\mathrm{O}_{3}$ or $\mathrm{NO}_{\mathrm{x}}$ and satellite observations of AOD and $\mathrm{NO}_{2}$.

\subsection{Future directions, perspectives and recommendations}

It is clear that the online modelling approach is a prospective way for future single-atmosphere modelling systems, providing advantages for all three communities, Met modelling including NWP, AQ modelling including CWF, and climate modelling. However, there is not necessarily one integrated online modelling approach/system suitable for all communities.

Comprehensive online modelling systems, built for research purposes and including all important mechanisms of interactions, will help to understand the importance of different processes and interactions and to create specific model configurations that are tailored for their respective purposes.

Regarding CWF and AQ modelling the online approach will certainly improve forecast capabilities as it allows a correct way of jointly and consistently describing meteorological and chemical processes within the same model time steps and grid cells. This also includes harmonised parametrizations of physical and chemical processes in the ABL. There are many studies and measurements supportive of this conclusion (Grell et al., 2004; Grell, 2008; Zhang, 2008; Korsholm et al., 2009; Grell and Baklanov, 2011; Forkel et al., 2012; Saide et al., 2012; Zhang et al., 2013). In particular, due to the strong nonlinearities involved, offline coupling can lead to inaccuracies in chemical composition simulations.

For meteorological modelling, the advantages of online approaches are less evident and need to be further investigated and justified. It is clear that online models for shortterm applications like NWP do not require full comprehensive chemistry (which would increase the CPU cost tremendously). Rather, the main improvements for NWP that are possible through an online integrated approach will be related to improvements in (i) meteorological data assimilation (first of all remote sensing data, radiation characteristics, which require detailed distributions of aerosols in the atmosphere) and (ii) description of aerosol-cloud and aerosolradiation interactions, yielding improved forecasting of precipitation, visibility, fog and extreme weather events. While these improvements might not be statistically significant as averaged over longer periods of time, it is clear that for specific episodes and for urban weather forecasts, there are large potential benefits. In summary, meteorology modelling including NWP should benefit from including such feedbacks as aerosol-cloud-radiation interactions, aerosol dynamics along with simplified chemistry (with a focus on aerosol precursors and formation, e.g. sulfur chemistry).

For climate modelling, the feedbacks (forcing mechanisms) are the most important and the main improvements are related to climate-chemistry/aerosols interactions. However, the online approach is not strictly necessary for all purposes in this field. Many GCMs or RCMs are using an offline approach for describing GHG and aerosol forcing processes (by chemistry/aerosol parametrizations or prescription 
or reading outputs of CTMs). For global climate, in the EU project MEGAPOLI, a sensitivity study compared online vs. offline approaches and showed that for long-lived GHG forcing the online approach did not give large improvements (Folberth et al., 2011). On the other hand, for short-lived climate forcers, especially aerosols and for regional or urban climate, the outcome was very different, with online modelling being of substantial benefit. The online approach for climate modelling is mostly important for studies of shortlived climate forcers, which represent one of the main uncertainties in current climate models and are in particular at the core of political and socio-economic assessments of future climate change mitigation strategies. It will be impossible to answer the main questions about aerosol short-lived climate forcers and mitigation strategies without employing fully online coupled modelling systems that include aerosol dynamics and feedbacks.

Based on the analysis of the models included in this review, we suggest aiming at eventually migrating from separate MetM and CTM systems to online integrated coupled meteorology chemistry models. Only this type of model allows the consideration of two-way interactions (i.e. feedbacks) in a consistent way. The integration has not only the advantage of a single-atmosphere model, for instance where water vapour and other atmospheric gases are no longer treated numerically differently simply because of historical separation of the different disciplines. Furthermore, the integration has the advantage of saving computational resources, since several processes (e.g. vertical diffusion) have to be described in both MetMs and CTMs. Moreover, it will also reduce the overall efforts in research and development, maintenance and application leading to cost savings for both types of models.

The main recommendations from this study are briefly summarised in the following sections. If a recommendation is mainly relevant for one type of the application (Meteorology or Chemistry simulations), this is explicitly mentioned.

\subsubsection{Emissions and depositions}

Emission and deposition are both close-to-surface processes and dependent on meteorology processes. In order to improve their treatment in MetChem models the following is needed:

- Time dependence of anthropogenic emissions should be better described, and open-ocean ship emissions should be better characterised (time, amount, compounds). Currently their parametrizations still have large uncertainties (Jalkanen et al., 2012).

- Accurate characterisation of land use, soil moisture and vegetation should be used for more accurate representations of meteorologically dependent emissions.
- Emissions and heat fluxes from forest fires and volcanic eruptions need to be better known and improved in the models.

- Treatment of anthropogenic VOC emissions need to be improved/ updated, both because of their contributions to $\mathrm{O}_{3}$ and SOA formation.

- Emissions of primary aerosols and in particular their number and size distributions and physical properties (hydrophilic/hydrophobic) need to be better represented, both for atmospheric composition and for interaction with meteorology.

- Ammonia emissions should be calculated online with a more accurate representation of temporal variation, and account should be taken of their interactions with soil/vegetation (bi-directional fluxes, deposition or emission).

- Dry and wet deposition processes are directly driven by meteorology and, therefore, more accurate representations of their interplays with chemistry and meteorology are needed.

- Accurate parametrizations of land surface processes and accurate land use/land cover data sets are needed because of their profound impacts on both natural emissions and dry deposition fluxes.

\subsubsection{Model formulations}

Migrate from offline to online integrated modelling systems is recommended as only the latter approach can guarantee a consistent treatment of processes and allow two-way interactions of physical and chemical components of Met-Chem systems, particularly for CWF and NWP communities. Online integrated models, however, need harmonised formulations of all processes influencing meteorology and chemistry. In particular the following model treatments need to be considered:

- Our parametrization/understanding of aerosolradiation-cloud-chemistry interactions is still incomplete and further research on the model representations of these interactions is needed.

- Key aerosol properties (size distribution, phase, hygroscopicity, mixing state and optical depths) and processes (chemistry, thermodynamics for SOA and dynamics) need to be better represented for AQ simulations.

- Cloud properties (droplet number concentrations, size distribution, optical depths), processes (microphysics, dynamics, wet scavenging, aqueous phase chemistry) and cloud-aerosol interactions for all types of clouds (in particular for convective and ice clouds) need to be better represented. 
- A major challenge for most online models is the adequate treatment of indirect aerosol effects. Its implementation with affordable computational requirements and evaluation against laboratory/field data would greatly facilitate this transition.

- As more meteorological and chemical variables are assimilated into a model, one must be cautious about possible diminishing returns and possible antagonistic effects due to the interactions between meteorological variables and chemical concentrations. Consequently, the development of optimal methods for data assimilation is warranted.

\subsubsection{Real-time application}

To achieve the objective of online coupled meteorology and chemistry simulation in forecast models some specific aspects should be considered:

- National weather centres should consider progressively including aerosol-chemistry interactions into NWP systems which will lead to potential improvements and extending them to CWF using online coupled models for cross evaluations, benefitting both disciplines.

- The online integrated approach is well suited for applications where a frequent integration between meteorology and chemistry models is required to properly account for the effects of mesoscale events in highresolution CTMs.

- The online coupling of meteorology, physics and emissions and their accurate representations are essential for CWF; the implementation of aerosol feedbacks is important mostly for specific episodes and extreme cases.

\subsubsection{Model evaluation}

For online models the evaluation can no longer be conducted for meteorology or chemistry separately. Interacting processes will need specific attention to avoid the situation where the "right" results are obtained for the wrong reasons. In this regard, efforts should focus on conducting dynamic evaluation to establish the models' credibility in accurately simulating the changes in weather and air quality conditions observed in the real world. To achieve this, attention should be given to:

- An international test bed for evaluation of urban models and mesoscale models for online MetChem models. A first step into this direction has been taken by the AQMEII consortium for the regional scale, but extension for higher resolving models is important.
- Special variables (e.g. shortwave and longwave radiation, photolytic rate of $\mathrm{NO}_{2}, \mathrm{AOD}, \mathrm{COT}, \mathrm{CCN}$, CDNC, precipitation) should be included routinely into a model evaluation for online coupled models. Reliable measurements are needed on a routine basis.

- Routine, long-term measurements of aerosol size distributions, chemical composition and optical properties in operational ground-based networks are urgently needed to verify meteorology/climate-chemistry feedbacks.

- Ground-based and satellite remote-sensing measurements of aerosol and cloud properties (e.g. optical depths, CCN, IN, CDNC and SW and LW radiation) are very important to study aerosol indirect effects and should be included for validation of meteorology chemistry feedbacks.

- Last but not least, there is a need to evaluate routinely the atmospheric mixing processes in models, in particular within the ABL, using measurements on fluxes of meteorological parameters and chemical species in all three directions.

\subsection{Outlook}

This review paper is the first to summarise the status of online coupled models in Europe. As the developments in the past decades and especially in the last few years have shown, more online coupled models will become available and more feedbacks will be included. The COST Action ES1004 aims at determining the most relevant processes for coupling. However, it is already clear today that the coupling of models will not be restricted only for meteorology and chemistry, but will extend to biological processes such as the uptake and emission of gases as well as the water vapour evaporation all depend on the same biological activity of plants, which are currently only simply described. It is also important to promote and maintain international collaboration in developing, testing, and demonstrating the added value of advanced modelling tools to the scientific and policy-making communities.

\section{Appendix A}

\section{Model descriptions}

Short model descriptions are given here. Tabular overviews can be found at http://www.mi.uni-hamburg.de/costmodinv.

\section{A1 BOLCHEM, Italy}

BOLCHEM (BOLAM + CHEM; Mircea et al., 2008) is a model based on a project that started in 2002 at CNR-ISAC. Gas and aerosol transport, diffusion, removal and transformation processes are included in BOLAM meteorological 
hydrostatic limited area model (Buzzi et al., 2003). Applications range from regional to hot-spot, with timescales ranging from few days (air quality forecasts) to decades (climatological). Equations for atmospheric dynamics, thermodynamics, radiation, microphysics and chemistry are solved simultaneously on the same spatio-temporal grid making every feedback potentially available.

BOLCHEM was run in forecast mode over Europe during the GEMS project (http://gems.ecmwf.int/; Huijnen et al., 2010; Zyryanov et al., 2012) and is currently running to forecast Air Quality over Italy in the MACC project (http: //www.gmes-atmosphere.eu/). It also participated within the CityZen project (http://www.cityzen-project.eu) to regional trend and future scenario studies (Colette et al., 2011). In addition, several specific studies were performed: volcanic emission event (Villani et al., 2006), forest fire episodes (Pizzigalli et al., 2012), aerosol direct effects (Russo et al., 2010), Saharan dust transport over the Mediterranean Sea (Mircea et al., 2008), composition data assimilation (Messina et al., 2011), scale bridging technique (Maurizi et al., 2012).

\section{A2 COSMO-ART, Germany}

COSMO-ART (ART stands for Aerosols and Reactive Trace gases, Vogel et al., 2009) is a regional to continental scale model coupled online to the COSMO regional NWP and climate model (Baldauf et al., 2011). COSMO is used by several European countries for operational weather forecast. The gaseous chemistry in COSMO-ART is solved by a modified version of the Regional Acid Deposition Model, Version 2 (RADM2) mechanism (Stockwell et al., 1990), which has been extended to describe secondary organic aerosol formation and hydroxyl recycling due to isoprene chemistry and heterogeneous reactions as hydrolysis of $\mathrm{N}_{2} \mathrm{O}_{5}$. Aerosols are represented by the modal aerosol module MADEsoot (Riemer et al., 2003). The five modes that represent the aerosol population contain: pure soot, secondary mixtures of sulfates, nitrates, ammonium, organics and water (nucleation and accumulation) and the internal mixtures of all these species in both modes. Separate fine and coarse emission modes for sea-salt, dust (Stanelle et al., 2010), and rest anthropogenic species are treated by six additional modes. Specific modules are included to simulate the dispersion of pollen grains (Vogel et al., 2008) and other biological particles. Meteorology affected emissions are also online coupled within the model system. The equilibrium between phases of the inorganic material is achieved through the ISORROPIA II module (Fountoukis and Nenes, 2007). The simulation of secondary organic aerosol chemistry and of organic mass transfer between phases in COSMO-ART is currently treated with the SORGAM scheme (Schell et al., 2001). That scheme was recently replaced by a VBS (volatility basic set) scheme (Athanasopoulo et al., 2013). The radiation scheme used within the model to calculate the vertical profiles of shortwave and longwave radiative fluxes is GRAALS (Ritter and
Geleyn, 1992). Radiative fluxes are modified online by the aerosol mass, and its soot fraction. In order to account for the interaction of aerosol particles with the cloud microphysics and radiation, COSMO-ART uses the two moment cloud microphysics scheme of Seifert and Beheng (2006) and parameterizations of cloud condensation and ice nuclei (Bangert et al., 2011, 2012). A first evaluation of the model system can be found in Knote et al. (2011).

\section{A3 COSMO-MUSCAT, Germany}

The multiscale model system COSMO-MUSCAT (Wolke et al., 2004a, b, 2012) is used for process studies as well as operational pollutant forecasting at local and regional scales. Different horizontal resolutions can be used for individual sub-domains in the developed multi-block approach, which allows finer grid sizes in selected regions of interest (e.g. urban areas or around large point sources). The chemistry transport model MUSCAT, which treats the atmospheric transport as well as chemical transformations for several gas phase species and particulate matters, is coupled online with the operational NWP model COSMO (Steppeler et al., 2003) of the German Meteorological Service (DWD). The transport processes include advection, turbulent diffusion, sedimentation as well as dry and wet deposition. The chemical reaction system RACM-MIM2 (Karl et al., 2006; Stockwell et al., 1997) with 87 species and over 200 reactions is applied for 3-D air quality applications. The particle size distribution and aerosol dynamical processes is described with the modal aerosol model M7 (Vignati et al., 2004), extended to nitrate and ammonium. In this approach, the total particle population is aggregated from seven log-normal modes with different compositions. The gas-to-particle partitioning of inorganic species is performed using the thermodynamic aerosol model ISORROPIA (Nenes et al., 1998). Alternatively, a more simplified mass based particle model is available especially for long-term simulations.

The modelling system has been used for several AQ applications (Stern et al., 2008; Hinneburg et al., 2009; Renner and Wolke, 2010) and investigating large scale transport of Saharan dust, including its sources and sinks (e.g. Heinold et al., 2007; Helmert et al., 2007). In addition to parametrizing particle fluxes and transformations, the influence of aerosols by modifying solar and thermal radiative fluxes on temperature, wind fields, and cloud dynamics are considered (Heinold et al., 2011a; Meier et al., 2012b). Furthermore, the distribution of the Volcano ash plume over $\mathrm{Eu}-$ rope has been analysed (Heinold et al., 2011b).

\section{A4 Enviro-HIRLAM, Denmark and HIRLAM countries}

Enviro-HIRLAM is developed as a fully online integrated NWP and CTM system for research and forecasting of meteorological, chemical and biological weather. The integrated 
modelling system is developed by DMI and other collaborators (Chenevez et al., 2004; Baklanov et al., 2008a, 2011b; Korsholm et al., 2008, 2009; Korsholm, 2009) and included as the baseline system of the Chemical Branch of the HIRLAM consortium. The model development was initiated at DMI more than a decade ago and is used now in several countries. The first version of Enviro-HIRLAM was based on the DMI-HIRLAM NWP model with online integrated pollutant transport and dispersion (Chenevez et al., 2004), chemistry, deposition and indirect effects (Korsholm, 2009) and later aerosol dynamics (Baklanov, 2003; Gross and Baklanov, 2004). To make the model suitable for chemical weather forecasting in urban areas the meteorological part was improved by implementation of urban sub-layer parametrizations (Baklanov et al., 2008b). The model's dynamic core was improved by adding a locally mass conserving semi-Lagrangian numerical advection scheme (Kaas, 2008; Sørensen, 2012), which improves forecast accuracy and enables performing longer runs. The current version of Enviro-HIRLAM (Nuterman et al., 2013) is based on the reference HIRLAM version 7.2 with a more sophisticated and effective chemistry scheme, multi-compound modal approach aerosol dynamics modules, aerosol feedbacks on radiation (direct and semi-direct effects) and on cloud microphysics (first and second indirect effects). This version is still under development and needs further validation.

The modelling system is being used for operational pollen forecasting in Denmark since 2009 and for different research studies since 2004. Following the main strategic development within HIRLAM (HIRLAM-B project), further developments of Enviro-HIRLAM will shift to the new HARMONIE NWP platform incorporating the Enviro-HIRLAM chemistry modules and aerosol-radiation-cloud interactions into the future Enviro-HARMONIE integrated system (Baklanov, 2008; Baklanov et al., 2011a).

\section{A5 GEM-AQ, Canada (also used in Poland)}

The GEM-AQ model (Kaminski et al., 2008) is a comprehensive chemical weather model in which air quality processes (chemistry and aerosols) and tropospheric chemistry are solved online in the operational weather prediction model GEM. GEM is the Global Environmental Multiscale model, developed at Environment Canada (Côté et al., 1998). Recently, the model was extended to account for chemistry-radiation feedback, where modelled (chemically active) ozone, water vapour and aerosols are used to calculate heating rates. For regional Arctic simulations the model chemistry was extended to account for reactive bromine species in order to investigate ozone depletion in the boundary layer (Toyota et al., 2011).

The GEM-AQ model in LAM configuration is used in a semi-operational air quality forecast for Europe and Poland (e.g. Struzewska and Kaminski, 2008). The model is run on several regional domains with horizontal resolutions of $\sim 15 \mathrm{~km}$ (whole Europe), $\sim 5 \mathrm{~km}$ (Poland) and $\sim 1 \mathrm{~km}$ for agglomerations (Krakow), where urban effects are represented by the TEB (Town Energy Balance) parameterization (Masson, 2000).

\section{A6 IFS-MOZART/C-IFS (MACC/ECMWF)}

The ECMWF (European Centre for Medium-Range Weather Forecast) meteorological forecast and data assimilation system IFS (Integrated Forecast System, http://www.ecmwf.int/ research/ifsdocs) has been coupled to an updated version of the global chemistry transport model MOZART-3 (Model for Ozone And Related Tracers, version 3; Kinnison et al., 2007) in order to build the coupled MACC system IFS-MOZART (Flemming et al., 2009). For coupled simulations, both models are run in parallel and exchange meteorological fields as well as 3-D source and sink terms every hour using the OASIS4 coupling software developed in the PRISM project (Valcke and Redler, 2006). The coupled system is currently used to provide analysis and forecast of atmospheric composition (http://www.gmes-atmosphere.eu). The coupled system will be superseded by the online integration of the chemical mechanisms into the IFS (C-IFS) following the implementation of aerosol modules (Morcrette et al., 2009).

\section{A7 MCCM, Germany}

The online coupled regional meteorology chemistry model MCCM (Mesoscale climate chemistry model, Grell et al., 2000) was developed at the IMK-IFU. MCCM is based on the non-hydrostatic NCAR/Penn State University mesoscale model MM5. It offers the choice between the tropospheric gas phase chemistry mechanisms RADM2, RACM, and RACM-MIM. BVOC emissions and photolysis are calculated online. Aerosols are described by the modal MADE/SORGAM aerosol module. Like MM5, MCCM can be applied from the continental to the urban scale.

Applications of MCCM include various AQ studies for Europe and Mexico City, the first online coupled regional climate chemistry simulation (Forkel and Knoche, 2006), and the simulation of the 2010 Eyjafjallajökull ash plume (Emeis et al., 2011).

\section{A8 MEMO/MARS, Greece}

The MEMO/MARS-aero modelling system combines the mesoscale meteorological model MEMO (Moussiopoulos et al., 1997) with the chemical dispersion model MARS-aero (Moussiopoulos et al., 1995) in an online or offline coupling configuration. The aerosol phase is described in MARS-aero as a multimodal (fine, accumulation and coarse) internally mixed distribution. For inorganics, an equilibrium model has been built especially for dry, coastal and urban regions, which contains common inorganic species and also crustal species. For secondary organics (SOA), the SORGAM module has been incorporated into the model. Radiative effects 
of air pollutants and cloud layers are introduced in the coupled configuration using an extended version of the radiation module IRIS (Halmer, 2012) which incorporates the OPAC (Optical Properties of Aerosols and Clouds) software library (d'Almeida et al., 1991). OPAC defines a data set of typical clouds and internally mixed aerosol components, which can be externally mixed to simulate a wide range of tropospheric aerosols.

The MEMO/MARS-aero modelling system forms the operational core of the Air Quality Management System used by the environmental ministry of the Republic of Cyprus (Moussiopoulos et al., 2012). The performance of the coupled system was evaluated in an urban case application for Paris, France (Halmer et al., 2010) by analysing the response of the primary meteorological variables and dispersion fields to the introduction of the direct aerosol effect.

\section{A9 Meso-NH, France}

Meso-NH is a non-hydrostatic mesoscale atmospheric model coupled online with chemistry, which has been jointly developed by CNRM (Météo France) and Laboratoire d'Aérologie (CNRS) (Lafore et al., 1998). Meso-NH simulates synoptic scale (horizontal resolution of several tens of kilometres) to small scale (LES type, horizontal resolution of a few meters) and can be run in a two-way nested mode. The model is used for research for both meteorological and chemical weather. Different sets of parametrization are included in the model for convection (Bechtold et al., 2001), cloud micro-physics (Pinty and Jabouille, 1998; Cohard and Pinty, 2000; Khairoudinov and Kogan, 2000), turbulence (Cuxart et al., 2000), biosphere-atmosphere thermodynamic exchanges (Noilhan and Mahfouf, 1996) and for urban-atmosphere interactions (Masson, 2000). The physical package dedicated to the mesoscale has been included in the NWP model AROME that is operational since 2008 over France at $2.5 \mathrm{~km}$ resolution.

The model includes online gaseous chemistry (Suhre et al., 2000; Tulet et al., 2003), online aerosols chemistry (Tulet et al., 2005) and online cloud chemistry including mixed phase cloud (Leriche et al., 2012). Several chemistry mechanisms are available for the gas phase. RACM and ReLACS (Crassier et al., 2000), which is a reduced mechanism from RACM, are dedicated to the modelling of ozone, $\mathrm{NO}_{\mathrm{x}}$ and VOC chemistry system in the troposphere. Furthermore, CACM (Caltech Atmospheric Chemistry Mechanism, Griffin et al., 2002) and ReLACS2 (Tulet et al., 2006), which is a reduced mechanism from CACM, are dedicated, in addition to the modelling of the ozone, NOx, VOC chemistry system, to the modelling of the semi-volatile organic compounds, precursors of SOA formation.

\section{A10 MetUM (Met Office Unified Model), UK}

The Met Office Unified Model (MetUM) (Davies et al., 2005) uses the aerosol scheme CLASSIC (Bellouin et al., 2011) that previously was applied in climate and air quality configurations. The chemistry scheme is the UKCA scheme (Morgenstern et al., 2009; O' Connor et al., 2013) which offers several choices of chemical mechanism. A two moment modal aerosol scheme, UKCA-GLOMAP-mode, has also been developed for use with the MetUM ported from the offline model TOMCAT (Mann et al., 2010). The model is two-way coupled with the direct radiative effects of gases/aerosols and the indirect effects of aerosols are also capable of being treated.

MetUM is used across a very wide range of spatial and temporal scales from short range weather forecasting at $1.5 \mathrm{~km}$ resolution to multi-decadal simulations in an earth system model configuration (Collins et al., 2011).

\section{A11 M-SYS (online version), Germany}

The multi-scale community model system M-SYS (Trukenmüller et al., 2004), with its development coordinated at the University of Hamburg, combines the non-hydrostatic MEsoscale TRAnsport- and Stream model METRAS (Schlünzen, 1990; Schlünzen and Pahl, 1992 at resolutions of $1-5 \mathrm{~km})$ with the obstacle-resolving MIcroscale model MITRAS (Schlünzen et al., 2003; Bohnenstengel et al., 2004 at resolution 1-10 m) using 1-way nesting in dependence of application and characteristic scales (Schlünzen et al., 2011). Both models calculate transport and solve 3-D gas-phase chemistry (RADM2 mechanism, Stockwell et al., 1990) and aerosol reactions, when coupled to the corresponding chemistry modules (MECTM/MICTM). Advection and diffusion are solved in flux form using the same numerical schemes for meteorology and chemistry. For resolutions of at least $1 \mathrm{~km}$, the sectional aerosol model SEMA is employed (von Salzen and Schlünzen, 1999a, b). Non-reacting tracers, e.g. pollen emissions (Schueler and Schlünzen, 2006) and pollen fertility (Schueler et al., 2005) are calculated online with dependence on meteorology. Other processes solved with direct dependence of meteorology include, dry deposition (Schlünzen an Pahl, 1992), sedimentation (von Salzen and Schlünzen, 1999a) and biogenic emissions. The models consider several subgrid-scale land covers per grid cell and employ a flux aggregation method (von Salzen et al., 1996) to describe more realistically typical surface characteristics (Schlünzen and Katzfey, 2003); this is also considered in the online coupled sea-ice model, where several ice classes plus water might occur in one grid cell (Lüpkes and Birnbaum, 2005). To better describe urban effects the BEP scheme has been included (Grawe et al., 2012).

Early applications, e.g. for coastal (von Salzen and Schlünzen, 1999c) or urban areas (Schlünzen et al., 2003), and biogenic emissions (Renner and Münzenberg, 2003), 
revealed that online modelling was too resources consuming at that time and hindered scientific progress. Therefore, the data exchange interval has been increased from online integrated to $15 \mathrm{~min}$ up to $3 \mathrm{~h}$, depending on the application (e.g. Lenz et al., 2000; Müller et al., 2001; Schlünzen and Meyer, 2007; Meyer and Schlünzen, 2011). Applications of the online integrated system concern atmospheric inputs into the marginal seas and mud-flat areas (Schlünzen and Pahl, 1992; Schlünzen et al., 1997; von Salzen and Schlünzen, 1999c), aerosol load and concentrations within street canyons (Schlünzen et al., 2003) or biogenic emissions and gene flow on a landscape level (Renner and Münzenberg, 2003; Schueler and Schlünzen, 2006; Buschboom et al., 2012).

\section{A12 NMMB/BSC-CTM (BSC-CNS), Spain}

The NMMB/BSC-CTM is a new fully online chemical weather prediction system under development at the Earth Sciences Department of the Barcelona Supercomputing Center (BSC) in collaboration with several research institutions (National Centers for Environmental Predictions (NCEP), NASA Goddard Institute for Space Studies, and the University of California, Irvine). The basis of the development is the NCEP new global/regional Non-hydrostatic Multiscale Model on the B grid (NMMB; Janjic et al., 2011; Janjic and Gall, 2012). Its unified non-hydrostatic dynamical core allows regional and global simulations and forecasts. A mineral dust module has been coupled within NMMB (Pérez et al., 2011). The new system simulates the atmospheric life cycle of the eroded desert dust. The main characteristics are its online coupling of the dust scheme with the meteorological driver, the wide range of applications from meso to global scales, and the dust shortwave and longwave radiative feedbacks on meteorology. In order to complement such development, an online gas-phase chemical mechanism has been implemented (Jorba et al., 2012). Chemical species are advected and mixed at the corresponding time steps of the meteorological tracers using the same numerical scheme of the NMMB. Advection is Eulerian, positive definite and monotone. The final objective of the work is to develop a fully coupled chemical weather prediction system, namely NMMB/BSC-CTM, able to resolve gasaerosol-meteorology interactions from global to local scales. Current efforts are oriented to incorporate a multi-component aerosol module within the system with the aim to solve the life-cycle of relevant aerosols at global scale (dust, sea salt, sulfate, black carbon and organic carbon).

\section{A13 RACMO2/LOTOS-EUROS, the Netherlands}

The regional climate model RACMO2 (Van Meijgaard et al., 2008) is online coupled to the regional chemistry transport model LOTOS-EUROS (Schaap et al., 2008). They are coupled through a 3-hourly exchange of meteorology and aerosol concentrations, and the system therefore has some features of an online access model. In addition to differences in internal time steps, both models run on their native grids (rotated pole for RACMO2 versus regular lat-lon for LOTOS-EUROS), with a typical resolution of $25 \mathrm{~km}$, although a resolution of the order of $10 \mathrm{~km}$ is also feasible. Since LOTOS-EUROS only covers the lowest $3.5 \mathrm{~km}$ of the atmosphere, as it was designed as an air quality model, RACMO2 has to use climatology for the rest of the vertical dimension. A vertical extension of LOTOS-EUROS is being developed.

RACMO2 is a semi-Lagrangian model based on the dynamics of the HIRLAM model, combined with the physics of the ECMWF IFS system. It has taken part in ensemble studies with other regional climate models and is used for the downscaling of climate scenarios for the Netherlands. LOTOS-EUROS is a Eulerian model, using CBM-IV for gaseous chemistry and EQSAM (Metzger et al., 2002) for secondary inorganic aerosols. Secondary organics are not accounted for yet. Biogenic, dust and sea spray emissions are calculated online. The model currently uses a bulk approach for aerosol $\left(\mathrm{PM}_{2.5}\right.$ and $\left.\mathrm{PM}_{10}\right)$ although $\mathrm{M} 7$ (Vignati et al., 2004) is available. LOTOS-EUROS is a part of the MACC ensemble and has taken part in EURODELTA and AQMEII model intercomparison exercises. It is used in the Netherlands for smog forecasting and policy oriented studies. A one-way coupled version was used to study the impact of climate change on air quality (Manders et al., 2012). A twoway coupled version including the direct impact of aerosol on radiation (Savenije et al., 2012) and on cloud condensation number (Van Meijgaard et al., 2012) is now available.

\section{A14 RAMS/ICLAMS, USA/Greece}

The Integrated Community Limited Area Modelling System (ICLAMS; Solomos et al., 2011) has been developed at the University of Athens, with contributions from ATMET LLc, USA and Georgia Institute of Technology, as an extended version of RAMS6.0 atmospheric model (Cotton et al., 2003). It is a new generation integrated modelling system that includes two-way interactive nesting, detailed surface (soil, vegetation) and explicit cloud microphysics. The desert dust module SKIRON (Spyrou et al., 2010) has been implemented in RAMS/ICLAMS and the model includes also a sea-salt module, gas and aqueous phase chemistry, heterogeneous chemical processes and an improved radiation scheme (RRTM). Photodissociation rates, radiative transfer corrections as well as aerosol-cloud interactions are calculated online. The same radiative transfer scheme is used for both physical and photochemical processes. All prognostic aerosols in the model are allowed to act as CCN/GCCN/IN for the activation of cloud droplets and ice particles following the formulations of Nenes and Seinfeld (2003) and Barahona and Nenes (2009). CCN/GCCN/IN are treated in an explicit way. 
The model capabilities make RAMS/ICLAMS appropriate for studying complicated atmospheric processes related to chemical weather interactions and quantifying forcing from them.

\section{A15 RegCM-Chem, Italy}

RegCM4-Chem is the ICTP-Regional Climate Model online coupled with the atmospheric chemical transport model. The climate component of the coupled model is RegCM. The chemistry component in RegCM4 depends on the condensed gas-phase chemistry which is based on CBM-Z (Zaveri and Peters, 1999). During the last years RegCM has been coupled with simplified chemistry/aerosol modules of increasing complexity, such as a simplified sulfur chemistry scheme including direct and indirect aerosol radiative effects (Qian and Giorgi, 1999; Qian et al., 2001), a simple carbon aerosol module (Solmon et al., 2006), a desert dust model (Zakey et al., 2006) and a sea salt scheme (Zakey et al., 2008).

Studies of regional chemistry-climate interactions with the RegCM system include the effects of direct effects of sulfate on the climate of east Asia (Giorgi et al., 2002, 2003), the effects of desert dust on the African monsoon (Konare et al., 2008; Solmon et al., 2008, 2012), the effect of European aerosol (Zanis et al., 2012), and the effects of dust storms on East Asia climate (Zhang et al., 2009).

\section{A16 REMOTE/REMO-HAM, Germany}

The regional three-dimensional online climatechemistry/aerosol model REMOTE (Regional Model with Tracer Extension) is based on the former regional weather forecast system of the German Meteorological Service (Majewski, 1991), extended with gas phase and aerosol chemistry. A basic description is available from Langmann (2000). For the determination of aerosol dynamics and thermodynamics, the M7 module is implemented (Vignati et al., 2004). The aerosol dynamical processes in M7 include nucleation, coagulation and condensation. The aerosol size spectrum is represented by the superposition of seven log-normal distributions subdivided into soluble and insoluble coarse, accumulation and Aitken modes and an additional soluble nucleation mode. The five aerosol components considered in $\mathrm{M} 7$ are sulfate, black carbon, organic carbon, sea salt and mineral dust (Langmann et al., 2008). Photochemical production and loss in REMOTE are determined by the RADM II chemical scheme (Stockwell et al., 1990). Based on REMOTE, the REMO-HAM has recently been developed and evaluated (Pietikäinen et al., 2012). It uses the same chemical mechanism but is based on a newer version of the meteorology model REMO (B. Langmann, personal communication, 2013).

Several evaluation studies and applications in different regions of the Earth and for different kinds of aerosols (anthropogenic emissions, mineral dust, volcanic emissions, biomass burning emissions) and feedback studies focusing on cloud-aerosol feed-backs have been performed (e.g. Coleman et al., 2013; Langmann et al., 2012; O'Dowd et al., 2012; Pfeffer et al., 2012).

\section{A17 WRF-Chem, USA (also used in Germany, UK, Spain and others countries)}

The Weather Research and Forecast (WRF; http://www. wrf-model.org/) model coupled with Chemistry (WRFChem; Grell et al., 2005; Fast et al., 2006) provides the capability to simulate chemistry and aerosols from cloud scales to regional scales. WRF-Chem is a community model. The development is led by NOAA/ESRL with contributions from National Center for Atmospheric Research (NCAR), Pacific Northwest National Laboratory (PNNL), EPA, and university scientists (http://www.wrf-model.org/WG11). WRFChem is an online model which includes the treatment of the aerosol direct and indirect effect. Standard gas phase chemistry options of WRF-Chem include the RADM2, MOZART, CRIMech, and the CBMZ mechanism, additional chemistry options are available with a preprocessing tool based on KPP. For aerosols, it offers the choice between bulk, modal, and sectional schemes. The Volatile Basis Set (VBS) approach is also available for the modal and sectional aerosol approaches to treat Secondary Organic Aerosol formation. Among other options MEGAN may be used for biogenic emissions, two pre-processors are available for wildfires (injection heights are being calculated online).

WRF-Chem is used for research applications or for forecasting of air quality (e.g. http://verde.lma.fi.upm.es/ wrfchemeu), volcanic ash dispersion, and weather. Due to its versatility, WRF-Chem is attracting a large user and developer community world-wide and also in Europe. WRF-Chem is continually developed and additional options are being implemented. References from model applications and/or developments can be found at http://ruc.noaa.gov/wrf/WG11/ References/WRF-Chem.references.htm. There are also several versions and branches/lines of the modelling system under development (see e.g. Zhang, 2008, 2010a, 2012c, 2013; Li et al., 2010).

\section{A18 WRF-CMAQ Coupled System, USA (also used in UK and other countries)}

The Community Multiscale Air Quality (CMAQ) modelling system (Byun and Schere, 2006) developed by USEPA since 1990 s is one of the decision tools for regulatory applications. Traditionally, meteorological models are not built in the CMAQ model. The users need to run a meteorological model, like the Fifth-Generation Pennsylvania State University-National Center for Atmospheric Research Model (MM5) or WRF (Skamarock et al., 2008) model first and then use the meteorological model output to drive CMAQ. There 
is no chemistry feedback to meteorology in the offline version.

The new version CMAQ 5.0 (officially released in February 2012, http://www.cmaq-model.org/) includes an option to run the model in a 2-way coupled (online access) mode with the WRFv3.3 model (Pleim et al., 2008; Mathur et al., 2010; Wong et al., 2012). A coupler is used to link these two models, ensuring exchange between the meteorology and atmospheric chemistry modelling components. In this 2-way coupled system, simulated aerosol composition and size distribution are used to estimate the optical properties of aerosols, which are then used in the radiation calculations in WRF. CMAQv5.0 includes a new version of the SAPRC gas-phase chemical mechanism - SAPRC07TB (Carter et al., 2010), the new version CB05 with updated toluene chemistry (Whitten et al., 2010) and a new aerosol module AERO6. These are to be used with CAM and RRTMG (two radiation schemes options in WRF-CMAQ) to calculate the aerosol extinction, single scattering albedo, and asymmetry factor for shortwave (SW) radiation and aerosol extinction for longwave (LW) radiation. The latest version of the two-way coupled WRF-CMAQ model has also included aerosol indirect effects (Yu et al., 2001). The aerosol chemical species calculated by CMAQ are combined into five groups: watersoluble, insoluble, sea-salt, black carbon, and water. The refractive indices for these species are taken from the OPAC database (Hess et al., 1998) using linear interpolation to the central wavelength of the CAM and RRTMG wavelength intervals (Wong et al., 2012).

Offline WRF-CMAQ has been used in a number of projects throughout Europe for air quality regulatory applications including EC FP7 funded projects MEGAPOLI and TRANSPHORM. Appel et al. (2012) have demonstrated the WRF-CMAQ modelling system used in the AQMEII (phase 1) model evaluation. The online 2-way coupled WRF-CMAQ model will be used in AQMEII (phase 2) within the online coupled model evaluation exercise and to explore air quality and climate change interactions. 


\section{Appendix B}

Table B1. List of effects of meteorology on chemistry.

\begin{tabular}{|c|c|c|}
\hline $\begin{array}{l}\text { Meteorological } \\
\text { parameter }\end{array}$ & Effect on ... & Model variables \\
\hline \multirow{3}{*}{ temperature } & chemical reaction rates & $\mathrm{T}$, reaction rate coefficients \\
\hline & biogenic emissions & BVOC emission rates, isoprene, terpenes, DMS, pollen \\
\hline & $\begin{array}{l}\text { aerosol dynamics (coagulation, evaporation, } \\
\text { condensation) }\end{array}$ & $\begin{array}{l}\text { aerosol number size distributions scattering and absorption } \\
\text { coefficients PM mass and composition }\end{array}$ \\
\hline \multirow[t]{2}{*}{ temperature and humidity } & aerosol formation, gas/ aerosol partitioning & $\begin{array}{l}\text { gas phase } \mathrm{SO}_{2}, \mathrm{HNO}_{3}, \mathrm{NH}_{3} \text {; particulate } \mathrm{NO}_{3}{ }^{-}, \mathrm{SO}_{4}{ }^{2-}, \mathrm{NH}_{4}{ }^{+} \text {, } \\
\text { VOCs, } \mathrm{SOA}\end{array}$ \\
\hline & $\begin{array}{l}\text { aerosol water take-up, aerosol solid/liquid phase } \\
\text { transition }\end{array}$ & $\begin{array}{l}\text { PM size distributions, extinction coefficient, } \\
\text { aerosol water content }\end{array}$ \\
\hline SW radiation & photolysis rates & JNO2, JO1D, etc. \\
\hline $\begin{array}{l}\text { photosynthetic active } \\
\text { radiation }\end{array}$ & biogenic emissions & SW radiation, BVOC emissions, isoprene \& terpene conc. \\
\hline \multirow[t]{3}{*}{$\begin{array}{l}\text { cloud liquid water and } \\
\text { precipitation }\end{array}$} & wet scavenging of gases and particles & $\begin{array}{l}\text { wet deposition }\left(\mathrm{HSO}_{3--}, \quad \mathrm{SO}_{4-,}, \quad \mathrm{NO}_{3-,}, \quad \mathrm{NH}_{4-,}, \mathrm{Hg}\right) \text {, } \\
\text { precipitation (rain and total precip), cloud liq. water path }\end{array}$ \\
\hline & wet phase chemistry, e.g. sulfate production & $\begin{array}{l}\mathrm{SO}_{2}, \mathrm{H}_{2} \mathrm{SO}_{4}, \mathrm{SO}_{4}{ }^{2-} \text { in ambient air and in cloud and rain } \\
\text { water }\end{array}$ \\
\hline & $\begin{array}{l}\text { aerosol dynamics (activation, coagulation) } \\
\text { aerosol cloud processing }\end{array}$ & aerosol mass and number size distributions \\
\hline \multirow[t]{2}{*}{ soil moisture } & dust emissions, pollen emissions & surface soil moisture, dust and pollen emission rates \\
\hline & dry deposition (biosphere and soil) & $\begin{array}{l}\text { deposition velocities, dry deposition rates (e.g. } \mathrm{O}_{3}, \mathrm{HNO}_{3} \text {, } \\
\mathrm{NH}_{3} \text { ) }\end{array}$ \\
\hline \multirow[t]{2}{*}{ wind speed } & $\begin{array}{l}\text { transport of gases and aerosols, on- vs. offline } \\
\text { coupling interval, transport in mesoscale flows, } \\
\text { bifurcation, circulations, etc. }\end{array}$ & $\mathrm{U}, \mathrm{V},(\mathrm{W})$ \\
\hline & emissions of dust, sea salt and pollen & $\mathrm{U}, \mathrm{V}$ dust, sea salt and pollen emission rates \\
\hline $\begin{array}{l}\text { atmospheric boundary layer } \\
\text { parameters }\end{array}$ & $\begin{array}{l}\text { turbulent and convective mixing of gases and } \\
\text { aerosols in ABL, intrusion from free troposphere, } \\
\text { dry deposition at surface }\end{array}$ & $\begin{array}{l}\text { T, Q, TKE, surface fluxes (latent and sensible heat, } \mathrm{SW} \text { and } \\
\mathrm{LW} \text { radiation); deposition velocities, dry deposition } \\
\text { fluxe }\left(\mathrm{O}_{3}, \mathrm{HNO}_{3}, \mathrm{NH}_{3}\right)\end{array}$ \\
\hline lightning & NO emissions & $\mathrm{NO}, \mathrm{NO}_{2}$, lightning $\mathrm{NO}$ emissions \\
\hline water vapour & OH radicals & $\mathrm{Q}, \mathrm{OH}, \mathrm{HO}_{2}, \mathrm{O}_{3}$ \\
\hline
\end{tabular}


Table B2. List of effects of chemistry on meteorology.

\begin{tabular}{|c|c|c|}
\hline Chemical parameter & Effect on ... & Model variables \\
\hline aerosols (direct effect) & $\begin{array}{l}\text { Radiation (SW scattering/absorption, } \\
\text { LW absorption) }\end{array}$ & $\begin{array}{l}\text { AOD, aerosol extinction, single scattering albedo, } \mathrm{SW} \\
\text { radiation at ground (up- and downward), aerosol mass and } \\
\text { number size distributions, aerosol composition: } \mathrm{EC} \text { (fresh } \\
\text { soot, coated), OC, } \mathrm{SO}_{4}{ }^{2-}, \mathrm{NO}_{3}{ }^{-}, \mathrm{NH}_{4}{ }^{+}, \mathrm{Na}, \mathrm{Cl}, \mathrm{H}_{2} \mathrm{O} \text { dust, } \\
\text { metals, base cations }\end{array}$ \\
\hline aerosols (direct effect) & visibility, haze & $\begin{array}{l}\text { aerosol absorption \& scattering coefficients, RH, aerosol } \\
\text { water content }\end{array}$ \\
\hline aerosols (indirect effect) & $\begin{array}{l}\text { cloud droplet or crystal number and hence } \\
\text { cloud optical depth }\end{array}$ & $\begin{array}{l}\text { interstitial/activated fraction, CCN number, IN number, } \\
\text { cloud droplet size/number, cloud liquid and ice water } \\
\text { content }\end{array}$ \\
\hline aerosols (indirect effect) & cloud lifetime & cloud cover \\
\hline aerosols (indirect effect) & precipitation (initiation, intensity) & precipitation (grid scale and convective) \\
\hline aerosols (semi-direct effect) & ABL meteorology & $\begin{array}{l}\text { AOD, ABL height, surface fluxes (sensible and latent heat, } \\
\text { radiation) }\end{array}$ \\
\hline $\mathrm{O}_{3}$ & UV radiation & $\mathrm{O} 3, \mathrm{SW}$ radiation $<320 \mathrm{~nm}$ \\
\hline $\mathrm{O}_{3}$ & thermal IR radiation, temperature & $\mathrm{O} 3, \mathrm{LW}$ radiation \\
\hline $\mathrm{NO}_{2}, \mathrm{CO}, \mathrm{VOCs}$ & $\begin{array}{l}\text { precursors of } \mathrm{O}_{3}, \quad \text { hence indirect } \\
\text { contributions to } \mathrm{O}_{3} \text { radiative effects }\end{array}$ & $\mathrm{NO} 2, \mathrm{CO}$, total $\mathrm{OH}$ reactivity of $\mathrm{VOCs}$ \\
\hline $\mathrm{SO}_{2}, \mathrm{HNO}_{3}, \mathrm{NH}_{3}, \mathrm{VOCS}$ & $\begin{array}{l}\text { precursors of secondary inorganic and } \\
\text { organic aerosols, hence indirect contributors } \\
\text { to aerosol direct and indirect effects }\end{array}$ & $\begin{array}{l}\mathrm{SO} 2, \mathrm{HNO} 3, \mathrm{NH} 3, \\
\text { VOC components (e.g. terpenes, aromatics, isoprene) }\end{array}$ \\
\hline soot deposition on ice & surface albedo change & snow albedo \\
\hline
\end{tabular}


Table B3. Observation data sets available for model evaluation (name, number of sites, frequency of measurements, preferred model output type).

\begin{tabular}{|c|c|c|c|c|c|}
\hline Parameter & Evaluation datasets & \# sites & Database & $\begin{array}{l}\text { Frequency } \\
H-\text { hourly } \\
D-\text { daily } \\
W-\text { weekly } \\
M-\text { monthly } \\
\text { I-irregular }\end{array}$ & $\begin{array}{l}\text { Model } \\
\text { output } \\
\text { type } \\
L P-\text { local profiles } \\
2 D c-2 D \text { column }\end{array}$ \\
\hline PM2.5 & $\begin{array}{l}\text { various techniques } \\
\text { gravimetric, TEOM, etc. }\end{array}$ & $\begin{array}{l}835 \\
50\end{array}$ & $\begin{array}{l}\text { EEA Airbase } \\
\text { EMEP }\end{array}$ & $\begin{array}{l}\text { D } \\
\text { H, D, W }\end{array}$ & $\begin{array}{l}\text { in-situ } \\
\text { in-situ }\end{array}$ \\
\hline PM10 & $\begin{array}{l}\text { various techniques } \\
\text { gravimetric, TEOM, etc. }\end{array}$ & $\begin{array}{l}3000 \\
80\end{array}$ & $\begin{array}{l}\text { EEA Airbase } \\
\text { EMEP }\end{array}$ & $\begin{array}{l}\text { D } \\
\text { H, D, W }\end{array}$ & $\begin{array}{l}\text { in-situ } \\
\text { in-situ }\end{array}$ \\
\hline $\begin{array}{l}\text { aerosol optical depth } \\
\text { (AOD) and Angstrom } \\
\text { exponent (ratio of AOD at } \\
\text { different wavelengths) }\end{array}$ & $\begin{array}{l}\text { AERONET AOD @ 443,490,555, } 667 \mathrm{~nm} \text {, } \\
\text { Angström parameter } \\
\text { MODIS (AOD, Angstr. exponent) } \\
\text { CALIPSO }\end{array}$ & $\begin{array}{l}60-80 \\
\text { satellite } \\
\text { satellite }\end{array}$ & $\begin{array}{l}\text { AERONET } \\
\text { MODIS } \\
\text { CALIPSO }\end{array}$ & $\begin{array}{l}\mathrm{H} \\
\text { twice D } \\
\text { I }\end{array}$ & $\begin{array}{l}\text { in-situ } \\
\text { 2Dc } \\
\text { LP }\end{array}$ \\
\hline $\begin{array}{l}\text { aerosol extinction, } \\
\text { absorption and } \\
\text { scattering coefficients }\end{array}$ & $\begin{array}{l}\text { nephelometer, aethalometer } \\
\text { AERONET single scattering albedo }\end{array}$ & $\begin{array}{l}10-15 \\
60-80\end{array}$ & $\begin{array}{l}\text { EMEP, EUSAAR } \\
\text { AERONET }\end{array}$ & $\begin{array}{l}\mathrm{H} \\
\mathrm{H}\end{array}$ & $\begin{array}{l}\text { in-situ } \\
\text { in-situ }\end{array}$ \\
\hline aerosol size distribution & SMPS/DMPS & 24 & EMEP, EUSAAR & $\mathrm{H}$ & in-situ \\
\hline $\begin{array}{l}\text { aerosol composition } \\
\text { (non-refractory PM1) }\end{array}$ & $\begin{array}{l}\text { aerosol mass spectrometry } \\
\text { (AMS) }\end{array}$ & $\begin{array}{l}9 \\
\text { (campaigns) }\end{array}$ & EMEP & $\mathrm{H}$ & in-situ \\
\hline $\begin{array}{l}\text { aerosol elemental and } \\
\text { organic carbon }\end{array}$ & EC/OC monitors, thermo-optical & 18 & EMEP, EUSAAR & $\mathrm{D}, \mathrm{W}$ & in-situ \\
\hline $\begin{array}{l}\text { inorganic aerosol comp. } \\
\mathrm{NO}_{3}{ }^{-}, \mathrm{SO}_{4}{ }^{2-}, \mathrm{NH}_{4}{ }^{+}\end{array}$ & $\begin{array}{l}\text { filterpack, mini-denuders } \\
\text { MARGA }\end{array}$ & $\begin{array}{l}90 \\
2\end{array}$ & $\begin{array}{l}\text { EMEP } \\
\text { MARGA }\end{array}$ & $\begin{array}{l}\mathrm{D} \\
\mathrm{H}\end{array}$ & $\begin{array}{l}\text { in-situ } \\
\text { in-situ }\end{array}$ \\
\hline $\mathrm{O}_{3}$ & $\begin{array}{l}\text { ozone monitor } \\
\text { ozone monitor } \\
\text { MOZAIC }\end{array}$ & $\begin{array}{l}3000 \\
100 \\
\text { aircraft }\end{array}$ & $\begin{array}{l}\text { EEA Airbase } \\
\text { EMEP/EBAS } \\
\text { MOZAIC }\end{array}$ & $\begin{array}{l}\mathrm{H} \\
\mathrm{H} \\
\sim \mathrm{D}\end{array}$ & $\begin{array}{l}\text { in-situ } \\
\text { in-situ } \\
\text { LP }\end{array}$ \\
\hline $\mathrm{NO}_{2}$ & $\begin{array}{l}\mathrm{NO}_{\mathrm{x}} \text { monitors (significant interference } \\
\text { from } \mathrm{HNO}_{3}, \mathrm{PAN} \text { ) } \\
\text { chemiluminescence, filterpack, abs. } \\
\text { solution, etc. } \\
\text { satellite } \mathrm{NO}_{2} \text { columns } \\
\text { (OMI, GOME-2, SCIA) }\end{array}$ & $\begin{array}{l}3200 \\
85 \\
\text { satellite }\end{array}$ & $\begin{array}{l}\text { EEA Airbase } \\
\text { EMEP } \\
\text { TEMIS }\end{array}$ & $\begin{array}{l}\mathrm{H} \\
\mathrm{H}, \mathrm{D} \\
\sim \mathrm{D}\end{array}$ & $\begin{array}{l}\text { in-situ } \\
\text { in-situ } \\
\text { 2D }\end{array}$ \\
\hline $\mathrm{CO}$ & $\mathrm{CO}$ monitor & 1300 & EEA Airbase & $\mathrm{H}$ & in-situ \\
\hline $\mathrm{SO}_{2}$ & $\mathrm{SO}_{2}$ monitor & $\begin{array}{l}2000 \\
90\end{array}$ & $\begin{array}{l}\text { EEA Airbase } \\
\text { EMEP }\end{array}$ & $\begin{array}{l}\text { H, D } \\
\text { H, D }\end{array}$ & $\begin{array}{l}\text { in-situ } \\
\text { in-situ }\end{array}$ \\
\hline $\mathrm{HNO}_{3}, \mathrm{NH}_{3}$ & $\begin{array}{l}\text { filterpack } \\
\text { MARGA }\end{array}$ & $\begin{array}{l}90 \\
2\end{array}$ & $\begin{array}{l}\text { EMEP } \\
\text { MARGA }\end{array}$ & $\begin{array}{l}\mathrm{D}, \mathrm{W} \\
\mathrm{H}\end{array}$ & $\begin{array}{l}\text { in-situ } \\
\text { in-situ }\end{array}$ \\
\hline
\end{tabular}


Table B3. Continued.

\begin{tabular}{|c|c|c|c|c|c|}
\hline $\mathrm{OH}$ radicals & $\begin{array}{l}\text { selected ROx meas. } \\
\text { (PERCA, LIF, open path) }\end{array}$ & - & - & - & in-situ \\
\hline $\begin{array}{l}\text { wet deposition: } \mathrm{HSO}_{3-}, \mathrm{SO}_{4-} \\
-, \mathrm{NO}_{3-}, \mathrm{NH}_{4-}, \mathrm{Hg}\end{array}$ & EMEP wet deposition & 90 & EMEP & $\mathrm{W}$ & in-situ \\
\hline $\begin{array}{l}\text { dry deposition: } \mathrm{O}_{3}, \mathrm{HNO}_{3} \text {, } \\
\mathrm{NH}_{3} \text {, etc. }\end{array}$ & $\begin{array}{l}\text { no routine observations, selected eddy flux } \\
\text { campaigns }\end{array}$ & - & - & - & in-situ \\
\hline precipitation & EMEP precipitation & 90 & EMEP & W & in-stiu \\
\hline VOCs incl. isoprene & GC-MS, GC-FID & 11 & EMEP & twice W & in-situ \\
\hline soot deposition on ice & MODIS (black sky) albedo & satellite & MODIS & 8-daily & surface albedo \\
\hline $\begin{array}{l}\text { temperature, humidity, } \\
\text { wind, pressure }\end{array}$ & $\begin{array}{l}\text { SYNOP } \\
\text { RAOB }\end{array}$ & $\begin{array}{l}1300 \\
100\end{array}$ & $\begin{array}{l}\text { SYNOP } \\
\text { RAOB }\end{array}$ & $\begin{array}{l}\mathrm{H} \\
\text { twice } \mathrm{D}\end{array}$ & $\begin{array}{l}\text { in-situ } \\
\text { LP }\end{array}$ \\
\hline $\begin{array}{l}\text { SW and LW radiation at } \\
\text { ground }\end{array}$ & $\begin{array}{l}\text { global radiation (direct+diffuse), } \\
\text { longwave downward radiation }\end{array}$ & 13 & BSRN & $\mathrm{H}$ & in-situ \\
\hline $\begin{array}{l}\text { photolysis rates }\left(\mathrm{J}_{\mathrm{NO} 2}, \mathrm{~J}_{\mathrm{O} 1 \mathrm{D}}\right. \\
\text { etc. }\end{array}$ & no routine obs. available & - & - & - & - \\
\hline $\begin{array}{l}\text { precipitable water } \\
\text { (water vapour column) }\end{array}$ & $\begin{array}{l}\text { AERONET } \\
\text { RAOB }\end{array}$ & $\begin{array}{l}60-80 \\
100\end{array}$ & $\begin{array}{l}\text { AERONET } \\
\text { RAOB }\end{array}$ & $\begin{array}{l}\mathrm{H} \\
\text { twice } \mathrm{D}\end{array}$ & $\begin{array}{l}\text { in-situ, LP } \\
\text { LP }\end{array}$ \\
\hline $\begin{array}{l}\text { boundary layer } \\
\text { turbulence, TKE } \\
\text { PBL height }\end{array}$ & $\begin{array}{l}\text { selected tall tower \& FLUXNET sites } \\
\text { Radiosondes } \\
\text { Select. Lidars/Ceilometers }\end{array}$ & $\begin{array}{l}85 \\
100 \\
-\end{array}$ & $\begin{array}{l}\text { FLUXNET } \\
\text { RAOB } \\
-\end{array}$ & $\begin{array}{l}\mathrm{H} \\
\text { twice D } \\
-\end{array}$ & $\begin{array}{l}\text { in-situ } \\
\text { LP, 2D } \\
\text { - }\end{array}$ \\
\hline $\begin{array}{l}\text { cloud cover, cloud top, } \\
\text { cloud optical depth, cloud } \\
\text { base }\end{array}$ & $\begin{array}{l}\text { SEVIRI } \\
\text { MODIS } \\
\text { AVHRR } \\
\text { CALIPSO Lidar } \\
\text { Cloudnet } \\
\text { Selected Lidars, Ceilometers }\end{array}$ & $\begin{array}{l}\text { satellite } \\
\text { satellite } \\
\text { satellite } \\
\text { satellite } \\
3 \\
-\end{array}$ & $\begin{array}{l}\text { Cloudnet } \\
-\end{array}$ & $\begin{array}{l}\mathrm{H} \\
\text { twice D } \\
\mathrm{D} \\
\mathrm{I} \\
\mathrm{H} \\
\mathrm{H}\end{array}$ & $\begin{array}{l}\text { 2D } \\
2 \mathrm{D} \\
2 \mathrm{D} \\
\text { in-situ, LP } \\
\text { in-situ }\end{array}$ \\
\hline cloud liquid water path & $\begin{array}{l}\text { AERONET } \\
\text { Cloudnet }\end{array}$ & $\begin{array}{l}60-80 \\
3\end{array}$ & $\begin{array}{l}\text { AERONET } \\
\text { Cloudnet }\end{array}$ & $\begin{array}{l}\mathrm{H} \\
\mathrm{H}\end{array}$ & $\begin{array}{l}\text { in-situ, LP } \\
\text { in-situ, LP }\end{array}$ \\
\hline soil moisture & satellite soil moisture & satellite & ESA CCI & $\mathrm{D}$ & \\
\hline
\end{tabular}

Network/database acronyms and websites:

AERONET, Aerosol Robotic Network, http://aeronet.gsfc.nasa.gov/

BSRN, Baseline Surface Radiation Network, http://www.bsrn.awi.de/

CALIPSO, Cloud-Aerosol Lidar and Infrared Pathfinder, http://www-calipso.larc.nasa.gov/

Cloudnet, http://www.cloud-net.org/index.html

EEA Airbase, Air quality database of European Environmental Agency, http://acm.eionet.europa.eu/databases/airbase/

EMEP, European Monitoring and Evaluation Program, http://www.emep.int/index.html, http://ebas.nilu.no

ESA CCI soil moisture, http://www.esa-soilmoisture-cci.org/

EUCAARI, European Integrated Project on Aerosol Cloud Climate Air Quality Interactions, http://www.atm.helsinki.fi/eucaari/

EUSAAR, European Supersites for Atmospheric Aerosol Research, http://www.eusaar.net/, http://ebas.nilu.no

GPCP, Global Precipitation Climatology Project, http://www.gewex.org/gpcp.html, http://gpcc.dwd.de

MARGA, Monitor for aerosols and gases in air, http://products.metrohm.com/prod-MARGA.aspx

MODIS, Moderate Resolution Imaging Spectroradiometer, http://modis.gsfc.nasa.gov/

RAOB, WMO radiosonde observations network, http://www.esrl.noaa.gov/raobs/

SYNOP, WMO surface meteorology network, http://www.wmo.int/pages/prog/www/ois/rbsn-rbcn/rbsn-rbcn-home.html 


\section{Appendix C}

Table C1. Abbreviations and acronyms used in this article.

\begin{tabular}{|c|c|}
\hline $\mathrm{ABL}$ & Atmospheric Boundary Layer \\
\hline ACRANEB & Radiation scheme used in HARMONIE model (Ritter and Geleyn, 1992) \\
\hline ADOM & Acid Deposition and Oxidant Model \\
\hline AERO3 & 3rd generation CMAQ aerosol module \\
\hline AERO5 & 5th generation $\mathrm{CMAQ}$ aerosol module \\
\hline AERO6 & 6th generation $\mathrm{CMAQ}$ aerosol module \\
\hline AIRS & The Atmospheric Infrared Sounder (instrument on board the NASA Aqua satellite) \\
\hline ALADIN & Aire Limitée (pour l') Adaptation dynamique (par un) Développement InterNational (model and consortium) \\
\hline AOD & Aerosol Optical Depth \\
\hline $\mathrm{AQ}$ & Air Quality \\
\hline AQMEII & Air Quality Model Evaluation International Initiative \\
\hline AQUM & $\begin{array}{l}\text { Air Quality in the Unified Model: limited area forecast configuration of the UK Met Office Unified Model which uses the UKCA (UK Chemistry } \\
\text { and Aerosols) sub-model }\end{array}$ \\
\hline AROME & Application of Research to Operations at Mesoscale-model (Météo-France) \\
\hline ARW & The Advanced Research WRF solver (dynamical core) \\
\hline BEIS3 & Biogenic Emission Inventory System \\
\hline BOLAM & Meteorological hydrostatic limited area model developed at CNR-ISAC in Bologna (IT) \\
\hline BOLCHEM & Bologna limited area model for meteorology and chemistry (based on the BOLAM MetM) \\
\hline BSC & Barcelona Supercomputing Center \\
\hline BSC-CNS & Barcelona Supercomputing Center-Centro Nacional de Supercomputación \\
\hline CAC & Chemistry-Aerosol-Cloud model (tropospheric box model) \\
\hline CACM & Caltech Atmospheric Chemistry Mechanism \\
\hline CAF & Coarray Fortran \\
\hline CAM & The NCAR Community Atmospheric Model (CAM) Radiation Scheme \\
\hline CAMx & Comprehensive Air quality Model with extensions \\
\hline CAMX-AMWFG & Comprehensive Air Quality Model with Extensions - The Atmospheric Modeling and Weather Forecasting Group \\
\hline CB-IV & Carbon Bond IV (chemistry module) \\
\hline CBM-IV & The modified implementation of the Carbon Bond Mechanism version IV \\
\hline CBM-Z & CBM-Z extends the CBM-IV to include reactive long-lived species and their intermediates, isoprene chemistry, optional DMS chemistry \\
\hline CB05 & The 2005 update to the gas-phase Carbon Bond mechanism (Yarwood et al., 2005) \\
\hline CB06 & Update the Carbon-Bond chemical mechanism with new aromatic, isoprene, and inorganic reactions \\
\hline CBR & The Cuxart - Bougeault - Redelsperger turbulence closure scheme \\
\hline СCM3 & NCAR Community Climate Model (now Community Atmosphere Model - CAM) \\
\hline CCN & Cloud Condensation Nuclei \\
\hline CCTM-CMAQ & Chemistry-Transport Model of the CMAQ model \\
\hline CDNC & Cloud Droplet Number Concentration \\
\hline CDA & Chemical Data Assimilation \\
\hline CHIMERE & A multi-scale CTM for air quality forecasting and simulation \\
\hline C-IFS & Composition IFS (ECMWF) \\
\hline CISL & Cell-integrated semi-Lagrangian (transport scheme) \\
\hline CLASSIC & The Coupled Large-scale Aerosol Simulator for Studies In Climate (CLASSIC) aerosol scheme in MetUM \\
\hline CMAQ & Community Multiscale Air Quality Modelling System (US Environmental Protection Agency) \\
\hline CMAQ-MADRID & CMAQ-Model of Aerosol Dynamics, Reaction. lonization, and Dissolution \\
\hline CNR-ISAC & Institute of Atmospheric Sciences and Climate of the Italian National Research Council \\
\hline COPS & Convective and Orographically-induced Precipitation Study \\
\hline COST & European Cooperation in Science and Technology (http://www.cost.eu/) \\
\hline COSMO & Consortium for Small-Scale Modelling (LAM model formerly called LM) \\
\hline COSMO-ART & COSMO + Aerosols and Reactive Trace gases \\
\hline COSMO-MUSCAT & COSMO + Multi-Scale Chemistry Aerosol Transport (model) \\
\hline COT & Cloud Optical Thickness \\
\hline CPU & Central Processing Unit \\
\hline CTM & Chemistry-Transport Model \\
\hline CRIM & Common Representative Intermediates (CRI) mechanism \\
\hline CWF & Chemical Weather Forecasting \\
\hline CWFIS & Chemical Weather Forecasting and Information System \\
\hline DMAT & Dispersion Model for Atmospheric Transport \\
\hline DMI & Danish Meteorological Institute \\
\hline
\end{tabular}


Table C1. Continued.

\begin{tabular}{|c|c|}
\hline DREAM & Dust Regional Atmospheric Model \\
\hline DWD & German Meteorological Service \\
\hline ECMWF & European Centre of Medium-Range Weather Forecasts \\
\hline ECHAM5/6-HAMMOZ & $\begin{array}{l}\text { Global GCM ECHAM (version 5/6) + Aerosol chemistry and microphysics package HAM with additional parameterisations for } \\
\text { aerosol-cloud interactions + the atmospheric chemistry model MOZART (MPI for Meteorology, Hamburg) }\end{array}$ \\
\hline ECHAM5-HAM & Global aerosol-climate model \\
\hline ECHAM/MESSy & Atmospheric Chemistry (EMAC) Numerical chemistry and climate simulation system \\
\hline EEA/MDS & European Environment Agency/Model Documentation System \\
\hline EM & Europa-Modell (Former DWD's hydrostatic meso-alpha scale regional NWP model \\
\hline EMEP & European Monitoring and Evaluation Programme \\
\hline EnKF & Ensemble Kalman filter \\
\hline Enviro-HIRLAM & Hlgh Resolution Limited Area Model HIRLAM with chemistry (DMI) \\
\hline EQUISOLV II & Atmospheric gas-aerosol equilibrium solver \\
\hline ESCOMPTE & Expérience sur Site pour COntraindre les Modèles de Pollution atmosphérique et de Transport d'Emissions (Urban boundary layer experiment \\
\hline EuMetChem & The COST Action ES1004 - European framework for online integrated air quality and meteorology modelling \\
\hline EURAD & European Air Pollution Dispersion model \\
\hline ETA & $\begin{array}{l}\text { The ETA MetM (uses the Eta vertical coordinate), originally developed in the former Yugoslavia (Mesinger et al., 2012), it is the old version of the } \\
\text { WRF-model }\end{array}$ \\
\hline ETEX & European Tracer Experiment \\
\hline FARM & Flexible Air quality Regional Model \\
\hline FCT & Flux-corrected transport advection scheme \\
\hline GAMES & Gas Aerosol Modelling Evaluation System \\
\hline GATOR & Gas, Aerosol, TranspOrt, Radiation AQ model (Stanford University) \\
\hline GATOR-MMTD & GATOR - mesoscale meteorological and tracer dispersion model (also called GATORM) \\
\hline GAW & Global Atmosphere Watch (WMO Programme) \\
\hline GCM & General Circulation Models \\
\hline GEM & Global Environmental Multiscale model (Canadian Meteorological Centre NWP) \\
\hline GEM-AQ & GEM- + air quality processes online \\
\hline GEMS & Global and regional Earth-system (Atmosphere) Monitoring using Satellite and in-situ data \\
\hline GEOS-Chem & $\begin{array}{l}\text { GEOS-Chem is a global 3-D chemical transport model (CTM) for atmospheric composition driven by meteorological input from the Goddard Earth } \\
\text { Observing System (GEOS) of the NASA Global Modeling and Assimilation Office }\end{array}$ \\
\hline GESIMA & German non-hydrostatic modelling community \\
\hline GHG & Greenhouse gases \\
\hline GLOMAP & GLobal Model of Aerosol Processes \\
\hline GME & Global Model of DWD (DWD - German Weather Service) \\
\hline GMES & Global Monitoring for Environment and Security \\
\hline GOME & Nadir-scanning ultraviolet and visible spectrometer for global monitoring of atmospheric Ozone (on-board ERS-2) \\
\hline GPU & Graphical Processing Units \\
\hline GRAALS & radiation scheme to calculate vertical profiles of SW and LW radiative fluxes \\
\hline GURME & GAW Urban Research Meteorology and Environment Project \\
\hline HAM & Simplified global primary aerosol mechanism model \\
\hline HARMONIE & Hirlam Aladin Research on Meso-scale Operational NWP in Europe (model) \\
\hline HIRLAM & HIgh Resolution Limited Area Model (http://hirlam.org/) \\
\hline $\mathrm{HPC}$ & High Performance Computing \\
\hline IASI & Infrared Atmospheric Sounding Interferometer (onboard EUMETSAT METOP-A and then METOP-B satellite) \\
\hline IC & Initial Conditions \\
\hline ICLAMS & Integrated Community Limited Area Modeling System \\
\hline IFS & Integrated Forecast System (ECMWF) \\
\hline IN & Ice Nuclei \\
\hline ISAC & Institute of Atmospheric Sciences and Climate (Italian National Research Council - CNR) \\
\hline ISORROPIA & Thermodynamic aerosol model \\
\hline JPL-06 & Chemical Kinetics and Photochemical Data for Use in Atmospheric Studies (NASA Jet Propulsion Laboratory Publication 06-2) \\
\hline JRC-ENSEMBLE & The Joint Research Centre platform for model evaluation \\
\hline
\end{tabular}


Table C1. Continued.

\begin{tabular}{|c|c|}
\hline KIT & The Karlsruhe Institute of Technology \\
\hline KPP & Kinetic Pre-Processors \\
\hline LAI & Leaf Area Index \\
\hline LAM & Limited Area Model \\
\hline LAPS & Local Analysis and Prediction System \\
\hline LES & Large Eddy Simulation \\
\hline LMCSL & Locally Mass Conserving Semi-Lagrangian schemes (LMCSL-LL and LMCSL-3D) \\
\hline LOTOS-EUROS & LOng Term Ozone Simulation - EURopean Operational Smog model \\
\hline LW & Long-wave radiation \\
\hline M7 & Modal aerosol model \\
\hline MACC & Monitoring Atmospheric Composition and Climate (EU project) \\
\hline MADE & Modal Aerosol Dynamics model for Europe \\
\hline MADE-SORGAM & Modal Aerosol Dynamics model for Europe (MADE) with the Secondary Organic Aerosol Model \\
\hline MADEsoot & Modal aerosol module \\
\hline MADRID & Model of Aerosol Dynamics, Reaction, Ionization, and Dissolution \\
\hline MAM & Modal Aerosol Module \\
\hline MARS & Model for the Atmospheric Dispersion of Reactive Species \\
\hline MATCH & Multi-scale Atmospheric Transport and Chemistry Model \\
\hline MCCM & Multiscale Climate Chemistry Model \\
\hline MCM & Master Chemical Mechanism \\
\hline MC2 & Mesoscale Compressible Community (Canadian nonhydrostatic atmospheric model for Finescale Process Studies and Simulation) \\
\hline$M C 2-A Q$ & MC2 with air quality modelling \\
\hline MECCA & Revised MECCA1 (includes Aerosol chemistry submodule) \\
\hline MECCA1 & Module Efficiently Calculating the Chemistry of the Atmosphere (multi-purpose atmospheric chemistry model) \\
\hline MECTM & MEsoscale Chemistry Transport Model \\
\hline MEGAN & Model of Emissions of Gases and Aerosols from Nature \\
\hline MEGAPOLI & Megacities: Emissions, urban, regional and Global Atmospheric POLlution and climate effects, and Integrated tools for assessment and mitigation \\
\hline MELCHIOR & Gas phase chemistry mechanism \\
\hline MEMO & Eulerian non-hydrostatic prognostic mesoscale model (Aristotle University of Thessaloniki in collaboration with University of Karlsruhe) \\
\hline MEMO/MARS & MEMO + photochemical dispersion model MARS \\
\hline MARS-aero & $\begin{array}{l}\text { Chemistry-transport model for reactive species including four chemical reaction mechanisms for the gaseous phase, with calculation of secondary } \\
\text { aerosols, organic and inorganic }\end{array}$ \\
\hline MESIM & Mesoscale Sea Ice Model \\
\hline MESO-NH & Non-hydrostatic mesoscale atmospheric model (French research community) \\
\hline MesoNH-C & Mesoscale Nonhydrostatic Chemistry model (coupled dynamics and chemistry) \\
\hline MESOSCOP & Mesoscale flow and Cloud Model Oberpfaffenhofen ( $3 \mathrm{~d}$ model for simulating mesoscale and microscale atmospheric processes) \\
\hline MESSy & Modular Earth Submodel System \\
\hline MetChem & Meteorology-Chemistry \\
\hline MetM & Meteorological prediction model \\
\hline METRAS & MEsoscale TRAnsport and fluid (Stream) model \\
\hline MetUM & UK Met Office Unified Model \\
\hline MICTM & Mlcroscale Chemistry Transport Model \\
\hline MITRAS & Mlcroscale TRAnsport and fluid (Stream) model \\
\hline MIPAS & Michaelson Interferometer for Passive Atmospheric Sounding (Fourier transform infra-red spectrometer on the ENVISAT-1 space mission) \\
\hline MLS & Microwave Limb Sounder (on board NASA Earth Observing System Aura satellite) \\
\hline MM5 & Fifth Generation PSU/NCAR Mesoscale Model \\
\hline MM5-CAMx & MM5 - Comprehensive Air quality Model with extensions \\
\hline MM5-CHIMERE & MM5 - CHIMERE \\
\hline MM5-CHEM & MM5 + chemistry module \\
\hline MM5-CMAQ & Fifth Generation PSU/NCAR Mesoscale Model - Community Multiscale Air Quality Model \\
\hline MOCAGE & Modèle de Chimie Atmosphérique à Grande Echelle \\
\hline MOPITT & Measurements of Pollution in the Troposphere (on board NASA Terra satellite) \\
\hline MOSAIC & Model for Simulating Aerosol Interactions and Chemistry \\
\hline MOZAIC & Measurement of Ozone and water vapor by Airbus in-service airCraft \\
\hline MOZART & Model for Ozone And Related Tracers (global CTM) \\
\hline
\end{tabular}


Table C1. Continued.

\begin{tabular}{|c|c|}
\hline MOZART2, 3 and 4 & Model for Ozone And Related Tracers, version 2, 3, 4 \\
\hline MPI & Message Passing Interface \\
\hline MRF & Markov random field (diffusion scheme) \\
\hline M-SYS & Multiscale Model System consisting of components METRAS/MESIM, MITRAS, MECTM, MICTM \\
\hline MUSCAT & Multi-Scale Chemistry Aerosol Transport model \\
\hline NALROM & NOAA Aeronomy Lab Regional Oxidant Model \\
\hline NAME & Numerical Atmospheric-dispersion Modelling Environment \\
\hline NCAR & National Center for Atmospheric Research \\
\hline NCEP & National Centers for Environmental Prediction \\
\hline NMMB & Nonhydrostatic Multiscale Meteorological Model on the B grid \\
\hline NMMB/BSC-CTM & NMMB/BSC Chemical Transport Model \\
\hline NMMB/BSC-Dust & online dust model within the global-regional NCEP/NMMB NWP-model \\
\hline NRT & Near-Real Time \\
\hline NWP & Numerical Weather Prediction \\
\hline OCMC & Online Coupled Meteorology-Chemistry \\
\hline Ol & Optimal interpolation \\
\hline OMI & Ozone Monitoring Instrument (on board Aura satellite) \\
\hline OPAC & Optical Properties of Aerosols and Clouds (software library module) \\
\hline OPANA & Operational version of Atmospheric mesoscale Numerical pollution model for urban and regional Areas \\
\hline Open & MP Open Multi-Processing \\
\hline ORILAM & Three-moments aerosol scheme \\
\hline ORILAM-SOA & Organic Inorganic Lognormal Aerosol Model including Secondary Organic Aerosol \\
\hline ORISAM & Sectional aerosol model \\
\hline PAR & Photosynthetically Active Radiation \\
\hline PD-FiTE & Partial Derivative Fitted Taylor Expansion (gas/liquid equilibria in atmospheric aerosol particles) \\
\hline PEGASOS & EU FP7 project: Pan-European Gas-Aerosol-Climate interaction study (http://pegasos.iceht.forth.gr/) \\
\hline PM & Particulate Matter \\
\hline PMCAMx & $\begin{array}{l}\text { 3-D CTM simulating mass concentration and chemical composition of particulate matter (PM), based on the Comprehensive Air-quality Model } \\
\text { with Extensions (CAMx) }\end{array}$ \\
\hline PNC & Particle Number Concentration \\
\hline Polair3D/MAM & Coupled 3-D chemistry transport model Polair3D to the multiphase model MAM \\
\hline PROMOTE & PROtocol MOniToring for the GMES Service Element \\
\hline RACM & Regional Atmospheric Chemistry Mechanism \\
\hline RACM2 & RACM Version2 \\
\hline RACM-MIM & RACM with the MIM (Mainzer Isopren Mechanismus) isoprene mechanism \\
\hline RADM & Regional Acid Deposition Model \\
\hline RADM2 & the 2nd generation Regional Acid Deposition Model Mechanism \\
\hline RADMK & Gas-phase chemistry module \\
\hline RAMS & Regional Atmospheric Modeling Systems \\
\hline RAQ & Regional Air quality \\
\hline RCA-GUESS & A model of the coupled dynamics of climate, vegetation and terrestrial ecosystem biogeochemistry for regional applications (SMHI) \\
\hline RCG REM3-CALGRID & Regional Eulerian Model - California Grid Model \\
\hline RCM & Regional Climate Model \\
\hline RegCM4 & Regional Climate Model system (version4) \\
\hline ReLACS & Regional Lumped Atmospheric Chemical Scheme \\
\hline RELACS-AQ & Regional Lumped Atmospheric Chemical Scheme with aqueous phase chemistry \\
\hline RELACS2 & Regional Lumped Atmospheric Chemical Scheme Version 2 \\
\hline REMO & Regional Model \\
\hline REMOTE & Regional Model with Tracer Extension \\
\hline RK3 & Runge-Kutta of 3rd order (Horizontal advection time splitting scheme) \\
\hline RRSQRT & Reduced-rank square root Kalman filter \\
\hline RRTM & Rapid radiative transfer model (retains the highest accuracy relative to line-by-line results for single column calculations). \\
\hline
\end{tabular}


Table C1. Continued.

\begin{tabular}{|c|c|}
\hline RRTMG & RRTM for GCM Applications (provides improved efficiency with minimal loss of accuracy for GCM applications) \\
\hline SAPRC 90 & The Statewide Air Pollution Research Center, Version 1999 for gas-phase reaction mechanism for the atmospheric photooxidation (Carter, 1990) \\
\hline SAPRC99 & SAPRC Version 1999 \\
\hline SAPRC07TB & New version of the SAPRC mechanism \\
\hline SBUV & Solar backscattered ultraviolet (to monitor ozone density and distribution in the atmosphere aboard NOAA satellite) \\
\hline SCIAMACHY & $\begin{array}{l}\text { SCanning Imaging Absorption SpectroMeter for Atmospheric ChartographY (satellite spectrometer designed to measure sunlight, transmitted, reflected and } \\
\text { scattered by the earth's atmosphere or surface aboard ESA's ENVISAT). }\end{array}$ \\
\hline SEMA & Sectional Multi-component Aerosol Model \\
\hline SILAM & Air Quality and Emergency Modelling System (Finnish Meteorological Institute) \\
\hline SLCF & Short-lived Climate Forcers \\
\hline SLICE & "Semi-Lagrangian Inherently Conserving and Efficient" scheme for mass-conserving transport on the sphere \\
\hline SOA & Secondary Organic Aerosol \\
\hline SORGAM & Secondary organic aerosol formation model \\
\hline STRACO & Soft TRAnsition and Condensation (Cloud scheme) \\
\hline SW & Short Wave radiation \\
\hline TANSO & Thermal And Near Infrared Sensor for Carbon Observation (on board the greenhouse gases observing satellite GOSAT) \\
\hline THOR & An integrated air pollution forecast and scenario management system (National Environmental Research Institute (NERI), Denmark) \\
\hline TKE & Turbulent Kinetic Energy \\
\hline TM5 & Transport Model (version5) (3-D atmospheric chemistry-transport ZOOM model) \\
\hline TNO & The Netherlands Organisation for Applied Scientific Research \\
\hline TTD & Turbulent Thermal Diffusion \\
\hline TUV & Tropospheric Ultraviolet and Visible (radiation model) \\
\hline TVD & Total Variation Diminishing (discretization scheme) \\
\hline UKCA & UK Chemistry and Aerosols model \\
\hline USSR & Union of Soviet Socialist Republics \\
\hline VBS & Volatility Basis Set (approach) \\
\hline VOTALP & Vertical Ozone Transports in the ALPs campaign \\
\hline WAF & Weighted Average Flux scheme \\
\hline WMO & World Meteorological Organization \\
\hline WRF & The Weather Research and Forecasting model (NCAR) \\
\hline WRF-Chem & The Weather Research and Forecast (WRF) model coupled with Chemistry \\
\hline 3/4DVar & 3 or 4-dimensional variational assimilation \\
\hline
\end{tabular}

Table C2. Chemical species.

\begin{tabular}{|c|c|}
\hline $\mathrm{BC}$ & Black carbon \\
\hline BVOC & Biogenic volatile organic compounds \\
\hline CFC & Chlorofluorocarbon compounds (e.g. $\mathrm{CFCl}_{3}$ and $\mathrm{CF}_{2} \mathrm{Cl}_{2}$ ) \\
\hline $\mathrm{CH}_{4}$ & Methane \\
\hline $\mathrm{CO}$ & Carbon monoxide \\
\hline $\mathrm{CO}_{2}$ & Carbon dioxide \\
\hline DMS & Dimethyl sulfide \\
\hline EC & Elemental carbon \\
\hline $\mathrm{HCHO}$ & Formaldehyde \\
\hline $\mathrm{HNO}_{3}$ & Nitric acid \\
\hline $\mathrm{NH}_{3}$ & Ammonia \\
\hline NO & Nitric oxide \\
\hline $\mathrm{NO}_{2}$ & Nitrogen dioxide \\
\hline $\mathrm{NO}_{\mathrm{x}}$ & Nitrogen oxides $\left(\mathrm{NO}+\mathrm{NO}_{2}\right)$ \\
\hline $\mathrm{NO}_{3}$ & Nitrate \\
\hline $\mathrm{N}_{2} \mathrm{O}$ & Nitrous oxide \\
\hline $\mathrm{N}_{2} \mathrm{O}_{5}$ & Dinitrogen pentoxide \\
\hline$O A$ & Organic aerosols and secondary (SOA) \\
\hline OC & Organic carbon \\
\hline $\mathrm{O}_{3}$ & Ozone \\
\hline $\mathrm{OH}$ & Hydroxyl radical \\
\hline $\mathrm{PM}_{2.5}$ & Particulate matter with diameter smaller than $2.5 \mu \mathrm{m}$ \\
\hline $\mathrm{PM}_{10}$ & Particulate matter with diameter smaller than $10 \mu \mathrm{m}$ \\
\hline POA & Primary organic aerosol \\
\hline SOA & Secondary organic aerosol \\
\hline $\mathrm{SO}_{2}$ & Sulfur dioxide \\
\hline VOC & Volatile organic compounds \\
\hline
\end{tabular}

Acknowledgements. This work was realised within and supported by the COST Action ES1004 EuMetChem. Several authors of this article are grateful for the support received from the following projects: EC FP7 TRANSPHORM and PEGASOS, Nordic EnsCLIM, the RF SOL No 11.G34.31.0078 and No 14.B37.21.0880 at RSHU, the US NSF EaSM program (AGS-1049200) at NCSU, the German Science Foundation grant No SCHL-499-4, the Spanish projects "Supercomputación y eCiencia" (CSD2007-0050) and
CGL2010-19652, Estonian grants ETAG 7895 and SF0180038s08, and the NASA's Air Quality Science Team (AQAST) programme.

Acknowledgements go to Ralf Wolke (IfT Leipzig, COSMOMUSCAT); Kristian Nielsen, Ashraf Zakey and Roman Nuterman (DMI, Enviro-HIRLAM), Jacek Kaminski, Joanna Struzewska (GEM-AQ); Fabien Solmon (ICTP, RegCM), Maud Leriche, Christine Lac (Meso-NH), Malte Uphoff (Univ. Hamburg, M-SYS), Erik van Meijgaard (KNMI, RACMO2), Claas Teichmann (CSC, REMO-HAM), Bärbel Langmann (Univ. Hamburg, REMOTE), Rohit Mathur, Jon Pleim, Christian Hogrefe (US EPA, WRFCMAQ) for providing detailed information on the named model systems and for valuable comments, Carlos Pérez García-Pando for permission of his figure use, Sabine Ehrenreich for a technical support with the manuscript revision, and all COST ES1004 members for collaboration and productive discussions during COST meetings. The editor David Topping, as well as David Schultz, Jaakko Kukkonen, Mark Z. Jacobson, Shaocai Yu, Peter Builtjes, Rahul Zaveri, Carsten A. Skjoth, Paul A. Makar and 3 anonymous reviewers are thanked for thorough reviews, and for many valuable comments that substantially improved this article.

Edited by: D. Topping

\section{References}

Abdul-Razzak, H., Ghan S. J., and Rivera-Carpio, C.: A parameterization of aerosol activation: 1. Single aerosol type, J. Geophys. Res., 103, 6123-6131, 1998.

Abdul-Razzak, H. and Ghan, S. J.: Parameterization of aerosol activation. 3. Sectional representation, J. Geophys. Res., 107, 4026, doi:10.1029/2001JD000483, 2002. 
Ackermann, I. J., Hass, H., Memmesheimer, M., Ebel, A., Binkowski, F. S., and Shankar, U.: Modal aerosol dynamics model for Europe: development and first applications, Atmos. Environ., 32, 2981-2999, 1998.

Ahmadov, R., McKeen, S. A., Robinson, A. L., Bahreini, R., Middlebrook, A. M., de Gouw, J. A., Meagher, J., Hsie, E.Y. Edgerton, E., Shaw, S., and Trainer, M.: A volatility basis set model for summertime secondary organic aerosols over the eastern United States in 2006, J. Geophys. Res., 117, D06301, doi:10.1029/2011JD016831, 2012.

Alapaty K., Mathur, R., Pleim, J., Hogrefe, Ch., Rao, S. T., Ramaswamy, V., Galmarini, S., Schaap, M., Vautard, R., Makar, P., Baklanov, A., Kallos, G., Vogel, B., and Sokhi, R.: New Directions: Understanding Interactions of Air Quality and Climate Change at Regional Scales, Atmos. Environ., 49, 419-421, 2012.

Albrecht, B. A.: Aerosols, cloud microphysics, and fractional cloudiness, Science, 245, 1227-1230, 1989

Alfaro, S. C. and Gomes, L.: Modeling mineral aerosol production by wind erosion: emission intensities and aerosol size distributions in source areas, J. Geophys. Res., 106, 18075-18084, 2001.

Alheit, R. R. and Hauf, T.: Vertical transport of trace species by thunderstorms - a transilient transport model, Ber. Bunsen. Phys. Chem., 96, 501-510, 1992.

Aouizerats, B., Thouron, O., Tulet, P., Mallet, M., Gomes, L., and Henzing, J. S.: Development of an online radiative module for the computation of aerosol optical properties in 3-D atmospheric models: validation during the EUCAARI campaign, Geosci. Model Dev., 3, 553-564, doi:10.5194/gmd-3-553-2010, 2010.

Appel, K. W., Bhave, P. V., Gilliland, A. B., Sarwar, G., and Roselle, S. J.: Evaluation of the community multiscale air quality (CMAQ) model version 4.5: sensitivities impacting model performance; Part II - Particulate matter, Atmos. Environ., 42, 6057-6066, doi:10.1016/j.atmosenv.2008.03.036, 2008.

Appel, K. W., Chemel, C., Roselle, S. J., Francis, X. V., Hu, R.M., Sokhi, R. S., Rao, S. T., and Galmarini, S.: Examination of the Community Multiscale Air Quality (CMAQ) model performance over the North American and European domains, Atmos. Environ., 53, 142-155, 2012.

Arakawa, A., Jung, J.-H., and Wu, C.-M.: Toward unification of the multiscale modeling of the atmosphere, Atmos. Chem. Phys., 11, 3731-3742, doi:10.5194/acp-11-3731-2011, 2011.

Arteta, J., Cautenet, S., Taghavi, M., and Audiffren, N.: Impact of two chemistry mechanisms fully coupled with mesoscale model on the atmospheric pollutants distribution, Atmos. Environ., 40, 7983-8001, 2006.

Athanasopoulou, E., Vogel, H., Vogel, B., Tsimpidi, A. P., Pandis, S. N., Knote, C., and Fountoukis, C.: Modeling the meteorological and chemical effects of secondary organic aerosols during an EUCAARI campaign, Atmos. Chem. Phys., 13, 625-645, doi:10.5194/acp-13-625-2013, 2013.

Augustin, W., Heuveline, V., Meschkat, G., Schlünzen, K. H., and Schroeder, G.: Open MP parallelization of the METRAS meteorology model: Application to the America's Cup, Springer Berlin Heidelberg, High Performance Computing in Science and Engineering '07, 2008.

Baklanov, A.: Numerical Modelling in Mine Aerology, USSR Academy of Science, Apatity, 200 pp., 1988 (in Russian).
Baklanov, A.: Modelling of formation and dynamics of radioactive aerosols in the atmosphere, in: Research on a Theory of Elementary Particles and Solid State, vol. 4, Yaroslavl Univ., Russia, 135-148, 2003.

Baklanov, A.: Integrated meteorological and atmospheric chemical transport modeling: perspectives and strategy for HIRLAM/HARMONIE, HIRLAM Newsletter, 53, 68-78, 2008.

Baklanov, A.: Chemical weather forecasting: a new concept of integrated modelling, Adv. Sci. Res., 4, 23-27, doi:10.5194/asr-423-2010, 2010.

Baklanov, A. and Korsholm, U.: On-line integrated meteorological and chemical transport modeling: advantatges and prospectives, in: Air Pollution Modelling and its Application XIX, Springer, 3-17, doi:10.1007/978-1-4020-8453-9, 2008.

Baklanov, A. A. and Nuterman, R. B.: Multi-scale atmospheric environment modelling for urban areas, Adv. Sci. Res., 3, 53-57, doi:10.5194/asr-3-53-2009, 2009.

Baklanov, A., Fay, B., Kaminski, J., Sokhi, R., Pechinger, U., De Ridder, K., Delcloo, A., Smith Korsholm, U., Gross, A., Mannik, A., Kaasik, M., Sofiev, M., Reimer, E., Schlunzen, H., Tombrou, M., Bossioli, E., Finardi, S., Maurizi, A., Castelli, S. T., Finzi, G., Carnevale, C., Pisoni, E., Volta, M., Struzewska, J., Kaszowski, W., Godlowska, J., Rozwoda, W., Miranda, A. I., SanJose, R., Persson, C., Foltescu, V., Clappier, A., Athanassiadou, M., Hort, M. C., Jones, A., Vogel, H., Suppan, P., Knoth, O., Yu, Y., Chemel, C., Hu, R.-M., Grell, G., Schere, K., Manins, P., and Flemming, J.: Overview of existing integrated (off-line and on-line) mesoscale meteorological and chemical transport modelling systems in Europe, WMO TD No. 1427, WMO, Geneva, Switzerland, 2007.

Baklanov, A., Korsholm, U., Mahura, A., Petersen, C., and Gross, A.: ENVIRO-HIRLAM: online coupled modelling of urban meteorology and air pollution, Adv. Sci. Res., 2, 41-46, doi:10.5194/asr-2-41-2008, 2008a.

Baklanov, A., Mestayer, P. G., Clappier, A., Zilitinkevich, S., Joffre, S., Mahura, A., and Nielsen, N. W.: Towards improving the simulation of meteorological fields in urban areas through updated/advanced surface fluxes description, Atmos. Chem. Phys., 8, 523-543, doi:10.5194/acp-8-523-2008, 2008 b.

Baklanov, A., Mahura, A., and Sokhi, R. (Eds.): Integrated Systems of Meso-Meteorological and Chemical Transport Models, Springer, 242 pp., doi:10.1007/978-3-642-13980-2, 2011a.

Baklanov, A. A., Korsholm, U. S., Mahura, A. G., Nuterman, R. B., Sass, B. H., and Zakey, A. S.: Physical and chemical weather forecasting as a joint problem: two-way interacting integrated modelling, in: American Meteorological Society 91st Annual Meeting, 23-27 January 2011, Seattle, WA, USA, Paper 7.1 (Invited Speaker), AMS2011 paper 7-1 fv.pdf, 2011b.

Baldauf, M., Seifert, A., Förstner, J., Majewski, D., Raschendorfer, M., and Reinhardt, T.: Operational convective-scale numerical weather prediction with the COSMO model: description and sensitivities, Mon. Weather Rev., 139, 3887-3905, doi:10.1175/MWR-D-10-05013.1, 2011.

Bangert, M., Kottmeier, C., Vogel, B., and Vogel, H.: Regional scale effects of the aerosol cloud interaction simulated with an online coupled comprehensive chemistry model, Atmos. Chem. Phys., 11, 4411-4423, doi:10.5194/acp-11-4411-2011, 2011.

Bangert, M., Nenes, A., Vogel, B., Vogel, H., Barahona, D., Karydis, V. A., Kumar, P., Kottmeier, C., and Blahak, U.: Saharan dust 
event impacts on cloud formation and radiation over Western Europe, Atmos. Chem. Phys., 12, 4045-4063, doi:10.5194/acp-124045-2012, 2012.

Barahona, D. and Nenes, A.: Parameterization of cloud droplet formation in large scale models: including effects of entrainment, J. Geophys. Res., 112, D16206, doi:10.1029/2007JD008473, 2007.

Barahona, D. and Nenes, A.: Parameterizing the competition between homogeneous and heterogeneous freezing in ice cloud formation - polydisperse ice nuclei, Atmos. Chem. Phys., 9, 59335948, doi:10.5194/acp-9-5933-2009, 2009.

Barahona, D., West, R. E. L., Stier, P., Romakkaniemi, S., Kokkola, H., and Nenes, A.: Comprehensively accounting for the effect of giant $\mathrm{CCN}$ in cloud activation parameterizations, Atmos. Chem. Phys., 10, 2467-2473, doi:10.5194/acp-10-2467-2010, 2010.

Barbu, A. L., Segers, A. J., Schaap, M., Heemink, A. W., and Builtjes, P. J. H.: A multicomponent data assimilation experiment directed to sulphur dioxide and sulphate over Europe, Atmos. Environ., 43, 1622-1631, 2009.

Barnard, J. C., Fast, J. D., Paredes-Miranda, G., Arnott, W. P., and Laskin, A.: Technical Note: Evaluation of the WRF-Chem "Aerosol Chemical to Aerosol Optical Properties" Module using data from the MILAGRO campaign, Atmos. Chem. Phys., 10, 7325-7340, doi:10.5194/acp-10-7325-2010, 2010.

Bash, J. O., Cooter, E. J., Dennis, R. L., Walker, J. T., and Pleim, J. E.: Evaluation of a regional air-quality model with bidirectional $\mathrm{NH}_{3}$ exchange coupled to an agroecosystem model, Biogeosciences, 10, 1635-1645, doi:10.5194/bg-10-1635-2013, 2013.

Bechtold, P., Bazile, E., Guichard, F., Mascart, P., and Richard, E.: A mass-flux convection scheme for regional and global models, Q. J. Roy. Meteor. Soc., 127, 869-886, 2001.

Bechtold, P., Köhler, M., Jung, T., Doblas-Reyes, F., Leutbecher, M., Rodwell, M. J., Vitart, F., and Balsamo, G.: Advances in simulating atmospheric variability with the ECMWF model: from synoptic to decadal time-scales, Q. J. Roy. Meteor. Soc., 134634, 1337-1351, doi:10.1002/qj.289, 2008.

Beljaars, A. C. M. and Viterbo, P.: The role of the boundary layer in a numerical weather prediction model, in: Clear and Cloudy Boundary Layers, edited by: Holtslag, A. A. M. and Duynkerke, P. G., North Holland Publishers, 287-304, 1999.

Bellouin, N., Rae, J., Jones, A., Johnson, C., Haywood, J., and Boucher, O.: Aerosol forcing in the Climate Model Intercomparison Project (CMIP5) simulations by HadGEM2ES and the role of ammonium nitrate, J. Geophys. Res.-Atmos., 116, D20206, doi:10.1029/2011JD016074, 2011.

Bellouin, N., Quaas, J., Morcrette, J.-J., and Boucher, O.: Estimates of aerosol radiative forcing from the MACC re-analysis, Atmos. Chem. Phys., 13, 2045-2062, doi:10.5194/acp-13-20452013, 2013.

Bey, I., Jacob, D. J., Yantosca, R. M., Logan, J. A., Field, B., Fiore, A. M., Li, Q., Liu, H., Mickley, L. J., and Schultz, M.: Global modeling of tropospheric chemistry with assimilated meteorology: model description and evaluation, J. Geophys. Res., 106, 23073-23096, 2001.

Binkowski, F. S. and Roselle, S. J.: Models-3 Community Multiscale Air Quality (CMAQ) model aerosol component, 1. Model description, J. Geophys. Res., 108, 4183, doi:10.1029/2001JD001409, 2003.

Birch, C. E., Brooks, I. M., Tjernström, M., Shupe, M. D., Mauritsen, T., Sedlar, J., Lock, A. P., Earnshaw, P., Persson, P. O.
G., Milton, S. F., and Leck, C.: Modelling atmospheric structure, cloud and their response to $\mathrm{CCN}$ in the central Arctic: ASCOS case studies, Atmos. Chem. Phys., 12, 3419-3435, doi:10.5194/acp-12-3419-2012, 2012.

Blackadar, A. K.: The vertical distribution of wind and turbulent exchange in a neutral atmosphere, J. Geophys. Res., 67, 30953102, 1962.

Bocquet, M.: Parameter field estimation for atmospheric dispersion: applications to the Chernobyl accident using 4D-Var, Q. J. Roy. Meteor. Soc., 138, 664-681, 2011.

Bohnenstengel, S., Schlünzen, K. H., and Grawe, D.: Influence of thermal effects on street Canyon Circulations, Meteorol. Z., 13, 381-386, 2004.

Boisgontier, H., Mallet, V., Berroir, J. P., Bocquet, M., Herlin, I., and Sportisse, B.: Satellite data assimilation for air quality forecast, Simul. Model. Pract. Th., 16, 1541-1545, doi:10.1016/j.simpat.2008.01.008, 2008.

Borrego, C. and Incecik, S.: Air Pollution Modeling and Its Application XVI, Kluwer Academic/Plenum Publishers, Dordrecht, 665 pp., 2004.

Bott, A.: The monotone area-preserving flux-form advection algorithm: reducing the timesplit error in the two-dimensional flow fields, Mon. Weather Rev., 121, 2638-2641, 1993.

Bou Karam, D., Flamant, C., Cuesta, J., Pelon, J., and Williams, E.: Dust emission and transport associated with a Saharan depression: February 2007 case, J. Geophys. Res., 115, D00H27, doi:10.1029/2009JD012390, 2010.

Bretherton, C. S., McCaa, J. R., and Grenier, H.: A new parameterization for shallow cumulus convection and its application to marine subtropical cloud-topped boundary layers. Part I: Description and 1-D results, Mon. Weather Rev., 132, 864-882, 2004.

Buchholz, J., Eidelman, A., Elperin, T., Grünefeld, G., Kleeorin, N., Krein, A., and Rogachevskii, I.: Experimental study of turbulent thermal diffusion in oscillating grids turbulence, Exp. Fluids, 36, 879-887, 2004.

Burk, S. and Thompson W.: A vertically nested regional numerical weather prediction model with second order closure physics, Mon. Weather Rev., 117, 2305-2324, 1989.

Burkhardt, U. and Kärcher, B.: Global radiative forcing from contrail cirrus, Nat. Clim. Chang., 1, 54-58, doi:10.1038/NCLIMATE1068, 2011.

Buschbom, J., Gimmerthal, S., Kirschner, P., Michalczyk, I. M., Sebbenn, A., Schueler, S., Schlünzen, K. H., and Degen B.: Spatial composition of pollen-mediated gene flow in sessile oak, Forstarchiv, 83, 12-18, doi:10.4432/0300-4112-83-12, 2012.

Buzzi, A., D'Isidoro, M., and Davolio, S.: A case-study of an orographic cyclone south of the Alps during the MAP SOP, Q. J. Roy. Meteor. Soc., 129, 1795-1818, doi:10.1256/qj.02.112, 2003.

Byun, D. W.: Dynamically consistent formulations in meteorological and air quality models for multiscale atmospheric studies. Part II: Mass conservations issues, J. Atmos. Sci., 56, 38083820, 1999.

Byun, D. and Schere, K. L.: Review of the governing equations, computational algorithms, and other components of the Models3 Community Multiscale Air Quality (CMAQ) modeling system, Appl. Mech. Rev., 59, 51-77, 2006.

Carlton, A. G., Turpin, B. J., Altieri, K. E., Seitzinger, S. P., Mathur, R., Roselle, S. J., and Weber, R. J.: CMAQ model performance 
enhanced when in-cloud secondary organic aerosol is included: comparisons of organic carbon prediction with measurements, Environ. Sci. Technol., 42, 8798-8802, 2008.

Carmichael, G. R., Sandu, A., Chai, T., Daescu, D. N., Constantinescu, E. M., and Tang, Y.: Predicting air quality: improvements through advanced methods to integrate models and measurements, J. Comput. Phys., 227, 3540-3571, 2008.

Carnevale, C., Decanini, E., and Volta, M.: Design and validation of a multiphase 3-D model to simulate tropospheric pollution, Sci. Total Environ., 390, 166-176, 2008.

Carslaw, K. S., Boucher, O., Spracklen, D. V., Mann, G. W., Rae, J. G. L., Woodward, S., and Kulmala, M.: A review of natural aerosol interactions and feedbacks within the Earth system, Atmos. Chem. Phys., 10, 1701-1737, doi:10.5194/acp-10-17012010, 2010

Carter, W. P. L.: A detailed mechanism for the gas-phase atmospheric reactions of organic compounds, Atmos. Environ., 24, 481-518, doi:10.1016/0960-1686(90)90005-8, 1990.

Carter, W. P. L.: Documentation of the SAPRC-99 Chemical Mechanism for VOC Reactivity Assessment, Report to the California Air Resources Board, College of Engineering, Center for Environmental Research and Technology, University of California, Riverside, CA, 2000.

Carter, W. P. L.: Development of the SAPRC-07 chemical mechanism, Atmos. Environ., 44, 5324-5335, 2010.

Chai, T., Carmichael, G. R., Sandu, A., Tang, Y., and Daescu, D. N.: Chemical data assimilation of Transport and Chemical Evolution over the Pacific (TRACE-P) aircraft measurements, J. Geophys. Res., 111, D02301, doi:10.1029/2005JD005883, 2006.

Chaboureau, J.-P., Richard, E., Pinty, J.-P., Flamant, C., Di Girolamo, P., Kiemle, C., Behrendt, A., Chepfer, H., Chiriaco, M., and Wulfmeyer, V.: Long-range transport of Saharan dust and its radiative impact on precipitation forecast: a case study during the Convective and Orographically-induced Precipitation Study (COPS), Q. J. Roy. Meteor. Soc., 137, 236-251, doi:10.1002/qj.719, 2011.

Chang, J. S., Brost, R. A., Isaksen, I. S. A., Madronich, S., Middleton, P., Stockwell, W. R., and Walcek, C. J.: A three dimensional Eulerian acid deposition model: physical concepts and formulation, J. Geophys. Res., 92, 14681-14700, 1987.

Chapman, E. G., Gustafson Jr., W. I., Easter, R. C., Barnard, J. C., Ghan, S. J., Pekour, M. S., and Fast, J. D.: Coupling aerosolcloud-radiative processes in the WRF-Chem model: Investigating the radiative impact of elevated point sources, Atmos. Chem. Phys., 9, 945-964, doi:10.5194/acp-9-945-2009, 2009.

Charnock, H.: Wind stress on a water surface, Q. J. Roy. Meteor. Soc., 81, 639-640, 1955.

Chen, C. and Cotton, W. R.: A one-dimensional simulation of the stratocumulus-capped mixed layer, Bound.-Lay. Meteorol., 25, 289-321, 1983.

Chen, J., Griffin, R. J., Grini, A., and Tulet, P.: Modeling secondary organic aerosol formation through cloud processing of organic compounds, Atmos. Chem. Phys., 7, 5343-5355, doi:10.5194/acp-7-5343-2007, 2007.

Chen, K. S., Ho, Y. T., Lai, C. H., and Chou, Y.-M.: Photochemical modeling and analysis of meteorological parameters during ozone episodes in Kaohsiung, Taiwan, Atmos. Environ., 37, 1811-1823, 2003.
Chenevez, J., Baklanov, A., and Sørensen, J. H.: Pollutant transport schemes integrated in a numerical weather prediction model: model description and verification results, Meteorol. Appl., 11, 265-275, 2004.

Ching, J., Riemer, N., and West, M.: Impacts of black carbon mixing state on black carbon nucleation scavenging - Insights from a particle-resolved model, J. Geophys. Res., 117, D23209, doi:10.1029/2012JD018269, 2012.

Cohard, J. M. and Pinty, J. P.: A comprehensive two-moment warm microphysical bulk scheme. Part I: Description and selective tests, Q. J. Roy. Meteor. Soc., 126, 1815-1842, 2000.

Coleman, Martin, L. D., Varghese, S., Jennings, S. G., and O'Dowd, C. D.: Assessment of changing meteorology and emissions on air quality using a regional climate model: impact on ozone, Atmos. Environ., 69, 198-210, 2013.

Colette, A., Granier, C., Hodnebrog, Ø., Jakobs, H., Maurizi, A., Nyiri, A., Bessagnet, B., D’Angiola, A., D'Isidoro, M., Gauss, M., Meleux, F., Memmesheimer, M., Mieville, A., Rouïl, L., Russo, F., Solberg, S., Stordal, F., and Tampieri, F.: Air quality trends in Europe over the past decade: a first multi-model assessment, Atmos. Chem. Phys., 11, 11657-11678, doi:10.5194/acp11-11657-2011, 2011.

Colette, A., Bessagnet, B., Vautard, R., Szopa, S., Rao, S., Schucht, S., Klimont, Z., Menut, L., Clain, G., Meleux, F., Curci, G., and Rouil, L.: European atmosphere in 2050, a regional air quality and climate perspective under CMIP5 scenarios, Atmos. Chem. Phys., 13, 7451-7471, doi:10.5194/acp-13-7451-2013, 2013.

Collins, W. J., Stevenson, D. S., Johnson, C. E., and Derwent, R. G.: Tropospheric ozone in a global-scale three-dimensional Lagrangian model and its response to NOX emission controls, J. Atmos. Chem., 26, 223-274, 1997.

Collins, W. J., Stevenson, D. S., Johnson, C. E., and Derwent, R. G.: Role of convection in determining the budget of odd hydrogen in the upper troposphere, J. Geophys. Res., 104, 26927-26941, 1999.

Collins, W. D., Rasch, P. J., Eaton, B. E., Khattatov, B. V., Lamarque, J.-F., and Zender, C. S.: Simulating aerosols using a chemical transport model with assimilation of satellite aerosol retrievals: methodology for INDOEX, J. Geophys. Res., 106, 7313-7336, 2001.

Collins, W. J., Bellouin, N., Doutriaux-Boucher, M., Gedney, N., Halloran, P., Hinton, T., Hughes, J., Jones, C. D., Joshi, M., Liddicoat, S., Martin, G., O'Connor, F., Rae, J., Senior, C., Sitch, S., Totterdell, I., Wiltshire, A., and Woodward, S.: Development and evaluation of an Earth-System model - HadGEM2, Geosci. Model Dev., 4, 1051-1075, doi:10.5194/gmd-4-10512011, 2011.

Conant, W. C., Nenes, A., and Seinfeld, J. H.: Black carbon radiative heating effects on cloud microphysics and implications for aerosol indirect forcing, 1, Extended Köhler theory, J. Geophys. Res., 107, 4604, doi:10.1029/2002JD002094, 2002.

Cooter, E. J., Bash, J. O., Benson, V., and Ran, L.: Linking agricultural crop management and air quality models for regional to national-scale nitrogen assessments, Biogeosciences, 9, 40234035, doi:10.5194/bg-9-4023-2012, 2012.

Côté, J., Gravel, S., Méthot, A., Patoine, A., Roch, A., and Staniforth, A.: The operational CMC- MRB global environmental multiscale (GEM) model. Part I: Design considerations and formulation, Mon. Weather Rev., 126, 1373-1395, 1998. 
Cotton, W. R., Pielke Sr., R. A., Walko, R. L., Liston, G. E., Tremback, C. J., Jiang, H., McAnelly, R. L., Harrington, J. Y., Nicholls, M. E., Carrio, G. G., and Mc Fadden, J. P.: RAMS2001: current status and future directions, Meteorol. Atmos. Phys., 82, $5-29,2003$.

Cousin, F., Liousse, C., Cachier, H., Bessagnet, B., Guillaume, B., and Rosset, R.: Aerosol modelling and validation during ESCOMPTE 2001, Atmos. Environ., 39, 1539-1550, 2004.

Couvidat, F., Sartelet, K., and Seigneur, C. Investigating the impact of aqueous-phase chemistry and wet deposition on organic aerosol formation using a molecular surrogate modeling approach, Environ. Sci. Technol., 47, 914-922, 2013.

Crassier, V., Suhre, K., Tulet, P., and Rosset, R.: Development of a reduced chemical scheme for use in mesoscale meteorological models, Atmos. Environ., 34, 2633-2644, 2000.

Crumeyrolle, S., Gomes, L., Tulet, P., Matsuki, A., Schwarzenboeck, A., and Crahan, K.: Increase of the aerosol hygroscopicity by cloud processing in a mesoscale convective system: a case study from the AMMA campaign, Atmos. Chem. Phys., 8, 6907-6924, doi:10.5194/acp-8-6907-2008, 2008.

Cubison, M. J., Ervens, B., Feingold, G., Docherty, K. S., Ulbrich, I. M., Shields, L., Prather, K., Hering, S., and Jimenez, J. L.: The influence of chemical composition and mixing state of Los Angeles urban aerosol on CCN number and cloud properties, Atmos. Chem. Phys., 8, 5649-5667, doi:10.5194/acp-8-5649-2008, 2008.

Cuxart, J., Bougeault, P., and Redelsperger, J. L.: A turbulence scheme allowing for mesoscale and large-eddy simulations, Q. J. Roy. Meteor. Soc., 126, 1-30, doi:10.1002/qj.49712656202, 2000.

D’Almeida, G. A., Koepke, P., and Shettle E. P.: Atmospheric aerosols: global climatology and radiative characteristics, A. Deepak Publishing, 561 pp., 1991.

Dandou, A., Tombrou, M., Schäfer, K., Emeis, S., Protonotariou, A. P., Bossioli, E., Soulakellis, N., and Suppan, P.: A comparison between modelled and measured mixing-layer height over Munich, Bound.-Lay. Meteorol., 131, 425-440, doi:10.1007/s10546-0099373-7, 2009.

Damian, V., Sandu, A., Damian, M., Potra, F., and Carmichael, G. R.: The Kinetic PreProcessor KPP - a software environment for solving chemical kinetics, Comput. Chem. Eng., 26, 1567-1579, 2002.

Davies, T., Cullen, M. J., Malcolm, A. J., Mawson, M. H., Staniforth, A., White, A. A., and Wood, N.: A new dynamical core for the Met Office's global and regional modeling of the atmosphere, Q. J. Roy. Meteor. Soc., 131, 1759-1782, doi:10.1256/qj.04.101, 2005.

De Leeuw, G., Andreas, E. L., Anguelova, M. D., Fairall, C. W., Lewis, E. R., O'Dowd, C., Schulz, M., and Schwarz, S. E.: Production of sea spray aerosol, Rev. Geophys., 49, RG2001, doi:10.1029/2010RG000349, 2011.

DeMott, P. J., Prenni, A. J., Liu, X., Kreidenweis, S. M., Petters, M. D., Twohy, C. H., Richardson, M. S., Eidhammer, T., and Rogers, D. C.: Predicting global atmospheric ice nuclei distributions and their impacts on climate, P. Natl. Acad. Sci. USA, 107, 1121711222, 2010.

Denier van der Gon, H. A. C., Visschedijk, A. J. H., Johansson, C., Hedberg Larsson, E., Harrison, R., and Beddows, D.: Sizeresolved pan European anthropogenic particle number inventory,
EUCAARI Deliverable report D141 (available on request from EUCAARI project office), 2009.

Dennis, R., Fox, T., Fuentes, M., Gilliland, A., Hanna, S., Hogrefe, C., Irwin, J., Rao, S., Scheffe, R., Schere, K., Steyn, D., and Venkatram, A.: A framework for evaluating regional- scale numerical photochemical modeling systems, Environ. Fluid Mech., 10, 471-489, doi:10.1007/s10652-009-9163-2, 2010.

Dergaoui, H., Debry, É., Sartelet, K., and Seigneur, C.: Modeling coagulation of externally mixed particles: sectional approach for both size and chemical composition, J. Aerosol Sci., 58, 17-32, 2013.

Dickerson, R. R., Kondragunta, S., Stenchikov, G., Civerolo, K. L., Doddridge, B. G., and Holben, B. N.: The impact of aerosols on solar ultraviolet radiation and photochemical smog, Science, 278, 827-830, 1997.

Donahue, N. M., Robinson, A. L., Stanier, C. O., and Pandis, S. N.: Coupled partitioning, dilution, and chemical aging of semivolatile organics, Environ. Sci. Technol., 40, 2635-2643, 2006.

Donahue, N. M., Epstein, S. A., Pandis, S. N., and Robinson, A. L.: A two-dimensional volatility basis set: 1. organic-aerosol mixing thermodynamics, Atmos. Chem. Phys., 11, 3303-3318, doi:10.5194/acp-11-3303-2011, 2011.

Edwards, J. M. and Slingo, A.: Studies with a flexible new radiation code. I: Choosing a configuration for a large-scale model, Q. J. Roy. Meteor. Soc., 122, 689-719, 1996.

Elbern, H. and Schmidt, H.: Ozone episode analysis by four dimensional variational chemistry data assimilation, J. Geophys. Res., 106, 3569-3590, 2001.

Elbern, H., Schmidt, H., and Ebel, A.: Variational data assimilation for tropospheric chemistry modeling, J. Geophys. Res., 102, 15967-15985, 1997.

Elbern, H., Strunk, A., Schmidt, H., and Talagrand, O.: Emission rate and chemical state estimation by 4-dimensional variational inversion, Atmos. Chem. Phys., 7, 3749-3769, doi:10.5194/acp7-3749-2007, 2007.

Elperin, T., Kleeorin, N., and Rogachevskii, I.: Turbulent thermal diffusion of small inertial particles, Phys. Rev. Lett., 76, 224 228, 1996.

Emeis, S., Forkel, R., Junkermann, W., Schäfer, K., Flentje, H., Gilge, S., Fricke, W., Wiegner, M., Freudenthaler, V., Groß, S., Ries, L., Meinhardt, F., Birmili, W., Münkel, C., Obleitner, F., and Suppan, P.: Measurement and simulation of the 16/17 April 2010 Eyjafjallajökull volcanic ash layer dispersion in the northern Alpine region, Atmos. Chem. Phys., 11, 2689-2701, doi:10.5194/acp-11-2689-2011, 2011.

Emmons, L. K., Walters, S., Hess, P. G., Lamarque, J.-F., Pfister, G. G., Fillmore, D., Granier, C., Guenther, A., Kinnison, D., Laepple, T., Orlando, J., Tie, X., Tyndall, G., Wiedinmyer, C., Baughcum, S. L., and Kloster, S.: Description and evaluation of the Model for Ozone and Related chemical Tracers, version 4 (MOZART-4), Geosci. Model Dev., 3, 43-67, doi:10.5194/gmd3-43-2010, 2010.

Engelen, R. J. and Bauer, P.: The use of variable $\mathrm{CO} 2$ in the data assimilation of AIRS and IASI radiances, Q. J. Roy. Meteor. Soc., 138, doi:10.1002/qj.919, 2011.

Eppel, D., Kapitza, H., Claussen, M., Jacob, D., Levkov, L., Mengelkamp, H.-T., and Werrmann, N.: The non-hydrostatic model 
GESIMA: Part II: parameterizations and application, Beitr. Phys. Atmos., 68, 15-41, 1995.

Ervens, B. and Volkamer, R.: Glyoxal processing by aerosol multiphase chemistry: towards a kinetic modeling framework of secondary organic aerosol formation in aqueous particles, Atmos. Chem. Phys., 10, 8219-8244, doi:10.5194/acp-10-8219-2010, 2010.

Ervens, B., Turpin, B. J., and Weber, R. J.: Secondary organic aerosol formation in cloud droplets and aqueous particles (aqSOA): a review of laboratory, field and model studies, Atmos. Chem. Phys., 11, 11069-11102, doi:10.5194/acp-1111069-2011, 2011.

Faraji, M., Kimura, Y., McDonald-Buller, E., and Allen, D.: Comparison of the carbon and SAPRC photochemical mechanisms under conditions relevant to southeast Texas, Atmos. Environ., 42, 5821-5836, 2008.

Farina, S. C., Adams, P. J., and Pandis, S. N.: Modeling global secondary organic aerosol formation and processing with the volatility basis set: implications for anthropogenic secondary organic aerosol, J. Geophys. Res., 115, D09202, doi:10.1029/2009JD013046, 2010.

Fast, J. D., Gustafson Jr., W. I., Easter, R. C., Zaveri, R. A., Barnard, J. C., Chapman, E. G., and Grell, G. A.: Evolution of ozone, particulates, and aerosol direct forcing in an urban area using a new fully-coupled meteorology, chemistry, and aerosol model, J. Geophys. Res., 111, D21305, doi:10.1029/2005JD006721, 2006.

Fine, J., Vuilleumier, L, Reynolds, S., Roth, P., and Brown, N.: Evaluating uncertainties in regional photochemical air quality modeling, Annu. Rev. Env. Resour, 28, 59-106, 2003.

Fitzgerald, J. W.: Dependence of the Supersaturation Spectrum of CCN on Aerosol Size Distribution and Composition, J. Atmos. Sci., 30, 628-634, 1973.

Flanner, M. G., Zender, C. S., Hess, P. G., Mahowald, N. M., Painter, T. H., Ramanathan, V., and Rasch, P. J.: Springtime warming and reduced snow cover from carbonaceous particles, Atmos. Chem. Phys., 9, 2481-2497, doi:10.5194/acp-9-24812009, 2009

Flemming, J., Stern, R., and Yamartino, R. J.: A new air quality regime classification scheme for $\mathrm{O}_{3}, \mathrm{NO}_{2}, \mathrm{SO} 2$ and $\mathrm{PM}_{10}$ observations sites, Atmos. Environ., 39, 6121-6129, 2005.

Flemming, J., Inness, A., Flentje, H., Huijnen, V., Moinat, P., Schultz, M. G., and Stein, O.: Coupling global chemistry transport models to ECMWF's integrated forecast system, Geosci. Model Dev., 2, 253-265, doi:10.5194/gmd-2-253-2009, 2009.

Folberth G. A., Rumbold, S., Collins, W. J., and Butler, T.: Regional and Global Climate Changes due to Megacities using Coupled and Uncoupled Models, D6.6, MEGAPOLI Scientific Report 1107, MEGAPOLI-33-REP-2011-06, 18 pp., 2011.

Foreman, R. and Emeis, S.: Revisiting the definition of the drag coefficient in the marine atmospheric boundary layer, J. Phys. Oceanogr., 40, 2325-2332, 2010.

Forkel, R. and Knoche, R.: Regional climate change and its impact on photooxidant concentrations in southern Germany: simulations with a coupled regional climate-chemistry model, J. Geophys. Res., 111, D12302, doi:10.1029/2005JD006748, 2006.

Forkel, R., Werhahn, J., Hansen, A. B., McKeen, S., Peckham, S., Grell, G., and Suppan, P.: Effect of aerosol-radiation feedback on regional air quality - a case study with WRF/Chem, Atmos. Environ., 53, 202-211, 2012.
Fortuin, J. P. F. and Langematz, U.: An update on the global ozone climatology and on concurrent ozone and temperature trends, P. Soc. Photo-Opt. Ins., 2311, 207-216, 1994.

Fountoukis, C. and Nenes, A.: Continued development of a cloud droplet formation parameterization for global climate models, $\mathrm{J}$ Geophys. Res., 110, D11212, doi:10.1029/2004JD005591, 2005.

Fountoukis, C. and Nenes, A.: ISORROPIA II: a computationally efficient thermodynamic equilibrium model for $\mathrm{K}^{+}$. $\mathrm{Ca}^{2+}-\mathrm{Mg}^{2+}-\mathrm{NH}^{+}-\mathrm{Na}^{+}-\mathrm{SO}^{2-}-\mathrm{NO}^{-}-\mathrm{Cl}^{-}-\mathrm{H}$ O aerosols, Atmos. Chem. Phys., 7, 4639-4659, doi:10.5194/acp-7-4639-2007, 2007.

Fouquart, Y. and Bonnel, B.: Computation of solar heating of the earth's atmosphere: a new parameterisation, Contrib. Atmos. Phys., 53, 35-63, 1980.

Galmarini, S., Rao, S. T., and Steyn, D. G.: AQMEII: an international initiative for the evaluation of regiona-scale air quality models - Phase 1, preface, Atmos. Environ., 53, 1-3, doi:10.1016/j.atmosenv.2012.03.001, 2012.

Gantt, B., Meskhidze, N., Zhang, Y., and Xu, J.: The Effect of Oceanic Isoprene Emissions on Secondary Organic Aerosol and Ozone Formation in the Coastal United States, Atmos. Environ., $44,115-121,2010$.

Garand, L.: Some improvements and complements to the infrared emissivity algorithm including a parameterization of the absorption in the continuum region, J. Atmos. Sci., 40, 230-244, 1983.

Garand, L. and Mailhot, J.: The influence of infrared radiation on numerical weather forecasts, in: Preprints 7 th Conference on Atmospheric Radiation, 23-27 July 1990, San Francisco, California, 146-151, 1990.

Geiger, H., Barnes, I., Bejan, I., Benter, T., and Spittler, M.: The tropospheric degradation of isoprene: an updated module for the regional atmospheric chemistry mechanism, Atmos. Environ., 37, 1503-1519, doi:10.1016/S1352-2310(02)01047-6, 2003.

Generoso, S., Bréon, F.-M., Chevallier, F., Balkanski, Y., Schulz, M., and Bey, I.: Assimilation of POLDER aerosol optical thickness into the LMDz-INCA model: implications for the Arctic aerosol burden, J. Geophys. Res., 112, D02311, doi:10.1029/2005JD006954, 2007

Gerard, L., Piriou, J.-M., Brozkova, R., Geleyn, J.-F., and Banciu D.: Cloud and Precipitation Parameterization in a MesoGamma_scale Operational Weather Prediction Model, Mon. Wea. Rev., 137, 3960-3977, 2009

Gery, M. W., Whitten, G. Z., Killus, J. P., and Dodge, M. C.: A photochemical kinetics mechanism for urban and regional scale computer modelling, J. Geophys. Res., 94, 12925-12956, 1989.

Gettelman, A., Liu, X., Ghan, S. J., Morrison, H., Park, S., Conley, A. J., Klein, S. A., Boyle, J., Mitchell, D. L., and Li, J. L. F.: Global simulations of ice nucleation and ice supersaturation with an improved cloud scheme in the Community Atmosphere Model, J. Geophys. Res., 115, D18216, doi:10.1029/2009jd013797, 2010.

Ghan, S. J., Leung, L. R., Easter, R. C., and Abdul-Razzak, H.: Prediction of droplet number in a general circulation model, J. Geophys. Res., 102, 21777-21794, 1997.

Gilliland, A. B., Hogrefe, C., Pinder, R. W., Godowitch, J. M., Foley, K. L., and Rao, S. T.: Dynamic evaluation of regional air quality models: assessing changes in $\mathrm{O}_{3}$ stemming from changes in emissions and meteorology, Atmos. Environ., 42, 5110-5123, doi:10.1016/j.atmosenv.2008.02.018, 2008 
Giorgi, F., Marinucci, M. R., and Bates, G. T.: Development of a second generation regional climate model $(\mathrm{reg} \mathrm{cm} 2)$ in: boundary layer and radiative transfer processes, Mon. Weather Rev., 121, 2794-2813, 1993.

Giorgi, F., Bi, X., and Qian, Y.: Direct radiative forcing and regional climatic effects of anthropogenic aerosols over east Asia: a regional coupled climate-chemistry/aerosol model study, J. Geophys. Res., 107, 4439, doi:10.1029/2001JD001066, 2002.

Giorgi, F., Bi, X., and Qian, Y.: Indirect vs. direct effects of anthropogenic sulfate on the climate of east asia as simulated with a regional coupled climate-chemistry/aerosol model, Climate Change, 58, 345-376, 2003.

Givati, A. and Rosenfeld, D.: Quantifying precipitation suppression due to air pollution, J. Appl. Meteorol., 43, 1038-1056, 2004.

Godowitch, J. M., Gilliam, R. C., and RAO, S. T.: Diagnostic evaluation of ozone production and horizontal transport in a regional photochemical Air Quality Modeling System, Atmos. Environ., 45, 3977-3987, doi:10.1016/j.atmosenv.2011.04.062, 2011.

Gong, W., Stroud, C., and Zhang, L.: Cloud processing of gases and aerosols in air quality modeling, Atmosphere, 2, 567-616, 2011.

Grawe, D., Thompson, H. L., Salmond, J. A., Caia, X.-M., and Schlünzen, K. H.: Modelling the impact of urbanization on regional climate in the Greater London Area, Int. J. Climatol., 32, 2388-2401, doi:10.1002/joc.3589, 2012.

Grell, G. A.: Prognostic evaluation of assumptions used by cumulus parameterizations within a generalized framework, Mon. Weather Rev., 121, 764-787, 1993.

Grell, G. A.: Coupled weather chemistry modeling, in: Large-Scale Disasters: Prediction, Control, Mitigation, edited by: Gad-elHak, M., Cambridge University Press, 302-317, 2008.

Grell, G. A. and Baklanov, A.: Integrated modelling for forecasting weather and air quality: a call for fully coupled approaches, Atmos. Environ., 45, 6845-6851, 2011.

Grell, G. A. and Devenyi, D.: A generalized approach to parameterizing convection combining ensemble and data assimilation techniques, Geophys. Res. Lett., 29, 38-1-38-4, doi:10.1029/2002GL015311, 2002.

Grell, G. A. and Freitas, S. R.: A scale and aerosol aware stochastic convective parameterization for weather and air quality modeling, Atmos. Chem. Phys. Discuss., 13, 23845-23893, doi:10.5194/acpd-13-23845-2013, 2013.

Grell, G. A., Dudhia, J., and Stauffer, D. R.: A description of the fifth-generation Penn State/NCAR Mesoscale Model (MM5), NCAR/TN-398+STR, National Center for Atmospheric Research, Boulder, CO, 138 pp., 1994.

Grell, G. A., Emeis, S., Stockwell, W. R., Schoenemeyer, T., Forkel, R., Michalakes, J., Knoche, R., and Seidl, W.: Application of a multiscale, coupled MM5/chemistry model to the complex terrain of the VOTALP valley campaign, Atmos. Environ., 34, 1435-1453, 2000.

Grell, G. A., Knoche, R., Peckham, S. E., and McKeen, S.: Online versus offline air quality modeling on cloud-resolving scales, Geophys. Res. Lett., 31, L16117, doi:10.1029/2004GL020175, 2004

Grell, G. A., Peckham, S. E., Schmitz, R., McKeen, S. A., Frost, G., Skamarock, W. C., and Eder, B.: Fully coupled online chemistry within the WRF model, Atmos. Environ., 39, 6957-6975, 2005.

Grell, G., Freitas, S. R., Stuefer, M., and Fast, J.: Inclusion of biomass burning in WRF-Chem: impact of wildfires on weather forecasts, Atmos. Chem. Phys., 11, 5289-5303, doi:10.5194/acp11-5289-2011, 2011.

Griffin, R. J., Dabdub, D., and Seinfeld, J. H.: Secondary organic aerosol 1. Atmospheric chemical mechanism for production of molecular constituents, J. Geophys. Res., 107, 4342, doi:10.1029/2001JD000541, 2002.

Grini, A., Thulet, P., and Gomes, L.: Dusty weather forecasts using the MesoNH mesoscale atmospheric model, J. Geophys. Res., 111, 2156-2202, doi:10.1029/2005JD007007, 2006.

Gross, A. and Baklanov, A.: Modelling the influence of dimethyl sulphid on the aerosol production in the marine boundary layer, Int. J. Environ. Pollut., 22, 51-71, 2004.

Guenther, A. B., Monson, R. K., and Fall, R.: Isoprene and monoterpene emission rate variability: observations with Eucalyptus and emission rate algorithm development, J. Geophys. Res., 96, 10799-10808, doi:10.1029/91JD00960, 1991.

Guenther, A. B., Zimmerman, P. R., Harley, P. C., Monson, R. K., and Fall, R.: Isoprene and monoterpene emission rate variability: model evaluations and sensitivity analyses, J. Geophys. Res., 98, 12609-12617, 1993.

Guenther, A., Hewitt, C. N., Erickson, D., Fall, R., Geron, C., Graedel, T., Harley, P., Klinger, L., Lerdau, M., McKay, W. A., Pierce, T., Scholes, B., Steinbrecher, R., Tallamraju, R., Taylor, J., and Zimmerman, P.: A global model of natural volatile organic compound emissions, J. Geophys. Res., 100, 8873-8892, doi:10.1029/94jd02950, 1995.

Guenther, A., Karl, T., Harley, P., Wiedinmyer, C., Palmer, P. I., and Geron, C.: Estimates of global terrestrial isoprene emissions using MEGAN (Model of Emissions of Gases and Aerosols from Nature), Atmos. Chem. Phys., 6, 3181-3210, doi:10.5194/acp-63181-2006, 2006.

Guenther, A. B., Jiang, X., Heald, C. L., Sakulyanontvittaya, T., Duhl, T., Emmons, L. K., and Wang, X.: The Model of Emissions of Gases and Aerosols from Nature version 2.1 (MEGAN2.1): an extended and updated framework for modeling biogenic emissions, Geosci. Model Dev., 5, 1471-1492, doi:10.5194/gmd-51471-2012, 2012.

Gustafson Jr., W. I., Chapman, E. G., Ghan, S. J., and Fast, J. D. Impact on modeled cloud characteristics due to simplified treatment of uniform cloud condensation nuclei during NEAQS 2004, Geophys. Res. Lett., 34, L19809, doi:10.1029/2007GL030021, 2007.

Halmer, G.: Umfassendes Modell für den Einfluss des Aerosols auf die Vorgänge in der Atmosphäre von Ballungsgebieten, Dissertation, Karlsruher Institut für Technologie (KIT), Fak. f. Maschinenbau, Karlsruhe, 2012.

Halmer, G., Douros, I., Tsegas, G., and Moussiopoulos, N.: Using a coupled meteorological and chemical transport modelling scheme to evaluate the impact of the aerosol direct effect on pollutant concentration fields in Paris, in: Proceedings of the 31th NATO/SPS International Technical Meeting on Air Pollution Modelling and its Application (ITM2010), Turin, Italy, 27 September-1 October, 1.4, 2010.

Hansen, J. and Nazarenko, L.: Soot climate forcing via snow and ice albedos, P. Natl. Acad. Sci. USA, 101, 423-428, 2004.

Hansen, J. E., Sato, M., and Ruedy, R.: Radiative forcing and climate response, J. Geophys. Res., 102, 6831-6864, 1997.

Harrington, J. Y.: The Effects of Radiative and Microphysical Processes on Simulated Warm and Transition Season Arctic Stratus, 
Ph.D. Thesis, Colorado State University, Ft. Collins, CO, 298 pp., 1997.

Hegg, D. A. and Hobbs, P. V.: Cloud condensation nuclei in the marine atmosphere: a review, in: Nucleation and Atmospheric Aerosols, Deepak Publishing, Hampton, VA, 181-192, 1992.

Heinold, B., Helmert, J., Hellmuth, O., Wolke, R., Ansmann, A., Marticorena, B., Laurent, B., and Tegen I.: Regional modeling of Saharan dust events using LM-MUSCAT: model description and case studies, J. Geophys. Res., 112, D11204, doi:10.1029/2006JD007443, 2007.

Heinold, B., Tegen, I., Schepanski, K., and Hellmuth, O.: Dust radiative feedback on Saharan boundary layer dynamics and dust mobilization, Geophys. Res. Lett., 35, L20817, doi:10.1029/2008GL035319, 2008.

Heinold, B., Tegen, I., Esselborn, M., Kandler, K., Knippertz, P., Müller, D., Schladitz, A., Tesche, M., Weinzierl, B., Ansmann, A., Althausen, D., Laurent, B., Maßling, A., Müller, T., Petzold, A., Schepanski, K., and Wiedensohler, A.: Regional Saharan dust modelling during the SAMUM 2006 campaign, Tellus B, 61, 307-324, doi:10.1111/j.1600-0889.2008.00387.x, 2009.

Heinold, B., Tegen, I., Bauer, S., and Wendisch, M.: Regional modelling of Saharan dust and biomass-burning smoke Part 2: Direct radiative forcing and atmospheric dynamic response, Tellus B, 63, 800-813, 2011a.

Heinold, B., Tegen, I., Schepanski, K., Tesche, M., Esselborn, M., Freudenthaler, V., Gross, S., Kandler, K., Knippertz, P., Mueller, D., Schladitz, A., Toledano, C., Weinzierl, B., Ansmann, A., Althausen, D., Mueller, T., Petzold, A., and Wiedensohler, A.: Regional modelling of Saharan dust and biomass-burning smoke Part I: Model description and evaluation, Tellus B, 63, 781-799, $2011 b$.

Helmert, J., Heinold, B., Tegen, I., Hellmuth, O., and Wendisch, M.: On the direct and semidirect effect of Saharan dust over Europe: a modeling study, J. Geophys. Res., 112, D11204, doi:10.1029/2006JD007444, 2007.

Henze, D. K., Seinfeld, J. H., Ng, N. L., Kroll, J. H., Fu, T.-M., Jacob, D. J., and Heald, C. L.: Global modeling of secondary organic aerosol formation from aromatic hydrocarbons: highvs. low-yield pathways, Atmos. Chem. Phys., 8, 2405-2420, doi:10.5194/acp-8-2405-2008, 2008.

Herrmann, H., Tilgner, A., Barzaghi, P., Majdik, Z., Gligorovski, S., Poulain, L., and Monod, A.: Towards a more detailed description of tropospheric aqueous phase organic chemistry: CAPRAM 3.0, Atmos. Environ., 39, 1352-2310, doi:10.1016/j.atmosenv.2005.02.016, 2005.

Hess, M., Koepke, P., and Schult, I.: Optical properties of aerosols and clouds: the software package OPAC, B. Am. Meteorol. Soc., 79, 831-844, 1998.

Hidalgo, J., Masson, V., Baklanov, A., Pigeon, G., and Gimeno, L.: Advances in urban climate modeling, Trends and directions in climate research, Ann. NY Acad. Sci., 1146, 354-374, doi:10.1196/annals.1446.015, 2008.

Hill, G. E.: Factors controlling the size and spacing of cumulus clouds as revealed by numerical experiments, J. Atmos. Sci., 31, 646-673, 1974.

Hinneburg, D., Renner, E., and Wolke, R.: Formation of secondary inorganic aerosols by power plant emissions exhausted through cooling towers in Saxony, Environ. Sci. Pollut. R., 16, 25-35, 2009
Hogrefe, C., Hao, W., Zalewsky, E. E., Ku, J.-Y., Lynn, B., Rosenzweig, C., Schultz, M. G., Rast, S., Newchurch, M. J., Wang, L., Kinney, P. L., and Sistla, G.: An analysis of long-term regional-scale ozone simulations over the Northeastern United States: variability and trends, Atmos. Chem. Phys., 11, 567-582, doi:10.5194/acp-11-567-2011, 2011.

Hollingsworth, A., Engelen, R. J., Textor, C., Benedetti, A., Boucher, O., Chevallier, F., Dethof, A., Elbern, H., Eskes, H., Flemming, J., Granier, C., Kaiser, J. W., Morcrette, J. J., Rayner, P., Peuch, V.-H., Rouil, L., Schultz, M., Simmons, A., and the GEMS consortium: Toward a monitoring and forecasting system for atmospheric composition, B. Am. Meteorol. Soc., 89, 1147 1164, doi:10.1175/2008BAMS2355.1, 2008.

Holtslag, A. A. M. and Bouville, B. A.: Local versus nonlocal boundary-layer diffusion in a global climate model, J. Climate, 6, 1825-1842, 1993.

Holtslag, A. A. M. and Moeng, C.H.: Eddy diffusivity and counter gradient transport in the convective atmospheric boundary layer, J. Atmos. Sci., 48, 1690-1698, doi:10.1175/15200469(1991)048<1690:EDACTI>2.0.CO;2, 1991.

Hong, S. Y., Noh, Y., and Dudhia, J.: A new vertical diffusion package with an explicit treatment of entrainment processes, Mon. Weather Rev., 134, 2318-2341, 2006.

Hoose, C., Lohmann, U., Erdin, R., and Tegen, I.: The global influence of dust mineralogical composition on heterogeneous ice nucleation in mixed-phase clouds, Environ. Res. Lett., 3, 025003, doi:10.1088/1748-9326/3/2/025003, 2008.

Hoose, C., Kristiansson, J. E., and Burrows, S. M.: How important is biological ice nucleation in clouds on a global scale, Environ. Res. Lett., 5, 024009, doi:10.1088/1748-9326/5/2/024009, 2010a.

Hoose, C., Kristjansson, J. E., Chen, J. P., and Hazra, A.: A classical-theory-based parameterization of heterogeneous ice nucleation by mineral dust, soot, and biological particles in a global climate model, J. Atmos. Sci., 67, 2483-2503, 2010 b.

Horn, S.: ASAMgpu V1.0 - a moist fully compressible atmospheric model using graphics processing units (GPUs), Geosci. Model Dev., 5, 345-353, doi:10.5194/gmd-5-345-2012, 2012.

Horowitz, L. W.: A global simulation of tropospheric ozone and related tracers: description and evaluation of MOZART, version 2, J. Geophys. Res., 108, 4784, doi:10.1029/2002JD002853, 2003.

Hortal, M.: The development and testing of a new two-time-level semi-Lagrangian scheme (SETTLS) in the ECMWF forecast model, Q. J. Roy. Meteor. Soc., 128, 1671-1687, 2002.

Houze, R.: Cloud Dynamics, Int. Geophys. Series, vol. 53, Academic Press, San Diego, California, 573 pp., 1994.

Huijnen, V., Eskes, H. J., Poupkou, A., Elbern, H., Boersma, K. F., Foret, G., Sofiev, M., Valdebenito, A., Flemming, J., Stein, O., Gross, A., Robertson, L., D'Isidoro, M., Kioutsioukis, I., Friese, E., Amstrup, B., Bergstrom, R., Strunk, A., Vira, J., Zyryanov, D., Maurizi, A., Melas, D., Peuch, V.-H., and Zerefos, C.: Comparison of $\mathrm{OMI} \mathrm{NO}_{2}$ tropospheric columns with an ensemble of global and European regional air quality models, Atmos. Chem. Phys., 10, 3273-3296, doi:10.5194/acp-10-3273-2010, 2010.

Iacono, M., Mlawer, E., Clough, S., and Morcrette, J.: Impact of an improved longwave radiation model, RRTM, on the energy budget and thermodynamic properties of the NCAR community climate model, CCM3, J. Geophys. Res., 105, 14873-14890, doi:10.1029/2000JD900091, 2000. 
Inness, A., Baier, F., Benedetti, A., Bouarar, I., Chabrillat, S., Clark, H., Clerbaux, C., Coheur, P., Engelen, R. J., Errera, Q., Flemming, J., George, M., Granier, C., Hadji-Lazaro, J., Huijnen, V., Hurtmans, D., Jones, L., Kaiser, J. W., Kapsomenakis, J., Lefever, K., Leitão, J., Razinger, M., Richter, A., Schultz, M. G., Simmons, A. J., Suttie, M., Stein, O., Thépaut, J.-N., Thouret, V., Vrekoussis, M., Zerefos, C., and the MACC team: The MACC reanalysis: an 8 yr data set of atmospheric composition, Atmos. Chem. Phys., 13, 4073-4109, doi:10.5194/acp-13-4073-2013, 2013.

Jacobson, M. Z.: Developing, coupling, and applying a gas, aerosol, transport,and radiation model to study urban and regional air pollution, PhD. Dissertation, Dept. of Atmospheric Sciences, UCLA, 436 pp., 1994.

Jacobson, M. Z.: Development and application of a new air pollution modeling system. Part II: Aerosol module structure and design, Atmos. Environ. A, 31, 131-144, 1997a.

Jacobson, M. Z.: Development and application of a new air pollution modeling system. Part III: Aerosol-phase simulations, Atmos. Environ. A, 31, 587-608, 1997b.

Jacobson, M. Z.: Studying the effects of calcium and magnesium on size-distributed nitrate and ammonium with EQUISOLV II, Atmos. Environ., 33, 3635-3649, 1999.

Jacobson, M. Z.: Control of fossil-fuel particulate black carbon plus organic matter, possibly the most effective method of slowing global warming, J. Geophys. Res., 107, 4410, doi:10.1029/2001JD001376, 2002.

Jacobson, M. Z.: Climate response of fossil fuel and biofuel soot, accounting for soot's feedback to snow and sea ice albedo and emissivity, J. Geophys. Res., 109, D21201, doi:10.1029/2004JD004945, 2004.

Jacobson, M. Z.: Fundamentals of Atmospheric Modeling, 2nd edn., Camb. Univ. Press, New York, 813 pp., 2005.

Jacobson, M. Z.: Effects of absorption by soot inclusions within clouds and precipitation on global climate, J. Phys. Chem. A, 110, 6860-6873, 2006.

Jacobson, M. Z.: Investigating cloud absorption effects: Global absorption properties of black carbon, tar balls, and soil dust in clouds and aerosols, J. Geophys. Res., 117, D06205, doi:10.1029/2011JD017218, 2012.

Jacobson, M. Z. and Ginnebaugh, D. L.: Global-through-urban nested three-dimensional simulation of air pollution with a 13600-reaction photochemical mechanism, J. Geophys. Res., 115, D14304, doi:10.1029/2009JD013289, 2010.

Jacobson, M. Z., Turco, R. P., Jensen, E. J., and Toon, O. B.: Modeling coagulation among particles of different composition and size, Atmos. Environ., 28, 1327-1338, 1994.

Jacobson, M. Z., Lu, R., Turco, R. P., and Toon, O. B.: Development and application of a new air pollution model system - Part I: Gasphase simulations, Atmos. Environ., 30, 1939-1963, 1996.

Jacobson, M. Z., Kaufmann, Y. J., and Rudich, Y.: Examining feedbacks of aerosols to urban climate with a model that treats 3-D clouds with aerosol inclusions, J. Geophys. Res., 112, D24205, doi:10.1029/2007JD008922, 2007.

Jalkanen, J.-P., Johansson, L., Kukkonen, J., Brink, A., Kalli, J., and Stipa, T.: Extension of an assessment model of ship traffic exhaust emissions for particulate matter and carbon monoxide, Atmos. Chem. Phys., 12, 2641-2659, doi:10.5194/acp-12-26412012, 2012.
Janjic, J. and Gall, R.: Scientific documentation of the NCEP nonhydrostatic multiscale model on the B grid (NMMB). Part 1 Dynamics, NCAR/TN-489+STR, 75 pp., 2012.

Janjic, Z. I.: Comments on "Development and evaluation of a convection scheme for use in climate models", J. Atmos. Sci., 57, 3686-3686, 2000.

Janjic, Z.: Nonsingular implementation of the Mellor-Yamada level 2.5 scheme in the NCEP Meso model, National Centers for Environmental Prediction, USA, Office Note No. 437, 2002.

Janjic, Z., Janjic, T., and Vasic, R.: A class of conservative fourthorder advection schemes and impact of enhanced formal accuracy on extended-range forecasts, Mon. Weather Rev., 13, 15561568, 2011.

Janssen, P. A. E. M., Doyle, J. D., Bidlot, J.-R., Hansen, B., Isaksen, L., and Viterbo, P.: Impact and feedback of ocean waves on the atmosphere, Atmosphere-Ocean Interactions., 1, 155-197, 2002.

Jamieson, S.: Likert scales: how to (ab) use them, Med. Educ., 38, 1217-1218, 2004.

Jenkin, M. E., Saunders, S. M., and Pilling, M. J.: The tropospheric degradation of volatile organic compounds: a protocol for mechanism development, Atmos. Environ., 31, 81-104, 1997.

Jeuken, A. B. M., Eskes, H. J., Velhoven, P. F. J., Kelder, H. M., and Hólm, E. V.: Assimilation of total ozone satellite measurements in a three-dimensional tracer transport model, J. Geophys. Res., 104, 5551-5563, 1999.

Jiang, H., Xue, H., Teller, A., Feingold, G., and Levin, Z.: Aerosol effects on the lifetime of shallow cumulus, Geophys. Res. Lett., 33, L14806, doi:10.1029/2006GL026024, 2006.

Jöckel, P., von Kuhlmann, R., Lawrence, M. G., Steil, B., Brenninkmeijer, C. A. M., Crutzen, P. J., Rasch, P. J., and Eaton, B.: On a fundamental problem in implementing flux-form advection schemes for tracer transport in 3-dimensional general circulation and chemistry transport models, Q. J. Roy. Meteor. Soc., 127, 1035-1052. doi:10.1002/qj.49712757318, 2001.

Jonson, J. E., Simpson, D., Fagerli, H., and Solberg, S.: Can we explain the trends in European ozone levels?, Atmos. Chem. Phys., 6, 51-66, doi:10.5194/acp-6-51-2006, 2006.

Jorba, O., Dabdub, D., Blaszczak-Boxe, C., Pérez, C., Janjic, Z., Baldasano, J. M., Spada, M., Badia, A., and Gonçalves, M.: Potential significance of photoexcited $\mathrm{NO}_{2}$ on global air quality with the NMMB/BSC chemical transport model, J. Geophys. Res., 117, D13301, doi:10.1029/2012JD017730, 2012.

Kaas, E.: A simple and efficient locally mass conserving semiLagrangian transport scheme, Tellus A, 60A, 305-320, 2008.

Kain, J. S. and Fritsch, J. M.: Convection parameterization for mesoscale models: the Kain-Fritsch scheme, Meteor. Mon., 24, 165-170, 1993.

Kallos, G., Solomos, S., and Kushta, J.: Air quality - Meteorology Interaction Processes in the ICLAMS Modeling System, in: 30th NATO/SPS International Technical Meeting on Air Pollution Modelling and its Application, San Francisco, 18-22 May 2009, 2009.

Kalnay, E.: Atmospheric Modeling, Data Assimilation and Predictability, Camb. Univ. Press, New York, 341 pp., 2003.

Kamınski, J. W., Neary, L., Lupu, A., McConnell, J. C., Struzewska, J., Zdunek, M., and Lobocki, L.: High Resolution Air Quality Simulations with MC2-AQ and GEM-AQ, Nato Chal. M., XVII, 714-720, 2007. 
Kaminski, J. W., Neary, L., Struzewska, J., McConnell, J. C., Lupu, A., Jarosz, J., Toyota, K., Gong, S. L., Côté, J., Liu, X., Chance, K., and Richter, A.: GEM-AQ, an on-line global multiscale chemical weather modelling system: model description and evaluation of gas phase chemistry processes, Atmos. Chem. Phys., 8, 3255-3281, doi:10.5194/acp-8-3255-2008, 2008.

Kang, D., Hogrefe, C., Foley, K. L., Napelenok, S. L., Mathur, R., and Rao, S. T.: Application of the Kolmogorov-Zurbenko filter and the decoupled direct 3D method for the dynamic evaluation of a regional air quality model, Atmos. Environ., 80, 58-69, doi:10.1016/j.atmosenv.2013.04.046, 2013.

Kapitza, H. and Eppel, D. P.: A case study in atmospheric lead pollution of north German coastal regions, J. Appl. Meteorol., 39, 576-588, 2000.

Kärcher, B., Hendricks, J., and Lohmann, U.: Physically based parameterization of cirrus cloud formation for use in global atmospheric models, J. Geophys. Res., 111, D01205, doi:10.1029/2005JD006219, 2006.

Karl, M., Dorn, H. P., Holland, F., Koppmann, R., Poppe, D. Rupp, L., Schaub, A., and Wahner, A.: Product study of the reaction of $\mathrm{OH}$ radicals with isoprene in the atmosphere simulation chamber, SAPHIR, J. Atmos. Chem., 55, 167-187, 2006.

Kaufman, Y. J. and Fraser, R. S.: The effect of smoke particles on clouds and climate forcing, Science, 277, 1636-1638, 1997.

Kessler, E.: On the distribution and continuity of water substance in atmospheric circulations, Meteor. Mon., 10, 84 pp., American Meteorological Society in Boston, Series: Meteorological monographs, v. 10, no. 32, 84 pp., ID Numbers Open Library: OL14104211M, 1969.

Khain, A. P.: Notes on state-of-the-art investigations of aerosol effects on precipitation: a critical review. Environ. Res. Lett., 4, 015004, doi:10.1088/1748-9326/4/1/015004, 2009.

Khain, A. P., BenMoshe, N., and Pokrovsky, A.: Factors determining the impact of aerosols on surface precipitation from clouds: an attempt of classification, J. Atmos. Sci., 65, 1721-1748, 2008.

Khairoutdinov, M. and Kogan, Y.: A new cloud physics parameterization in a large-eddy simulation model of marine stratocumulus, Mon. Weather Rev., 128, 229-243, 2000.

Kiehl, J. T., Hack, J. J., Bonan, G. B., Boville, B. A., Briegleb, B. P., Williamson, D. L., and Rasch, P. J.: Description of the NCAR Community Climate Model (CCM3), NCAR Tech. Note NCAR/TN-420+STR, 143 pp., 1996.

Kim, Y., Sartelet, K., and Seigneur, C.: Comparison of two gasphase chemical kinetic mechanisms of ozone formation over Europe, J. Atmos. Chem., 62, 89-119, doi:10.1007/s10874-0099142-5, 2009

Kim, Y., Sartelet, K., and Seigneur, C.: Formation of secondary aerosols over Europe: comparison of two gas-phase chemical mechanisms, Atmos. Chem. Phys., 11, 583-598, doi:10.5194/acp-11-583-2011, 2011.

Kinne, S., Schulz, M., Textor, C., Guibert, S., Balkanski, Y., Bauer, S. E., Berntsen, T., Berglen, T. F., Boucher, O., Chin, M., Collins, W., Dentener, F., Diehl, T., Easter, R., Feichter, J., Fillmore, D., Ghan, S., Ginoux, P., Gong, S., Grini, A., Hendricks, J., Herzog, M., Horowitz, L., Isaksen, I., Iversen, T., Kirkevåg, A., Kloster, S., Koch, D., Kristjansson, J. E., Krol, M., Lauer, A., Lamarque, J. F., Lesins, G., Liu, X., Lohmann, U., Montanaro, V., Myhre, G., Penner, J., Pitari, G., Reddy, S., Seland, O., Stier, P., Takemura, T., and Tie, X.: An AeroCom initial assessment - optical properties in aerosol component modules of global models, Atmos. Chem. Phys., 6, 1815-1834, doi:10.5194/acp-6-1815-2006, 2006.

Kinnison, D. E., Brasseur, G. P., Walters, S., Garcia, R. R., Marsh, D. R, Sassi, F., Harvey, V. L., Randall, C. E., Emmons, L., Lamarque, J. F., Hess, P., Orlando, J. J., Tie, X. X., Randel, W., Pan, L. L., Gettelman, A., Granier, C., Diehl, T., Niemeier, U., and Simmons, A. J.: Sensitivity of chemical tracers to meteorological parameters in the MOZART-3 chemical transport model, J. Geophys. Res, 112, D03303, doi:10.1029/2008JD010739, 2007.

Kitada, T., Kaki, A., Ueda, H., and Peters, L. K.: Estimation of vertical air motion from limited horizontal wind data - a numerical experiment, Atmos. Environ., 17, 2181-2192, 1983.

Kleeman, M. J. and Cass, G. R.: A 3-D Eulerian source-oriented model for an externally mixed aerosol, Environ. Sci. Technol., 35, 4834-4848, 2001.

Knote, C. and Brunner, D.: An advanced scheme for wet scavenging and liquid-phase chemistry in a regional online-coupled chemistry transport model, Atmos. Chem. Phys., 13, 1177-1192, doi:10.5194/acp-13-1177-2013, 2013.

Knote, C., Brunner, D., Vogel, H., Allan, J., Asmi, A., Äijälä, M., Carbone, S., van der Gon, H. D., Jimenez, J. L., KiendlerScharr, A., Mohr, C., Poulain, L., Prévôt, A. S. H., Swietlicki, E., and Vogel, B.: Towards an online-coupled chemistry-climate model: evaluation of trace gases and aerosols in COSMO-ART, Geosci. Model Dev., 4, 1077-1102, doi:10.5194/gmd-4-10772011, 2011.

Koch, D. and Del Genio, A. D.: Black carbon semi-direct effects on cloud cover: review and synthesis, Atmos. Chem. Phys., 10, 7685-7696, doi:10.5194/acp-10-7685-2010, 2010.

Konare, A., Zakey, A. S., Solmon, F., Giorgi, F., Rauscher, S., Ibrah, $\mathrm{S}$., and $\mathrm{Bi}, \mathrm{X}$.: A regional climate modeling study of the effect of desert dust on the West African monsoon, J. Geophys. Res., 113, D12206, doi:10.1029/2007JD009322, 2008.

Korsholm, U. S.: Integrated modeling of aerosol indirect effects development and application of a chemical weather model, $\mathrm{PhD}$ thesis University of Copenhagen, Niels Bohr Institute and Danish Meteorological Institute, Research department, available at: http://www.dmi.dk/dmi/sr09-01.pdf (last access: 28 April 2013), 2009.

Korsholm, U. S., Baklanov, A., Gross, A., Mahura, A., Hansen Sass, B., and Kaas, E.: Online coupled chemical weather forecasting based on HIRLAM - overview and prospective of EnviroHIRLAM, HIRLAM Newsletter, 54, 151-168, 2008.

Korsholm, U. S., Baklanov, A., Gross, A., and Sørensen, J. H.: On the importance of the meteorological coupling interval in dispersion modeling during ETEX-1, Atmos. Environ., 43, 4805-4810, 2009.

Krinner, G., Boucher, O., and Balkanski, Y.: Ice-free glacial northern Asia due to dust deposition on snow, Clim. Dynam., 27, 613625, 2006.

Krupa, S. V., Booker, F. L., Burkey, K. O., Chevone, B. I., Tuttle McGrath, M., Chappelka, A. H., Pell, E. J., and Zilinskas, B. A.: Ambient ozone and plant health, Plant Dis., 85, 4-12, 2000.

Kuell, V., Gassmann, A., and Bott, A.: Towards a new hybrid cumulus parameterization scheme for use in non-hydrostatic weather prediction models, Q. J. Roy. Meteorol. Soc., 133, 479-490, 2007. 
Kuenen, J. H., Denier van der Gon, H., Visschedijk, A., and van der Brugh, H.: High resolution European emission inventory for the years 2003-2007, TNO report TNO-060-UT-2011-00588, TNO, Utrecht, the Netherlands, 2011.

Kuhn, M., Builtjes, P. J. H., Poppe, D., Simpson, D., Stockwell, W. R., Andersson-Sköld, Y., Baart, A., Das, M., Fiedler, F., Hov, Ø., Kirchner, F., Makar, P. A., Milfor, J. B., Roemer, M. G. M., Ruhnke, R., Strand, A., Vogel, B., and Vogel, H.: Intercomparison of the gas-phase chemistry in several chemistry and transport models, Atmos. Environ., 32, 693-709, 1998.

Kukkonen, J., Olsson, T., Schultz, D. M., Baklanov, A., Klein, T., Miranda, A. I., Monteiro, A., Hirtl, M., Tarvainen, V., Boy, M., Peuch, V.-H., Poupkou, A., Kioutsioukis, I., Finardi, S., Sofiev, M., Sokhi, R., Lehtinen, K. E. J., Karatzas, K., San José, R., Astitha, M., Kallos, G., Schaap, M., Reimer, E., Jakobs, H., and Eben, K.: A review of operational, regional-scale, chemical weather forecasting models in Europe, Atmos. Chem. Phys., 12, 1-87, doi:10.5194/acp-12-1-2012, 2012.

Kumar, P., Sokolik, I. N., and Nenes, A.: Parameterization of cloud droplet formation for global and regional models: including adsorption activation from insoluble CCN, Atmos. Chem. Phys., 9, 2517-2532, doi:10.5194/acp-9-2517-2009, 2009.

Lafore, J. P., Stein, J., Asencio, N., Bougeault, P., Ducrocq, V., Duron, J., Fischer, C., Héreil, P., Mascart, P., Masson, V., Pinty, J. P., Redelsperger, J. L., Richard, E., and Vilà-Guerau de Arellano, J.: The Meso-NH Atmospheric Simulation System. Part I: adiabatic formulation and control simulations, Ann. Geophys., 16, 90-109, doi:10.1007/s00585-997-0090-6, 1998.

Landgraf, J. and Crutzen, P. J.: An efficient method for online calculations of photolysis and heating rates, J. Atmos. Sci., 55, 863878, 1998.

Langmann, B.: Numerical modelling om regional scale transport and photochemistry directly together with meteorological processes, Atmos. Environ., 34, 3585-3598, doi:10.1016/S13522310(00)00114-X, 2000.

Langmann, B., Varghese, S., Marmer, E., Vignati, E., Wilson, J., Stier, P., and O'Dowd, C.: Aerosol distribution over Europe: a model evaluation study with detailed aerosol microphysics, Atmos. Chem. Phys., 8, 1591-1607, doi:10.5194/acp-8-1591-2008, 2008.

Langmann, B., Sellegri K., and Freney, E.: Secondary organic aerosol formation during summer 2010 over Central Europe, in: EAC 20012, Granada, Spain, 3-7 September 2012, abstract CWG09S1P03, 2012.

Lau, K.-M. and Kim, K.-M.: Observational relationships between aerosol and Asian monsoon rainfall, and circulation, Geophys. Res. Lett., 33, L21810, doi:10.1029/2006GL027546, 2006.

Lauritzen P. H. and Thuburn, J.: Evaluating advection/transport schemes using interrelated tracers, scatter plots and numerical mixing diagnostics, Q. J. Roy. Meteor. Soc., 138, 906-918, doi:10.1002/qj.986, 2011.

Lauritzen, P. H., Nair, R. D., and Ullrich, P. A.: A conservative semi-Lagrangian multi-tracer transport scheme (CSLAM) on the cubed-sphere grid, J. Comput. Phys., 229, 1401-1424, doi:10.1016/j.jcp.2009.10.036, 2010.

Lauritzen, P. H., Ullrich, P. A., Jablonowski, C., Bosler, P. A., Calhoun, D., Conley, A. J., Enomoto, T., Dong, L., Dubey, S., Guba, O., Hansen, A. B., Kaas, E., Kent, J., Lamarque, J.-F., Prather, M. J., Reinert, D., Shashkin, V. V., Skamarock, W. C., Sørensen,
B., Taylor, M. A., and Tolstykh, M. A.: A standard test case suite for two-dimensional linear transport on the sphere: results from a collection of state-of-the-art schemes, Geosci. Model Dev. Discuss., 6, 4983-5076, doi:10.5194/gmdd-6-4983-2013, 2013.

Lauvaux, T., Pannekoucke, O., Sarrat, C., Chevallier, F., Ciais, P., Noilhan, J., and Rayner, P. J.: Structure of the transport uncertainty in mesoscale inversions of $\mathrm{CO}_{2}$ sources and sinks using ensemble model simulations, Biogeosciences, 6, 1089-1102, doi:10.5194/bg-6-1089-2009, 2009.

Law, K. S., Plantevin, P.-H., Shallcross, D. E., Rogers, H. L., Pyle, J. A., Grouhel, C., Thouret, V., and Marenco, A.: Evaluation of modeled O3 using Measurement of Ozone by Airbus In- Service Aircraft (MOZAIC) data, J. Geophys. Res., 103, 25721-25737, 1998.

Lee, D. S., Fahey, D. W., Forster, P. M., Newton, P. J., Wit, R. C. N., Lim, L. L., Owen, B., and Sausen, R.: Aviation and global climate change in the 21st century, Atmos. Environ., 43, 35203537, doi:10.1016/j.atmosenv.2009.04.024, 2009.

Lee, L. A., Carslaw, K. S., Pringle, K. J., Mann, G. W., and Spracklen, D. V.: Emulation of a complex global aerosol model to quantify sensitivity to uncertain parameters, Atmos. Chem. Phys., 11, 12253-12273, doi:10.5194/acp-11-12253-2011, 2011.

Lee, S. S. and Penner, J. E.: Dependence of aerosol-cloud interactions in stratocumulus clouds on liquid-water path, Atmos. Environ., 45, 6337-6346, 2011.

Lenderink, G. and Holtslag, A. A. M.: An updated lengthscale formulation for turbulent mixing in clear and cloudy boundary layers, Q. J. Roy. Meteor. Soc., 130, 3405-3427, doi:10.1256/qj.03.117, 2004.

Lenz, C.-J., Müller, F., and Schlünzen, K. H.: The sensitivity of mesoscale chemistry transport model results to boundary values, Enviton. Monit. Assess., 65, 287-295, 2000.

Leriche, M., Pinty, J.-P., Mari, C., and Gazen, D.: A cloud chemistry module for the 3-D cloud-resolving mesoscale model Meso-NH with application to idealized cases, Geosci. Model Dev., 6, 12751298, doi:10.5194/gmd-6-1275-2013, 2013.

Li, J. and Barker, H. W.: A radiation algorithm with correlated-k distribution. Part I: Local thermal equilibrium, J. Atmos. Sci., 62, 296-309, 2005.

Li, G., Lei, W., Zavala, M., Volkamer, R., Dusanter, S., Stevens, P., and Molina, L. T.: Impacts of HONO sources on the photochemistry in Mexico City during the MCMA-2006/MILAGO Campaign, Atmos. Chem. Phys., 10, 6551-6567, doi:10.5194/acp-106551-2010, 2010.

Lilly, D. K.: On the numerical simulation of buoyant convection, Tellus, 14, 148-172, 1962.

Lim, Y. B., Tan, Y., Perri, M. J., Seitzinger, S. P., and Turpin, B. J.: Aqueous chemistry and its role in secondary organic aerosol (SOA) formation, Atmos. Chem. Phys., 10, 1052110539, doi:10.5194/acp-10-10521-2010, 2010.

Lin, S.-J. and Rood, R. B.: Multidimensinal flux-form semiLagrangian transport schemes, Mon. Weather Rev., 124, 20462070, 1996.

Lin, Y.-L., Fraley, R. D., and Orville, H. D.: Bulk parameterization of the snow field in a cloud model, J. Clim. Appl. Meteorol., 22, 1065-1092, 1983.

Liu, X., Penner, J. E., Ghan, S. J., and Wang, M.: Inclusion of ice microphysics in the NCAR community atmospheric model version 3 (CAM3), J. Climate, 20, 4526-4547, 2007. 
Liu, X.-H., Zhang, Y., Cheng, S.-H., Xing, J., Zhang, Q., Streets, D. G., Jang, C. J., Wang, W.- X., and Hao, J.-M.: Understanding of regional air pollution over china using CMAQ: Part I. Performance evaluation and seasonal variation, Atmos. Environ., 44, 2415-2426, 2010.

Liu, X., Easter, R. C., Ghan, S. J., Zaveri, R., Rasch, P., Shi, X., Lamarque, J.-F., Gettelman, A., Morrison, H., Vitt, F., Conley, A., Park, S., Neale, R., Hannay, C., Ekman, A. M. L., Hess, P., Mahowald, N., Collins, W., Iacono, M. J., Bretherton, C. S., Flanner, M. G., and Mitchell, D.: Toward a minimal representation of aerosols in climate models: description and evaluation in the Community Atmosphere Model CAM5, Geosci. Model Dev., 5, 709-739, doi:10.5194/gmd-5-709-2012, 2012.

Liu, Y., Daum, P. H., and McGraw, R. L.: Size truncation effect, threshold behavior, and a new type of autoconversion parameterization, Geophys. Res. Lett., 32, L11811, doi:10.1029/2005GL022636, 2005.

Liu, Z., Liu, Q., Lin, H.-C., Schwartz, C. S., Lee, Y.-H., and Wang, T.: Three-dimensional variational assimilation of MODIS aerosol optical depth: implementation and application to a dust storm over East Asia, J. Geophys. Res., 116, D23206, doi:10.1029/2011JD016159, 2011.

Lock, A. B., Brown, A. R., Bush, M. R., Martin, G. M., and Smith, R. N. B.: A new boundary layer mixing scheme. Part I. Scheme description and single-column model tests, Mon. Weather Rev., 128, 3187-3199, 2000.

Lohmann, U.: A glaciation indirect aerosol effect caused by soot aerosols, Geophys. Res. Lett., 29, 11-1-11-4, doi:10.1029/2001GL014357, 2002.

Lohmann, U.: Aerosol effects on clouds and climate, Space Sci. Rew., 125, 129-137, 2006.

Lohmann, U. and Diehl, K.: Sensitivity studies of the importance of dust ice nuclei for the indirect aerosol effect on stratiform mixed phase clouds, J. Atmos. Sci., 63, 968-982, 2006.

Lohmann, U. and Kärcher, B.: First interactive simulations of cirrus clouds formed by homogeneous freezing in the ECHAM GCM, J. Geophys. Res., 107, AAC 8-1-AAC 8-13, doi:10.1029/2001JD000767, 2002.

Lohmann, U. and Roeckner, E.: Design and performance of a new cloud microphysics scheme developed for the ECHAM general circulation model, Clim. Dynam., 12, 557-572, 1996.

Louis, J.-F.: A parametric model of vertical eddy fluxes in the atmosphere, Bound.-Lay. Meteorol., 17, 187-202, 1979.

Lu, J. and Bowman, F. M.: A detailed aerosol mixing state model for investigating interactions between mixing state, semivolatile partitioning, and coagulation, Atmos. Chem. Phys., 10, 40334046, doi:10.5194/acp-10-4033-2010, 2010.

Luecken, D. J., Phillips, S., Sarwar, G., and Jang, C.: Effects of using the CB05 vs. SPARC99 vs. CB4 chemical mechanism on model predictions: ozone and gas-phase photochemical precursor concentrations, Atmos. Environ., 42, 5805-5820, 2008.

Lundgren, K., Vogel, B., Vogel, H., and Kottmeier, C.: Direct radiative effects of sea salt for the Mediterranean Region at conditions of low to moderate wind speeds, J. Geophys. Res., 118, 1906-1923, doi:10.1029/2012JD018629, 2012.

Lüpkes, C. and Birnbaum, G.: Surface drag in the Arctic marginal sea-ice zone: a comparison of different parameterisation concepts, Bound.-Lay. Meteorol., 117, 179-211, 2005.
Lüpkes, C. and Schlünzen, K. H.: Modelling the Arctic convective boundary-layer with different turbulence parameterizations, Bound.-Lay. Meteorol., 79, 107-130, 1996.

Machenhauer, B., Kaas, E., and Lauritzen P. H.: Finite Volume Methods in Meteorology, Handbook of Numerical Analysis, 14, Elsevier, 3-120, 2009.

Madronich, S.: Photodissociation in the atmosphere: 1. Actinic flux and the effects of ground reflections and clouds, J. Geophys. Res., 92, 9740-9752, 1987.

Majewski, D.: Europa-Modell of the Deutscher Wetterdienst, ECMWF Seminar on numerical methods in atmospheric models, Vol. 2, ECMWF, Reading, UK, 2, 147-191, 1991.

Manabe, S., Smagorinsky, J., and Strickler, R. F.: Simulated climatology of a general circulation model with a hydrologic cycle, Mon. Weather Rev., 93, 769-798, 1965.

Manders, A. M. M., van Meijgaard, E., Mues, A. C., Kranenburg, R., van Ulft, L. H., and Schaap, M.: The impact of differences in large-scale circulation output from climate models on the regional modeling of ozone and PM, Atmos. Chem. Phys., 12, 9441-9458, doi:10.5194/acp-12-9441-2012, 2012.

Mann, G. W., Carslaw, K. S., Spracklen, D. V., Ridley, D. A., Manktelow, P. T., Chipperfield, M. P., Pickering, S. J., and Johnson, C. E.: Description and evaluation of GLOMAP-mode: a modal global aerosol microphysics model for the UKCA composition-climate model, Geosci. Model Dev., 3, 519-551, doi:10.5194/gmd-3-519-2010, 2010.

Marchuk, G. I.: Mathematical Modelling in the Environmental Problems, Nauka, Moscow, 1982

Marticorena, B. and Bergametti, G.: Modeling of the atmospheric dust cycle: 1. design of a soil derived dust emission scheme, J. Geophys. Res., 100, 16415-16429, 1995.

Martin, G. M., Johnson, D. W., and Spice, A.: The measurement and parameterization of effective radius of droplets in warm stratocumulus clouds, J. Atmos. Sci., 51, 1823-1842, 1994.

Masson, V.: A physically-based scheme for the urban energy budget in atmospheric models, Bound.-Lay. Meteorol., 94, 357-397, 2000.

Mathur, R. and Peters, L.: Adjustment of wind fields for application in air pollution modeling. Atmos. Environ., 24, 1095-1106, 1990.

Mathur, R., Roselle, S., Pouliot, G., and Sarwar, G.: Diagnostic analysis of the three-dimensional sulphur distributions of the Eastern United States using the CMAQ model and measurements from the ICARTT field experiment, in: Air Pollution Modeling and Its Application XIX, edited by: Borrego, C. and Miranda, A. I., Springer, the Netherlands, 496-504, 2008.

Mathur, R., Pleim, J., Wong, D., Otte, T., Gilliam, R., Roselle, S., Young, J., Binkowski, F., and Xiu, A.: The WRF-CMAQ integrated on-line modeling system: development, testing, and initial applications, in: Air Pollution Modeling and Its Application XX, Springer, 155-159, 2010.

Maurizi, A., Russo, F., D’Isidoro, M., and Tampieri, F.: Nudging technique for scale bridging in air quality/climate atmospheric composition modelling, Atmos. Chem. Phys., 12, 3677-3685, doi:10.5194/acp-12-3677-2012, 2012.

McKeen, S., Chung, S. H., Wilczak, J., Grell, G., Djalalova, I., Peckham, S., Gong, W., Bouchet, V., Moffet, R., Tang, Y., Carmichael, G. R., Mathur, R., and Yu, S.: Evaluation of several $\mathrm{PM}_{2.5}$ forecast models using data collected during 
the ICARTT/NEAQS2004 field study, J. Geophys. Res., 112, D10S20, doi:10.1029/2006JD007608, 2007.

Meier, J., Tegen, I., Mattis, I., Wolke, R., Alados-Arbroledas, L., Apituley, A., Balis, D., Barnaba, F., Chaikovsky, A., Sicard, M., Pappalardo, G., Pietruczuk, A., Stoyanov, D., Ravetta, F., and Rizi, V.: A regional model of European aerosol transport: evaluation with sun photometer, lidar and air quality data, Atmos. Environ., 47, 519-532, doi:10.1016/j.atmosenv.2011.09.029, 2012a.

Meier, J., Tegen I., Heinold, B., and Wolke, R.: Direct and semidirect radiative effects of absorbing aerosols in Europe: Results from a regional model, Geophys. Res. Lett., 39, L09802, doi:10.1029/2012GL050994, 2012b.

Mellor, G. L. and Yamada, T.: A hierarchy of turbulence closure models for planetary boundary layers, J. Atmos. Sci., 31, 17911806, 1974.

Menon, S.: Current uncertainties in assessing aerosol effects on climate, Ann. Rev. Environ. Resources, 29, 1-30, doi:10.1146/annurev.energy.29.063003.132549, 2004.

Menon, S., Del Genio, A. D., Koch, D., and Tselioudis, G.: GCM simulations of the aerosol indirect effect: sensitivity to cloud parameterization and aerosol burden, J. Atmos. Sci., 59, 692-713, 2002.

Meskhidze, N., Xu, J., Gantt, B., Zhang, Y., Nenes, A., Ghan, S. J., Liu, X., Easter, R., and Zaveri, R.: Global distribution and climate forcing of marine organic aerosol: 1. Model improvements and evaluation, Atmos. Chem. Phys., 11, 11689-11705, doi:10.5194/acp-11-11689-2011, 2011.

Messina, P., D'Isidoro, M., Maurizi, A., and Fierli, F.: Impact of assimilated observations on improving tropospheric ozone simulations, Atmos. Environ., 45, 6674-6681, doi:10.1016/j.atmosenv.2011.08.056, 2011.

Mesinger, F., Chou, S. C., Gomes, J. L., Jovic, D., Bastos, P., Bustamante, J. F., Lazic, L., Lyra, A. A., Morelli, S., Ristic, I., and Veljovic, K.: An upgraded version of the Eta model, Meteorol. Atmos. Phys., 116, 63-79, doi:10.1007/s00703-012-0182-z, 2012.

Metzger, S., Dentener, F. J., Pandis, S. N., and Lelieveld, J.: Gas/aerosol partitioning: 1. a computationally efficient model, J. Geophys. Res., 107, 4312, doi:10.1029/2001JD001102, 2002.

Meyer, E. M. I. and Schlünzen, K. H.: The influence of emission changes on ozone concentrations and nitrogen deposition into the southern North Sea, Meteorol. Z., 20, 75-84, doi:10.1127/09412948/2011/0489, 2011.

Meyers, M. P., Walko, R. L., Harrington, J. Y., and Cotton, W. R.: New RAMS cloud microphysics parameterization. Part II: The two-moment scheme, Atmos. Res., 45, 3-39, 1997.

Michalakes, J. and Vachharajani, M.: GPU Acceleration of Numerical Weather Prediction, Parallel Process. Lett., 18, 531-548, 2008.

Mircea, M., Facchini, M. C., Decesari, S., Fuzzi, S., and Charlson, R. J.: The influence of the organic aerosol component on CCN supersaturation spectra for different aerosol types, Tellus B, 54, 74-81, 2002.

Mircea, M., D’Isidoro, M., Maurizi, A., Vitali, L., Monforti, F., Zanini, G., and Tampieri, F.: A comprehensive performance evaluation of the air quality model BOLCHEM to reproduce the ozone concentrations over Italy, Atmos. Environ., 42, 11691185,2008
Mlawer, E. J., Taubman, S. J., Brown, P. D., Iacono, M. J., and Clough, S. A.: Radiative transfer for inhomogeneous atmospheres: RRTM, a validated correlated-k model for the longwave, J. Geophys. Res., 102, 16663-16682, 1997.

Moran, M.D., Ménard, S., Talbot, D., Huang, P., Makar, P. A., Gong, W., Landry, H., Gravel, S., Gong, S., Crevier, L.-P., Kallaur, A., and Sassi, M.: Particulate-matter forecasting with GEMMACH15, a new Canadian air-quality forecast model, in: Air Pollution Modelling and Its Application XX, edited by: Steyn, D. G. and Rao, S. T., Springer, Dordrecht, the Netherlands, 289292, 2010.

Morcrette, J. J.: Radiation and cloud radiative properties in the ECMWF operational weather forecast model, J. Geophys. Res., 96, 9121-9132, 1991.

Morcrette, J.-J., Boucher, O., Jones, L., Salmond, D., Bechtold, P., Beljaars, A., Benedetti, A., Bonet, A., Kaiser, J. W., Razinger, M., Schulz, M., Serrar, S., Simmons, A. J., Sofiev, M., Suttie, M., Tompkins, A. M., and Untch A.: Aerosol analysis and forecast in the European Centre for Medium-Range Weather Forecasts Integrated Forecast System: forward modeling, J. Geophys. Res., 114, D06206, doi:10.1029/2008JD011235, 2009.

Morgenstern, O., Braesicke, P., O'Connor, F. M., Bushell, A. C., Johnson, C. E., Osprey, S. M., and Pyle, J. A.: Evaluation of the new UKCA climate-composition model - Part 1: The stratosphere, Geosci. Model Dev., 2, 43-57, doi:10.5194/gmd-2-432009, 2009.

Morrison, H. and Gettelman, A.: A new two-moment bulk stratiform cloud microphysics scheme in the Community Atmosphere Model, Version 3 (CAM3). Part I: Description and numerical tests, J. Climate, 21, 3642-3659, 2008.

Morrison, H., Curry, J. A., and Khvorostyanov, V. I.: A new doublemoment microphysics scheme for application in cloud and climate models. Part I: Description, J. Atmos. Sci., 62, 1665-1677, 2005.

Moussiopoulos, N.: An efficient scheme to calculate radiative transfer in mesoscale models, Environ. Softw., 2, 172-191, 1987.

Moussiopoulos, N., Sahm, P., and Kessler, C.: Numerical simulation of photochemical smog formation in Athens, Greece - a case study, Atmos. Environ., 29, 3619-3632, 1995.

Moussiopoulos, N., Sahm, P., Kunz, R., Vögele, T., Schneider, C., and Kessler, C.: High resolution simulations of the wind flow and the ozone formation during the Heilbronn ozone experiment, Atmos. Environ., 31, 3177-3186, 1997.

Moussiopoulos, N., Douros, I., Tsegas, G., Kleanthous, S., and Chourdakis, E.: An air quality management system for policy support in Cyprus, Adv. Meteorol., 2012, 959280, doi:10.1155/2012/959280, 2012.

Müller, F., Schlünzen, K. H., and Schatzmann, M.: Test of two numerical solvers for chemical reaction mechanisms in 3D air quality models, Environ. Modell. Softw., 15, 639-646, 2000.

Müller, F., Schlünzen, K. H., and Schatzmann, M.: Evaluation of the chemistry transport model MECTM using TRACTmeasurements - effect of different solvers for the chemical mechanism, Nato Chal. M., 14, 583-590, 2001.

Nair, R. D. and Machenhauer, B.: The mass-conservative cellintegrated semi-Lagrangian advection scheme on the sphere, Mon. Weather Rev., 130, 649-667, 2002.

Napelenok, S. L., Foley, K. M., Kang, D., Mathur, R., Pierce, T., and Rao, S. T.: Dynamic evaluation of regional air quality model's 
response to emissions in the presence of uncertain emission inventories, Atmos. Environ., 45, 4091-4098, 2011.

Neggers, R. A. J.: A dual mass flux framework for boundary layer convection, part II: clouds, J. Atmos. Sci., 66, 1489-1506, doi:10.1175/2008JAS2636.1, 2009.

Nemitz, E., Flynn, M., Williams, P. I., Milford, C., Theobald, M. R., Blatter, A., Gallagher, M. W., and Sutton, M. A.: A relaxed eddy accumulation system for the automated measurement of atmospheric ammonia fluxes, Water Air Soil Poll., 1, 189-202, 2001.

Nenes, A. and Seinfeld, J. H.: Parameterization of cloud droplet formation in global climate models, J. Geophys. Res., 108, 4415, doi:10.1029/2002JD002911, 2003.

Nenes, A., Pilinis, C., and Pandis, S. N.: ISORROPIA: a new thermodynamic model for multiphase multicomponent inorganic aerosols, Aquat. Geochem., 4, 123-152, 1998.

Nenes, A., Conant, W. C. and Seinfeld, J. H.: Black carbon radiative heating effects on cloud microphysics and implications for the aerosol indirect effect, 2, Cloud microphysics, J. Geophys. Res., 107, 4605, doi:10.1029/2002JD002101, 2002.

Nickovic, S., Papadopoulos, A., Kakaliagou, O., and Kallos, G.: Model for prediction of desert dust cycle in the atmosphere, J. Geophys. Res., 106, 18113-18129, 2001.

Nielsen, K. P., Gleeson, E., and Rontu, L.: Aerosol-radiation interactions in and SW radiation tests of HARMONIE and EnviroHIRLAM, Geosci. Model Dev. Discuss., submitted, 2013.

Niu, T., Gong, S. L., Zhu, G. F., Liu, H. L., Hu, X. Q., Zhou, C. H., and Wang, Y. Q.: Data assimilation of dust aerosol observations for the CUACE/dust forecasting system, Atmos. Chem. Phys., 8, 3473-3482, doi:10.5194/acp-8-3473-2008, 2008.

Noilhan, J. and Mahfouf, J.: The ISBA land surface parameterization scheme, Global Planet. Change, 13, 145-159, 1996.

Nordeng, T. E.: Extended versions of the convective parametrization scheme at ECMWF and their impact on the mean and transient activity of the model in the tropics, Technical Memorandum No. 206, October 1994, ECMWF Research Department, European Centre for Medium Range Weather Forecasts, Reading, UK, 41 pp., 1994

Numrich, R. W. and Reid, J. K.: Co-Array Fortran for parallel programming, ACM SIGPLAN Fortran Forum, 17, 1-31, 1998.

Nuterman, R., Korsholm, U., Zakey, A., Nielsen, K. P., Sørensen, B., Mahura, A., Rasmussen, A., Mažeikis, A., GonzalezAparicio, I., Morozova, E., Sass, B. H., Kaas, E., and Baklanov, A.: New developments in Enviro-HIRLAM online integrated modeling system, Geophys. Res. Abstracts, vol. 15, EGU201312520-1, 2013.

O'Connor, F. M., Johnson, C. E., Morgenstern, O., Abraham, N. L., Braesicke, P., Dalvi, M., Folberth, G. A., Sanderson, M. G., Telford, P. J., Young, P. J., Zeng, G., Collins, W. J., and Pyle, J. A.: Evaluation of the new UKCA climate-composition modelPart 2: The Troposphere, Geosci. Model Dev. Discuss., 6, 17431857, doi:10.5194/gmdd-6-1743-2013, 2013.

O'Dowd, C., Varghese, S., Martin, D., Flanagan, R., Ceburnis, D., Ovadnevaite, J., Martucci, G., Bialek, J., Monahan, C., Berresheim, H., Vaishya, A., Grigas, T., Jennings, G., Langmann, B., Semmler, T., and McGrath, R.: The Eyjafjallajökull ash plume - part 2: forecasting ash cloud dispersion, Atmos. Environ., 48, 143-151, doi:10.1016/j.atmosenv.2011.10.037, 2012.

Odman, M. T. and Russell, A. G.: Mass conservative coupling of non-hydrostatic meteorological models with air quality models, in: Air pollution modeling and its application XIII, edited by: Gryning, S.-E. and Batcharova, E., Kluver Academic/Plenum Publishers, New York, 651-658, 2000.

Odum, J. R., Hoffmann, T., Bowman, F., Collins, D., Flagan, R. C., and Seinfeld, J. H.: Gas/particle partitioning and secondary organic aerosol yields, Environ. Sci. Technol., 30, 2580-2585, 1996.

Oshima, N., Koike, M., Zhang, Y., Kondo, Y., Moteki, N., Takegawa, N., and Miyazaki, Y.: Aging of black carbon in outflow from anthropogenic sources using a mixing state resolved model: model development and evaluation, J. Geophys. Res., 114, D06210, doi:10.1029/2008JD010680, 2009.

Ovadnevaite, J., O'Dowd, C., Dall'Osto, M., Ceburnis, D., Worsnop, D. R., and Berresheim, H.: Detecting high contributions of primary organic matter to marine aerosol: a case study, Geophys. Res. Lett., 38, L02807, doi:10.1029/2010GL046083, 2011.

Pagowski, M. and Grell, G. A.: Experiments with the assimilation of fine aerosols using an ensemble Kalman filter, J. Geophys. Res., 117, D21302, doi:10.1029/2012JD018333, 2012.

Pagowski, M., Grell, G. A., McKeen, S. A., Peckham, S. E., and Devenyi, D.: Three-dimensional variational data assimilation of ozone and fine particulate matter observations: some results using the weather research and forecasting - chemistry model and grid-point statistical interpolation, Q. J. Roy. Meteor. Soc., 136, 2013-2024, 2010.

Painter, T. H., Barrett, A. P., Landry, C. C., Neff, J. C., Cassidy, M. P., Lawrence, C. R., McBride, K. E., and Farmer, G. L.: Impact of disturbed desert soils on duration of mountain snow cover, Geophys. Res. Lett., 34, L12502, doi:10.1029/2007GL030284, 2007.

Panofsky, H. A.: Objective weather-map analysis, J. Appl. Meteor., 6, 386-392, 1949.

Penenko, V. V. and Aloyan, A. E.: Models and methods for environment protection problems, Nauka, Novosibirsk, 1985 (in Russian).

Péré, J. C., Mallet M., Bessagnet, B., and Pont V.: Evidence of the aerosol core-shell mixing state over Europe during the heat wave of summer 2003 by using CHIMERE simulations and AERONET inversions, Geophys. Res. Lett., 36, L09807, doi:10.1029/2009GL037334, 2009.

Pérez, C., Nickovic, S., Pejanovic, G., Baldasano, J. M., and Özsoy, E.: Interactive dust-radiation modeling: a step to improve weather forecasts, J. Geophys. Res., 111, D16206, doi:10.1029/2005JD006717, 2006.

Pérez, C., Haustein, K., Janjic, Z., Jorba, O., Huneeus, N., Baldasano, J. M., Black, T., Basart, S., Nickovic, S., Miller, R. L., Perlwitz, J. P., Schulz, M., and Thomson, M.: Atmospheric dust modeling from meso to global scales with the online NMMB/BSC-Dust model - Part 1: Model description, annual simulations and evaluation, Atmos. Chem. Phys., 11, 1300113027, doi:10.5194/acp-11-13001-2011, 2011.

Peters, L. K., Berkowitz, C., Carmichael, G., Easter, R., Fairweather, G., Ghan, S., Hales, J., Saylor, R., Leung, R., Pennell, W., Potra, F., and Tsang, T.: The current status and future direction of Eulerian models in simulating tropospheric chemistry and transport of trace species: a review, Atmos. Environ., 29, 189$222,1995$. 
Petrik, R., Baldauf, M., Schlünzen, K. H., and Gassmann, A.: Validating of a mesoscale weather prediction model using subdomain budgets, Tellus A, 63A, 707-726, doi:10.1111/j.16000870.2011.00528.x, 2011.

Petrik, R., Grawe, D., Bungert, U., and Schlünzen, K. H.: Investigating the impact of anthropogenic heat on urban climate using a top-down methodology, Urban climate, in preparation, 2013.

Pfeffer, M. A., Langmann, B., Heil, A., and Graf, H.-F.: Numerical simulations examining the possible role of anthropogenic and volcanic emissions during the 1997 Indonesian fire, Air Qual. Atmos. Health, 5, 277-292, doi:10.1007/s11869-010-0105-4, 2012.

Phillips, V. T. J., DeMott, P. J., and Andronache, C.: An empirical parameterization of heterogeneous ice nucleation for multiple chemical species of aerosol, J. Atmos. Sci., 65, 2757-2783, 2008.

Pietikäinen, J.-P., O’Donnell, D., Teichmann, C., Karstens, U., Pfeifer, S., Kazil, J., Podzun, R., Fiedler, S., Kokkola, H., Birmili, W., O’Dowd, C., Baltensperger, U., Weingartner, E., Gehrig, R., Spindler, G., Kulmala, M., Feichter, J., Jacob, D., and Laaksonen, A.: The regional aerosol-climate model REMO-HAM, Geosci. Model Dev., 5, 1323-1339, doi:10.5194/gmd-5-13232012, 2012.

Pinder, R. W., Gilliam, R. C., Appel, K. W., Napelenok, S. L., Foley, K. M., and Gilliand, A. B., Efficient Probabilistic Estimates of Surface Ozone Concentration Using an Ensemble of Model Configurations and Direct Sensitivity Calculations, Environ. Sci. Technol., 43, 2388-2393, 2009.

Pinty, J. P. and Jabouille, P.: A mixed-phase cloud parameterization for use in mesoscale nonhydrostatic model: simulations of a squall line and of orographic precipitations, in: Proc. Conf. of Cloud Physics, Everett, WA, USA, August 1999, Amer. Meteor. Soc., 217-220, 1998.

Pizzigalli, C., Cesari, R., D’Isidoro, M., Maurizi, A., and Mircea, M.: Modelling wildfires in the Mediterranean area during summer 2007, Nuovo Cimento, 35, 2012.

Pleim, J.: Development and evaluation of an ammonia bidirectional flux parameterization for air quality models, J. Geophys. Res., 118, 3794-3806, doi:10.1002/jgrd.50262, 2013.

Pleim, J. and Ran, L: Surface flux modeling for air quality applications, Atmosphere, 2, 271-302, 2011.

Pleim, J., Young, J., Wong, D., Gilliam, R., Otte, T., and Mathur, R.: Two-way coupled meteorology and air quality modeling, in: Air Pollution Modeling and Its Application XIX, edited by: Borrego, C. and Miranda, A. I., Springer, the Netherlands, 496-504, ISBN 978-1-4020-8452-2, 2008.

Plumb, R. A.: Tracer interrelationships in the stratosphere, Rev. Geophys., 45, RG4005, doi:10.1029/2005RG000179, 2007.

Pummer, B. G., Bauer, H., Bernardi, J., Bleicher, S., and Grothe, H.: Suspendable macromolecules are responsible for ice nucleation activity of birch and conifer pollen, Atmos. Chem. Phys., 12, 2541-2550, doi:10.5194/acp-12-2541-2012, 2012.

Pun, B., Griffin, R., Seigneur, C., and Seinfeld, J.: Secondary organic aerosol 2. Thermodynamic model for gas/particle partitioning of molecular constituents, J. Geophys. Res., 107, 433, doi:10.1029/2001JD000542, 2002.

Pun, B., Seigneur, C., and Lohman, K.: Modeling secondary organic aerosol formation via multiphase partitioning with molecular data, Environ. Sci. Technol., 40, 4722-4731, doi:10.1021/es0522736, 2006.
Qian, Y. and Giorgi, F.: Interactive coupling of regional climate and sulfate aerosol models over east Asia, J. Geophys. Res., 104, 6477-6499, 1999.

Qian, Y., Giorgi, F., and Huang, Y.: Regional simulation of anthropogenic sulfur over east asia and its sensitivity to model parameters, Tellus, 53, 171-191, 2001.

Qian, Y., Gustafson Jr., W. I., Leung, L. R., and Ghan, S. J.: Effects of soot-induced snow albedo change on snowpack and hydrological cycle in western United States based on Weather Research and Forecasting chemistry and regional climate simulations, J. Geophys. Res., 114, D03108, doi:10.1029/2008JD011039, 2009.

Rančić, M.: Semi-Lagrangian piecewise biparabolic scheme for two-dimensional horizontal advection of a passive scalar, Mon. Weather Rev., 120, 1394-1406, 1992.

Rao, S. T., Galmarini, S., and Puckett, K.: Air Quality Model Evaluation International Initiative (AQMEII): Advancing the State of the Science in Regional Photochemical Modeling and Its Applications, B. Am. Meteor. Soc., 92, 23-30, 2011.

Rasch, P. and Kristjansson, J.: A comparison of the CCM3 Model Climate using diagnosed and predicted condensate parameterizations, J. Climate, 11, 1587-1614, 1998.

Rasch, P. J. and Williamson, D. L.: Computational aspects of moisture transport in global models of the atmosphere, Q. J. Roy. Meteor. Soc., 116, 1071-1090, 1990.

Reid, J.: ISO/IEC JTC1/SC22/WG5 N1824, Coarrays in the next Fortran Standard, available at: ftp://ftp.nag.co.uk/sc22wg5/ N1801-N1850/N1824.pdf (last access: 28 April 2013), 2010a.

Reid, J.: ISO/IEC JTC1/SC22/WG5 N1828, The new features of Fortran 2008, available at: ftp://ftp.nag.co.uk/sc22wg5/ N1801-N1850/N1828.pdf (last access: 28 April 2013), 2010 b.

Reid, J. S., Eck, T. F., Christopher, S. A., Koppmann, R., Dubovik, O., Eleuterio, D. P., Holben, B. N., Reid, E. A., and Zhang, J.: A review of biomass burning emissions part III: intensive optical properties of biomass burning particles, Atmos. Chem. Phys., 5, 827-849, doi:10.5194/acp-5-827-2005, 2005.

Renner, E. and Münzenberg, A.: Impact of biogenic terpene emissions from Brassica napus on tropospheric ozone over Saxony (Germany) - numerical investigation, Environ. Sci. Pollut. R., 10, 147-153, 2003.

Renner, E. and Wolke, R.: Modelling the formation and atmospheric transport of secondary inorganic aerosols with special attention to regions with high ammonia emissions, Atmos. Environ., 44, 1904-1912, 2010.

Richardson, L. F.: Weather Prediction by Numerical Process, The University press, Cambridge, 236 pp., 1922.

Riedel, T. P., Bertram, T. H., Ryder, O. S., Liu, S., Day, D. A., Russell, L. M., Gaston, C. J., Prather, K. A., and Thornton, J. A.: Direct N2O5 reactivity measurements at a polluted coastal site, Atmos. Chem. Phys., 12, 2959-2968, doi:10.5194/acp-12-29592012, 2012.

Riemer, N., Vogel, H., Vogel, B., and Fiedler, F.: Modeling aerosols on the mesoscale- $\gamma$ : treatment of soot aerosol and its radiative effects, J. Geophys. Res., 109, 4601, doi:10.1029/2003JD003448, 2003.

Riemer, N., West, M., Zaveri, R. A., and Easter, R. C.: Simulating the evolution of soot mixing state with a particleresolved aerosol model, J. Geophys. Res., 114, D09202, doi:10.1029/2008JD011073, 2009. 
Ritter, B. and Geleyn, J.-F.: A comprehensive scheme for numerical weather prediction models with potential applications in climate simulations, Mon. Weather Rev., 120, 303-325, 1992.

Rosenfeld, D.: TRMM observed first direct evidence of smoke from forest fires inhibiting rainfall, Geophys. Res. Lett., 26, 31053108, 1999.

Rosenfeld, D. and Woodley, W. L.: Satellite-inferred impact of aerosols on the microstructure of Thai convective clouds, in: Seven WMO Scientific Conference on Weather Modification, Chiang Mai, Thailand, 17-22 February 1999, 17-20, 1999.

Rosenfeld, D., Dai, J., Yu, X., Yao, Z., Xu, X., Yang, X., and Du, C.: Inverse relations between amounts of air pollution and orographic precipitation, Science, 315, 1396-1398, 2007.

Rosenfeld, D., Woodley, W. L., Axisa, D., Freud, E., Hudson, J. G., and Givati, A.: Aircraft measurements of the impacts of pollution aerosols on clouds and precipitation over the Sierra Nevada, J. Geophys. Res., 113, D15203, doi:10.1029/2007JD009544, 2008.

Roustan, Y. and Bocquet, M.: Inverse modelling for mercury over Europe, Atmos. Chem. Phys., 6, 3085-3098, doi:10.5194/acp-63085-2006, 2006.

Russo, F., Maurizi, A., D'Isidoro, M., and Tampieri, F.: Introduction of the aerosol feedback process in the model BOLCHEM, in: EGU General Assembly 2010, Vienna, Austria, 2-7 May 2010, EGU2010-8561, 2010.

Saide, P., Carmichael, G., Spak, S., Minnis, P., and Ayers, J.: Improving aerosol distributions below clouds by assimilating satellite-retrieved cloud droplet number, P. Natl. Acad. Sci. USA, 109, 11939-11943, 2012.

Saide, P. E., Carmichael, G. R., Liu, Z., Schwartz, C. S., Lin, H. C., da Silva, A. M., and Hyer, E.: Aerosol optical depth assimilation for a size-resolved sectional model: impacts of observationally constrained, multi-wavelength and fine mode retrievals on regional scale analyses and forecasts, Atmos. Chem. Phys., 13, 10425-10444, doi:10.5194/acp-13-10425-2013, 2013.

Salzmann, M., Ming, Y., Golaz, J.-C., Ginoux, P. A., Morrison, H., Gettelman, A., Krämer, M., and Donner, L. J.: Two-moment bulk stratiform cloud microphysics in the GFDL AM3 GCM: description, evaluation, and sensitivity tests, Atmos. Chem. Phys., 10, 8037-8064, doi:10.5194/acp-10-8037-2010, 2010.

Sander, R., Kerkweg, A., Jöckel, P., and Lelieveld, J.: Technical note: The new comprehensive atmospheric chemistry module MECCA, Atmos. Chem. Phys., 5, 445-450, doi:10.5194/acp-5445-2005, 2005.

Sandu, A. and Sander, R.: Technical note: Simulating chemical systems in Fortran90 and Matlab with the Kinetic PreProcessor KPP-2.1, Atmos. Chem. Phys., 6, 187-195, doi:10.5194/acp-6187-2006, 2006.

Sarwar, G., Luecken, D., Yarwood, G., Whitten, G. Z., and Carter, W. P. L.: Impact of an updated carbon bond mechanism on predictions from the CMAQ modeling system: preliminary assessment, J. Appl. Meteorol. Clim., 47, 3-14, 2008.

Sass, B. H.: A research version of the STRACO cloud scheme, Danish Meteorological Institute, Technical report no 02-10, http://www.dmi.dk/fileadmin/user_upload/Rapporter/TR/ 2002/tr02-10.pdf, 2002.

Sass, B. H. and Yang, X.: Recent tests of proposed revisions to the STRACO cloud scheme, HIRLAM Newslett., 41, 167-174, 2002.
Saunders, S. M., Jenkin, M. E., Derwent, R. G., and Pilling, M. J.: Protocol for the development of the Master Chemical Mechanism, MCM v3 (Part A): tropospheric degradation of nonaromatic volatile organic compounds, Atmos. Chem. Phys., 3, 161-180, doi:10.5194/acp-3-161-2003, 2003

Savage, N. H., Agnew, P., Davis, L. S., Ordóñez, C., Thorpe, R., Johnson, C. E., O'Connor, F. M., and Dalvi, M.: Air quality modelling using the Met Office Unified Model (AQUM OS24-26): model description and initial evaluation, Geosci. Model Dev., 6 , 353-372, doi:10.5194/gmd-6-353-2013, 2013.

Savenije, M., van Ulft, L. H., van Meijgaard, E., Henzing, J. S., aan de Brugh, J. M. J., Manders-Groot, A. M. M., and Schaap, M.: Two-Way Coupling of RACMO2 and LOTOS-EUROS, Implementation of the Direct Effect of Aerosol on Radiation, TNO 060-UT-2012-00508, 2012.

Savijärvi, H.: Fast radiation parameterization schemes for mesoscale and short-range forecast models, J. Appl. Meteorol., 29, 437-447, 1990.

Schaap, M., Timmermans, R. M. A., Roemer, M., Boersen, G. A. C., Builtjes, P. J. H., Sauter, F. J., Velders, G. J. M., and Beck, J. P.: The LOTOS-EUROS model: description, validation and latest developments, Int. J. Environ. Pollut., 32, 270-290, 2008.

Schaap, M., Manders, A. M. M., Hendriks, E. C. J., Cnossen, J. M., Segers, A. J. S., Denier van der Gon, H. A. C., Jozwicka, M., Sauter, F., Velders, G., Matthijsen, J., and Builtjes, P. J. H.: Regional modelling of particulate matter for the Netherlands, PBL Report 500099008, Netherlands Environmental Assessment Agency, AH Bilthoven, the Netherlands, 2009.

Schäfer, K., Emeis, S., Forkel, R., Hoffmann, M., Jahn, C., Suppan, P., and Münkel, C.: Continuous detection of mixing layer heights applied for evaluation of numerical simulations of air pollution episodes, VDI-Berichte, 2113 (2011), 305-310, VDITagung "Neue Entwicklungen bei der Messung und Beurteilung der Luftqualität" UMTK 2011, Baden-Baden, 11-12 May 2011, 2011.

Schell, B., Ackermann, I. J., Binkowski, F. S., and Ebel, A.: Modeling the formation of secondary organic aerosol within a comprehensive air quality model system, J. Geophys. Res., 106, 2827528293, 2001

Scherea, K., Flemming, J., Vautard, R., Chemel, C., Colette, A., Hogrefe, C., Bessagnet, B., Meleux, F., Mathur, R., Roselle, S., Hu, R.-M., Sokhi, R. S., Rao, S. T., and Galmarini, S. Trace gas/aerosol boundary concentrations and their impacts on continental-scale AQMEII modeling domains, Atmos. Environ., 53, 38-50, doi:10.1016/j.atmosenv.2011.09.043, 2012.

Schlünzen, K. H.: Das mesoskalige Transport- und Strömungsmodell "METRAS" - Grundlagen, Validierung, Anwendung, Hamb. Geophys. Einzelschr, 88, 139 pp., 1988 (in German with abstract in English).

Schlünzen, K. H.: Numerical studies on the inland penetration of sea breeze fronts at a coastline with tidally flooded mudflats, Beitr. Phys. Atmos., 63, 243-256, 1990.

Schlünzen, K. H.: Mesoscale modelling in complex terrain - an overview on the German non- hydrostatic models, Beitr. Phys. Atmos., 67, 243-253, 1994.

Schlünzen, K. H. and Katzfey, J. J.: Relevance of sub-grid-scale land-use effects for mesoscale models, Tellus, 55, 232-246, 2003. 
Schlünzen, K. H. and Meyer, E. M. I.: Impacts of meteorological situations and chemical reactions on daily dry deposition of nitrogen into the Southern North Sea, Atmos. Environ., 41, 289302, 2007.

Schlünzen, K. H. and Niemeier, U.: Changes in nitrogen deposition due to sea level rise in the coastal area of Germany - a numerical case study performed with a nonhydrostatic mesoscale model, 88th Annual Meeting and Exhibition A\&WMA, San Antonio, Texas, 18-23 June, 1995, 95-WP74B. 03, 14, 1995.

Schlünzen, K. H. and Pahl, S.: Modification of dry deposition in a developing sea-breeze circulation - a numerical case study, Atmos. Environ., 26, 51-61, 1992.

Schlünzen, K. H. and Sokhi, R. (Eds.): Overview on Tools and Methods for mesoscale model evaluation and user training, Joint Report of COST Action 728 and GURME, GAW Report 181, WMO/TD-No. 1457, World Meteorological Organization (WMO), Geneva, Switzerland, ISBN 978-1-905313-59-4, 2008.

Schlünzen, K. H., Stahlschmidt, T., Rebers, A., Niemeier, U., Kriews, M., and Dannecker, W.: Atmospheric input of lead into the German Bight - a high resolution measurement and model case study for 23 to 30 April 1991, Mar. Ecol.-Prog. Ser., 156, 299-309, 1997.

Schlünzen, K. H., Hinneburg, D., Knoth, O., Lambrecht, M., Leitl, B., Lopez, S., Lüpkes, C., Panskus, H., Renner, E., Schatzmann, M., Schoenemeyer, T., Trepte, S., and Wolke, R.: Flow and transport in the obstacle layer - first results of the microscale model MITRAS, J. Atmos. Chem., 44, 113-130, 2003.

Schlünzen, K. H., Grawe, D., Bohnenstengel, S. I., Schlüter I., and Koppmann R.: Joint modelling of obstacle induced and mesoscale changes - current limits and challenges, J. Wind Eng. Ind. Aerodyn., 99, 217-225, doi:10.1016/j.jweia.2011.01.009, 2011.

Schlünzen, K. H., Flagg, D. D., Fock, B. H., Gierisch, A., Lüpkes, C., Reinhardt, V., and Spensberger, C.: Scientific Documentation of the Multiscale Model System M-SYS (METRAS, MITRAS, MECTM, MICTM, MESIM). MEMI Technical Report 4, Meteorological Institute, Univ. Hamburg, available at: http://www. mi.uni-hamburg.de/fileadmin/files/forschung/techmet/nummod/ metras/M-SYSScientificDocumentation2012-02-09.pdf (last access: 29 April 2013), 2012.

Schroeder, G., Schlünzen, K. H., and Schimmel, F.: Use of (weighted) essentially non-oscillatory advection schemes in a mesoscale model, Q. J. Roy. Meteor. Soc., 132, 1509-1526, doi:10.1256/qj.04.191, 2006.

Schueler, S. and Schlünzen, K. H.: Modeling of oak pollen dispersal on the landscape level with a mesoscale atmospheric model, Environ. Model. Assess., 11, 179-194, 2006.

Schueler, S., Schlünzen, K. H., and Scholz, F.: Viability and sunlight sensitivity of oak pollen and its implications for pollen-mediated gene flow, Trees-struct. Funct., 19, 154-161, 2005.

Schürmann, G. J., Algieri, A., Hedgecock, I. M., Manna, G., Pirrone, N., and Sprovieri, F.: Modelling local and synoptic scale influences on ozone concentrations in a topographically complex region of Southern Italy, Atmos. Environ., 43, 4424-4434, 2009.

Schwartz, C. S., Liu, Z., Lin, H.-C., and McKeen, S. A.: Simultaneous three-dimensional variational assimilation of surface fine particulate matter and MODIS aerosol optical depth, J. Geophys. Res., 117, D13202, doi:10.1029/2011JD017383, 2012.
Seigneur, C., Pun, B., Pai, P., Louis, J.-F., Solomon, P., Emery, C., Morris, R., Zahniser, M., Worsnop, D., Koutrakis, P., White, W., and Tombach, I.: Guidance for the performance evaluation of three-dimensional air quality modeling systems for particulate matter and visibility, J. Air Waste Manage., 50, 588-599, doi:10.1080/10473289.2000.10464036, 2000.

Seifert, A. and Beheng, K. D.: A double-moment parameterization for simulating autoconversion, accretion and selfcollection, Atmos. Res., 59, 265-281, 2001.

Seifert, A. and Beheng, K. D.: A two-moment cloud microphysics parameterization for mixed-phase clouds. Part 1: Model description, Meteorol. Atmos. Phys., 92, 45-66, doi:10.1007/s00703005-0112-4, 2006.

Seinfeld, J. H. and Pandis, S. N.: Atmospheric Chemistry and Physics, John Wiley and Sons, Inc., 2003.

Semane, N., Peuch, V.-H., Pradier, S., Desroziers, G., El Amraoui, L., Brousseau, P., Massart, S., Chapnik, B., and Peuch, A.: On the extraction of wind information from the assimilation of ozone profiles in Météo-France 4-D-Var operational NWP suite, Atmos. Chem. Phys., 9, 4855-4867, doi:10.5194/acp-9-4855-2009, 2009.

Sesartic, A., Lohmann, U., and Storelvmo, T.: Bacteria in the ECHAM5-HAM global climate model, Atmos. Chem. Phys., 12, 8645-8661, doi:10.5194/acp-12-8645-2012, 2012.

Shalaby, A., Zakey, A. S., Tawfik, A. B., Solmon, F., Giorgi, F., Stordal, F., Sillman, S., Zaveri, R. A., and Steiner, A. L.: Implementation and evaluation of online gas-phase chemistry within a regional climate model (RegCM-CHEM4), Geosci. Model Dev., 5, 741-760, doi:10.5194/gmd-5-741-2012, 2012.

Siebesma, A. P., Soares, P. M. M., and Teixeira, J.: A combined Eddy-diffusivity massflux approach for the convective boundary layer, J. Atmos. Sci., 64, 1230-1248, doi:10.1175/JAS3888.1, 2007.

Simpson, D., Gelencsér, A., Caseiro, A., Klimont, Z., Kupiainen, K., Legrand, M., Pio, C., Puxbaum, H., Vestreng, V., and Yttri, K. E.: Modeling carbonaceous aerosol over Europe: analysis of the CARBOSOL and EMEP EC/OC campaigns, J. Geophys. Res., 112, D23S14, doi:10.1029/2006JD008158, 2007.

Sitch, S., Cox, P. M., Collins, W. J., and Huntingford, C.: Indirect forcing of climate change through ozone effects on the landcarbon sink, Nature, 448, 791-794, 2007.

Shao, Y.: A model for mineral dust emission, J. Geophys. Res., 106, 20239-20254, 2001.

Shrivastava, M., Fast, J., Easter, R., Gustafson Jr., W. I., Zaveri, R. A., Jimenez, J. L., Saide, P., and Hodzic, A.: Modeling organic aerosols in a megacity: comparison of simple and complex representations of the volatility basis set approach, Atmos. Chem. Phys., 11, 6639-6662, doi:10.5194/acp-11-6639-2011, 2011.

Skamarock, W. C., Klemp, J. B., Dudhia, J., Gill, D. O., Barker, D. M., Wang, W., and Powers, J. G.: A description of the advanced research WRF version 2, NCAR Technical Note, 25, NCAR/TN468+STR, 88 pp., 2005.

Skamarock, W. C., Klemp, J. B., Dudhia, J., Gill, D. O., Barker, D. M., Duda, M. G., Huang, X.-Y., Wang, W., and Powers, J. G.: A description of the Advanced Research WRF version 3, National Center for Atmospheric Research Tech. Note, NCAR/TN475+STR, 113 pp., 2008. 
Smagorinsky, J.: General circulation experiments with the primitive equations, i. the basic experiment, Mon. Weather Rev., 91, 99164,1963

Smith, B., Samuelsson, P., Wramneby, A., and Rummukainen, M.: A model of the coupled dynamics of climate, vegetation and terrestrial ecosystem biogeochemistry for regional applications, Tellus, 63, 87-106, 2011.

Smolarkiewicz, P. K. and Grabowski, W. W.: The multidimensional positive definite advection transport algorithm: nonoscillatory option, J. Comput. Phys., 86, 355-375, 1990.

Sofiev, M., Bousquet, J., Linkosalo, T., Ranta, H., RantioLehtimaki, A., Siljamo, P., Valovirta, E., and Damialis, A.: Pollen, allergies and adaptation, in: Biometeorology and Adaptation to Climate Variability and Change, edited by: Ebi, K., McGregor, G., and Burton, I., Springer Science, 75-107, 2009a.

Sofiev, M., Sofieva, V., Elperin, T., Kleeorin, N., Rogachevski, I., and Zilitnkevich, S.: Turbulent diffusion and turbulent thermal diffusion of aerosols in stratified atmospheric flows, J. Geophys. Res., 114, D18209, doi:10.1029/2009JD011765, 2009b.

Sokhi, R., Baklanov, A., and Schluenzen, H. (Eds.): Mesoscale Meteorological Modelling for air Pollution and Dispersion Applications, COST728 Final Book, Anthem Press, in press, 260 pp., 2014

Sokolik, I. N. and Toon, O. B.: Incorporation of mineralogical composition into models of the radiative properties of mineral aerosol from UV to IR wavelengths, J. Geophys. Res., 104, 9423-9444, doi:10.1029/1998JD200048, 1999.

Solazzo, E., Bianconi, R., Vautard, R., Appel, K. W., Moran, M. D., Hogrefe, C., Bessagnet, B., Brandt, J., Christensen, J. H., Chemel, C., Coll, I., van der Gon, H. D., Ferreira, J., Forkel, R., Francis, X. V., Grell, G., Grossi, P., Hansen, A. B., Jeričević, A., Kraljević, L., Miranda, A. I., Nopmongcol, U., Pirovano, G., Prank, M., Riccio, A., Sartelet, K. N., Schaap, M., Silver, J. D., Sokhi, R. S., Vira, J., Werhahn, J., Wolke, R., Yarwood, G., Zhang, J., Rao, S. T., and Galmarini, S.: Model evaluation and ensemble modelling of surface-level ozone in Europe and North America in the context of AQMEII, Atmos. Environ., 53, 60-74, doi:10.1016/j.atmosenv.2012.01.003, 2012a.

Solazzo, E., Bianconi, R., Pirovano, G., Matthias, V., Vautard, R., Moran, M. D., Appel, K. W., Bessagnet, B., Brandt, J., Christensen, J. H., Chemel, C., Coll, I., Ferreira, J., Forkel, R., Francis, X. V., Grell, G., Grossi, P., Hansen, A. B., Miranda, A. I., Nopmongcol, U., Prank, M., Sartelet, K. N., Schaap, M., Silver, J. D., Sokhi, R. S., Vira, J., Werhahn, J., Wolke, R., Yarwood, G., Zhang, J., Rao, S. T., and Galmarini, S.: Operational model evaluation for particulate matter in Europe and North America in the context of AQMEII, Atmos. Environ., 53, 75-92, doi:10.1016/j.atmosenv.2012.02.045, 2012b.

Solazzo, E., Bianconi, R., Pirovano, G., Moran, M. D., Vautard, R., Hogrefe, C., Appel, K. W., Matthias, V., Grossi, P., Bessagnet, B., Brandt, J., Chemel, C., Christensen, J. H., Forkel, R., Francis, X. V., Hansen, A. B., McKeen, S., Nopmongcol, U., Prank, M., Sartelet, K. N., Segers, A., Silver, J. D., Yarwood, G., Werhahn, J., Zhang, J., Rao, S. T., and Galmarini, S.: Evaluating the capability of regional-scale air quality models to capture the vertical distribution of pollutants, Geosci. Model Dev., 6, 791-818, doi:10.5194/gmd-6-791-2013, 2013a.

Solazzo, E., Riccio, A., Kioutsioukis, I., and Galmarini, S.: Pauci ex tanto numero: reduce redundancy in multi-model ensembles,
Atmos. Chem. Phys., 13, 8315-8333, doi:10.5194/acp-13-83152013, 2013b.

Solmon, F., Sarrat, C., Serča, D., Tulet, P., and Rosset, R.: Isoprene and monoterpenes biogenic emissions in France: modeling and impact during a regional pollution episode, Atmos. Environ., 38, 3853-3865, doi:10.1016/j.atmosenv.2004.03.054, 2004.

Solmon, F., Giorgi, F., and Liousse, C.: Aerosol modelling for regional climate studies: application to anthropogenic particles and evaluation over a European/African domain, Tellus B, 58, 51-72, 2006.

Solmon, F., Mallet, M., Elguindi, N., Giorgi, F., Zakey, A., and Konare, A.: Dust aerosol impact on regional precipitation over western africa, mechanisms and sensitivity to absorption properties, Geophys. Res. Lett., 35, 124705, doi:10.1029/2008GL035900, 2008.

Solmon, F., Elguindi, N., and Mallet, M.: Radiative and climatic effects of dust over West Africa, as simulated by a regional climate model, Clim. Res., 2, 97-113, 2012.

Solomos, S., Kallos, G., Kushta, J., Astitha, M., Tremback, C., Nenes, A., and Levin, Z.: An integrated modeling study on the effects of mineral dust and sea salt particles on clouds and precipitation, Atmos. Chem. Phys., 11, 873-892, doi:10.5194/acp11-873-2011, 2011

Sørensen, B.: New mass conserving multi-tracer efficient transport schemes focusing on semi-Lagrangian and Lagrangian methods for online integration with chemistry, PhD Thesis, University of Copenhagen, Danish Meteorological Institute, Copenhagen, Denmark, 2012.

Sørensen, B., Kaas, E., and Korsholm, U. S.: A mass-conserving and multi-tracer efficient transport scheme in the online integrated Enviro-HIRLAM model, Geosci. Model Dev., 6, 1029 1042, doi:10.5194/gmd-6-1029-2013, 2013.

Spichtinger, P. and Gierens, K. M.: Modelling of cirrus clouds Part 1a: Model description and validation, Atmos. Chem. Phys. 9, 685-706, doi:10.5194/acp-9-685-2009, 2009.

Spyrou, C., Mitsakou, C., Kallos, G., Louka, P., and Vlastou, G.: An improved limited-area model for describing the dust cycle in the atmosphere, J. Geophys. Res., 115, D17211, doi:10.1029/2009JD013682, 2010.

Stanelle, T., Vogel, B., Vogel, H., Bäumer, D., and Kottmeier, C.: Feedback between dust particles and atmospheric processes over West Africa during dust episodes in March 2006 and June 2007, Atmos. Chem. Phys., 10, 10771-10788, doi:10.5194/acp10-10771-2010, 2010.

Staudt, M., Bertin, N., Hansen, U., Seufert, G., Ciccioli, P., Foster, P., Frenzel, B., and Fugit, J.-L.: The BEMA-project: seasonal and diurnal patterns of monoterpene emissions from Pinus pinea (L.), Atmos. Environ., 31, 145-156, 1997.

Stern, R., Builtjes, P., Schaap, M., Timmermans, R., Vautard, R., Hodzic, A., Memmesheimer, M., Feldmann, H., Renner, E., Wolke, R., and Kerschbaumer, A.: A model intercomparison study focussing on episodes with elevated $\mathrm{PM}_{10}$ concentrations, Atmos. Environ., 42, 4567-4588, 2008.

Stensrud, D. J.: Parameterisations Schemes. Keys to Understanding Numerical Weather Prediction Models, Cambridge University Press, 459 pp., 2007.

Steppeler, J., Doms, G., Schättler, U., Blitzer, H. W., Gassmann, A., Damrath, U., and Gregoric, G.: Meso-gamma scale forecasts 
using the nonhydrostatic model LM, Meteorol. Atmos. Phys., 82, 75-96, 2003.

Stockwell, W. R., Middleton, P., and Chang, J. S.: The second generation regional acid deposition model chemical mechanism for regional air quality modelling, J. Geophys. Res., 95, 16343-16367, 1990.

Stockwell, W. R., Kirchner, F., Kuhn, M., and Seefeld, S.: A new mechanism for regional atmospheric chemistry modeling, J. Geophys. Res., 102, 25847-25879, doi:10.1029/97JD00849, 1997.

Stone, D., Evans, M. J., Commane, R., Ingham, T., Floquet, C. F. A., McQuaid, J. B., Brookes, D. M., Monks, P. S., Purvis, R., Hamilton, J. F., Hopkins, J., Lee, J., Lewis, A. C., Stewart, D., Murphy, J. G., Mills, G., Oram, D., Reeves, C. E., and Heard, D. E.: $\mathrm{HO}_{\mathrm{x}}$ observations over West Africa during AMMA: impact of isoprene and $\mathrm{NO}_{\mathrm{x}}$, Atmos. Chem. Phys., 10, 9415-9429, doi:10.5194/acp-10-9415-2010, 2010.

Storelvmo, T., Kristjansson, J. E., and Lohmann, U.: Aerosol influence on mixed-phase clouds in CAM-Oslo, J. Atmos. Sci., 65, 3214-3230, doi:10.1175/2008JAS2430.1, 2008.

Struzewska, J. and Kaminski, J. W.: Formation and transport of photooxidants over Europe during the July 2006 heat wave - observations and GEM-AQ model simulations, Atmos. Chem. Phys., 8, 721-736, doi:10.5194/acp-8-721-2008, 2008.

Suhre, K., Crassier, V., Mari, C., Rosset, R., Johnson, D. W., Osborne, S., Wood, R., Andreae, M. O., Bandy, B., Bates, T. S., Businger, S., Gerbig, C., Raes, F., and Rudolph, J.: Chemistry and aerosols in the marine boundary layer: 1-D modelling of the three ACE-2 Lagrangian experiments, Atmos. Environ., 34, 5079-5094, 2000.

Sundqvist, H.: A parameterization scheme for non-convective condensation including prediction of cloud water content, Q. J. Roy. Meteor. Soc., 104, 677-690, 1978.

Sutton, M. A., Burkhardt, J. K., Guerin, D., Nemitz, E., and Fowler, D.: Development of resistance models to describe measurements of bi-directional ammonia surface-atmosphere exchange, Atmos. Environ., 32, 473-480, 1998.

Sutton, M. A., Reis, S., Riddick, S. N., Dragosits, U., Nemitz, E., Theobald, M. R., Tang, Y. S., Braban, C. F., Vieno, M., Dore, A. J., Mitchell, R. F., Wanless, S, Daunt, F., Fowler, D., Blackall, T. D., Milford, C., Flechard, C. R., Loubet, B., Massad, R., Cellier, P., Personne, E., Coheur, P. F., Clarisse, L., Van Damme, M., Ngadi, Y., Clerbaux, C., Skjøth, C. A., Geels, C., Hertel, O., Wichink Kruit, R. J., Pinder, R. W., Bash, J. O., Walker, J. T., Simpson, D., Horváth, L., Misselbrook, T. H., Bleeker, A., Dentener, F., and de Vries, W.: Towards a climate-dependent paradigm of ammonia emission and deposition, Philos. Trans. R. Soc. B. Biol. Sci., 368, 20130166, doi:10.1098/rstb.2013.0166, 2013.

Svensson, G., Holtslag, A. A. M., Kumar, V., Mauritsen, T., Steeneveld, G. J., Angevine, W. M., Bazile, E., Beljaars, A., de Bruijn, E. I. F., Cheng, A., Conangla, L., Cuxart, J., Ek, M., Falk, M. J., Freedman, F., Kitagawa, H., Larson, V. E., Lock, A., Mailhot, J., Masson, V., Park, S., Pleim, J., Soderberg, S., Weng, W., and Zampieri, M.: Evaluation of the diurnal cycle in the atmospheric boundary layer over land as represented by a variety of single- column models: the second GABLS experiment, Bound.Lay. Meteorol., 140, 177-206, doi:10.1007/s10546-011-9611-7, 2011.
Szidat, S., Jenk, T. M., Synal, H.-A., Kalberer, M., Wacker, L., Hajdas, I., Kasper-Giebl, A., and Baltensperger, U.: Contributions of fossil fuel, biomass burning, and biogenic emissions to carbonaceous aerosols in Zurich as traced by 14 C, J. Geophys. Res., 111, D07206, doi:10.1029/2005JD006590, 2006.

Szopa, S., Aumont, B., and Madronich, S.: Assessment of the reduction methods used to develop chemical schemes: building of a new chemical scheme for VOC oxidation suited to threedimensional multiscale $\mathrm{HO}_{\mathrm{X}}-\mathrm{NO}_{\mathrm{X}}$-VOC chemistry simulations, Atmos. Chem. Phys., 5, 2519-2538, doi:10.5194/acp-5-25192005, 2005.

Tang, Y., Carmichael, G. R., Thongboonchoo, N., Chai, T., Horowitz, L. W., Pierce, R. B., Al-Saadi, J. A., Pfister, G., Vukovich, J. M., Avery, M. A., Sachse, G. W., Ryerson, T. B., Holloway, J. S., Atlas, E. L., Flocke, F. M., Weber, R. J., Huey, L. G., Dibb, J. E., Streets, D. G., and Brune, W. H.: The influence of lateral and top boundary conditions on regional air quality prediction: a multi-scale study coupling regional and global chemical transport models, J. Geophys. Res., 112, D10S18, doi:10.1029/2006JD007515, 2007.

Tatang, M. A., Pan, W., Prinn, R. G., and McRae, G. J.: An efficient method for parametric uncertainty analysis of numerical geophysical models, J. Geophys. Res.-Atmos., 102, 21925-21932, 1997.

Thuburn, J. and Tan, D. G. H.: A parameterization of mixdown time for atmospheric chemicals, J. Geophys. Res., 102, 13037-13049, 1997.

Tiedtke, M.: A comprehensive mass flux scheme for cumulus parameterization in large-scale models, Mon. Weather Rev., 117, 1779-1799, 1989.

Tilgner, A., Schroedner, R., Braeuer, P., Wolke, R., and Herrmann, H.: SPACCIM Simulations of Chemical Aerosol-Cloud Interactions with the Multiphase Chemistry Mechanism MCMCAPRAM3.0, in: American Geophysical Union, Fall Meeting 2010, Abstract \#A21K-05, 2010.

Tingey, D. T., Manning, M., Grothaus, L. C., and Burns, W. F.: Influence of light and temperature on monoterpene emission rates from slash pine, Plant Physiol., 65, 797-801, 1980.

Tompkins, A. M., Gierens, K., and Radel, G.: Ice supersaturation in the ECMWF integrated forecast system, Q. J. Roy. Meteor. Soc., 133, 53-63, 2007.

Topping, D., Lowe, D., and McFiggans, G.: Partial Derivative Fitted Taylor Expansion: an efficient method for calculating gas-liquid equilibria in atmospheric aerosol particles: 1. Inorganic compounds, J. Geophys. Res., 114, D04304, doi:10.1029/2008JD010099, 2009.

Topping, D., Lowe, D., and McFiggans, G.: Partial Derivative Fitted Taylor Expansion: an efficient method for calculating gas/liquid equilibria in atmospheric aerosol particles - Part 2: Organic compounds, Geosci. Model Dev., 5, 1-13, doi:10.5194/gmd-51-2012, 2012.

Toro, E. F.: The weighted average flux method applied to the time dependent Euler equations, Philos. T. R. Soc. Lond., 341, 499530, 1992.

Tost, H., Jöckel, P., Kerkweg, A., Sander, R., and Lelieveld, J.: Technical note: A new comprehensive SCAVenging submodel for global atmospheric chemistry modelling, Atmos. Chem. Phys., 6, 565-574, doi:10.5194/acp-6-565-2006, 2006. 
Tost, H., Jöckel, P., and Lelieveld, J.: Lightning and convection parameterisations - uncertainties in global modelling, Atmos. Chem. Phys., 7, 4553-4568, doi:10.5194/acp-7-4553-2007, 2007.

Toyota, K., McConnell, J. C., Lupu, A., Neary, L., McLinden, C. A., Richter, A., Kwok, R., Semeniuk, K., Kaminski, J. W., Gong, S.-L., Jarosz, J., Chipperfield, M. P., and Sioris, C. E.: Analysis of reactive bromine production and ozone depletion in the Arctic boundary layer using 3-D simulations with GEM-AQ: inference from synoptic-scale patterns, Atmos. Chem. Phys., 11, 3949-3979, doi:10.5194/acp-11-3949-2011, 2011.

Tremback, C. J.: Numerical simulation of a mesoscale convective complex model development and numerical results, $\mathrm{Ph}$.D. dissertation, Atmos. Sci. Paper No. 465, Department of Atmospheric Science, Colorado State University, Fort Collins, CO 80523, 247 pp., 1990.

Tremback, C. J., Powell, J., Cotton, W. R., and Pielke, R. A.: The forward-in-time upstream advection scheme: extension to higher orders, Mon. Weather Rev., 115, 540-555, 1987.

Trukenmüller A., Grawe D., and Schlünzen K. H.: A model system for the assessment of ambient air quality conforming to EC directives, Meteorol. Z., 13, 387-394, 2004.

Tuccella, P., Curci, G., Visconti, G., Bessagnet, B., Menut, L., and Park, R. J.: Modeling of gas and aerosol with WRF/Chem over Europe: evaluation and sensitivity study, J. Geophys. Res., 117, D03303, doi:10.1029/2011JD016302, 2012.

Tulet, P. and Villeneuve, N.: Large scale modeling of the transport, chemical transformation and mass budget of the sulfur emitted during the April 2007 eruption of Piton de la Fournaise, Atmos. Chem. Phys., 11, 4533-4546, doi:10.5194/acp-11-45332011, 2011.

Tulet, P., Maalej, A., Crassier, V., and Rosset, R.: An episode of photooxidant plume pollution over the Paris region, Atmos. Environ., 33, 1651-1662, 1999.

Tulet, P., Crassier, V., Solmon, F., Guedalia, D., and Rosset, R.: Description of the mesoscale nonhydrostatic chemistry model and application to a transboundary pollution episode between northern France and southern England, J. Geophys. Res., 108, 4021, ACH 5-1-ACH 5-11, 2003.

Tulet, P., Crassier, V., Cousin, F., Shure, K., and Rosset, R.: ORILAM, a three moment lognormal aerosol scheme for mesoscale atmospheric model. On-line coupling into the MesoNH- C model and validation on the Escompte campaign, J. Geophys. Res., 110, D18201, doi:10.1029/2004JD005716, 2005.

Tulet, P., Grini, A., Griffin, R., and Petitcol, S.: ORILAM-SOA: a computationally efficient model for predicting secondary organic aerosols in 3-D atmospheric models, J. Geophys. Res., 111, D23208, doi:10.1029/2006JD007152, 2006.

Turner, N. C., Waggoner, P. E., and Rich, S.: Removal of ozone from the atmosphere by soil and vegetation, Nature, 250, 486489, 1974

Twomey, S.: The Influence of Pollution on the Shortwave Albedo of Clouds, J. Atmos. Sci., 34, 1149-1152, 1977.

Uphoff, M.: Photolyeratenberechnung in atmosphärischen Chemiemodellen, Dissertation in preparation, Univ. Hamburg, 2013.

Valcke, S. and Redler, R.: OASIS4 User Guide (OASIS4 0 2), PRISM Support Initiative Report No. 4, CERFACS, Toulouse, France, 60 pp., 2006. van Loon, M., Vautard, R.,Schaap, M., Bergström, R., Bessagnet, B., Brandt, J., Builtjes, P. J. H., Christensen J. H., Cuvelier, C., Graff, A., Jonson, J. E., Krol, M., Langner J., Roberts, P., Rouil, L., Stern, R., Tarrasón, L., Thunis, P., Vignati, E., White, L., and Wind, P.: Evaluation of long-term ozone simulations from seven regional air quality models and their ensemble, Atmos. Environ., 41, 2083-2097, doi:10.1016/j.atmosenv.2006.10.073, 2007.

van Meijgaard, E., Van Ulft, L. H., Van de Berg, W. J., Bosveld, F. C., Van den Hurk, B. J. J. M., Lenderink, G., and Siebesma, A. P.: The KNMI regional atmospheric climate model RACMO version 2.1, KNMI Technical report, TR-302, De Bilt, the Netherlands, 2008.

van Meijgaard, E., Van Ulft, L. H., Lenderink, G., de Roode, S. R., Wipfler, L., Boers, R., and Timmermans, R. M. A.: Refinement and application of a regional atmospheric model for climate scenario calculations of Western Europe, Climate changes Spatial Planning publication: KvR 054/12, ISBN/EAN 978-908815-046-3, 44 pp., 2012.

Vautard, R., Builtjes, P. H. J., Thunis, P., Cuvelier, C., Bedogni, M., Bessagnet, B., Honoré, C., Moussiopoulos, N., Pirovano, G., Schaap, M., Stern, R., Tarrason, L., and Wind, P.: Evaluation and intercomparison of ozone and $\mathrm{PM}_{10}$ simulations by several chemistry transport models over four European cities within the CityDelta project, Atmos. Environ., 41, 173-188, doi:10.1016/j.atmosenv.2006.07.039, 2007.

Vautard, R., Moran, M. D., Solazzo, E., Gilliam, R. C., Matthias, V., Bianconi, R., Chemel, C., Ferreira, J., Geyer, B., Hansen, A. B., Jericevic, A., Prank, M., Segers, A., Silver, J. D., Werhahn, J., Wolke, R., Rao, S. T., and Galmarini, S.: Evaluation of the meteorological forcing used for the Air Quality Model Evaluation International Initiative (AQMEII) air quality simulations, Atmos. Environ., 53, 15-37, doi:10.1016/j.atmosenv.2011.10.065, 2012.

Venkatram, A., Karamchandani, P. K., and Misra, P. K.: Testing a comprehensive acid deposition model, Atmos. Environ., 22, 737-747, 1988.

Vignati, E., Wilson, J., and Stier, P.: M7: an efficient sizeresolved aerosol microphysics module for large-scale aerosol transport models, J. Geophys. Res., 109, D22202, doi:10.1029/2003JD004485, 2004

Villani, M. G., Mona, L., Maurizi, A., Pappalardo, G., Tiesi, A., Pandolfi, M., D'Isidoro, M., Cuomo, V., and Tampieri, F.: Transport of volcanic aerosol in the troposphere: the case study of the 2002 Etna plume, J. Geophys. Res.-Atmos., 111, D21102, doi:10.1029/2006JD007126, 2006.

Vivanco, M. G., Palomino, I., Martí n, F., Palacios, M., Jorba, O., Jiménez, P., Baldasano, J. M., and Azula, O.: An Evaluation of the Performance of the CHIMERE Model over Spain Using Meteorology from MM5 and WRF Models, in: Computational Science and Its Applications - ICCSA 2009, Seoul, Korea, 29 June2 July 2009, Lect. Notes Comput. Sci., vol. 5592, 107-117, 2009.

Vogel, B., Fiedler, F., and Vogel, H.: Influence of topography and biogenic volatile organic compounds emission in the state of Baden-Württemberg on ozone concentrations during episodes of high air temperatures, J. Geophys. Res., 100, 22907-22928, doi:10.1029/95JD01228, 1995.

Vogel, B., Vogel, H., Bäumer, D., Bangert, M., Lundgren, K., Rinke, R., and Stanelle, T.: The comprehensive model system COSMOART - Radiative impact of aerosol on the state of the atmo- 
sphere on the regional scale, Atmos. Chem. Phys., 9, 8661-8680, doi:10.5194/acp-9-8661-2009, 2009.

Vogel, H., Pauling, A., and Vogel, B.: Numerical simulation of birch pollen dispersion with an operational weather forecast system, Int. J. Biometeorol., 52, 805-814, doi:10.1007/s00484-0080174-3, 2008.

Volkamer, R., Jimenez, J. L., San Martini, F., Dzepina, K., Zhang, Q., Salcedo, D., Molina, L. T., Worsnop, D. R., and Molina, M. J.: Secondary organic aerosol formation from anthropogenic air pollution: rapid and higher than expected, Geophys. Res. Lett., 33, L17811, doi:10.1029/2006GL026899, 2006.

von Salzen, K. and Schlünzen, K. H.: A prognostic physicochemical model of secondary and marine inorganic multicomponent aerosols: I. Models description, Atmos. Environ., 33, 567576, 1999a.

von Salzen, K. and Schlünzen, K. H.: A prognostic physicochemical model of secondary and marine inorganic multicomponent aerosols: II. Model tests, Atmos. Environ., 33, 1543-1552, 1999b.

von Salzen, K. and Schlünzen, K. H.: Simulation of the dynamics and composition of secondary and marine inorganic aerosols in the coastal atmosphere, J. Geophys. Res., 23, 30201-30217, 1999c.

von Salzen, K., Claussen, M., and Schlünzen, K. H.: Application of the concept of blending height to the calculation of surface fluxes in a mesoscale model, Meteorol. Z., 5, 60-66, 1996.

Waked, A., Seigneur, C., Couvidat, F., Kim, Y., Sartelet, K., Afif, C., Borbon, A., Formenti, P., and Sauvage, S.: Modeling air pollution in Lebanon: evaluation at a suburban site in Beirut during summer, Atmos. Chem. Phys., 13, 5873-5886, doi:10.5194/acp13-5873-2013, 2013.

Wang, J., Cubison, M. J., Aiken, A. C., Jimenez, J. L., and Collins, D. R.: The importance of aerosol mixing state and size-resolved composition on $\mathrm{CCN}$ concentration and the variation of the importance with atmospheric aging of aerosols, Atmos. Chem. Phys., 10, 7267-7283, doi:10.5194/acp-10-7267-2010, 2010.

Wang, K., Zhang, Y., Jang, C. J., Phillips, S., and Wang, B.-Y.: Modeling study of intercontinental air pollution transport over the trans-pacific region in 2001 using the community multiscale air quality modeling system, J. Geophys. Res., 114, D04307, doi:10.1029/2008JD010807, 2009.

Wang, M. and Penner, J. E.: Cirrus clouds in a global climate model with a statistical cirrus cloud scheme, Atmos. Chem. Phys., 10, 5449-5474, doi:10.5194/acp-10-5449-2010, 2010.

Wang, X., Mallet, V., Berroir, J.-P., and Herlin, I.: Assimilation of $\mathrm{OMI} \mathrm{NO} 2$ retrievals into a regional chemistry-transport model for improving air quality forecasts over Europe, Atmos. Environ., 45, 485-492, 2011.

Warren, S. G. and Wiscombe, W. J.: A model for the spectral albedo of snow. II: Snow containing atmospheric aerosols, J. Atmos. Sci., 37, 2734-2745, 1980.

Warren, S. G. and Wiscombe, W. J.: Dirty snow after nuclear war, Nature, 313, 469-470, 1985.

Wesely, M. L.: Parameterization of surface resistances to gaseous dry deposition in regional- scale numerical models, Atmos. Environ., 23, 1293-1304, 1989.

Watson, L. A., Shallcross, D. E., Utembe, S. R., and Jenkin, M. E.: A Common Representative Intermediates (CRI) mechanism for VOC degradation - Part 2: Gas phase mechanism reduction, Atmos. Environ., 42, 7196-7204, doi:10.1016/j.atmosenv.2008.07.034, 2008.

Wexler, A. S. and Seinfeld, J. H.: Second-generation inorganic aerosol model, Atmos. Environ., 25, 2731-2748, 1991.

Whitten, G. Z., Heo, G., Kimura, Y., McDonald-Buller, E., Allen, D., Carter, W. P. L., and Yarwood, G.: A new condensed toluene mechanism for Carbon Bond: CB05-TU, Atmos. Environ., 44, 5346-5355, 2010.

Wicker, L. J. and Skamarock, W. C.: Time splitting methods for elastic models using forward time schemes, Mon. Weather Rev., 130, 2088-2097, 2002.

Wichink Kruit, R. J., Schaap, M., Sauter, F. J., van Zanten, M. C., and van Pul, W. A. J.: Modeling the distribution of ammonia across Europe including bi-directional surface-atmosphere exchange, Biogeosciences, 9, 5261-5277, doi:10.5194/bg-9-52612012, 2012.

Winner, D. A., Cass, G. R., and Harley, R. A.: Effect of alternative boundary conditions on predicted ozone control strategy: a case study in Los Angeles area, Atmos. Environ., 29, 3451-3464, 1995.

Wolke, R., Hellmuth, O., Knoth, O., Schröder, W., Heinrich, B., and Renner, E.: The chemistry transport modelling system LMMUSCAT: description and CityDelta applications, in: Air Pollution Modeling and Its Application XVI, Proceedings of twentysixth NATO/CCMS international technical meeting on air pollution modeling and its application, edited by: Borrego, C. and Incecik, S., Kluver Academic/Plenum Publishers, New York, 427437, 2004a.

Wolke, R., Knoth, O., Hellmuth, O., Schröder, W., and Renner, E.: The parallel model system LM-MUSCAT for chemistrytransport simulations: coupling scheme, parallelization and application, in:, Parallel Computing: Software Technology, Algorithms, Architectures, and Applications, edited by: Joubert, G. R., Nagel, W. E., Peters, F. J., and Walter, W. V., Elsevier, Amsterdam, the Netherlands, 363-370, 2004b.

Wolke, R., Schröder, W., Schrödner, R., and Renner, E.: Influence of grid resolution and meteorological forcing on simulated European air quality: a sensitivity study with the modeling system COSMO-MUSCAT, Atmos. Environ., 53, 110-130, 2012.

Wong, D. C., Pleim, J., Mathur, R., Binkowski, F., Otte, T., Gilliam, R., Pouliot, G., Xiu, A., Young, J. O., and Kang, D.: WRFCMAQ two-way coupled system with aerosol feedback: software development and preliminary results, Geosci. Model Dev., 5, 299-312, doi:10.5194/gmd-5-299-2012, 2012.

Wu, L., Mallet, V., Bocquet, M., and Sportisse, B.: A comparison study of data assimilation algorithms for ozone forecasts, J. Geophys. Res., 113, D20310, doi:10.1029/2008JD009991, 2008.

Wu, Z. J., Hu, M., Shao, K. S., and Slanina, J.: Acidic gases, $\mathrm{NH}_{3}$ and secondary inorganic ions in $\mathrm{PM}_{10}$ during summer time in Beijing, China and their relation to air mass history, Chemosphere, 76, 1028-1035, 2009.

Xue, H. and Feingold, G.: Large eddy simulations of trade wind cumuli: investigation of aerosol indirect effects, J. Atmos. Sci., 63, 1605-1622, 2006.

Yarwood, G., Rao, S., Yocke, M. and Whitten, G. Z.: Updates to the Carbon Bond Mechanism: CB05. US EPA Final Report, 161 pp., available at: http://www.camx.com/publ/pdfs/CB05_Final_ Report_120805.pdf, 2005. 
Yienger, J. J. and Levy II, H.: Empirical model of global soil biogenic $\mathrm{NO}_{\mathrm{x}}$ emissions, J. Geophys. Res., 100, 11447-11464, 1995.

Ying, Q. and Li, J.: Implementation and initial application of the near-explicit Master Chemical Mechanism in the 3-D Community Multiscale Air Quality (CMAQ) Model, Atmos. Environ., 45, 3244-3256, 2011.

Yu, S. C., Kasibhatla, P. S., Wright, D. L., Schwartz, S. E., McGraw, R., and Deng, A: Moment-based simulation of microphysical properties of sulfate aerosols in the eastern United States: Model description, evaluation, and regional analysis, J. Geophys. Res., 108, 4353, doi:10.1029/2002JD002890, 2003.

Yu, S., Mathur, R., Pleim, J., Wong, D., Carlton, A. G., Roselle, S., and Rao, S. T.: Simulation of the indirect radiative forcing of climate due to aerosols by the two-way coupled WRF-CMAQ over the eastern United States, in: Air ollution Modeling and its Application XXI, edited by: Steyn, D. G. and Trini Castelli, S., Springer Netherlands, Netherlands, 579-583, 2011.

Zabkar, R., Rakovec, J., and Koracin, D.: The roles of regional accumulation and advection of ozone during high ozone episodes in Slovenia: a WRF/Chem modelling study, Atmos. Environ., 45, 1192-1202, 2011.

Zakey, A. S., Solmon, F., and Giorgi, F.: Implementation and testing of a desert dust module in a regional climate model, Atmos. Chem. Phys., 6, 4687-4704, doi:10.5194/acp-6-4687-2006, 2006.

Zakey, A. S., Giorgi, F., and Bi, X.: Modeling of sea salt in a regional climate model: fluxes and radiative forcing, J. Geophys. Res., 113, D14221, doi:10.1029/2007JD009209, 2008.

Zanis, P., Ntogras, C., Zakey, A., Pytharoulis, I., and Karacostas, T.: Regional climate feedback of anthropogenic aerosols over Europe using RegCM3, Clim. Res., 2, 267-278, 2012.

Zaveri, R. and Peters, L. K.: A new lumped structure photochemical mechanism for large-scale applications, J. Geophys. Res., 104, 30387-30415, 1999.

Zaveri, R. A., Easter, R. C., and Peters, L. K.: A computationally efficient Multicomponent Equilibrium Solver for Aerosols (MESA), J. Geophys. Res., 110, D24203, doi:10.1029/2004JD005618, 2005.

Zaveri, R. A., Easter, R. C., Fast, J. D., and Peters, L. K.: Model for Simulating Aerosol Interactions and Chemistry (MOSAIC), J. Geophys. Res., 113, D13204, doi:10.1029/2007JD008782, 2008.

Zerroukat, M., Wood, N., and Staniforth, A.: SLICE-S: a semiLagrangian inherently conserving and efficient scheme for transport problems on the sphere, Q. J. Roy. Meteor. Soc., 130, 26492664, 2004

Zerroukat M., Wood, N., and Staniforth, A.: Application of the parabolic spline method (PSM) to a multi-dimensional conservative semi-Lagrangian transport scheme (SLICE), J. Comput. Phys., 225, 935-948, 2007.

Zhang, D. F., Zakey, A. S., Gao, X. J., Giorgi, F., and Solmon, F.: Simulation of dust aerosol and its regional feedbacks over East Asia using a regional climate model, Atmos. Chem. Phys., 9, 1095-1110, doi:10.5194/acp-9-1095-2009, 2009.

Zhang, G. J. and McFarlane, N. A.: Sensitivity of climate simulations to the parameterization of cumulus convection in the Canadian Climate Centre general circulation model, Atmos. Ocean, 33, 407-446, 1995.
Zhang, L., Gong, S., Padro, J., and Barrie, L.: A size-segregated particle dry deposition scheme for an atmospheric aerosol module, Atmos. Environ., 35, 549-560, 2001.

Zhang, L., Brook, J. R., and Vet, R.: A revised parameterization for gaseous dry deposition in air-quality models, Atmos. Chem. Phys., 3, 2067-2082, doi:10.5194/acp-3-2067-2003, 2003.

Zhang, L., Jacob, D. J., Downey, N.V., Wood, D. A., Blewitt, D., Carouge, C. C., van Donkelaar, A., Jones, D. B. A., Murray, L. T., and Wang, Y.: Improved estimate of the policy-relevant background ozone in the United States using the GEOS-Chem global model with $1 / 2^{\circ} 2 / 3^{\circ}$ horizontal resolution over North America, Atmos. Environ., 45, 6769-6776, 2011.

Zhang, R., Li, G., Fan, J., Wu, D. L., and Molina, M. J.: Intensification of Pacific storm track linked to Asian pollution, P. Natl. Acad. Sci. USA, 104, 5295-5299, 2007.

Zhang, Y.: Online-coupled meteorology and chemistry models: history, current status, and outlook, Atmos. Chem. Phys., 8, 2895 2932, doi:10.5194/acp-8-2895-2008, 2008.

Zhang, Y., Seigneur, C., Seinfeld, J. H., Jacobson, M., and Binkowski, F. S.: Simulation of aerosol dynamics: a comparative review of algorithms used in air quality models, Aerosol Sci. Tech., 31, 487-514, 1999.

Zhang, Y., Seigneur, C., Seinfeld, J. H., Jacobson, M., Clegg, S. L., and Binkowski, F. S.: A comparative review of inorganic aerosol thermodynamic equilibrium models: similarities, differences, and their likely causes, Atmos. Environ., 34, 117-137, 2000 .

Zhang, Y., Wu, S.-Y., Krishnan, S., Wang, K., Queen, A., Aneja, V. P., and Arya, P.: Modeling agricultural air quality: current status, major challenges, and outlook, Atmos. Environ., 42, 3218-3237, 2008.

Zhang, Y., Vijayaraghavan, K., Wen, X.-Y., Snell, H. E., and Jacobson, M. Z.: Probing into regional ozone and particulate matter pollution in the United States: 1. A 1-year CMAQ simulation and evaluation using surface and satellite data, J. Geophys. Res., 114, D22304, doi:10.1029/2009JD011898, 2009a.

Zhang, Y., Wen, X.-Y., Wang, K., Vijayaraghavan, K., and Jacobson, M. Z.: Probing into regional ozone and particulate matter pollution in the United States: 2. An examination of formation mechanisms through a process analysis technique and sensitivity study, J. Geophys. Res., 114, D22305, doi:10.1029/2009JD011900, 2009b.

Zhang, Y., Pan, Y., Wang, K., Fast, J. D., and Grell, G A.: WRF/Chem-MADRID: incorporation of an aerosol module into WRF/Chem and its initial application to the TexAQS2000 episode, J. Geophys. Res., 115, D18202, doi:10.1029/2009JD013443, 2010a.

Zhang, Y., Wen, X.-Y., and Jang, C. J.: Simulating chemistryaerosol-cloud-radiation-climate feedbacks over the continental US using the online-coupled Weather Research Forecasting Model with chemistry (WRF/Chem), Atmos. Environ., 44, 3568-3582, doi:10.1016/j.atmosenv.2010.05.056, 2010b.

Zhang, Y., Seigneur, C., Bocquet, M., Mallet, V., and Baklanov, A.: Real-time air quality forecasting, Part I: History, techniques, and current status, Atmos. Environ., 60, 632-655, 2012a.

Zhang, Y., Seigneur, C., Bocquet, M., Mallet, V., and Baklanov, A.: Real-time air quality forecasting, Part II: State of the science, current research needs, and future prospects, Atmos. Environ., 60, 656-676, 2012b. 
Zhang, Y., Karamchandani, P., Glotfelty, T., Streets, D. G., Grell, G., Nenes, A., Yu, F.-Q., and Bennartz, R.: Development and Initial Application of the Global-Through-Urban Weather Research and Forecasting Model with Chemistry (GU-WRF/Chem), J. Geophys. Res., 117, D20206, doi:10.1029/2012JD017966, 2012c.

Zhang, Y., Chen, Y.-C., Sarwa, G., and Schere, K.: Impact of gasphase mechanisms on WRF/Chem predictions: mechanism implementation and comparative evaluation, J. Geophys. Res., 117, D01301, doi:10.1029/2011JD015775, 2012d.

Zhang, Y., Sartelet, K., Zhu, S., Wang, W., Wu, S.-Y., Zhang, X., Wang, K., Tran, P., Seigneur, C., and Wang, Z.-F.: Application of WRF/Chem-MADRID and WRF/Polyphemus in Europe - Part 2: Evaluation of chemical concentrations and sensitivity simulations, Atmos. Chem. Phys., 13, 6845-6875, doi:10.5194/acp-136845-2013, 2013.

Zilitinkevich, S. and Baklanov, A.: Calculation of the height of stable boundary layers in practical applications, Bound.-Lay. Meteorol., 105, 389-409, 2002.
Zilitinkevich, S. S., Hunt, J. C. R., Grachev, A. A., Esau, I. N., Lalas, D. P., Akylas, E., Tombrou, M., Fairall, C. W., Fernando, H. J. S., Baklanov, A., and Joffre, S. M.: The influence of large convective eddies on the surface layer turbulence, Q. J. Roy. Meteor. Soc., 132, 1423-1456, 2006.

Zubler, E. M., Folini, D., Lohmann, U., Lüthi, D., Schär, C., and Wild, M.: Simulation of dimming and brightening in Europe from 1958 to 2001 using a regional climate model, J. Geophys. Res., 116, D18205, doi:10.1029/2010JD015396, 2011.

Zyryanov, D., Foret, G., Eremenko, M., Beekmann, M., Cammas, J.-P., D’Isidoro, M., Elbern, H., Flemming, J., Friese, E., Kioutsioutkis, I., Maurizi, A., Melas, D., Meleux, F., Menut, L., Moinat, P., Peuch, V.-H., Poupkou, A., Razinger, M., Schultz, M., Stein, O., Suttie, A. M., Valdebenito, A., Zerefos, C., Dufour, G., Bergametti, G., and Flaud, J.-M.: 3-D evaluation of tropospheric ozone simulations by an ensemble of regional Chemistry Transport Model, Atmos. Chem. Phys., 12, 3219-3240, doi:10.5194/acp-12-3219-2012, 2012. 